MARCOS COELHO MATURANA

APLICAÇÃO DE REDES BAYESIANAS NA ANÁLISE DA CONTRIBUIÇÃO DO ERRO HUMANO EM ACIDENTES DE COLISÃO 
MARCOS COELHO MATURANA

\title{
APLICAÇÃO DE REDES BAYESIANAS NA ANÁLISE DA CONTRIBUIÇÃO DO ERRO HUMANO EM ACIDENTES DE COLISÃO
}

\author{
Dissertação apresentada à Escola \\ Politécnica da Universidade de São Paulo \\ para obtenção do título de Mestre em \\ Ciência
}

São Paulo 
Termo de Julgamento 
MARCOS COELHO MATURANA

\title{
APLICAÇÃO DE REDES BAYESIANAS NA ANÁLISE DA CONTRIBUIÇÃO DO ERRO HUMANO EM ACIDENTES DE COLISÃO
}

\author{
Dissertação apresentada à Escola \\ Politécnica da Universidade de São Paulo \\ para obtenção do título de Mestre em \\ Ciência \\ Área de Concentração: \\ Engenharia Naval e Oceânica \\ Orientador: \\ Prof. Dr. \\ Marcelo Ramos Martins
}

São Paulo

2010 


\section{FICHA CATALOGRÁFICA}

\section{Maturana, Marcos Coelho}

Aplicação das redes bayesianas na análise da contribuição do erro humano em acidentes de colisão / M.C. Maturana. -- São Paulo, 2009.

$161 \mathrm{p}$.

Dissertação (Mestrado) - Escola Politécnica da Universidade de São Paulo. Departamento de Engenharia Naval e Oceânica.

1. Redes neurais 2. Segurança à navegação 3 . Colisão marítima 4. Normas de segurança 5 . Navio tanque I. Universidade de São Paulo. Escola Politécnica. Departamento de Engenharia Naval e Oceânica II. t. 
Dedico este trabalho aos meus pais e à minha esposa. 


\section{AGRADECIMENTOS}

Agradeço aos professores e ao pessoal do Departamento de Engenharia Naval e Oceânica, em especial ao meu orientador que, muito além de exercer suas atribuições, foi um amigo nos momentos de incerteza. Também agradeço a CAPES pela bolsa concedida, auxílio que facilitou a execução deste trabalho e permitiu sua conclusão em tempo hábil. 


\section{RESUMO}

Recentemente, na indústria naval, a normatização por sociedades classificadoras e pela IMO (International Maritime Organization) tem apresentado uma mudança paulatina, migrando dos procedimentos prescritivos para uma estrutura regulatória baseada em risco. Tal perspectiva oferece algumas vantagens para operadores e armadores (empresas que exploram comercialmente as embarcações): 1) maior capacidade de incorporar projetos inovadores, tecnicamente superiores, a custos aceitáveis; 2) maior confiança quanto à segurança; 3) melhor entendimento de eventos de periculosidade, dos riscos enfrentados em novos projetos e de medidas de mitigação. Especificamente no setor petrolífero, a análise, a avaliação e o gerenciamento de risco são vitais, em face da potencial gravidade dos acidentes no que diz respeito à vida humana, ao meio-ambiente e ao patrimônio. Dado que a maior parte dos acidentes nesta área são motivados por fatores humanos, o propósito deste trabalho é apresentar uma metodologia e técnicas eficientes de análise de confiabilidade humana aplicáveis a esta indústria.

Durante as últimas décadas, se desenvolveram várias técnicas para o estudo quantitativo da confiabilidade humana. Na década de oitenta foram desenvolvidas técnicas que modelam o sistema por meio de árvores binárias, não permitindo a representação do contexto em que as ações humanas ocorrem. Desta forma, a representação dos indivíduos, suas inter-relações e a dinâmica do sistema não podem ser bem trabalhadas pela aplicação destas técnicas. Estas questões tornaram latente a necessidade de aprimoramento dos métodos utilizados para a HRA (Human Reliability Analysis). No intuito de extinguir, ou ao menos atenuar, estas limitações alguns autores vêm propondo a modelagem do sistema por meio de Redes Bayesianas. Espera-se que a aplicação desta ferramenta consiga suprimir boa parte das deficiências na modelagem da ação humana com o uso de árvores binárias. Este trabalho apresenta uma breve descrição da aplicação de Redes Bayesianas na HRA. Além disto, apresenta a aplicação desta técnica no estudo da operação de um navio petroleiro, tendo como foco a quantificação da contribuição do fator humano em cenários de colisão. Por fim, são feitas considerações a respeito dos fatores que podem influenciar no desempenho humano e no risco de colisão.

Palavras-chave: PSA (Probabilistic Safety Assessment); HRA; Redes Bayesianas; Colisão; Petroleiro. 


\begin{abstract}
Recently, in the naval industry, the normalization of classification societies and IMO (International Maritime Organization) has presented a gradual change, going from prescriptive procedures to a regulatory structure based on risk. That perspective offers some advantages to operators and constructors: 1) greater capacity to incorporate innovations in design, technically superiors, at acceptable cost; 2) greater confidence as to security; 3) better understanding of hazardous events, the risks faced by new projects and measures of mitigation. Specifically in the oil sector, the analyze, evaluation, and management of risk are vital, in face of the accidents severity potential in respect to human life, environment and property. Given that the greater part of the accidents on this sector is caused by human factors, the purpose of this dissertation is present a methodology and efficient techniques to HRA (Human Reliability Analysis) that can be applied in this industry.

During the last decades many techniques were developed to a quantitative study of the human reliability. In the eighties were developed some techniques based in the modeling by means of binaries trees. These techniques do not consider the representation of the context in which the human actions occur. Thus, the representation of individuals, their inter-relationships and dynamics of the system cannot be better worked by the application of these techniques. These issues became the improvement of the used methods for HRA a latent need. With the aim of extinguish, or attenuate at least, these weaknesses some authors proposed the modeling of the human system by means of Bayesians Network. It is expected that with the application of this tool can be suppressed great part of the deficiencies of the human action modeling by means of binaries trees. This work presents a brief description about the application of Bayesians Network in HRA. Additionally, is presented the application of this technique in the study of an oil tanker operation, focusing in the human factor quantification in scenarios of collision. Besides, are presented some considerations about the factors that can influence the human performance and the collision risk.
\end{abstract}

Keywords: PSA (Probabilistic Safety Assessment); HRA; Bayesian Networks; Collision; Tanker. 


\section{SUMÁRIO}

LISTA DE ACRÔNIMOS................................................................................. XII

LISTA DE ILUSTRAÇÕES .................................................................................. XIII

LISTA DE TABELAS ............................................................................................. XIV

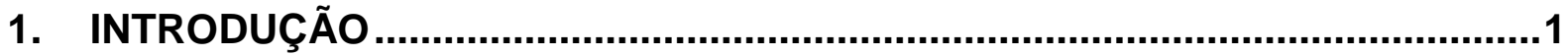

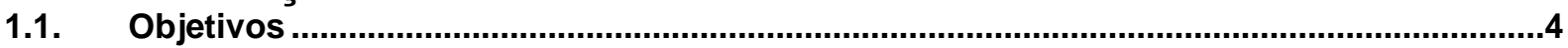

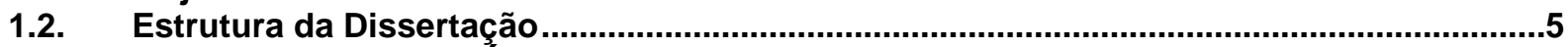

2. FUNDAMENTOS TEÓRICOS ........................................................................

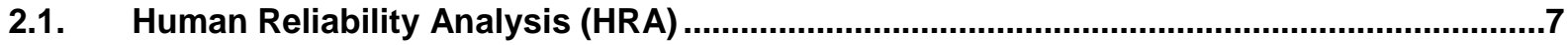

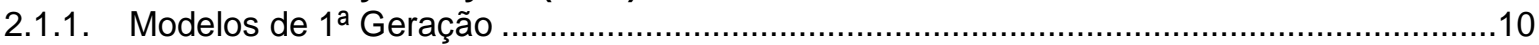

2.1.1.1. Human Error Assessment and Reduction Technique (HEART) .................................. 10

2.1.1.2. Technique for Human Error Rate Prediction (THERP) ........................................11

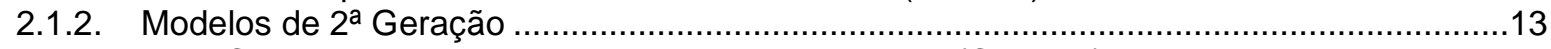

2.1.2.1. Cognitive Reliability and Error Analysis Method (CREAM) ....................................13

2.1.2.2. A Technique for Human Error Analysis (ATHEANA) ..........................................14

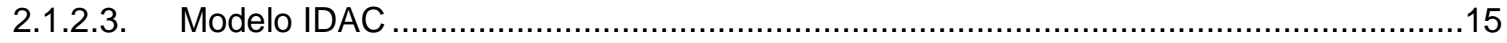

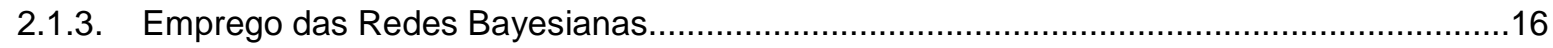

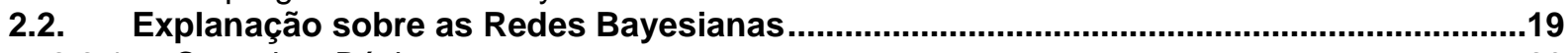

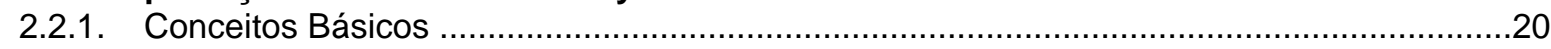

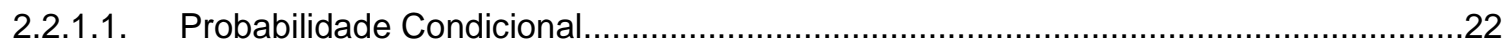

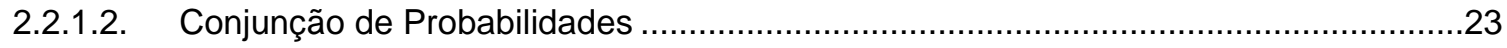

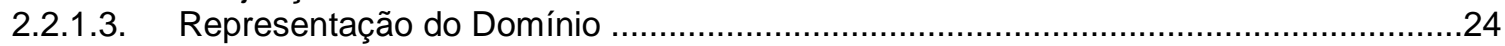

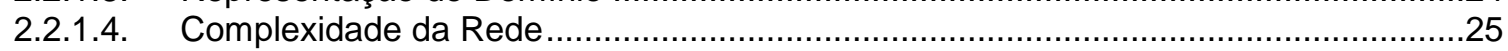

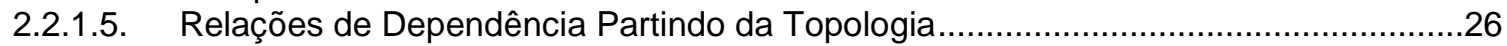

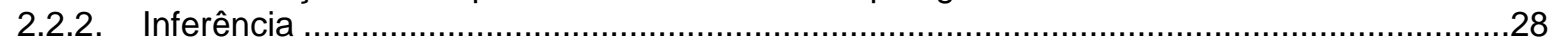

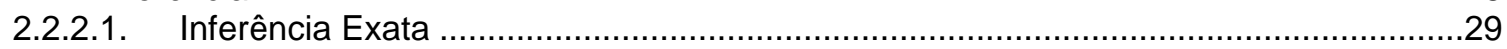

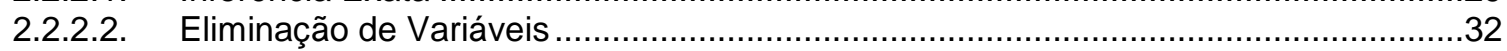

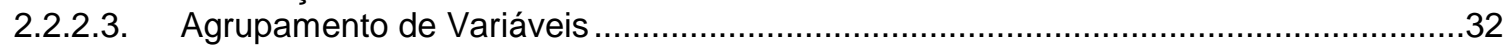

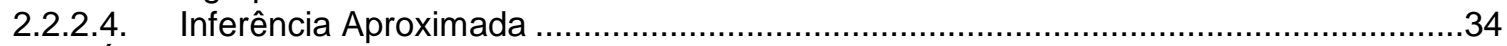

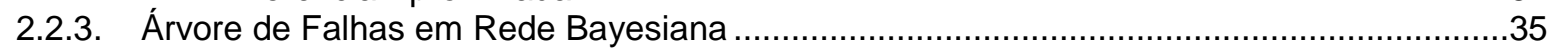

2.3. Modelagem por Meio de Redes Bayesianas.................................................................

2.3.1. Procedimento para a Construção de Redes Bayesianas na Análise de Confiabilidade ......42

3. METODOLOGIA PARA HRA VIA REDES BAYESIANAS ..............................44

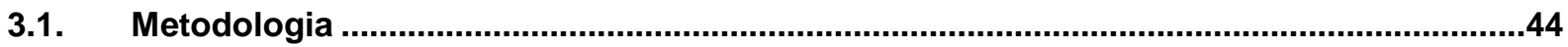

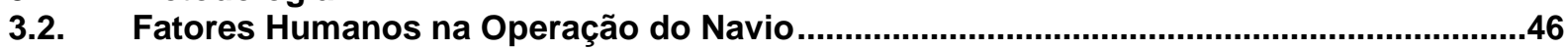

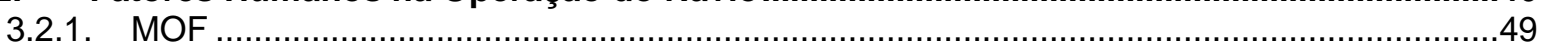

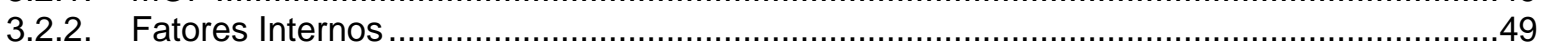

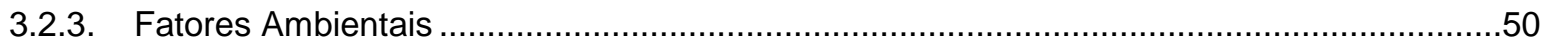

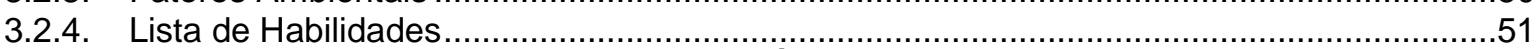

3.3. Integração das Redes Bayesianas com a Árvore de Falhas ..........................................52

4. APLICAÇÃO AO ESTUDO DA COLISÃO ..................................................54

4.1. Descrição do Sistema e Aproveitamento de Dados Quantitativos ...................................55

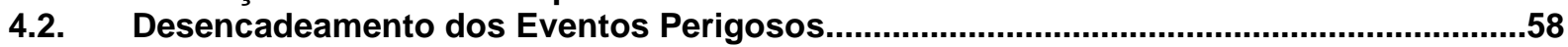

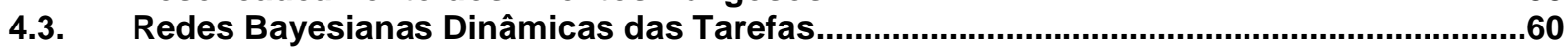

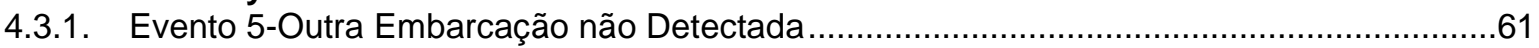

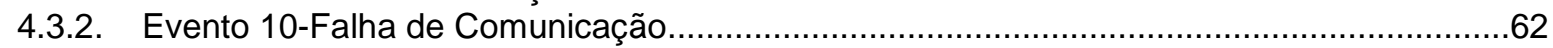

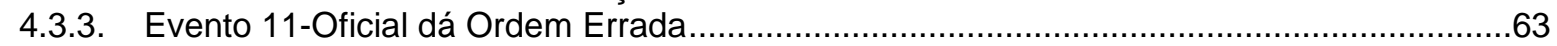

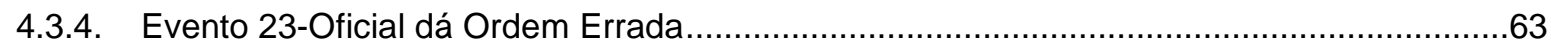

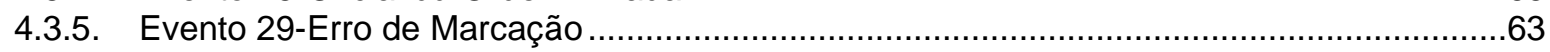

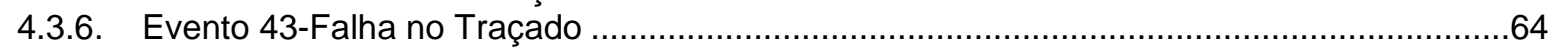

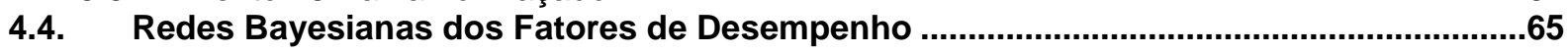

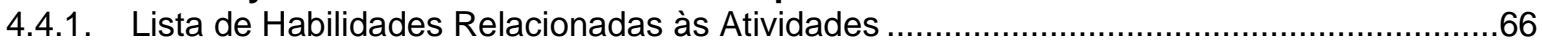

4.4.2. Rede dos Fatores de Desempenho para Monitoramento do Tráfego ......................................66 
4.5. Preenchimento das Tabelas de Probabilidades Condicionais..........................................69

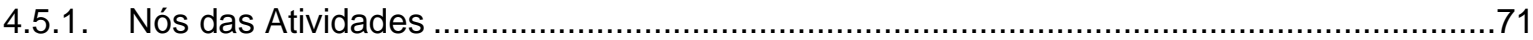

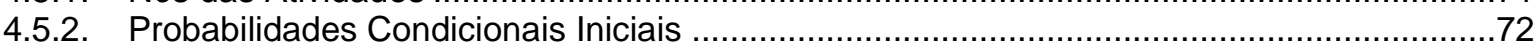

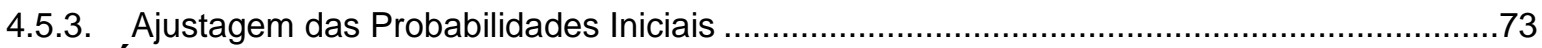

5. ANÁLISE DO MODELO ...............................................................................80

5.1. Análise dos Eventos Básicos, dado o Evento Topo ........................................................81

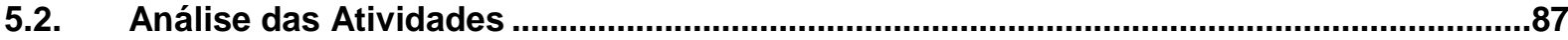

5.3. Análise dos Fatores Internos e Habilidades.......................................................................92

5.4. Análise dos MOF ...............................................................................................................98

6. CONCLUSÕES E RECOMENDAÇÕES PARA TRABALHOS FUTUROS ......103

7. REFERÊNCIAS ..................................................................................107

APÊNDICE A: TABELAS COMPLEMENTARES PARA OS FATORES DE DESEMPENHO.......................................................................................110 APÊNDICE B: REDES BAYESIANAS DINÂMICAS E REDES DOS FATORES DE

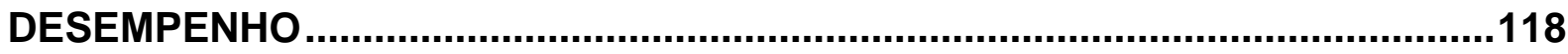




\section{LISTA DE ACRÔNIMOS}

Al

ATHEANA

CREAM

DAG

EFC

EPC

FINEP

FPSO

FSA

GPS

HEART

HEP

HFE

HRA

IDAC

IMO

LabRisco

MCT

MOF

ON

PSA

PSF

RIPEAM

SMS

THERP

TPC

UA

USP
Artificial Intelligence

A Technique for Human Error Analysis

Cognitive Reliability and Error Analysis Method

Directed Acyclic Grafh

Error-forcing Context

Error Producing Condition

Financiadora de Estudos e Projetos

Floating Production System and Offloading

Formal Safety Assessment

Global Positioning System

Human Error Assessment and Reduction Technique

Human Error Probability

Human Failure Events

Human Reliability Analysis

Information, Decision and Action in Crew Context

International Maritime Organization

Laboratório de Análise de Risco da Escola Politécnica da USP

Ministério da Ciência e Tecnologia

Management and Organizational Factor

Oficial de Náutica

Probabilistic Safety Assessment

Performance Shaping Factor

Regulamento Internacional Para Evitar Abalroamento no Mar

Safety Management System

Technique for Human Error Rate Prediction

Tabela de Probabilidades Condicionais

Unsafe Actions

Universidade de São Paulo 


\section{LISTA DE ILUSTRAÇÕES}

Figura 1 - Número de técnicas para HRA (Hollnagel, 2005) ................................10

Figura 2 - Exemplos de grafos direcionados …………....................................20

Figura 3 - Rede Bayesiana típica demonstrando a topologia e as TPC .................21

Figura 4 - Estrutura da rede exemplo .........................................................26

Figura 5 - Dependência do nó $A$, dados os nós pais ...........................................27

Figura 6 - Markov Blanket para o nó $A$.........................................................27

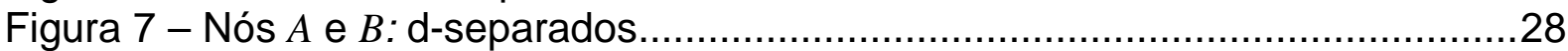

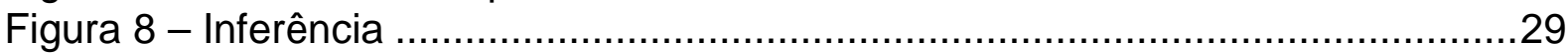

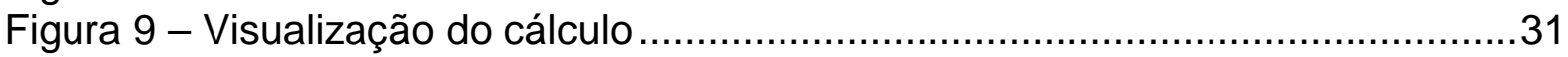

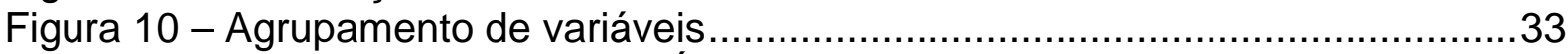

Figura 11 - Portas empregadas em Árvores de Falhas ........................................35

Figura 12 - Árvore de Falha com portas "E", "OU" e "OU Exclusivo"..........................36

Figura 13 - Rede obtida da Árvore com Porta "E" ..................................................37

Figura 14 - Rede obtida da Árvore com Porta "OU Exclusivo" .................................39

Figura 15 - Exemplo de rede dinâmica.........................................................4 4

Figura 16 - Metodologia para realização da HRA por meio das Redes Bayesianas 45

Figura 17 - Modelagem dos fatores que influenciam o desempenho humano ..........47

Figura 18 - Rede Genérica para Fatores de Desempenho..................................48

Figura 19 - llustração da integração Árvore de Falhas-Redes Bayesianas...............53

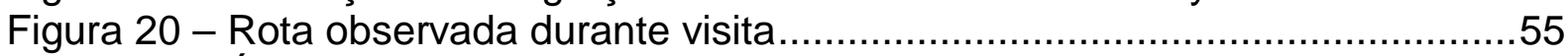

Figura 21 - Árvore de Falhas para Colisão .......................................................59

Figura 22 - Rede Bayesiana para o desencadeamento de eventos perigosos .........60

Figura 23 - Rede Bayesiana Dinâmica para a tarefa de monitoramento do tráfego.62

Figura 24 - Rede Bayesiana Dinâmica para a tarefa de comunicação ......................62

Figura 25 - Rede Bayesiana Dinâmica para ordem dos oficiais .............................63

Figura 26 - Rede Bayesiana Dinâmica para a tarefa de marcação de posição........64

Figura 27 - Rede Bayesiana Dinâmica para a tarefa de traçado da rota...................65

Figura 28 - Rede dos Fatores de Desempenho para Monitoramento do Tráfego ....69

Figura 29 - Rede para o evento 6 - Falha no Procedimento Padrão (RIPEAM) .......75

Figura 30 - Variação da probabilidade do evento 6 em função de $\alpha$ e $\beta$..................75

Figura 31 - Pares de $\alpha$ e $\beta$ possíveis para se encontrar $50 \%$ no Evento 6 ................76

Figura 32 - Diagrama dos desencadeamentos modelados na Figura 21 .................84

Figura 33 - Queda na probabilidade de falha ……….......................................95

Figura 34 - Probabilidade de Colisão em Função dos MOF ...................................99

Figura 35 - Probabilidade do MOF, dada uma evidência de Colisão......................101

Figura 36 - Quantidade de arcos para cada MOF ..........................................101

Figura 37 - Rede para o evento 5 - Outra Embarcação Não Detectada ................118

Figura 38 - Rede para o evento 10 - Falha de Comunicação ................................120

Figura 39 - Rede para o evento 11 - Oficial dá Ordem Errada .............................125

Figura 40 - Rede para o evento 14 - Timoneiro dá Resposta Errada .....................127

Figura 41 - Rede para o evento 29 - Erro de Marcação .......................................129

Figura 42 - Rede para o evento 32 - Capitão Falha...........................................133

Figura 43 - Rede para o evento 36 - Erro de Atenção........................................134

Figura 44 - Rede para o evento 43 - Falha no Traçado.....................................136 


\section{LISTA DE TABELAS}

Tabela 1 - Correlação entre os passos da FSA e da HRA (IMO, 2002) ....................7

Tabela 2 - Vantagens e desvantagens da HEART ............................................11

Tabela 3 - Vantagens e desvantagens da THERP ..........................................13

Tabela 4 - Vantagens e desvantagens do CREAM ............................................14

Tabela 5 - Vantagens e desvantagens da ATHEANA …...................................16

Tabela 6 - Vantagens e desvantagens do modelo IDAC .................................17

Tabela 7 - Vantagens das Redes Bayesianas na HRA .........................................18

Tabela 8 - Conjunção de Probabilidades das variáveis $A$ e $B \ldots \ldots \ldots \ldots \ldots \ldots \ldots \ldots \ldots \ldots \ldots . . .23$

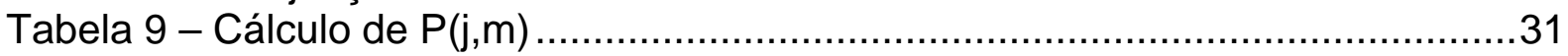

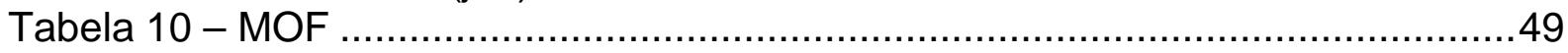

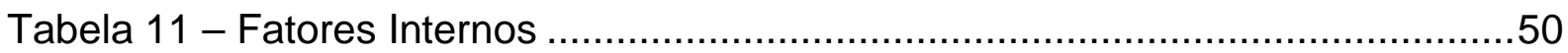

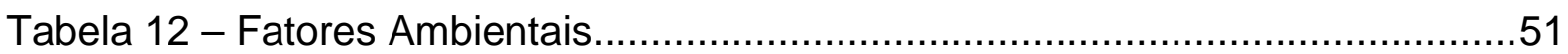

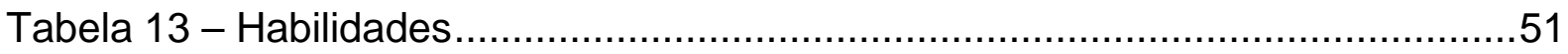

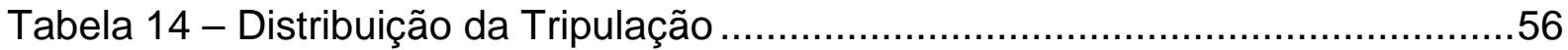

Tabela 15 - Eventos Básicos e atividades relacionadas.......................................61

Tabela 16 - Habilidades relacionadas às atividades.........................................67

Tabela 17 - Fatores de desempenho para monitoramento com RADAR ................68

Tabela 18 - TPC para o nó DectarVisualmente ………..................................... 72

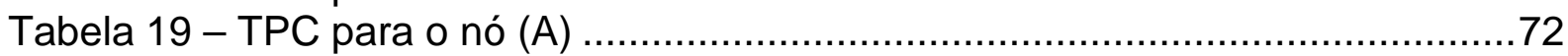

Tabela 20 - TPC para o nó Falha do Procedimento Padrão (RIPEAM)...................77

Tabela 21 - TPC para o nó Percepção 6 ………….............................................77

Tabela 22 - TPC para o nó Equipe e Comunicação 1 ..........................................77

Tabela 23 - TPC para o nó Conhecimento de Procedimento 1 …….......................77

Tabela 24 - TPC para o nó Qualidade do Sono 3 …….........................................77

Tabela 25 - TPC para o nó Tratamento Dado a Falha 1 .......................................77

Tabela 26 - TPC para o nó Habilidade 1 ……................................................

Tabela 27 - TPC para o nó Condição Física 3 …...............................................78

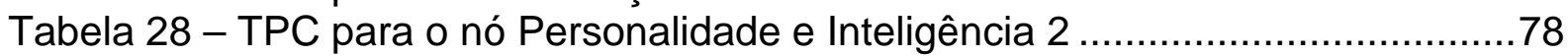

Tabela 29 - TPC para o nó Estado Atual 2 .........................................................

Tabela 30 - TPC para o nó Conhecimento das Normas 2 ...................................78

Tabela 31 - Probabilidades associadas aos eventos básicos ...............................81

Tabela 32 - Correlação entre fatores e eventos da árvore de falhas.......................82

Tabela 33 - Desencadeamento mais provável ..................................................85

Tabela 34 - Desencadeamentos com probabilidade maior que 1\% .......................86

Tabela 35 - Probabilidades para as atividades................................................87

Tabela 36 - Probabilidades para as atividades, dadas as atividades precedentes...88

Tabela 37 - Probabilidades de erro obtidos no trabalho anterior ............................91

Tabela 38 - Análise dos PSF para a Tarefa 6 - Procedimento RIPEAM .................93

Tabela 39 - Análise dos PSF para a atividade DecidirFazerContato.......................96

Tabela 40 - Análise dos PSF para a atividade ConseguirContatoRadio ...................96

Tabela 41 - Análise dos PSF para a atividade DecidirContatoOutroMeio .................96

Tabela 42 - Análise dos PSF para a atividade EntenderInterlocutor .......................96

Tabela 43 - Análise dos PSF para a atividade EntenderInterlocutor2 ….................97

Tabela 44 - Análise dos PSF para a atividade EntendeDemanda1 .......................97

Tabela 45 - Análise dos PSF para a atividade TomadadeDecisao1 1.......................97

Tabela 46 - Análise dos PSF para a atividade DeteccaodoErro1 1...........................98 


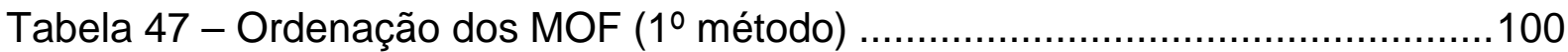

Tabela 48 - Atividade 6-1: Falha do Procedimento RIPEAM ...............................110

Tabela 49 - Atividade 10-1: Decidir Fazer Contato por Rádio ..............................110

Tabela 50 - Atividade 10-2: Conseguir Fazer Contato......................................110

Tabela 51 - Atividade 10-3: Entender Interlocutor ..........................................110

Tabela 52 - Atividade 10-4: Decidir Fazer Contato por Outro Meio ......................111

Tabela 53 - Atividade 10-5: Entender Interlocutor .............................................111

Tabela 54 - Atividade 11-1: Entende Corretamente .......................................111

Tabela 55 - Atividade 11-2: Tomada de Decisão.............................................111

Tabela 56 - Atividade 11-3: Detecção do Erro ................................................... 112

Tabela 57 - Atividade 14-1: Resposta Errada..................................................112

Tabela 58 - Atividade 23-1: Entende Corretamente .........................................112

Tabela 59 - Atividade 23-2: Tomada de Decisão.............................................112

Tabela 60 - Atividade 23-3: Detecção do Erro.................................................113

Tabela 61 - Atividade 25-1: Resposta Errada......................................................113

Tabela 62 - Atividade 29-1: Checagem de Equipamento .................................113

Tabela 63 - Atividade 29-3: Respeito dos Intervalos .......................................113

Tabela 64 - Atividade 29-4: Leitura de posição ..............................................113

Tabela 65 - Atividade 29-5: Marcação na Carta Náutica .......................................114

Tabela 66 - Atividade 29-6: Comandante Detecta o Erro .....................................114

Tabela 67 - Atividade $32-1$ : Capitão Falha ......................................................114

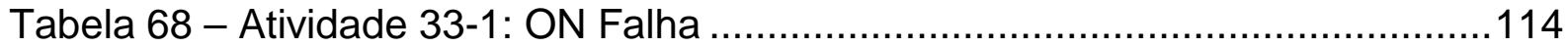

Tabela 69 - Atividade 36-1: Erro de Atenção................................................115

Tabela 70 - Atividade 39-1: Erro não Descoberto............................................115

Tabela 71 - Atividade 43-1: Atualização das Publicações ....................................115

Tabela 72 - Atividade 43-2: Leitura das Informações .........................................115

Tabela 73 - Atividade 43-3: Estabelecimento da Profundidade Mínima .................115

Tabela 74 - Atividade 43-4: Leitura da Profundidade ........................................116

Tabela 75 - Atividade 43-5: Identificar Áreas Restritas.....................................116

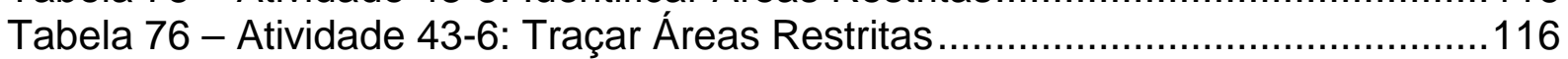

Tabela 77 - Atividade 43-7: Traçar Rumos Sucessivos .....................................116

Tabela 78 - Atividade 43-8: Identificar Way-Points ..........................................116

Tabela 79 - Atividade 43-9: Escolha dos Pontos ................................................116

Tabela 80 - Atividade 43-10: Revisão da Rota ON..........................................117

Tabela 81 - Atividade 43-11: Detecção de Falha Comandante ............................117

Tabela 82 - Eventos não apresentados no Apêndice .........................................118

Tabela 83 - TPC para o nó Percepção ............................................................119

Tabela 84 - TPC para o nó Concentração .......................................................119

Tabela 85 - TPC para o nó Percepcao1 ........................................................119

Tabela 86 - TPC para o nó Percepcao2 …..........................................................119

Tabela 87 - TPC para o nó DectarVisualmente ................................................119

Tabela 88 - TPC para o nó DetectarPorRadar ..................................................119

Tabela 89 - TPC para o nó DetectarPorAlarme ..................................................119

Tabela 90 - TPC para o nó OutraEmbarcacaoNãoDetectada5 ............................120

Tabela 91 - TPC para o nó Distrações ............................................................ 120

Tabela 92 - TPC para o nó TrabalhoMonotono ............................................. 120

Tabela 93 - TPC para o nó QualidadedoSono............................................... 120

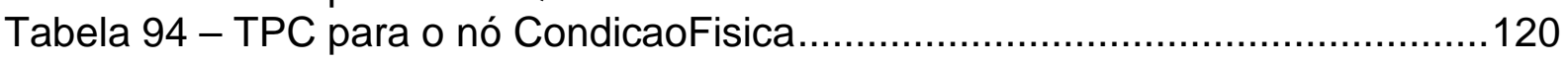

Tabela 95 - TPC para o nó QualidadedoSono2 .......................................... 121 


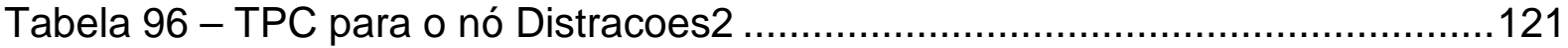

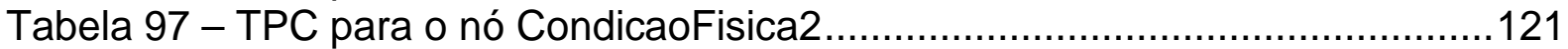

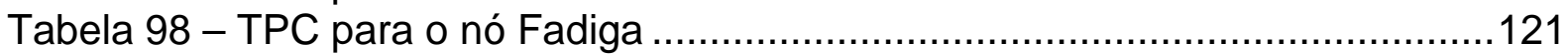

Tabela 99 - TPC para o nó Personalidadeelnteligencia ........................................121

Tabela 100 - TPC para o nó MotivacaoeAtitude ...............................................121

Tabela 101 - TPC para o nó ConhecimentodasNormas .....................................121

Tabela 102 - TPC para o nó EstadoAtual .......................................................121

Tabela 103 - TPC para o nó TratamentoDadoaFalha ........................................121

Tabela 104 - TPC para o nó ConhecimentodasNormas1 .....................................121

Tabela 105 - TPC para o nó EstadoAtual1 …………......................................122

Tabela 106 - TPC para o nó Personalidadeelnteligencia1 ...................................122

Tabela 107 - TPC para o nó Habilidade .......................................................122

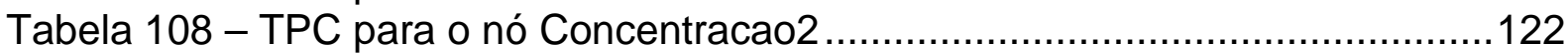

Tabela 109 - TPC para o nó Percepcao8 ……………..................................122

Tabela 110 - TPC para o nó ConhecimentodeProcedimento2 ……......................122

Tabela 111 - TPC para o nó Flexibilidade ........................................................122

Tabela 112 - TPC para o nó ConhecimentodeProcedimento …….........................122

Tabela 113 - TPC para o nó EquipeComunicacao ............................................122

Tabela 114 - TPC para o nó Percepcao7 ……………...................................123

Tabela 115 - TPC para o nó Interpretação .....................................................123

Tabela 116 - TPC para o nó Entenderlnterlocutor2 ..........................................123

Tabela 117 - TPC para o nó DecidirContatoOutroMeio ......................................123

Tabela 118 - TPC para o nó DecidirFazerContato ...........................................123

Tabela 119 - TPC para o nó ConseguirContatoRadio ........................................124

Tabela 120 - TPC para o nó EntenderInterlocutor ............................................124

Tabela 121 - TPC para o nó FalhadeComunicacao10 …....................................124

Tabela 122 - TPC para o nó Distracoes3 …...................................................125

Tabela 123 - TPC para o nó QualidadedoSono4 ….......................................125

Tabela 124 - TPC para o nó Fadiga1 ………............................................125

Tabela 125 - TPC para o nó CondicaoFisica4 …….......................................125

Tabela 126 - TPC para o nó Personalidadeelnteligencia3 ………………….......125

Tabela 127 - TPC para o nó TratamentoDadoaFalha2 ….................................125

Tabela 128 - TPC para o nó Percepcao9 …………....................................125

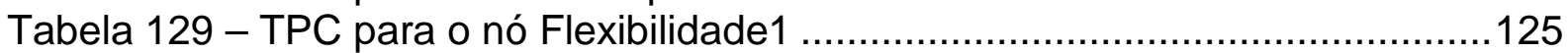

Tabela 130 - TPC para o nó Interpretacao1 ……….....................................125

Tabela 131 - TPC para o nó MotivacaoeAtitude1 …........................................126

Tabela 132 - TPC para o nó Habilidade2 ………........................................126

Tabela 133 - TPC para o nó Concentracao3 ……….......................................126

Tabela 134 - TPC para o nó EquipeComunicacao2 ……..................................126

Tabela 135 - TPC para o nó Planejamento …………...................................126

Tabela 136 - TPC para o nó DeteccaodoErro ..............................................126

Tabela 137 - TPC para o nó EntendeDemanda ……......................................126

Tabela 138 - TPC para o nó TomadadeDecisao ……........................................127

Tabela 139 - TPC para o nó OficialdaOrdemErrada11 .....................................127

Tabela 140 - TPC para o nó QualidadedoSono5 ................................................127

Tabela 141 - TPC para o nó Distracoes4 …................................................127

Tabela 142 - TPC para o nó TratamentoDadoaFalha3 ......................................128

Tabela 143 - TPC para o nó Habilidade3 …………........................................128

Tabela 144 - TPC para o nó CondicaoFisica5 ................................................128 
Tabela 145 - TPC para o nó Fadiga2 …………….....................................128

Tabela 146 - TPC para o nó EquipeComunicacao3 ……..................................128

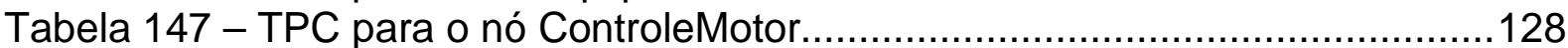

Tabela 148 - TPC para o nó Concentracao4 …...............................................128

Tabela 149 - TPC para o nó TimoneirodaRespErrada14 ….............................128

Tabela 150 - TPC para o nó TrabalhoMonotono2 ……....................................129

Tabela 151 - TPC para o nó QualidadedoSono8 ............................................129

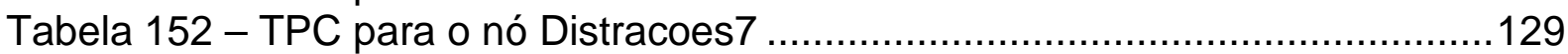

Tabela 153 - TPC para o nó CondicaoFisica8 ………....................................129

Tabela 154 - TPC para o nó Distracoes8 …..................................................130

Tabela 155 - TPC para o nó TrabalhoMonotono3 …….....................................130

Tabela 156 - TPC para o nó QualidadedoSono10 ..........................................130

Tabela 157 - TPC para o nó Habilidade6 .......................................................130

Tabela 158 - TPC para o nó TratamentoDadoaFalha6 .........................................130

Tabela 159 - TPC para o nó QualidadedoSono11 …........................................130

Tabela 160 - TPC para o nó TrabalhoMonotono4 ……....................................130

Tabela 161 - TPC para o nó Distracoes9 ……….........................................130

Tabela 162 - TPC para o nó ExperienciaTreinamento ......................................130

Tabela 163 - TPC para o nó CondicaoFisica9 .................................................130

Tabela 164 - TPC para o nó Percepcao13 …................................................130

Tabela 165 - TPC para o nó CondicaoFisica10 …..........................................131

Tabela 166 - TPC para o nó ErrodeMarcacao29 ….........................................131

Tabela 167 - TPC para o nó RespeitolntervalosdeMarcacao ...............................131

Tabela 168 - TPC para o nó LeituraPosicao...................................................131

Tabela 169 - TPC para o nó ComandanteDetectaErro........................................131

Tabela 170 - TPC para o nó FalhaMateriallmprevista ..........................................131

Tabela 171 - TPC para o nó MarcacaoCartaNautica............................................131

Tabela 172 - TPC para o nó ChecagemEquipamento ......................................132

Tabela 173 - TPC para o nó EquipeComunicacao 7 ….......................................132

Tabela 174 - TPC para o nó Percepcao12 …………..................................132

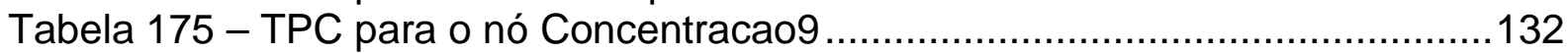

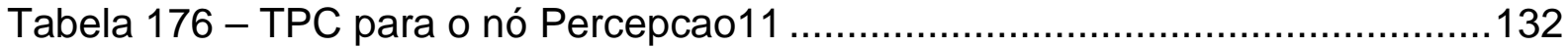

Tabela 177 - TPC para o nó Concentracao8 ……….......................................132

Tabela 178 - TPC para o nó Concentracao10 …..............................................132

Tabela 179 - TPC para o nó FrequenciaRepetitividade.....................................132

Tabela 180 - TPC para o nó ControleMotor2 ……...........................................133

Tabela 181 - TPC para o nó ConhecimentodeProcedimento3 ….........................133

Tabela 182 - TPC para o nó EquipeComunicacao8 ….....................................133

Tabela 183 - TPC para o nó CondicaoFisica11 ……......................................133

Tabela 184 - TPC para o nó Concentracao11 ……........................................133

Tabela 185 - TPC para o nó Percepca014 ...................................................134

Tabela 186 - TPC para o nó TrabalhoMonotono5 ……....................................134

Tabela 187 - TPC para o nó QualidadedoSono12 ..........................................134

Tabela 188 - TPC para o nó Habilidade7 .....................................................134

Tabela 189 - TPC para o nó TratamentoDadoaFalha7 .......................................134

Tabela 190 - TPC para o nó Distracoes10 ..................................................134

Tabela 191 - TPC para o nó ComandanteFalha32 …...........................................134

Tabela 192 - TPC para o nó Fadiga5 ………….............................................135

Tabela 193 - TPC para o nó CondicaoFisica13 …….......................................135 


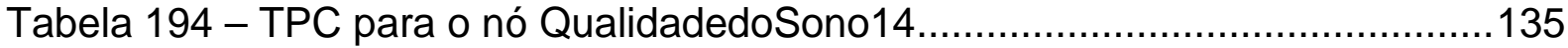

Tabela 195 - TPC para o nó TrabalhoMonotono7 ............................................. 135

Tabela 196 - TPC para o nó Distracoes12 ..................................................... 135

Tabela 197 - TPC para o nó ResistenciaFisica ................................................ 135

Tabela 198 - TPC para o nó Percepcao16 ........................................................ 135

Tabela 199 - TPC para o nó Concentracao13 ................................................. 135

Tabela 200 - TPC para o nó ErrodeAtencao36 ............................................ 135

Tabela 201 - TPC para o nó TratamentoDadoaFalha11 ..................................136

Tabela 202 - TPC para o nó CondicaoFisica17 ..............................................136

Tabela 203 - TPC para o nó QualidadedoSono18...........................................137

Tabela 204 - TPC para o nó TratamentoDadoaFalha10 ...................................137

Tabela 205 - TPC para o nó MotivacaoeAtitude3 ............................................137

Tabela 206 - TPC para o nó ExperienciaTreinamento1 ....................................137

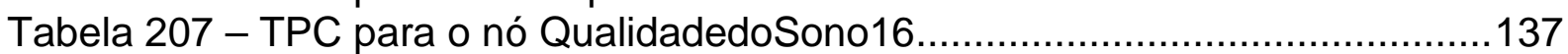

Tabela 208 - TPC para o nó QualidadedoSono17 ..............................................137

Tabela 209 - TPC para o nó Habilidade11 ................................................... 137

Tabela 210 - TPC para o nó Habilidade10 ........................................................137

Tabela 211 - TPC para o nó CondicaoFisica16 ...............................................137

Tabela 212 - TPC para o nó Personalidadeelnteligencia5 .................................137

Tabela 213 - TPC para o nó Distracoes14 .....................................................137

Tabela 214 - TPC para o nó CondicaoFisica15 ............................................... 138

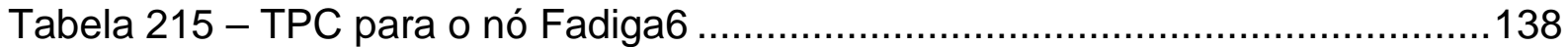

Tabela 216 - TPC para o nó Distracoes15 .................................................. 138

Tabela 217 - TPC para o nó TrabalhoMonotono9 ….......................................... 138

Tabela 218 - TPC para o nó TrabalhoMonotono10 ...........................................138

Tabela 219 - TPC para o nó Distracoes16 .................................................. 138

Tabela 220 - TPC para o nó TrabalhoMonotono11 ....................................... 138

Tabela 221 - TPC para o nó FalhanoTracado43 …..........................................138

Tabela 222 - TPC para o nó RevisaoOficialNautica1 .......................................138

Tabela 223 - TPC para o nó EscolhaPontosReferencia1 ..................................139

Tabela 224 - TPC para o nó IdentificarWayPoints1 ..........................................139

Tabela 225 - TPC para o nó TracarRumosSucessivos1 .....................................139

Tabela 226 - TPC para o nó TracarAreasRestritas 1 ..........................................139

Tabela 227 - TPC para o nó ProfundidadeMinima1 ...........................................139

Tabela 228 - TPC para o nó ConhecimentodeProcedimento 4 ............................139

Tabela 229 - TPC para o nó IdentificarAreasRestritas1 .....................................140

Tabela 230 - TPC para o nó LeituradeProfundidade1 .....................................140

Tabela 231 - TPC para o nó LeituradasInformacoes 1 .......................................140

Tabela 232 - TPC para o nó AtualizacaoPublicacoes 1 ......................................140

Tabela 233 - TPC para o nó RevisaoComandante1 ....................................... 140

Tabela 234 - TPC para o nó Concentracao15 .................................................. 140

Tabela 235 - TPC para o nó Concentracao17 ................................................... 140

Tabela 236 - TPC para o nó Percepcao20 ..........................................................141

Tabela 237 - TPC para o nó ResistenciaFisica1 ............................................... 141

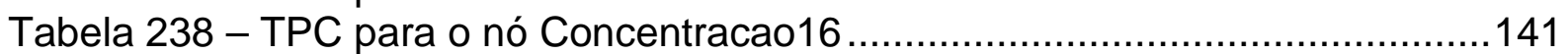

Tabela 239 - TPC para o nó Percepcao19 ...................................................... 141

Tabela 240 - TPC para o nó Percepcao18 ................................................... 141

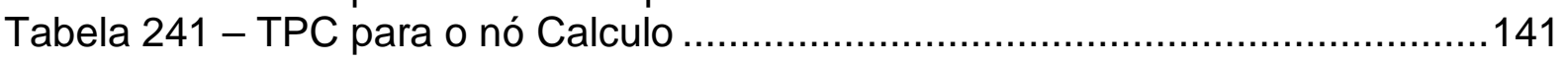

Tabela 242 - TPC para o nó ControleMotor3................................................ 141 
Tabela 243 - TPC para o nó EquipeComunicacao11

Tabela 244 - TPC para o nó EquipeComunicacao12

Tabela 245 - TPC para o nó Interpretacao3 


\section{INTRODUÇÃO}

Nos anos recentes, a análise, a avaliação e o gerenciamento de risco têm crescido substancialmente na indústria, tendo-se constituído em um instrumental de valor para apoio a decisões concernentes a segurança. Tornou-se possível a consideração de forma estruturada de eventos que envolvam periculosidade, permitindo o controle de riscos a custos aceitáveis.

Na indústria naval, a normatização por sociedades classificadoras e pela IMO tem apresentado uma mudança paulatina, migrando dos procedimentos prescritivos para uma estrutura regulatória baseada em risco. Tal perspectiva oferece as seguintes vantagens para operadores e armadores: 1) maior capacidade de incorporar projetos inovadores, tecnicamente superiores, a custos aceitáveis; 2) maior confiança quanto à segurança; 3) melhor entendimento de eventos de periculosidade, dos riscos enfrentados em novos projetos e de medidas de mitigação.

A concepção baseada em risco para tratamento de segurança de embarcações requer aplicação contínua e estruturada de técnicas de avaliação de risco, sendo fundamental o desenvolvimento de conhecimento e capacitação nesta área. O LabRisco, laboratório de análise de risco em fase de implantação no Departamento de Engenharia Naval e Oceânica da USP, com financiamento de recursos do MCT/FINEP, vem ao encontro deste propósito, alavancando, inclusive, o desenvolvimento deste projeto de pesquisa.

Quando se deseja avaliar os riscos envolvidos na operação de determinado sistema, é natural o pensamento de se listar todos os eventos que podem ocorrer e trazer conseqüências negativas. No entanto, nem todos os eventos listados terão a mesma probabilidade de ocorrência. Da mesma forma, alguns eventos trazem conseqüências desastrosas e outros trazem perdas secundárias. Assim, para sistemas complexos, um estudo puramente determinístico dos eventos de risco pode não ser o mais adequado (Beldford e Cooke, 2001). Isto porque para sistemas complexos torna-se inviável a manipulação de todos os fatores que trazem perigo à operação. Por outro lado, um estudo probabilístico permite classificar os eventos em termos de conseqüências e freqüências. Sendo que a escolha de limites para estes parâmetros é pautada pelo grau de segurança que se deseja garantir na operação. 
Os estudos probabilísticos dos riscos associados a sistemas estão agrupados no que se convencionou chamar PSA (Probabilistic Safety Assessment). A este respeito, a IMO publicou o "Guidelines for Formal Safety Assessment" (IMO, 2002). A intenção original desta publicação era formatar as propostas a serem encaminhadas para a IMO. Atualmente, no entanto, é utilizada por sociedades classificadoras como método para analisar e incrementar a segurança marítima (Martins e Goyano, 2007). A FSA (Formal Safety Assessment) aceita tanto uma caracterização quantitativa quanto qualitativa dos perigos e riscos envolvidos no problema a ser analisado e, consistentemente com os dados disponíveis, sua representação pode ser tanto matemática quanto descritiva. Nos casos em que os dados necessários para cada passo não estiverem disponíveis a metodologia prevê a participação de especialistas, desenvolvimento de modelos físicos, simulações e uso de modelos analíticos para sua produção. Entretanto, assim como na análise determinística, aquele que realiza a PSA pode se deparar com dificuldades. Como exemplos, podem-se citar:

- Falta de Dados: dificuldades associadas à falta de dados compreensíveis a respeito da área em consideração (como exemplo, isto pode ocorrer quando não existe para determinada área a cultura de se fazer registros, dificultando a obtenção de probabilidades; ou ainda porque se trata de uma área ou projeto inovador);

- Dados Escassos: dificuldades a respeito dos dados existentes associados a eventos raros (são poucos os dados existentes a respeito de acidentes catastróficos, restringindo a representatividade da amostra, por exemplo);

- Modelagem: modelos assumidos que não podem ser facilmente quantificados probabilisticamente (pouco entendimento de fenômenos físicos, ou do comportamento humano em regime de emergência, dificuldades nas considerações sobre dependências e simplificações para permitir a modelagem de sistemas complexos, por exemplo).

Desta forma, para que haja segurança nos resultados alcançados pela aplicação da PSA, é comum a adoção de intervalos ao invés de valores fixos para os dados assumidos (IAEA, 1995). Independentemente destas dificuldades, a PSA 
pode claramente sugerir caminhos tanto para o incremento na segurança dos projetos quanto para a melhora na operação de sistemas complexos (IAEA, 1992).

A análise do elemento humano em sistemas integrados também pode ser feita por meio da PSA. Neste caso, associa-se o fator humano à ocorrência dos acidentes, suas causas implícitas e conseqüências (IMO, 2002). O elemento humano pode ser incorporado à PSA por meio da HRA.

Especificamente no setor petrolífero, a análise, a avaliação e o gerenciamento de risco são vitais, em face da potencial gravidade dos acidentes no que diz respeito à vida humana, ao meio-ambiente, ao patrimônio, às operações e à imagem da empresa. Um navio que transporta petróleo e seus derivados está sujeito a eventos com conseqüências desta natureza. Por exemplo, quando um navio deixa a rota segura incorre em uma série de perigos associados a eventos de encalhe e colisão com potencial para gerar grandes prejuízos ambientais; além dos efeitos listados no início do parágrafo. Dado que a maior parte dos acidentes nesta área é motivada por fatores humanos (IMO, 2002), torna-se interessante encontrar uma metodologia e técnicas eficientes de análise de confiabilidade humana que possam ser aplicadas com sucesso nesta indústria.

Durante as últimas décadas se desenvolveram várias técnicas para o estudo quantitativo da confiabilidade humana. $\mathrm{Na}$ década de oitenta foram desenvolvidas técnicas que modelam o sistema por meio de árvores binárias (Gertman e Blackman, 1993). Estas técnicas não levam em conta a representação do contexto em que as ações humanas ocorrem (Hollnagel, 2005). Desta forma, a representação dos indivíduos, suas inter-relações e a dinâmica do sistema não podem ser bem trabalhadas pela aplicação destas técnicas (Droguett e Menêzes, 2007). Estas questões tornaram latente a necessidade de aprimoramento dos métodos utilizados para a HRA.

Com intuito de extinguir ou pelo menos atenuar estas limitações, alguns autores vêm propondo a modelagem do sistema por meio de Redes Bayesianas (Droguett e Menêzes, 2007; Eleye-Datubo, Wall e Wang, 2008). A intenção, ao aplicar esta ferramenta, é suprimir boa parte das deficiências na modelagem da ação humana com o uso de árvore binárias.

No próximo capítulo, este trabalho apresenta de forma sucinta algumas das 
principais técnicas dedicadas à HRA, com comentários a respeito de seus pontos fortes e fracos. Sobre esta base é justificado o emprego das Redes Bayesianas e, em seguida, é apresentada uma breve descrição dos principais conceitos que baseiam esta ferramenta.

A seguir são apresentados resumidamente os objetivos e a estrutura desta dissertação.

\subsection{OBJETIVOS}

O propósito deste trabalho é apresentar uma metodologia e técnicas eficientes de análise de confiabilidade humana aplicáveis a indústria naval. Para cumprir este propósito, foi desenvolvida uma metodologia que se baseia em trabalhos de outros autores (Swain e Guttmann, 1983; Droguett e Menêzes, 2007; Eleye-Datubo, Wall e Wang, 2008) e está apoiada no emprego das Redes Bayesianas para modelar o fator humano. Antes de sua apresentação, no entanto, este trabalho procura justificar o emprego das Redes Bayesianas, comparando suas características com as vantagens e desvantagens de algumas técnicas existentes de análise de confiabilidade humana.

Para auxiliar no entendimento da metodologia desenvolvida, foi proposto um estudo de caso. Com isto, procurou-se saber quais as dificuldades encontradas ao se trabalhar com Redes Bayesianas, quais informações podem ser extraídas do modelo obtido pela aplicação da metodologia proposta e sua significância, e como pode ser feito o aproveitamento de informações de modelos já desenvolvidos pela aplicação de outras técnicas.

O estudo de caso tratou da operação de um navio petroleiro, tendo como foco a análise quantitativa da contribuição do fator humano em cenários de colisão. A fim de comparar as ferramentas utilizadas, esta aplicação foi feita com apoio de um estudo inicial realizado no Departamento de Engenharia Naval e Oceânica da USP em 2007 (Maturana e Martins, 2008). Este estudo inicial abordou a aplicação da HRA, por meio da THERP (Technique for Human Error Rate Prediction), no estudo da operação de um navio petroleiro que percorre a rota entre a Bacia de Campos e São Sebastião realizando o alívio de plataformas tipo FPSO (Floating Production System and Offloading), também considerando cenários de colisão.

Visto o descrito nos parágrafos anteriores, ressalta-se que o objetivo deste 
estudo de caso não é a determinação da probabilidade de colisão do navio estudado - que seria avaliada mais adequadamente se a análise não se restringisse a operação do navio e fosse extrapolada para pontos não modelados (como a fase de projeto, períodos de manutenção da embarcação, etc.).

Buscando apresentar o potencial da metodologia proposta, foram feitas considerações a respeito dos fatores que podem influenciar no desempenho humano e na probabilidade de colisão (utilizando o modelo desenvolvido neste estudo de caso). Os MOF (Management and Organizational Factors) foram listados de acordo com a sua contribuição na probabilidade do acidente em estudo. $O$ mesmo é apresentado para as atividades realizadas no navio, comparando com os resultados obtidos no trabalho anterior, que não puderam ser quantitativos devido às dificuldades encontradas ao lidar com árvores binárias (ver Maturana e Martins, 2008). Todas estas análises foram feitas em função dos desencadeamentos de eventos que podem contribuir para a colisão.

\subsection{ESTRUTURA DA DISSERTAÇÃO}

Esta dissertação está organizada em 7 Capítulos, incluindo este inicial de introdução, objetivos e explicação resumida sobre a estrutura da dissertação.

No Capítulo 2 são apresentados os fundamentos teóricos, iniciando por uma breve discussão sobre os modelos de $1^{\text {a }}$ e $2^{2}$ geração aplicáveis à HRA, focando seus pontos fortes e fracos e a aplicação das Redes Bayesianas como instrumento para superar seus pontos fracos. Em seguida, este capítulo traz os conceitos básicos essenciais para o entendimento das Redes Bayesianas e seu emprego para fazer inferências. Neste contexto, um item é dedicado ao estudo da transformação das Árvores de Falhas em Redes Bayesianas.

No Capítulo 3 é apresentada a metodologia desenvolvida para realização da HRA por meio das Redes Bayesianas e, centralizando na operação de navios petroleiros, é estruturada uma forma para modelar o fator humano com o emprego desta ferramenta. Assim, são apresentados os principais fatores relacionados a esta operação e ao evento de colisão. Para encerrar, é apresentada a maneira empregada no estudo de caso para integrar por meio de uma Árvore de Falhas as redes que modelam tarefas, com objetivo de estudar o evento de colisão. 
No Capítulo 4 é apresentado um estudo de caso com o intuito de verificar a aplicação das Redes Bayesianas na modelagem do fator humano em acidentes de colisão. Para tanto, o sistema é apresentado e é feita uma breve consideração sobre as dificuldades quantitativas encontradas. Na seqüência são modelados os desencadeamentos dos eventos perigosos (aqueles que podem levar a embarcação a colidir), as tarefas que estão relacionadas aos eventos iniciadores destes desencadeamentos (eventos básicos da Árvore de Falhas) e os PSF (Performance Shaping Factors) relacionados a execução destas tarefas. Finalmente, é apresentado o método utilizado para preencher as TPC (Tabelas de Probabilidades Condicionais). Associados a este capítulo estão os Apêndices A e B que apresentam, respectivamente, as tabelas que relacionam os PSF às atividades das tarefas e as Redes Bayesianas Dinâmicas das Tarefas já integradas às Redes dos Fatores de Desempenho obtidas com a modelagem.

O Capítulo 5 é de análise, onde são apresentadas as informações extraídas do modelo descrito no capítulo anterior. Os eventos básicos são estudados em função do evento topo (colisão) de forma a ser encontrado o desencadeamento crítico de acordo com este critério, ou seja, dado o evento de colisão. Dando continuidade a este capítulo, as atividades, fatores internos, habilidades e MOF são analisados detalhadamente em função do evento topo. No caso das atividades, foi feita uma comparação com os resultados alcançados em trabalho anterior (Maturana e Martins, 2008). Para os MOF foram apresentados dois métodos equivalentes para determinar aqueles que mais contribuem para o evento de colisão.

No Capítulo 6 é feita a conclusão final, sendo apresentados os resultados do trabalho e as dificuldades encontradas, além das últimas considerações a respeito desta dissertação e recomendações para trabalhos futuros.

Por fim, no Capítulo 7 são apresentadas as referências consultadas que deram base para este trabalho e podem ser utilizadas para aprofundamento do conhecimento discutido, além de poderem servir para o desenvolvimento de trabalhos posteriores. 


\section{FUNDAMENTOS TEÓRICOS}

Neste capítulo, serão apresentados os fundamentos para o emprego das Redes Bayesianas na HRA. Primeiramente serão considerados alguns pontos a respeito da HRA e das técnicas dedicadas à sua aplicação. Dentro deste contexto, são apresentadas justificativas para o emprego das Redes Bayesianas como instrumento para a análise quantitativa da confiabilidade humana. Em seguida, é apresentada uma explanação a respeito desta ferramenta, focando os pontos considerados importantes para o entendimento do estudo de caso exposto no capítulo 4. Para encerrar, são apresentados alguns pontos sobre a modelagem de domínios por meio das Redes Bayesianas e um procedimento para sua construção na análise de confiabilidade.

\subsection{HUMAN RELIABILITY ANALYSIS (HRA)}

A HRA tem suas raízes no estudo do desempenho humano e tem grande aplicabilidade na indústria nuclear (Gertman e Blackman, 1993), onde a análise da segurança tem papel fundamental devido à grande responsabilidade em lidar com centrais nucleares e a complexidade do sistema como um todo.

A HRA é um procedimento que envolve atividades de análise com aplicação de técnicas especificas para cada estágio e, dependendo do nível de PSA que está sendo realizado, pode ser quantitativa ou qualitativa. Se for requerida a análise quantitativa completa, então HEP (Human Error Probabilities) devem ser determinadas para alimentar modelos tais como Árvores de Falhas e de Eventos (IMO, 2002), por exemplo. A HRA usualmente consiste dos seguintes estágios: 1) Identificação de Tarefas-chave; 2) Análise das Tarefas-chave; 3) Identificação dos Erros Humanos; 4) Análise dos Erros humanos; 5) Quantificação da Confiabilidade Humana. A Tabela 1 apresenta as relações entre os passos da FSA e as etapas previstas para a HRA (IMO, 2002).

\begin{tabular}{|c|c|c|c|c|c|}
\hline Passos da FSA & \begin{tabular}{|c|} 
Passo 1 \\
Identificação dos Perigos \\
\end{tabular} & $\begin{array}{c}\text { Passo } 2 \\
\text { Análise de Risco }\end{array}$ & $\begin{array}{c}\text { Passo } 3 \\
\text { Opções de Controle de } \\
\text { Risco } \\
\end{array}$ & $\begin{array}{c}\text { Passo } 4 \\
\text { Análise de Custo } \\
\text { Benefício } \\
\end{array}$ & $\begin{array}{c}\text { Passo } 5 \\
\text { Recomendações a } \\
\text { Tomada de Decisão }\end{array}$ \\
\hline $\begin{array}{c}\text { Tarefas } \\
\text { Requeridas } \\
\text { para a } \\
\text { Incorporação } \\
\text { da HRA }\end{array}$ & $\begin{array}{l}\text { - Perigos Relacionados } \\
\text { a Fatores Humanos; } \\
\text { - Análise de Tarefas de } \\
\text { Alto Nível; } \\
\text { - Descrição Preliminar } \\
\text { dos Resultados. }\end{array}$ & $\begin{array}{l}\text { - Análise Detalhada das } \\
\text { Tarefas Críticas; } \\
\text { - Análise do Erro } \\
\text { Humano; } \\
\text { - Quantificação do Erro } \\
\text { Humano. }\end{array}$ & $\begin{array}{l}\text { - Opções de } \\
\text { Controle de Risco } \\
\text { para o Elemento } \\
\text { Humano. }\end{array}$ & & \\
\hline
\end{tabular}

A seguir, apresenta-se uma descrição sucinta dos principais estágios da HRA 
relacionados com os passos da FSA:

- Passo 1 - Identificação de Perigos: Neste passo devem-se identificar as ações humanas que, se não executadas apropriadamente, podem levar o sistema a falhar. Por meio de ampla investigação, devem-se identificar as áreas de interesse (tarefas e sub-tarefas) e como os erros humanos podem contribuir para acidentes durante situações normais e de emergência. No desenvolvimento da análise das tarefas pode-se utilizar uma gama de técnicas - tais como entrevistas, observação, relatos de incidentes críticos - muitas das quais podem ser utilizadas diretamente na identificação de tarefas-chave. Adicionalmente, existe uma série de informações que podem ser consultadas, incluindo informações do projeto, experiências passadas e procedimentos de operação normais e em emergência. O resultado desta etapa é uma gama de tarefas, sub-tarefas e atividades associadas a perigos críticos;

- Passo 2 - Análise de Risco: O propósito deste passo é identificar as áreas em que o fator humano se coloca como de alto risco para a segurança do sistema e avaliar os fatores que influenciam no nível de risco. Pode ser composto das seguintes etapas:

- Análise Detalhada de Tarefas: Nesta etapa as tarefas críticas são detalhas em suas atividades principais, levando em consideração os objetivos de cada atividade e seus executores. Nesta fase também devem ser levantados os fatores que influenciam na execução da tarefa - tais como ambiente de trabalho, grau de dificuldade, interface homem-máquina, se é feita em condições normais ou de emergência;

- Análise do Erro Humano: O propósito desta análise é produzir uma lista de potenciais erros humanos que podem levar a conseqüências indesejadas. Estes erros precisam ser analisados quanto a sua causa provável, o potencial para correção do erro pelo próprio executor ou por outra pessoa, e as conseqüências do erro;

- Quantificação do Erro Humano: A quantificação do erro humano 
pode ser feita de diferentes maneiras - julgamento de especialistas, registros históricos e probabilidades genéricas de erro. Para estes dois últimos casos, existem técnicas associadas a banco de dados de erro humano, sendo que a THERP, que será detalhada adiante, é amplamente empregada. Ao se aplicar esta técnica para a quantificação do erro, geralmente utiliza-se uma aproximação da HEP, visto que não se pode dizer que os dados disponíveis (levantados em laboratório, em condições controladas) sempre se ajustam ao ambiente real de trabalho (Gertman e Blackman, 1993);

- Passo 3 - Opções de Controle de Risco: Para a realização deste passo é necessário definir ações para a redução da freqüência do erro por meio da mitigação de seus efeitos e/ou alívio das circunstâncias em que ocorre. O resultado esperado para este passo é uma série de opções de controle de risco a serem aplicadas no sistema - Por exemplo: treinamento da tripulação; mudanças de layout ou ergonômicas; especificação de informações a serem disponibilizadas e desenvolvimento de procedimentos de emergência.

Com o passar dos anos foram desenvolvidas diversas técnicas aplicadas a HRA. A compreensão do conjunto das técnicas existentes para a aplicação da HRA está atrelada ao entendimento da evolução histórica destas técnicas. É interessante notar a forte conexão entre o acidente em Three-Mile Island, em 28 de março de 1979, e o crescimento do número de técnicas para HRA - conforme apontado na Figura 1 (Hollnagel, 2005). Este acidente (melhor detalhado por General Accounting Office, 1980), é considerado um marco, já que a partir dele o fator humano se tornou uma das principais preocupações, tanto no projeto de salas de controle como em outros pontos das centrais nucleares.

Como demonstrado na Figura 1 (Hollnagel, 2005), os métodos considerados de 1a geração surgiram a partir de 1975, sendo o trabalho publicado por Rasmussen (NUREG-75/014, 1975) considerado pioneiro nesta área (Kirwan, 1994). Muitos métodos surgiram nos anos 80, com maior crescimento em 1984 . Este período foi acompanhado por outro menos acentuado em torno de 1996, que representou o 
aparecimento dos então chamados métodos de $2^{a}$ geração. Estes métodos tentaram suprimir as críticas então existentes à HRA (Hollnagel, 2005).

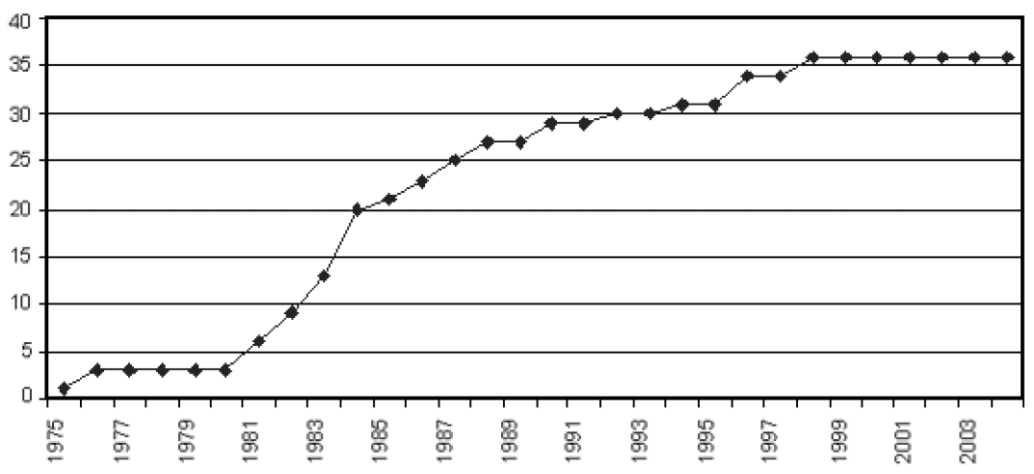

Figura 1 - Número de técnicas para HRA (Hollnagel, 2005)

Com o intuito de demonstrar a evolução atual das técnicas desenvolvidas para a HRA, a seguir serão apresentados rapidamente os principais métodos de $1^{\text {a }}$ geração, focalizando os seus pontos fortes e fracos. E, na seqüência, o mesmo será feito para os modelos de $2^{\underline{a}}$ geração. Para finalizar a discussão sobre as técnicas dedicadas à HRA, será apresentado um tópico a respeito das Redes Bayesianas como ferramenta para o estudo quantitativo da confiabilidade humana - objetivando a supressão de algumas das desvantagens dos modelos de $1^{\text {a }}$ e $2^{\underline{a}}$ geração, além da incorporação das suas principais vantagens.

\subsubsection{MODELOS DE 1aㅡ GERAÇÃO}

A maioria das técnicas de $1^{\text {ạ }}$ geração foi desenvolvida para a indústria nuclear e tem como característica marcante o trabalho com modelos dicotômicos para modelar e quantificar as situações que podem conduzir a erros. Dentre estas, destacam-se a HEART (Human Error Assessment and Reduction Technique) e a THERP que, por este motivo, foram escolhidas para uma breve apresentação. Como uma descrição detalhada de todas as técnicas disponíveis foge do escopo deste trabalho, recomenda-se Hollnagel (1998) que enumera uma lista de referências para diferentes métodos classificados como de $1^{\mathfrak{a}}$ geração.

\subsubsection{HUMAN ERROR ASSESSMENT AND REDUCTION TECHNIQUE (HEART)}

A HEART foi desenvolvida por Williams em 1986 (Kirwan, 1994). De maneira geral, é uma técnica que envolve a classificação de tarefas em grupos especificados por uma tabela. A cada grupo se associa uma HEP nominal. Para a obtenção da probabilidade final de erro humano na execução da tarefa, esta HEP nominal deve 
ser multiplicada por fatores (denominados EPC - Error Producing Condition) que consideram o cenário em que a ação se desenvolve. Todas estas associações devem ser apoiadas na opinião de especialistas. Os passos específicos para a aplicação da HEART são:

- Identificação de todas as atividades requeridas para que determinado operador do sistema realize a tarefa estudada;

- Com estas informações em mãos, solicita-se a opinião de especialistas sobre a probabilidade de haver erro na execução da tarefa;

- Consideram-se, de acordo com a opinião de especialistas, quais EPC podem ter efeito negativo sobre a execução da tarefa. Assim, determina-se o grau de efeito de cada EPC;

- Por fim, calcula-se a HEP para a atividade, considerando-se os EPC que inegavelmente têm influência na tarefa dentro do contexto em que ela se desenvolve.

A Tabela 2 apresenta um resumo das vantagens e desvantagens levantadas para esta técnica.

Tabela 2 - Vantagens e desvantagens da HEART

\section{Vantagens}

- É de aplicação rápida, clara e demanda poucos recursos;

- Proporciona ao usuário sugestões de como reduzir a ocorrência de erros;

- Provê um link imediato entre fatores ergonômicos e características de projeto do sistema;

- Permite análise de custo benefício;

- É altamente flexível e permite sua aplicação em uma ampla gama de áreas, o que pode justificar sua popularidade.

\section{Desvantagens (Kirwan, 1994)}

- Os dados apresentados que determinam os EPC nunca foram completamente validados;

- É fortemente dependente da opinião de especialistas, sendo os resultados influenciados por suas tendências (otimistas ou pessimistas);

- A interdependência entre os EPC não foi modelada.

\subsubsection{TECHNIQUE FOR HUMAN ERROR RATE PREDICTION (THERP)}

A THERP foi desenvolvida por Swain e Guttmann (1983) do Sandia National Laboratories para a U.S. Nuclear Regulatory Commission e se tornou um método bastante utilizado para a avaliação quantitativa da HRA (Gertman e Blackman, 1993).

Esta técnica combina um método de modelagem com uma coleção de dados empíricos para taxas básicas de falha humana (HEP) que são modificadas por uma 
série de fatores de forma (PSF). Além disto, emprega Árvores de Falhas e de Eventos para, através do uso de portas lógicas, representarem as relações de causa e conseqüência no sistema que está sendo analisado. Desta forma, são determinadas as probabilidades de ocorrência dos cenários de acidentes.

A utilização das árvores de probabilidades se dá de forma semelhante ao que se faz para a confiabilidade de sistemas, mas considerando, ao invés dos estados do sistema e equipamentos, as atividades humanas e as suas correspondentes probabilidades de erros. Isto permite ao analista avaliar a degradação do sistema homem-máquina considerando os erros dos indivíduos quando os equipamentos estão funcionando, os processos e operações a serem realizados, além de outras características humanas que podem influenciar o funcionamento do sistema. Para a aplicação da THERP são requeridos os seguintes passos:

- Definição das falhas do sistema: identificar todos os subsistemas na operação que podem ser influenciados ou afetados por fatores humanos;

- Listagem e análise das ações humanas relacionadas à operação do sistema: elaborar uma lista de tarefas considerando todas as operações humanas realizando uma análise detalhada de cada tarefa;

- Estimativa das probabilidades de erro relevantes (das atividades que trazem risco ao sistema, identificadas no passo anterior): determinar as probabilidades dos erros humanos (HEP) por meio de banco de dados, julgamento de especialistas e/ou experiência. A THERP considera os PSF para definir o valor da probabilidade de erro em uma atividade estes PSF são fatores que influenciam a tarefa no nível operacional. Para verificar a probabilidade de falha na tarefa são utilizadas Árvores de Eventos. Assim, com divisões binárias é representada a execução correta ou incorreta;

- Estimativa do efeito dos erros humanos nos eventos de falha do sistema: determinar os efeitos dos erros humanos ao integrar os erros humanos nas Árvores de Falhas;

- Opções de Controle de Risco: recomendar mudanças no sistema e 
recalcular as probabilidades de falhas do sistema modificado.

A Tabela 3 apresenta um resumo das vantagens e desvantagens levantadas para esta técnica.

Tabela 3 - Vantagens e desvantagens da THERP

Vantagens (IMO, 2002)

- Boa ferramenta para comparação relativa de riscos, ou seja, para verificar o efeito de mudanças em procedimentos operacionais ou mesmo comparar a magnitude do risco em plantas diferentes;

- Devido ao nível de detalhe requerido, força o analista a ganhar uma profunda visão do sistema e dos potenciais erros humanos envolvidos;

- Pode ser utilizada para verificar a participação do erro humano em termos de magnitude de risco, e não necessariamente em termos de probabilidades ou freqüências;

- Pode ser utilizada com as Árvores de Falhas na FSA;

- O seu banco de dados pode ser utilizado sistematicamente, permitindo inclusive a inserção de novos dados de erro quando disponíveis.

\section{Desvantagens}

- É difícil associar uma probabilidade ao erro humano, pois o ser humano pode se corrigir dependendo da situação, antes que o problema ocorra, trazendo incertezas às HEP disponibilizadas (Swain e Guttman, 1983);

- Consideração impessoal do erro: duas pessoas não possuem a mesma reação como equipamentos (Swain e Guttman, 1983);

- Não consideração de fatores tais como humor, disposição, ânimo, prudência, personalidade (Swain e Guttman, 1983);

- Falta de banco de dados específico para a área naval (IMO, 2002);

- Pode exigir recursos intensos devido ao nível de detalhe requerido para aplicá-la propriamente (IMO, 2002);

- Diante das dificuldades em modelar ações humanas utilizando árvores binárias de eventos, este método não considera a dependência entre eventos e entre fatores de desempenho (Hollnagel, 1998).

\subsubsection{MODELOS DE 2 a GERAÇÃO}

Com o intuito de superar as deficiências apontadas nos modelos de $1^{\text {a }}$ geração, surgiram, na década de 90, técnicas centradas em modelos de comportamento humano (considerando mais explicitamente os fatores cognitivos). Dentre estas técnicas destacam-se o CREAM (Cognitive Reliability and Error Analysis Method) e a ATHEANA (A Technique for Human Error Analysis). Estas técnicas serão descritas rapidamente a seguir, juntamente com o modelo IDAC (Information, Decision and Action in Crew Context), proposto por Chang e Mosleh (2007).

\subsubsection{COGNITIVE RELIABILITY AND ERROR ANALYSIS METHOD (CREAM)}

O CREAM, apresentado por Hollnagel (1998), é um método concebido para relacionar causas e conseqüências. Desta forma, com a aplicação deste método, pretende-se a determinação das causas dados os efeitos ou dos efeitos dadas as causas. 
Este modelo constitui uma tentativa de quantificar mais explicitamente a influência dos diversos fatores sobre o desempenho dos operários através de uma generalização da Árvore de Eventos numa classificação policotômica (Droguett e Menêzes, 2007). Ou seja, esta técnica se baseia no estabelecimento de cadeias de eventos integrando modos de erros, genótipos humanos, equipamentos e fatores organizacionais.

A Tabela 4 apresenta um resumo das vantagens e desvantagens levantadas para este método.

Tabela 4 - Vantagens e desvantagens do CREAM

\section{Vantagens (Salmon, Stanton e Walker, 2003)}

- Permite a quantificação direta dos HEP;

- É flexível, permitindo ao usuário adaptação ao contexto em que os eventos ocorrem;

- O método utiliza os mesmos princípios para a análise retrospectiva e para a preditiva.

\section{Desvantagens}

- Requer grande quantidade de recursos, incluindo tempo para ser completada (Salmon, Stanton e Walker, 2003);

- Requer conhecimento no campo de falhas humanas para perfeita aplicação, podendo ser muito complicada para usuários inexperientes (Salmon, Stanton e Walker, 2003);

- Não ajuda a apontar os potenciais pontos para a redução de erros (Salmon, Stanton e Walker, 2003);

- Não incorpora explicitamente o tratamento de contextos dinâmicos (Salmon, Stanton e Walker, 2003);

- Trabalha com a suposição de independência entre os eventos (Droguett e Menêzes, 2007).

\subsubsection{A TECHNIQUE FOR HUMAN ERROR ANALYSIS (ATHEANA)}

Esta técnica, desenvolvida para U.S. Nuclear Regulatory Commission (NUREG/CR-6350, 1996), foi concebida para a análise posterior de incidentes. Essencialmente, este é um método para reportar acidentes de forma estruturada e padronizada, de maneira que possa ser facilmente entendida e comunicada. Seu propósito principal é auxiliar a entender mais facilmente o comportamento humano em centrais nucleares. Para isto, procura uma estrutura psicológica robusta para avaliar e identificar os PSF - incluindo fatores organizacionais e de meio ambiente que tem levado a incidentes. O resultado alcançado pela aplicação desta técnica é a identificação de várias ações humanas e sua associação a situações contextuais que podem levar ao sucesso ou erro na execução da tarefa. Assim, o modelo resultante pode indicar soluções para incrementar a confiabilidade (NUREG/CR6350, 1996). Não existem, no entanto, aspectos numéricos envolvidos na metodologia utilizada para construir o modelo (como não traz como resultado uma HEP é marcantemente diferente dos métodos de 1a geração). Desta forma, esta 
técnica não é propícia para certos campos - tais como projetos comparativos e análises de sensibilidade. No entanto, não sendo preditiva, também pode ser útil como ferramenta para se fazer diagnósticos.

$\mathrm{Na}$ ATHEANA, os diversos fatores envolvidos em um acidente, e suas possíveis conseqüências, são agrupados levando em consideração: influência organizacional, fatores de desempenho, falhas mecânicas, ações inseguras, evento de erro humano, e resultados inaceitáveis. São sete os passos básicos desta técnica (NUREG-1880, 2007):

- Definir e interpretar o assunto em questão;

- Detalhar o escopo requerido da análise;

- Definição do cenário básico de acidente, considerando o ambiente, ações e processos;

- Definição dos HFE (Human Failure Events - são os possíveis erros nas ações) e/ou UA (Unsafe Actions - é a ação na qual o operador pode errar e, com isto, levar à operação insegura do sistema) que podem afetar a tarefa em questão;

- Categorização mais profunda dos HFE e suas relações com as UA;

- Procura de possíveis desvios do cenário básico de acidente em termos de prováveis divergências no ambiente de operação em virtude do contexto de emergência;

- De posse dos dados do passo anterior, são escolhidas combinações dos EFC (Error-forcing Context) e PSF, de acordo com o que for considerado adequado para a tarefa.

A Tabela 5 apresenta um resumo das vantagens e desvantagens levantadas para esta técnica.

\subsubsection{MODELO IDAC}

Na modelagem do comportamento humano, os idealizadores do modelo IDAC propõem a decomposição das atividades humanas em três tipos genéricos, no que convencionaram chamar processo I-D-A - as atividades podem ser de recebimento e processamento de informação (I), de solução de problemas e tomada de decisão 
(D), ou ainda de execução de ação no processo (A). Sendo proposto que estas atividades podem ser decompostas em atividades ainda mais simples, sendo cada uma classificada de acordo com o processo I-D-A (Chang e Mosleh, 2007).

Tabela 5 - Vantagens e desvantagens da ATHEANA

\begin{tabular}{l} 
Vantagens \\
\hline - \\
gentendimento mais rico e global das causas de incidentes do que os métodos de $1^{\underline{a}}$ \\
- Aumenta a garantia de que os riscos associados aos eventos de erro humano serão \\
identificados; \\
- Depois de aplicada, permite mais segurança nas estimativas das HEP ao definir os \\
fatores de desempenho e suas combinaçôes; \\
- Tem como característica a possibilidade de considerar dependência entre os fatores \\
associados à execução de determinada tarefa. \\
\hline - Análise preditiva quantitativa se torna mais demorada e dispendiosa; \\
- Não aprofunda o entendimento das causas e suas dependências com os diversos fatores \\
- de influência; \\
- As conseqüências dos erros humanos se limitam às seqüencias pré-definidas de \\
- É considerada ineficiente para a análise preditiva.
\end{tabular}

Em 2007, os autores publicaram uma série de cinco artigos oferecendo uma visão geral sobre o modelo IDAC e seus avanços até aquele momento (ver Chang e Mosleh, 2007, 2007b, 2007c, 2007d, e 2007e).

Como apoio para a modelagem, o diagrama de influência IDAC apresenta relações de causa e efeito entre PSF, provendo subsídios para a simulação do comportamento humano e sua interação com as outras partes do sistema, considerando basicamente que o modelo humano recebe informações e entrega ações humanas ao sistema (Mosleh e Chang, 2004).

A Tabela 6 enumera algumas vantagens e desvantagens relacionadas a este modelo.

\subsubsection{EMPREGO DAS REDES BAYESIANAS}

Como apontado nos subitens anteriores, cada técnica traz vantagens e desvantagens. Verifica-se que alguns dos pontos tidos como fortes na THERP (boa ferramenta para comparação preditiva de riscos, por exemplo) são vistos como pontos fracos da ATHEANA (não recomendada para análise preditiva). Na verdade, a incapacidade de atender a todas as demandas por uma única técnica parece ter sido a causa da atual variedade de modelos. 
Tabela 6 - Vantagens e desvantagens do modelo IDAC

\begin{tabular}{|c|}
\hline Vantagens \\
\hline $\begin{array}{l}\text { - Pode ser empregado para obtenção de resultados preditivos (Chang e Mosleh, 2007c); } \\
\text { - Provê vários cenários de acidente, permitindo uma análise quantitativa do desempenho } \\
\text { - } \text { - Abranano (Mosleh e Chang, 2004); } \\
\text { - Permite bom detalhamento e, por ser orientado à modelagem computacional, traz } \\
\text { resultados que dificilmente seriam considerados, mesmo por um analista experiente } \\
\text { - } \text { Posleh e Chang, 2004); } \\
\text { - Propõe uma metodologia para incremento gradual de conhecimento sobre o } \\
\text { comportamento humano (Mosleh e Chang, 2004). }\end{array}$ \\
\hline Desvantagens \\
\hline $\begin{array}{l}\text { - O modelo não representa todas as dependências entre as ações humanas e PSF } \\
\text { numerados (Droguett e Meneses, 2007); } \\
\text { - O modelo causal não foi validado (Mosleh e Chang, 2004); } \\
\text { - A influência de fatores relacionados às bases de conhecimento dos operadores ainda } \\
\text { não foi adequadamente considerada (Mosleh e Chang, 2004); } \\
\text { - Os modelos quantitativos não foram validados (Mosleh e Chang, 2004); } \\
\text { - } \text { humadelo ainda está em desenvolvimento e centraliza-se na modelagem do fator } \\
\text { distintos dos propostos pelos autores (Droguett e Meneses, 2007; Chang e Mosleh, } \\
\text { 2007e); } \\
\text { - Devido à variedade e complexidade de suas regras internas, é mais adequado para a } \\
\text { - } \text { simulação computacional (Chang e Mosleh, 2007c); } \\
\text { - Exige dados e evidências de difícil obtenção (Chang e Mosleh, 2007e). }\end{array}$ \\
\hline
\end{tabular}

Dentro da expectativa de minimizar as limitações das técnicas existentes, o uso das Redes Bayesianas vem sendo proposto como uma possibilidade de agregar as vantagens das principais técnicas. Em outras palavras, o uso das Redes Bayesianas vem sendo proposto como uma boa maneira para modelar os fatores de influência na ação humana (Mosleh e Chang, 2004; Droguett e Menêzes, 2007; Eleye-Datubo, Wall e Wang, 2008).

Dentre as limitações apontadas nas técnicas listadas estão alguns pontos fortes da modelagem por meio das Redes Bayesianas. A capacidade de representação dinâmica do sistema e a possibilidade de representar qualquer dependência entre os fatores de influência na atividade humana (dependendo apenas da opinião de especialistas) são excelentes exemplos. As vantagens associadas à representação do sistema por meio das Redes Bayesianas estão apresentadas na Tabela 7.

Apesar de todas as vantagens, as Redes Bayesianas não podem ser vistas como soluções em si mesmas. Com o intuito de averiguar tais vantagens e levantar possíveis dificuldades no seu emprego, foi realizado um estudo de caso aplicando 
uma metodologia de análise baseada no uso das Redes Bayesianas como ferramenta para modelar o fator humano. Trata-se da análise dos fatores humanos que influenciam em acidentes de colisão de navios petroleiros (isto foi feito com base em um artigo publicado por Maturana e Martins (2008) que traz o mesmo assunto avaliado por meio da THERP e Árvores de Falhas). A metodologia e este estudo de caso serão apresentados nos capítulos subseqüentes.

Tabela 7 - Vantagens das Redes Bayesianas na HRA

\begin{tabular}{l} 
Vantagens \\
\hline - Podem ser utilizadas para se fazer diagnósticos e prognósticos; \\
- Pode ser padronizado um mecanismo para a elaboração dos gráficos; \\
- Trazem resultados quantitativos. Permitem inferências diretamente da rede \\
(dependendo do programa utilizado); \\
- Podem ser alimentadas por dados já existentes; \\
transformadas em Redes Bayesianas); \\
Podem ser elaboradas redes dinâmicas para representar o desencadeamento de \\
eventos e a ordem em que as atividades de determinada tarefa é executada (bons \\
modelos causais); \\
- São recomendadas para análise comparativa de risco. Incluindo decisões a respeito \\
de qualidades requeridas de operadores.
\end{tabular}

Dentre as dificuldades encontradas no emprego das Redes Bayesianas durante o estudo de caso, podem-se citar:

- Manipulação de sistemas complexos: por permitirem grande detalhamento e a modelagem de qualquer dependência entre as variáveis do sistema, exigem bom conhecimento sobre o sistema a ser modelado, ou seja, é necessário conhecer bem o sistema para determinar quais dependências são significativas;

- Preenchimento das TPC: pode ser uma tarefa difícil, muitas vezes são necessárias probabilidades condicionais difíceis de serem obtidas;

- Para permitir a modelagem, pode ocorrer de serem empregadas variáveis discretas para modelar fenômenos contínuos na natureza, trazendo imprecisões ao modelo. 
As dificuldades encontradas serão discutidas mais propriamente no decorrer da dissertação e no capítulo final, com as conclusões deste trabalho.

A seguir, para facilitar o entendimento das Redes Bayesianas como ferramenta para a aplicação da HRA, serão apresentadas suas características principais e, na seqüência, alguns pontos sobre a modelagem do domínio por meio das Redes Bayesianas. Isto será feito antes da apresentação da metodologia de análise do fator humano empregando as Redes Bayesianas.

\subsection{EXPLANAÇÃO SOBRE AS REDES BAYESIANAS}

As Redes Bayesianas, também conhecidas como redes de opinião, redes causais, gráficos de dependência probabilística, são modelos gráficos para raciocínio baseado na incerteza, onde os nós representam as variáveis discretas ou contínuas, e os arcos representam a conexão direta entre eles (Charniak, 1991). Elas foram desenvolvidas no início dos anos 80 para facilitar a tarefa de predição e abdução em sistemas de Inteligência Artificial (AI) (Pear, 1988) e vêm se tornando a metodologia padrão para a construção dos sistemas que confiam no conhecimento probabilístico, sendo aplicáveis a uma variedade de atividades (medicina, engenharia, etc.).

Além disto, as Redes Bayesianas são uma maneira sucinta para representar conjunções de probabilidades. De modo direto e estruturado, elas apresentam as dependências entre as variáveis de um domínio. Esta representação leva este nome porque trabalha com conhecimento incerto e incompleto, tratado inicialmente por meio da teoria de probabilidade Bayesiana (publicada por Thomas Bayes, em 1763).

As Redes Bayesianas são particularmente úteis para a representação de domínios em que existem informações a respeito de dependência condicional entre suas variáveis. Partindo deste tipo de informação é possível, então, a representação compacta do domínio.

Para uma melhor compreensão, neste tópico as Redes Bayesianas serão estudadas em sua estrutura e conceitos básicos. E para o entendimento de sua aplicação no estudo de caso, serão discutidas as técnicas para inferência e a modelagem de Árvores de Falhas por meio das Redes Bayesianas. É importante ressaltar que este tópico não se destina a esgotar o tema, mas apenas servir de apoio para a compreensão dos assuntos subseqüentes. 


\subsubsection{CONCEITOS BÁSICOS}

Dado um evento $e^{l}$, o conceito de sua probabilidade é a medida da freqüência em que $e$ ocorre. Outra interpretação de probabilidade representa o grau de crença de uma pessoa que determinado evento irá ocorrer em um experimento único. A interpretação de probabilidade como freqüência em uma série de experimentos repetidos é referida como interpretação objetiva. De outra forma, a interpretação de probabilidade como grau de crença é chamado de interpretação subjetiva ou Bayesiana. Assim, na interpretação Bayesiana, a probabilidade sempre dependerá do conhecimento de quem a provê ou do que esta pessoa assume ser verdade.

Uma Rede Bayesiana é um grafo direcionado em que cada nó representa uma variável aleatória (que pode ser discreta ou contínua). Estes nós são conectados por arcos direcionados representando as dependências entre as variáveis do domínio que está sendo modelado. Se um dado arco parte do nó $Y$ e chega ao nó $Z$, diz-se que $Y$ é pai de $Z$, e que $Z$ é filho de $Y$. Quantitativamente, cada nó $X_{i}$ recebe uma distribuição de probabilidades condicionais $P\left(X_{i} \mid\right.$ pais $\left.\left(X_{i}\right)\right)$ exprimindo a influência dos nós pais (nesta expressão pais $\left(X_{i}\right)$ representa o conjunto dos nós pais do nó $X_{i}$ ). As redes bayesianas não apresentam ciclos direcionados, ou seja, não é possível passar duas vezes por determinado nó seguindo um caminho que respeite as orientações dos arcos - a Figura 2 apresenta um grafo cíclico e um acíclico. Devido a isto, é classificada como um grafo direcionado acíclico (ou DAG Directed Acyclic Grafh) na teoria dos grafos.

A seguir será apresentado um exemplo típico de Rede Bayesiana extraído de Russell e Norvig (2003) e que pode ser de grande auxílio para compreender a descrição acima. Neste exemplo as variáveis são booleanas.
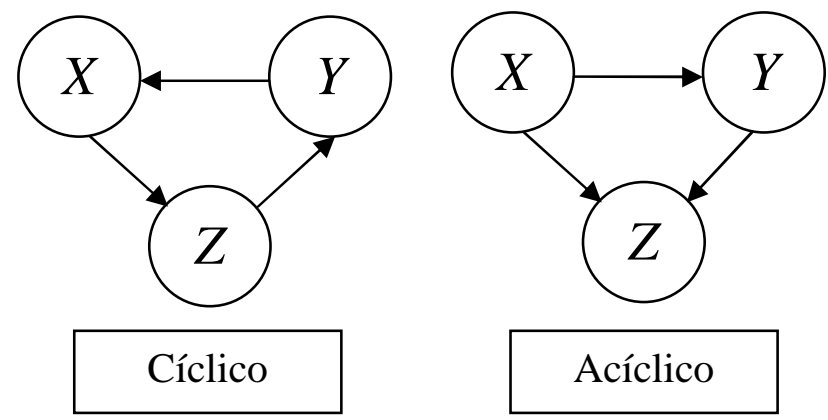

Figura 2 - Exemplos de grafos direcionados

\footnotetext{
${ }^{1}$ Neste trabalho, os eventos serão representados por letras minúsculas e as variáveis e nós, por maiúsculas. Aplicação de Redes Bayesianas na Análise da Contribuição da Falha Humana em Acidentes de Colisão - 20
} 
Considere-se a instalação de um novo sistema de alarme em uma residência. Este sistema é muito confiável para a detecção de ladrões, mas também responde em caso de pequenos terremotos. O dono da casa tem dois vizinhos, João e Maria, que se comprometeram a telefonar caso ouvissem o alarme. João sempre liga quando ouve o alarme, mas às vezes se confunde com o som do telefone da residência e liga também neste caso. Maria gosta de ouvir som alto e às vezes esquece o alarme. Pretende-se, por meio de uma Rede Bayesiana, estimar a probabilidade de haver um ladrão na casa, dada a evidência das ligações telefônicas (ou falta delas). Uma Rede Bayesiana para este caso está apresentada na Figura 3.

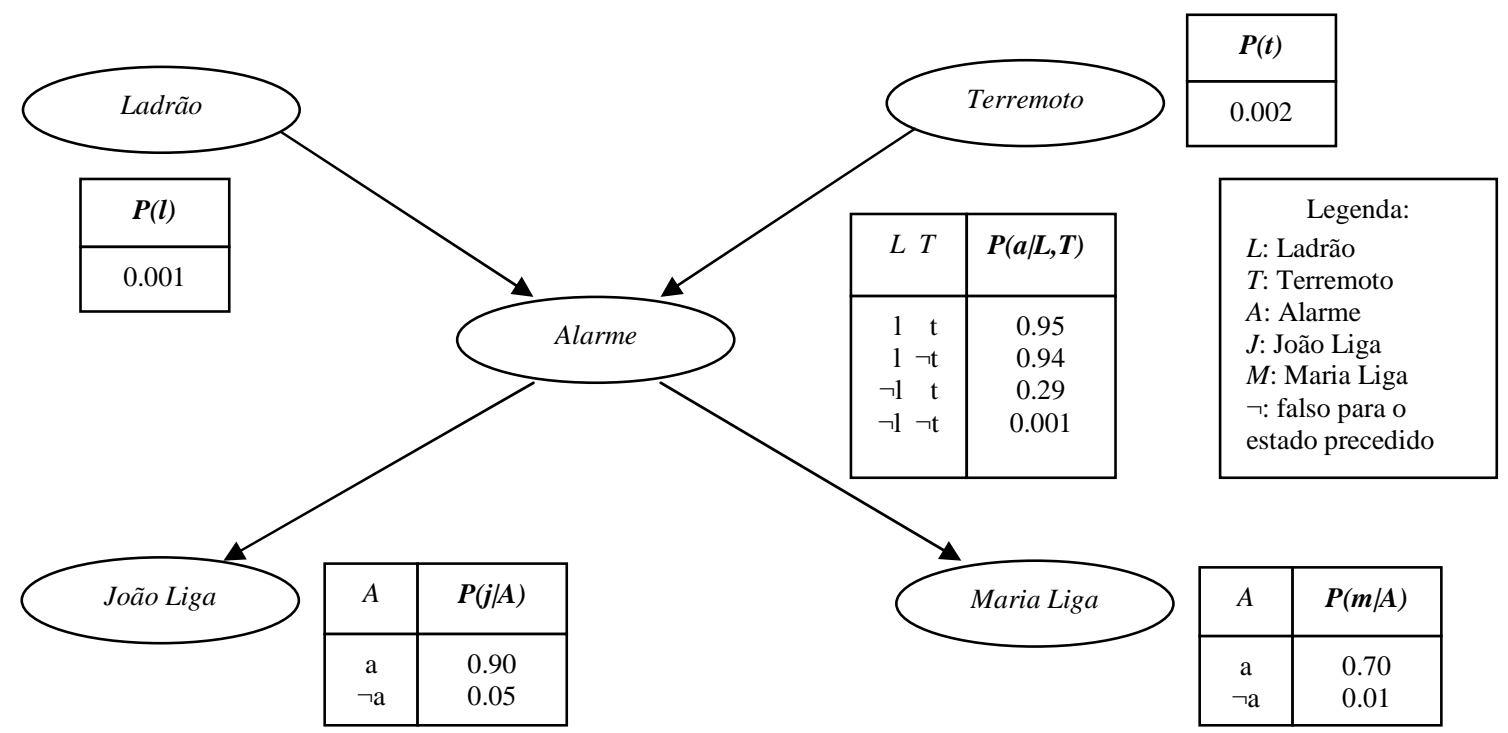

Figura 3 - Rede Bayesiana típica demonstrando a topologia e as TPC

Observa-se nesta figura a presença das TPC. Cada linha destas tabelas representa a probabilidade relacionada ao nó, dados os estados dos nós pais. Um nó (considerando variáveis booleanas) com $\mathrm{k}$ pais deverá apresentar $2^{\mathrm{k}}$ linhas em sua tabela de probabilidades condicionais. Um nó que não possui pais apresenta apenas as probabilidades iniciais relacionadas a cada valor da variável. Ainda em relação à Figura 3, nota-se que, para este exemplo, são apresentadas apenas as probabilidades relacionadas aos eventos positivos associados ao nó.

Conforme pode ser observado, a topologia da rede diz muito sobre o assumido em termos de dependência entre as variáveis do problema. Desta topologia pode-se concluir que tanto o terremoto quanto a entrada de ladrões afetam a probabilidade de o alarme ser acionado. Pode-se verificar que as ligações da Maria ou do João dependem apenas do acionamento do alarme. Desta forma, 
verifica-se que foi assumido que tanto Maria quanto João não percebem os ladrões diretamente, e que os terremotos são ignorados por eles. Outro ponto importante é que eles não se conferem antes de ligar.

Ao olhar para a proposição do problema e para a rede desenvolvida, algumas objeções poderiam ser feitas. Por exemplo: 1) não apresenta um nó correspondente ao momento em que Maria está ouvindo som alto; 2) não se representou a hipótese de confusão de João com o barulho do telefone; 3) as possíveis falhas no equipamento não foram especificadas (apesar de ter sido mencionada sua alta confiabilidade); 4) não se considerou que Maria ou João poderiam estar de férias, no supermercado, etc. Estas indagações são justificadas da seguinte maneira (Russell e Norvig, 2003): os fatores relacionados aos pontos 1 e 2 foram incluídos nas incertezas associadas aos arcos Alarme - João Liga e Alarme - Maria Liga porque se tornou difícil encontrar probabilidades específicas para estes casos; já em relação ao ponto 3 , estas possibilidades também foram representadas por meio de incremento nas probabilidades condicionais relacionadas ao nó Alarme; em relação ao ponto 4, por simplificação, houve também um incremento nas incertezas associadas aos arcos Alarme - João Liga e Alarme - Maria Liga.

Do parágrafo anterior, conclui-se que as probabilidades tentam sumarizar uma infinita gama de possibilidades para os eventos relacionados. De outra forma a representação se tornaria muito complexa ou mesmo inviável. Sendo assim, verificase que com simplificações é possível enfrentar problemas complexos, pelo menos aproximadamente.

Em relação aos conceitos probabilísticos envolvidos neste tipo de representação, está posta a seguir uma breve descrição dos conceitos probabilísticos básicos que permitem a representação dos domínios, de maneira compacta, por meio das Redes Bayesianas. Primeiramente serão apresentados os conceitos de probabilidade condicional e de conjunção de probabilidades e, na seqüência, as bases para a representação do domínio por meio das Redes Bayesianas.

\subsubsection{PROBABILIDADE CONDICIONAL}

A probabilidade condicional $P(a \mid b)=x$ se relaciona com a sentença: "dado o evento $b$, a probabilidade de $a$ é $x$ ". Uma regra fundamental que se extrai da 
definição de probabilidade condicional é conhecida como regra do produto. Esta propriedade está representada na Equação (2.1) para dois eventos.

$$
P(a, b)=P(a \mid b) P(b)
$$

Nesta equação $P(a, b)$ é a probabilidade de ocorrer $a^{\wedge} b^{2}$. Na seção 2.2.1.3, esta relação será explorada para demonstrar a plena representação do domínio por meio das Redes Bayesianas. Desta equação pode-se concluir que se os eventos $a \mathrm{e}$ $b$ são independentes, então $P(a \mid b)=P(a)$ e, portanto, $P(a, b)=P(a) P(b)$, que é a igualdade utilizada nas portas lógicas “E” numa Árvore de Falhas (ver item 2.2.3).

Outra relação que se extrai da definição de probabilidade condicional é a Equação (2.2). Da Equação (2.1), e lembrando que $P(a, b)=P(b, a)$, conclui-se:

$$
P(a \mid b)=\frac{P(b \mid a) P(a)}{P(b)}
$$

Esta relação é conhecida como Regra de Bayes e auxilia na obtenção da probabilidade a partir do surgimento de uma evidência. Ela será explorada no tópico sobre inferência exata.

\subsubsection{CONJUNÇÃO DE PROBABILIDADES}

A conjunção de probabilidades para as variáveis $A$ e $B$, ou $P(A, B)$, pode ser representada em uma tabela $\mathrm{n} \times \mathrm{m}$, onde $\mathrm{n}$ é o número de estados de $A$ e $\mathrm{m}$ o número de estados de $B^{3}$ (nas Redes Bayesianas cada estado pode ser um evento). Sendo $P(A)=\langle 0.4 ; 0.6\rangle^{4}$ e $P(B)=\langle 0.4 ; 0.4 ; 0.2\rangle$, tem-se para $P(A, B)$ a Tabela 8 .

Tabela 8 - Conjunção de Probabilidades das variáveis $A$ e
\begin{tabular}{|c|c|c|c|}
\hline & $b_{1}$ & $b_{2}$ & $b_{3}$ \\
\hline$a_{1}$ & 0.16 & 0.12 & 0.12 \\
\hline$a_{2}$ & 0.24 & 0.28 & 0.08 \\
\hline
\end{tabular}

Nesta tabela cada célula representa uma configuração para a conjunção de probabilidades (as entradas do domínio).

Nota-se que para um problema com grande número de variáveis é necessário um número ainda maior de entradas nesta tabela. Sendo assim, torna-se sensível a necessidade de uma representação mais simples para domínios complexos; com

\footnotetext{
${ }^{2}$ Probabilidade de ocorrência dos eventos $a$ e $b$.

${ }^{3}$ Ressalta-se que nada foi mencionado a respeito da dependência entre as variáveis.

${ }^{4}$ Onde cada valor representa a probabilidade de um possível estado da variável $A$.
} 
grande número de variáveis. A representação por Redes Bayesianas pode ser utilizada para suprir esta necessidade.

\subsubsection{REPRESENTAÇÃO DO DOMÍNIO}

As Redes Bayesianas promovem a representação completa do domínio, mas de maneira mais enxuta que as tabelas de conjunção de probabilidades. Por meio das relações de dependência condicional entre as variáveis do domínio, é possível determinar a topologia adequada para a Rede Bayesiana. Partindo das informações apresentadas nesta rede é possível identificar qualquer entrada do domínio modelado. A seguir está apresentada a obtenção de uma equação por meio da qual este propósito pode ser alcançado. Além disto, também está apresentado um exemplo de sua aplicação.

Genericamente, a notação $P\left(x_{1}, x_{2}, \ldots, x_{n}\right)$ é equivalente a $P\left(X_{1}=x_{1} \wedge X_{2}=x_{2} \wedge \text {... } X_{n}=x_{n}\right)^{5}$ e representa uma dada entrada do domínio. Observando a regra do produto, obtém-se a seguinte equação para esta entrada:

$$
P\left(x_{1}, x_{2}, \ldots, x_{n}\right)=P\left(x_{n} \mid x_{n-1}, \ldots, x_{1}\right) P\left(x_{n-1}, \ldots, x_{1}\right)
$$

A reaplicação sistemática da regra do produto gera a identidade apresentada nas Equações (2.4) e (2.5), conhecida como Regra da Cadeia.

$$
\begin{gathered}
P\left(x_{1}, x_{2}, \ldots, x_{n}\right)=P\left(x_{n} \mid x_{n-1}, \ldots, x_{1}\right) P\left(x_{n-1} \mid x_{n-2}, \ldots, x_{1}\right) \ldots P\left(x_{2} \mid x_{1}\right) P\left(x_{1}\right) \\
P\left(x_{1}, x_{2}, \ldots, x_{n}\right)=\prod_{i=1}^{n} P\left(x_{i} \mid x_{i-1}, \ldots, x_{1}\right)
\end{gathered}
$$

Para o caso de uma Rede Bayesiana, tem-se a Equação (2.6), que é válida se for considerada a restrição apresentada na Equação (2.7).

$$
\begin{gathered}
P\left(X_{i} \mid X_{i-1}, \ldots, X_{1}\right)=P\left(X_{i} \mid \operatorname{pais}\left(X_{i}\right)\right) \\
\operatorname{pais}\left(X_{i}\right) \subseteq\left\{X_{i-1, \ldots,}, X_{1}\right\}
\end{gathered}
$$

A Equação (2.6) aponta a independência de cada nó em relação aos seus predecessores, excetuando-se os nós pais. E a Equação (2.7) presume que os nós pais foram enumerados antes dos nós filhos (Charniak, 1991).

\footnotetext{
${ }^{5}$ Sendo $X_{i}$ uma denominação para uma variável e $x_{i}$ para um de seus estados
} 
Os resultados apresentados nas Equações (2.5) e (2.6) tornam possível a obtenção da Equação (2.8).

$$
P\left(x_{1}, x_{2}, \ldots, x_{n}\right)=\prod_{i=1}^{n} P\left(x_{i} \mid \operatorname{pais}\left(X_{i}\right)\right)
$$

Desta forma, cada entrada da conjunção de probabilidade pode ser obtida por meio da multiplicação dos elementos certos, presentes nas tabelas de probabilidades condicionais da rede.

A completa conjunção de probabilidades pode dar qualquer informação a respeito do domínio representado. A Rede Bayesiana pode ser utilizada para gerar os dados completos a respeito da conjunção podendo, desta forma, ser utilizada para representar o domínio, sem perda de informação. Como ilustração, pode-se calcular (utilizando o exemplo apresentado na Figura 3) a probabilidade de o alarme ter tocado, mas sem ter havido terremoto nem presença de ladrão, e João e Maria (ambos) terem ligado. O desenvolvimento do cálculo está apresentado nas Equações (2.9) e (2.10).

$$
\begin{aligned}
& P(j, m, a, \neg l, \neg t)=P(j \mid a) P(m \mid a) P(a \mid \neg l, \neg t) P(\neg l) P(\neg t) \\
& P(j, m, a, \neg l, \neg t)=0.9 * 0.7 * 0.001 * 0.999 * 0.998=0.00062
\end{aligned}
$$

Para encerrar a discussão sobre a representação do domínio por meio das Redes Bayesianas, serão considerados alguns pontos sobre a complexidade da rede e obtenção das TPC e sobre a obtenção de informações partindo da topologia da rede.

\subsubsection{COMPLEXIDADE DA REDE}

Assim como as tabelas de conjunção de probabilidades, as Redes Bayesianas são uma representação completa e não redundante do domínio. No entanto, são uma forma mais compacta de representação porque consideram as restrições no relacionamento entre as variáveis. Esta propriedade faz com que sejam úteis para o trabalho com domínios de muitas variáveis.

Para exemplificar esta característica pode-se tomar uma rede com 10 nós, com 2 estados cada, na qual 7 nós possuam 3 nós pais e os demais possuam apenas nós filhos (sem dependências condicionais), conforme Figura 4. Para este caso são necessários $7 \times 2^{3}+3=59$ números para preencher as TPC; já a tabela de 
conjunção de probabilidades necessitaria de $2^{10}=1024$ números. A quantidade de dados para popular uma rede bayesiana cresce linearmente com a quantidade de nós (mantendo fixa a quantidade de arcos por nó), enquanto na tabela da conjunção de probabilidade esta quantidade cresce exponencialmente.

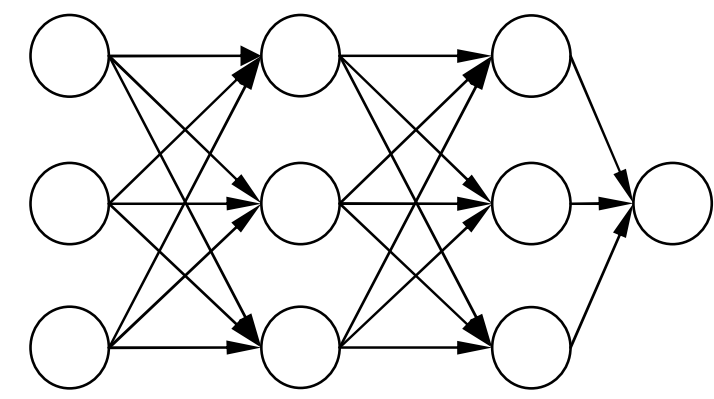

Figura 4 - Estrutura da rede exemplo

A complexidade da rede depende do grau de detalhamento requerido. É importante notar que o detalhamento pode trazer dificuldades para encontrar as probabilidades para popular a rede (preencher as TPC). No exemplo da rede da Figura 3 podem-se incluir as hipóteses de João ou Maria não ligarem porque no momento em que ouviram o alarme ocorria um terremoto, e consideraram ser este $o$ motivo de acionamento. Neste caso, deveria haver um arco entre Terremoto e João Liga e outro entre Terremoto e Maria Liga, e deveriam ser encontradas probabilidades tais como a de Maria ligar dado que houve terremoto e o alarme foi acionado. O que se deve ponderar é relação entre os ganhos com este detalhamento e os custos para se obter as informações necessárias a este incremento.

\subsubsection{RELAÇÕES DE DEPENDÊNCIA PARTINDO DA TOPOLOGIA}

Partindo das relações de dependência entre as variáveis de um domínio, é possível determinar a topologia da rede que representa este domínio. Neste ponto é justificado que, partindo de uma rede pronta, também é possível determinar as condições de dependência entre as variáveis do domínio, dada alguma evidência (ou não). Isto pode ser feito considerando, por exemplo, uma das seguintes assertivas (Russell e Norvig, 2003):

- Um nó é condicionalmente independente de todos os nós que não são seus descendentes, dados seus nós pais (a Figura 5 ilustra os subconjuntos formados para uma rede simples); 
- Um nó é condicionalmente independente de todos os outros da rede dados seus pais, seus filhos e os pais dos seus filhos - este subconjunto de nós é referido em Pearl (1988) como o Markov Blanket e está ilustrado na Figura 6 (formado pelos nós internos à zona pontilhada).

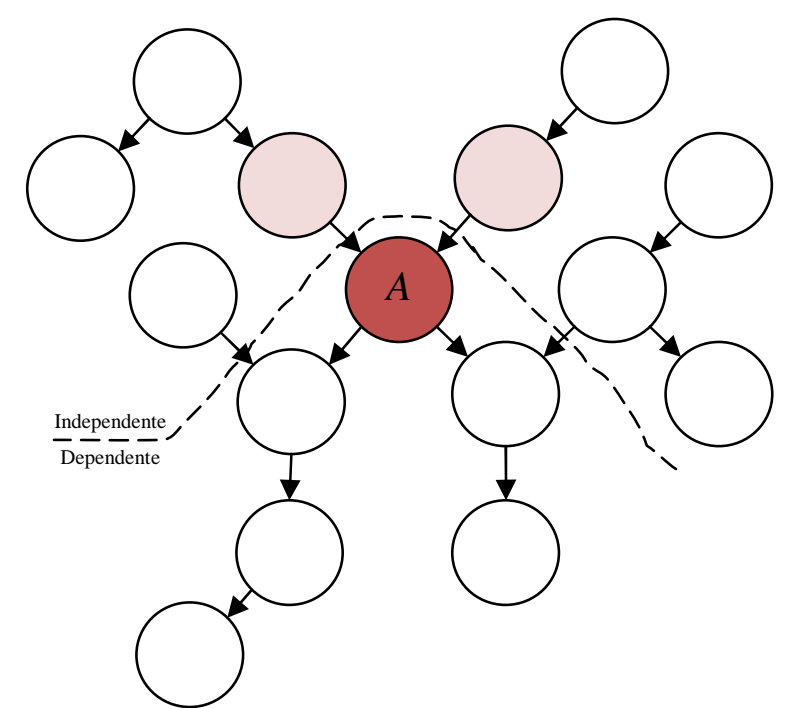

Figura 5 - Dependência do nó $A$, dados os nós pais

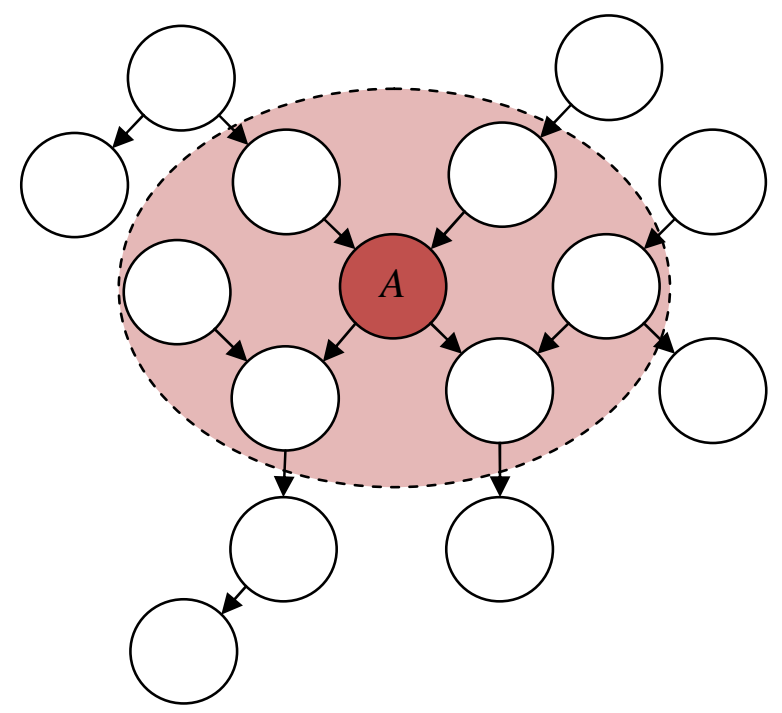

Figura 6 - Markov Blanket para o nó $A$

Outra maneira para verificar se um nó $A$ é independente de outro nó $B$ é observar o critério da d-separação (Pear, 1988; Charniak, 1991). Em outras palavras, este critério é utilizado para apontar a independência entre subconjuntos de nós. $O$ nó $A$ é dito d-separado (independente) de $B$ se todo caminho entre $A$ e $B$ se apresentar de alguma das formas apontadas na Figura 7 . 
Os nós $A$ e $B$ são condicionalmente independentes, dada a evidência $\mathrm{E}$, ou ocorrendo um nó como o $D$. Desta maneira, E (sendo $C$ um nó pertencente a E) e/ou $D$ bloqueiam o caminho ente $A$ e $B$. Em resumo, o bloqueio pode ocorrer de três formas:

- O nó $C$ possui um arco de entrada e um de saída no caminho;

- O nó $C$ possui dois arcos de saída no caminho;

- $\quad D$ não pertence a E, e $D$ possui dois arcos de chegada no caminho.

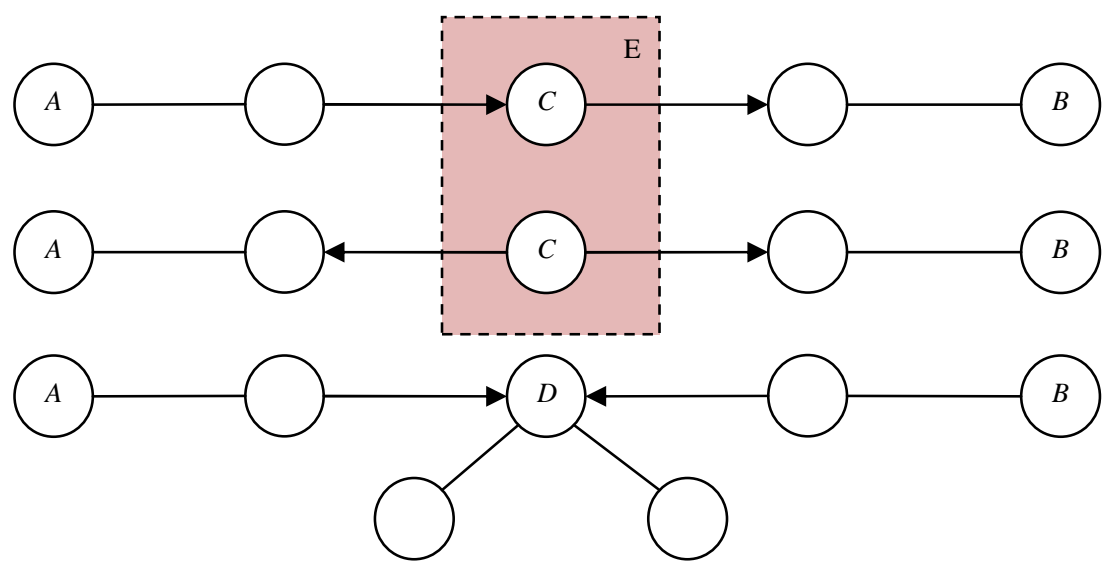

Figura 7 - Nós $A$ e $B$ : d-separados

A prova para estas assertivas pode ser encontrada em Pear (1988).

Encerrado o tópico sobre as relações de dependência dadas pela topologia, pode-se trabalhar com as TPC para obter informações probabilísticas da rede. A seguir serão discutidos alguns aspectos relevantes sobre inferência.

\subsubsection{INFERÊNCIA}

Além de representar o domínio de maneira compacta e intuitiva, as Redes Bayesianas possibilitam computar as probabilidades posteriores ${ }^{6}$ de certas variáveis, dado o conhecimento de certos eventos. As variáveis ligadas a estes eventos são classificados como variáveis de evidência. Com este recurso podem ser feitas inferências com três objetivos:

- Causas: dadas as causas obter as probabilidades dos efeitos;

- Diagnósticos: dados os efeitos, obter as probabilidades das causas;

${ }^{6}$ Probabilidades associadas aos estados dos nós da rede depois de encontrada alguma evidência. 
- Intercausais: dada a evidência de uma causa, obtém-se a probabilidade de outra causa.

Estas possibilidades foram ilustradas na Figura 8.
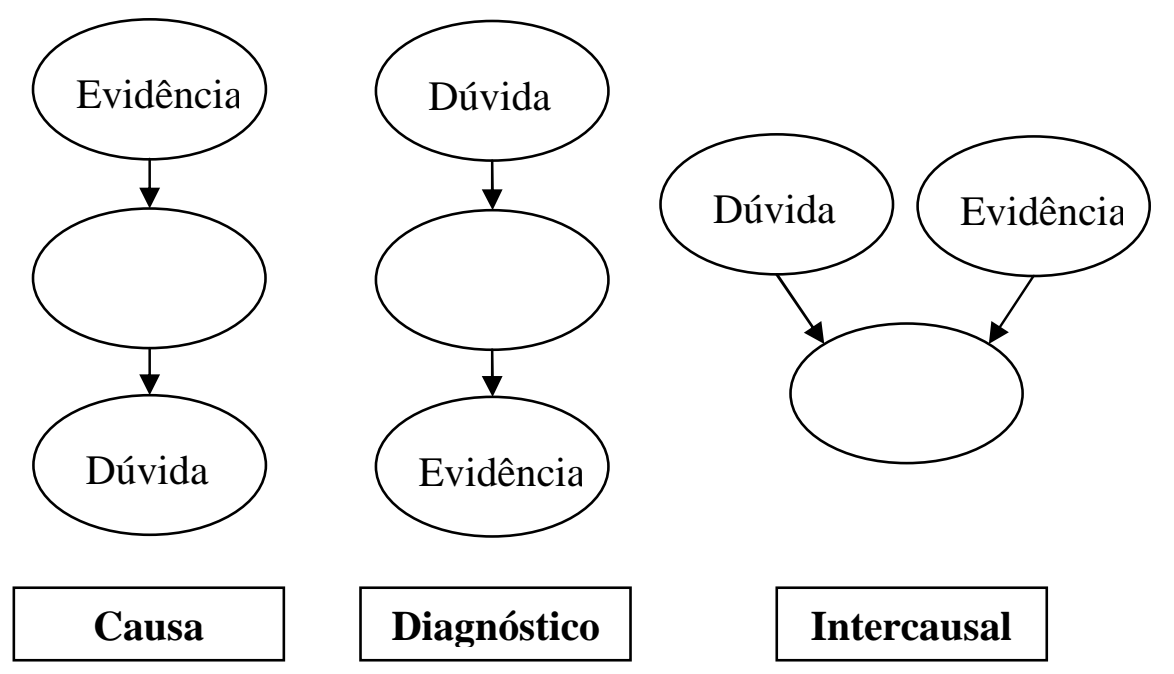

Figura 8 - Inferência

Além de consultas a partir de evidências, as Redes Bayesianas podem ser utilizadas para (Marques e Dutra, 2006): 1) tomar decisões baseadas em probabilidades; 2) decidir quais evidências adicionais devem ser observadas a fim de se obter informações úteis do sistema; 3) analisar o sistema a fim de buscar os aspectos do modelo que possuem maior impacto sobre as variáveis de consulta; 4) explicar os resultados de uma inferência probabilística a terceiros.

Os algoritmos desenvolvidos para a solução das redes bayesianas podem ser divididos entre os que trazem solução exata e os que trazem solução aproximada. Foge do propósito deste trabalho uma apresentação detalhada destas questões. Sendo assim, será apresentada apenas uma visão geral sobre estes algoritmos. A princípio serão apresentadas algumas técnicas para inferência exata e, por final, algo sobre as inferências aproximadas.

\subsubsection{INFERÊNCIA EXATA}

Considerando-se que $\mathrm{E}=\left\{E_{1}, \ldots, E_{m}\right\}$ represente 0 conjunto das variáveis de evidência de determinado domínio, sendo e uma dada evidência; seja $X$ uma variável qualquer não pertencente a $\mathrm{E}$; e $\mathrm{Y}=\left\{Y_{1}, \ldots, Y_{l}\right\}$ o conjunto das variáveis que não pertencem às classificações anteriores. Uma questão típica seria determinar a distribuição posterior de probabilidade de $X$, ou seja, determinar $P(X \mid \mathrm{E})$. 
Tome-se como exemplo o caso da rede da Figura 3. Considere-se que João Liga seja verdadeiro e que Maria Liga seja verdadeiro também. Neste caso, a probabilidade de haver ladrão na casa é igual a 0.284 . As probabilidades condicionais como esta podem ser obtidas pela soma das entradas da conjunção de probabilidades (Russell e Norvig, 2003). Esta afirmação pode ser justificada partindo-se da regra do produto (Equação (2.1)) e levando em consideração todos os possíveis estados para os nós pertencentes a Y. Desta forma, obtêm-se as relações apresentadas nas Equações (2.11) e (2.12).

$$
P(X \mid \mathrm{E})=\alpha P(X, \mathrm{E})=\alpha \sum_{y} P(X, \mathrm{E}, \mathrm{Y})
$$

sendo que:

$$
\alpha=\frac{1}{P(\mathrm{E})}
$$

O termo $P(X, \mathrm{E}, \mathrm{Y})$ pode ser obtido diretamente das tabelas de probabilidades condicionais pela utilização da Equação (2.8). Retornando ao exemplo citado, a distribuição de probabilidade da variável Ladrão, dada a evidência das ligações, pode ser obtida das Equações (2.13) e (2.14).

$$
\begin{gathered}
P(\text { Ladrão } \mid \text { João _ Liga }=\text { verdadeiro }, \text { Maria _ Liga }=\text { verdadeiro })=\alpha P(L, j, m) \\
\alpha P(L, j, m)=\alpha \sum_{t} \sum_{a} P(L, T, A, j, m)
\end{gathered}
$$

Sendo assim, para determinar a probabilidade de haver ladrão na casa, dada a evidência citada, utiliza-se a Equação (2.15).

$$
P(l \mid j, m)=\alpha P(l) \sum_{t} P(T) \sum_{a} P(A \mid l, T) P(j \mid A) P(m \mid A)
$$

A estrutura desta expressão (Equação (2.15)) pode ser visualizada na Figura 9 , onde as setas indicam as multiplicações a serem feitas. Os resultados finais de cada caminho devem ser multiplicados por $\alpha$ e somados.

Obtém-se, da maneira indicada, o resultado abaixo.

$$
P(l \mid j, m)=\alpha^{*} 0.00059224
$$


Falta agora a obtenção de $\alpha$. As Equações (2.17) e (2.18) cumprem este

papel.

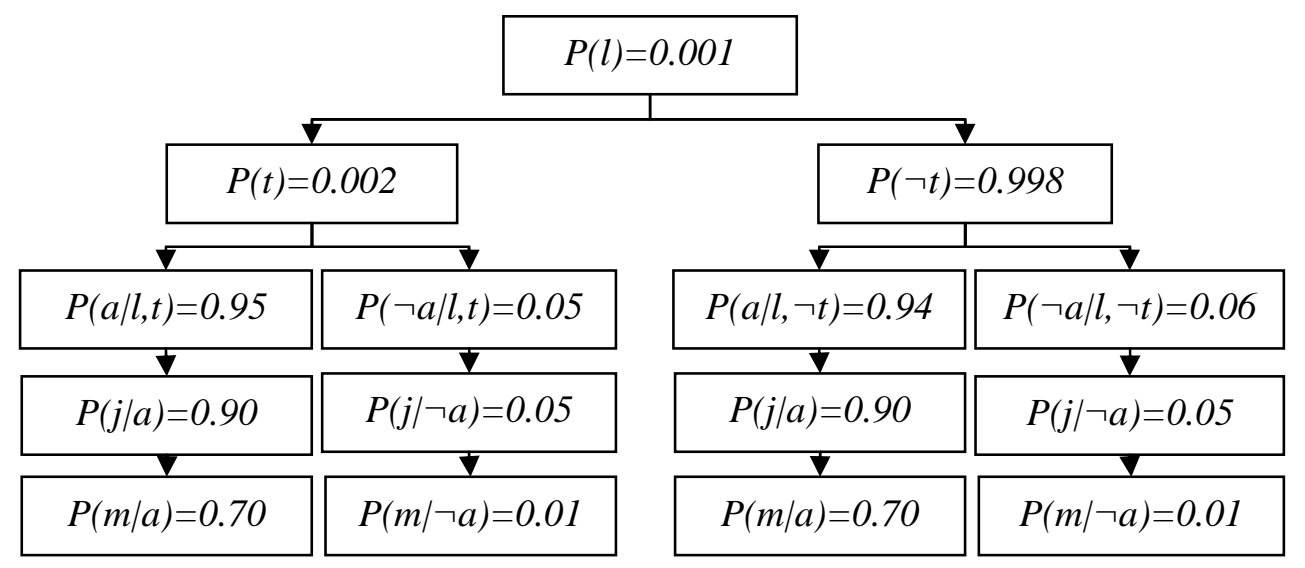

Figura 9 - Visualização do cálculo

$$
\begin{gathered}
\alpha=\frac{1}{P(j, m)}=\sum_{l} \sum_{t} \sum_{a} P(L, T, A, j, m) \\
P(j, m)=\sum_{l} \sum_{t} \sum_{a} P(L) P(T) P(A \mid L, T) P(j \mid A) P(m \mid A)
\end{gathered}
$$

Aplicando os dados do exemplo à Equação (2.18) obtêm-se os resultados da Tabela 9.

Tabela 9 - Cálculo de $\mathrm{P}(\mathrm{j}, \mathrm{m})$

\begin{tabular}{|c|c|c|c|c|c|c|}
\hline Estado do Sistema & $\boldsymbol{P}(\boldsymbol{L})$ & $\boldsymbol{P}(\boldsymbol{T})$ & $\boldsymbol{P}(\boldsymbol{A} \mid \boldsymbol{L}, \boldsymbol{T})$ & $\boldsymbol{P}(j \mid \boldsymbol{A})$ & $\boldsymbol{P}(\boldsymbol{m} \mid \boldsymbol{A})$ & Total \\
\hline$P(l, t, a, j, m)$ & 0.001 & 0.002 & 0.950 & 0.900 & 0.700 & $1.197 \mathrm{E}-06$ \\
\hline$P(l, t, \neg a, j, m)$ & 0.001 & 0.002 & 0.050 & 0.050 & 0.010 & $5.000 \mathrm{E}-11$ \\
\hline$P(l, \neg t, a, j, m)$ & 0.001 & 0.998 & 0.940 & 0.900 & 0.700 & $5.910 \mathrm{E}-04$ \\
\hline$P(l, \neg t, \neg a, j, m)$ & 0.001 & 0.998 & 0.060 & 0.050 & 0.010 & $2.994 \mathrm{E}-08$ \\
\hline$P(\neg l, t, a, j, m)$ & 0.999 & 0.002 & 0.290 & 0.900 & 0.700 & $3.650 \mathrm{E}-04$ \\
\hline$P(\neg l, t, \neg a, j, m)$ & 0.999 & 0.002 & 0.710 & 0.050 & 0.010 & $7.093 \mathrm{E}-07$ \\
\hline$P(\neg l, \neg t, a, j, m)$ & 0.999 & 0.998 & 0.001 & 0.900 & 0.700 & $6.281 \mathrm{E}-04$ \\
\hline$P(\neg l, \neg t, \neg a, j, m)$ & 0.999 & 0.998 & 0.999 & 0.050 & 0.010 & $4.980 \mathrm{E}-04$ \\
\hline \multicolumn{7}{|r|}{} \\
\hline
\end{tabular}

Com apoio da Tabela 9, obtêm-se as relações abaixo para $\alpha$.

$$
\alpha=\frac{1}{P(E)}=\frac{1}{P(j, m)}=479.82
$$

Com o explicitado, obtém-se a distribuição de probabilidade da variável Ladrão, dada a evidência de João e Maria terem ligado, apresentada na Equação (2.20), que era o objetivo inicial. Nesta equação, o primeiro valor indica a 
probabilidade de haver ladrão e o segundo, a de não haver.

$$
P(L \mid j, m)=\langle 0.284 ; 0.716\rangle
$$

A probabilidade de haver ladrão, dadas as evidências citadas no exemplo, pode parecer baixa, mas está atrelada à probabilidade de haver ladrão, sem as evidências $(P(l))$. No entanto, comparando o resultado acima com $P(l)$, é um valor 284 vezes maior. Se $P(l)$ fosse 0.003 (três vezes maior que no exemplo), então $P(l \mid j, m)$ seria 0.544 ; e para $P(l)=0.01$, então $P(l \mid j, m)$ seria 0.8 . Tudo isto considerando inalteradas as eficiências de João e Maria em perceber o alarme e as demais variáveis.

O procedimento seguido acima é preciso e pode ser utilizado para qualquer rede. No entanto, torna-se extremamente dispendioso para redes com muitos nós e relações de dependência. Para simplificar estes cálculos foram desenvolvidos diversos meios. A seguir são apresentadas as linhas gerais de três possibilidades de simplificação dos cálculos: 1) eliminação de variáveis; 2) agrupamento de variáveis; 3) métodos aproximados.

\subsubsection{ELIMINAÇÃO DE VARIÁVEIS}

Conforme pode ser observado na Figura 9, para uma rede simples, existem alguns cálculos que são repetidos. Numa rede maior esta repetição se torna ainda mais onerosa, em termos de custo de processamento e tempo. Desta forma, foram desenvolvidas várias técnicas baseadas no princípio de executar estes cálculos repetitivos uma única vez, guardando os resultados na memória, para consulta posterior. Em Russell e Norvig (2003) está apresentada a técnica de eliminação de variáveis ${ }^{7}$, que é considerada a técnica mais simples deste tipo.

\subsubsection{AGRUPAMENTO DE VARIÁVEIS}

O agrupamento de variáveis é uma técnica amplamente utilizada em muitas ferramentas comerciais que trabalham com Redes Bayesianas. Esta técnica consiste em agrupar certas variáveis da rede de forma que esta se torne uma rede simplesmente conexa.

Uma rede simplesmente conexa é aquela em que existe no máximo um caminho não direcionado (em que não importa a orientação dos arcos) entre um par

\footnotetext{
${ }^{7}$ Ressalta-se que são eliminadas as variáveis necessárias para a execução dos cálculos e não as da rede analisada. Aplicação de Redes Bayesianas na Análise da Contribuição da Falha Humana em Acidentes de Colisão - 32
} 
de nós. Uma rede com múltiplas conexões, em contrapartida, possui pares de nós se conectando por mais de uma combinação de arcos. A Figura 10 apresenta o exemplo de uma rede com múltiplas conexões simplificada pelo agrupamento de um par de seus nós.
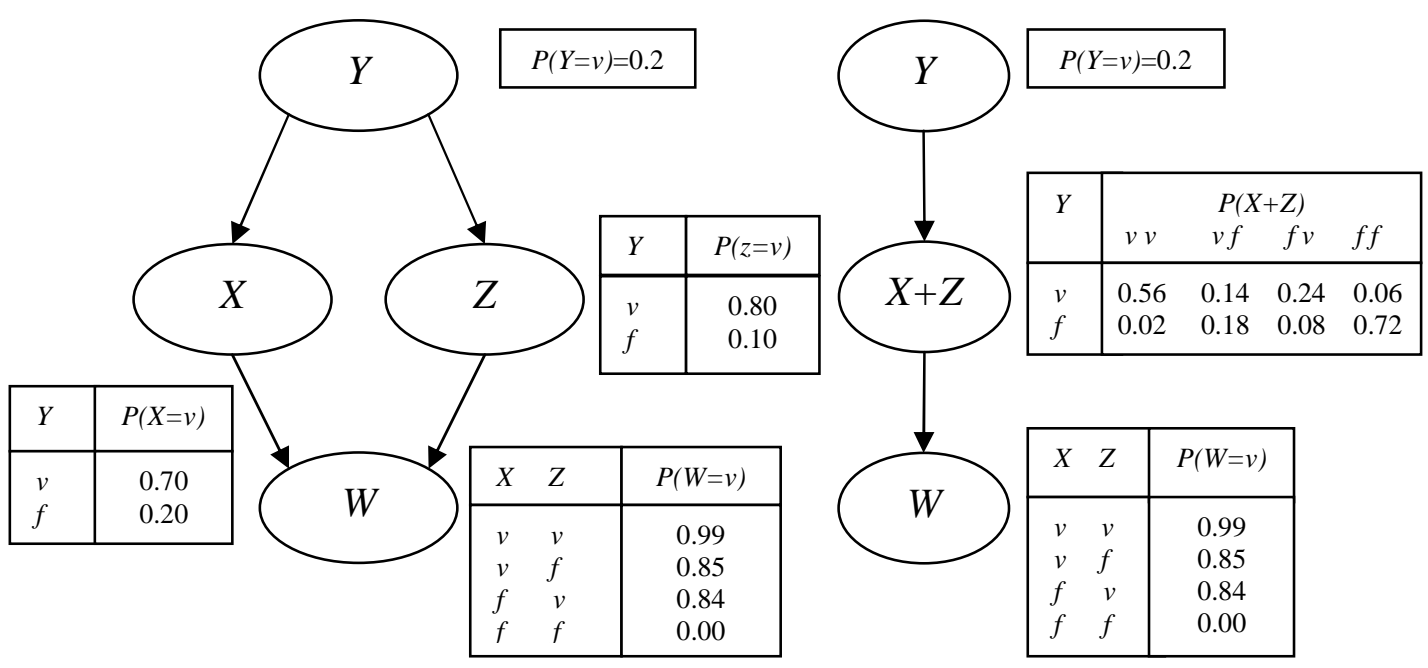

Múltiplas Conexões

Simplesmente Conexa

Figura 10 - Agrupamento de variáveis

Neste exemplo, com uma rede original com variáveis booleanas, o nó gerado pelo agrupamento de outros dois $(X \mathrm{e} Z)$ representa uma única variável com quatro estados que são combinações dos estados dos nós originais (são obtidos os estados $v v, v f, f v, e f f)$. A obtenção da TPC para o nó gerado $(X+Z)$ se faz pela combinação das probabilidades dos nós originais. Por exemplo, para o caso do novo estado $v v$ (representando os estados verdadeiro para $X$ e verdadeiro para $Z$ ), multiplica-se $P(X=v \mid Y=v)$ por $P(Z=v \mid Y=v)$, ou seja, 0.7 por 0.8 . Assim, obtém-se 0.56 para a probabilidade de $X$ e $Z$ serem verdadeiros, dado que $Y$ é verdadeiro.

A vantagem de se fazer inferências exatas utilizando redes simplesmente conexas está no tempo de processamento (linear com a quantidade de nós). No caso de redes agrupadas, a geração das tabelas de probabilidades condicionais para o nó agrupado também demanda tempo. Este tempo deve ser levado em consideração para a avaliação da complexidade da inferência exata utilizando esta técnica. 


\subsubsection{INFERÊNCIA APROXIMADA}

Dada a impossibilidade de tratamento adequado por meio de inferência exata em redes extensas e com múltiplas conexões, é essencial a consideração de métodos de inferência aproximados (Russell e Norvig, 2003). Os métodos aproximados utilizam simulação estocástica. Isto significa que para uma determinada rede são gerados resultados aleatórios que são trabalhados estatisticamente e fornecem uma aproximação para a condição desejada. Para melhor compreensão destas idéias, toma-se o exemplo da rede da Figura 10. Segue-se então o procedimento a seguir:

- Atribui-se um valor aleatório ao nó raiz $(Y)$ da rede (ponderado pela probabilidade da variável, ou seja, $P(Y))$;

- Dependendo do valor obtido no passo anterior, atribui-se um valor aleatório para as variáveis representadas pelos nós filhos $(X$ e $Z)$ do nó raiz (esta atribuição deve ponderar as probabilidades das TPC que consideram o estado obtido no passo anterior para o nó raiz);

- Os passos anteriores devem ser repetidos considerando que os nós pais passam a ser $X$ e $Z$, e o nó filho passa a ser $W$. E as considerações anteriores continuam válidas.

Da Figura 10, tem-se que $P(Y)=0.2$. Assim, se o procedimento acima for repetido $\mathrm{N}$ vezes (sendo $\mathrm{N}$ um número grande), espera-se que $Y$ seja igual a verdadeiro em $20 \%$ das rodadas.

Para a obtenção da probabilidade posterior $P(X=v \mid Y=v)$, por exemplo, deve-se repetir o procedimento descrito acima $\mathrm{N}$ vezes. Então, utilizando o princípio contido na Equação (2.1), contabiliza-se o número de vezes que a combinação $(Y=v) \bigcup(X=v)$ apareceu. Este resultado deve ser dividido pelo número de vezes que $(Y=v)$ ocorreu independentemente de $(X=v)$. O quociente obtido desta operação tende a se aproximar do valor exato da inferência conforme $\mathrm{N}$ aumenta (Marques e Dutra, 2006).

Muito mais poderia ser dito a respeito dos métodos de inferência. No entanto, conforme mencionado anteriormente, o apresentado aqui tem o objetivo de ser apenas o essencial para o entendimento do estudo de caso. Para o trabalho com as redes, neste estudo foi utilizado um programa comercial (Netica ${ }^{\mathrm{TM}} 4.08$ - ver Norsys 
Software Corp., 1996) disponibilizado pelo LabRisco-USP. Este programa, na versão disponibilizada, não trabalha com Árvores de Falhas. Sendo assim, tornam-se necessárias algumas considerações sobre a conversão de uma Árvore de Falhas em uma Rede Bayesiana. Este assunto será discutido a seguir.

\subsection{3. ÁRVORE DE FALHAS EM REDE BAYESIANA}

As Árvores de Falhas são diagramas seqüenciais utilizados para determinar a probabilidade de um evento final (evento topo), agregando um conjunto de desencadeamentos de eventos. Cada desencadeamento pode ser encontrado por meio de um estudo de causa e conseqüência, determinando também a interdependência entre eles. Nestes diagramas, os eventos se relacionam por meio de portas lógicas, que utilizam lógica booleana (NUREG-0492, 1981). Neste trabalho são empregados três tipos de porta:

- $E$ : quando todos os eventos predecessores devem ocorrer para que dado evento posterior ocorra;

- Ou: quando é suficiente que um ou mais eventos predecessores ocorram para que dado evento posterior ocorra;

- Ou Exclusivo: quando um evento posterior ocorre somente se exatamente um dos eventos predecessores ocorrer (sendo que neste trabalho esta porta foi empregada para eventos predecessores mutuamente exclusivos).

Os símbolos utilizados nas Árvores de Falhas para estas portas lógicas estão apresentados na Figura 11.

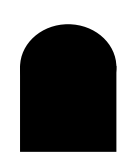

$\mathbf{E}$

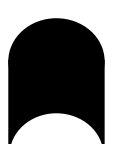

OU

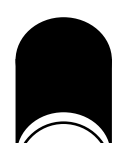

Exclusivo

Figura 11 - Portas empregadas em Árvores de Falhas

As Árvores de Falhas podem ser convertidas em Redes Bayesianas (Lampis e Andrews, 2008). Caso seja feita esta conversão, os nós das redes obtidas serão representantes de variáveis booleanas. Para demonstrar esta conversão serão 
apresentados três casos, cada um apresentando a conversão de uma Árvore de Falhas simples utilizando uma das portas lógicas descritas anteriormente.

Primeiramente, tome-se a Árvore de Falhas apresentada na Figura 12(a).

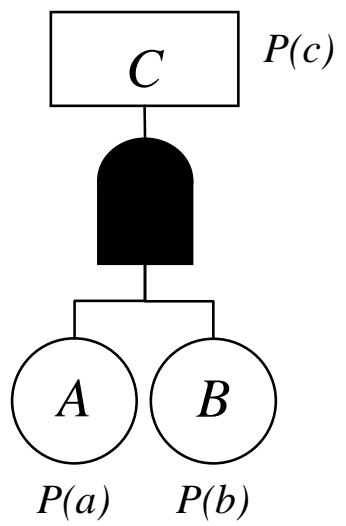

(a)

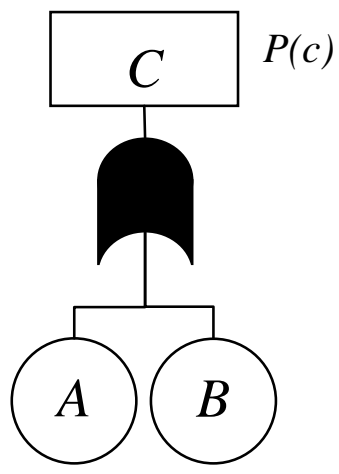

$P(a) \quad P(b)$

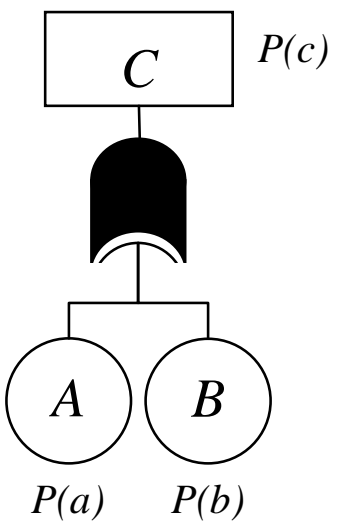

(c)

Figura 12 - Árvore de Falha com portas "E", "OU" e "OU Exclusivo"

Nesta árvore estão representados dois eventos básicos $A$ e $B$ independentes, além do evento topo $C$. Observa-se que a porta lógica que está sendo utilizada é a “ $E$ '. Desta forma, para este exemplo, a probabilidade de ocorrência de do evento $C$ é igual ao produto das probabilidades de ocorrência dos eventos $A$ e $B$, ou seja:

$$
P(c)=P(a) P(b)
$$

Como a Árvore de Falhas relaciona eventos de forma cronológica (desencadeamento de eventos), as seguintes probabilidades condicionais podem ser obtidas:

$$
\begin{gathered}
P(c \mid a, b)=1 \\
P(c \mid \neg a, b)=0 \\
P(c \mid a, \neg b)=0 \\
P(c \mid \neg a, \neg b)=0
\end{gathered}
$$

O desenvolvimento de uma Rede Bayesiana, que considere a independência entre os eventos $A$ e $B$, leva à estrutura gráfica apresentada na Figura 13, onde estes eventos são representados pelos nós de mesma denominação.

Na Figura 13 também estão representadas as probabilidades condicionais 
para o nó $C$, obtidas diretamente das relações acima.

Para obter-se a probabilidade de ocorrência do evento $C$ deve-se fazer uma inferência utilizando a rede desenvolvida (Figura 13). Assim, a probabilidade de ocorrência do evento $C$ pode ser obtida da Equação (2.26).

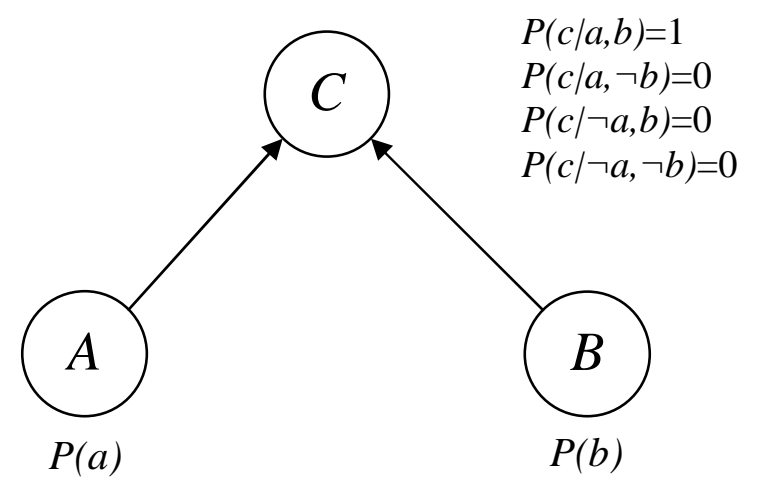

Figura 13 - Rede obtida da Árvore com Porta "E"

$$
P(c)=\frac{P(c, A, B)}{P(C, A, B)}
$$

onde, de (2.8) e considerando as probabilidades apresentadas nas Equações (2.22) a (2.25):

$$
\begin{gathered}
P(c, A, B)=\sum_{a, b} P(c \mid A, B) P(A) P(B)=P(a) P(b) \\
P(C, A, B)=\sum_{a, b, c} P(C \mid A, B) P(A) P(B)=1
\end{gathered}
$$

assim:

$$
P(c)=P(a) P(b)
$$

Estas equações demonstram que a rede desenvolvida se relaciona com a árvore original, já que este resultado (Equação (2.29)) é o esperado (Equação (2.21)).

De outra forma, se a porta lógica da Figura 12(a) fosse substituída pela porta "OU", com eventos independentes, conforme apresentado na Figura 12(b), a tabela de probabilidades condicionais para 0 evento $C$ seria baseada nos dados apresentados nas Equações de (2.30) a (2.33).

$$
\begin{gathered}
P(c \mid a, b)=1 \\
P(c \mid \neg a, b)=1
\end{gathered}
$$




$$
\begin{gathered}
P(c \mid a, \neg b)=1 \\
P(c \mid \neg a, \neg b)=0
\end{gathered}
$$

Como os eventos $A$ e $B$ não são mutuamente exclusivos, ou seja, não apresentam dependência condicional, a Figura 13 também representa a topologia de rede adequada para este caso.

Para obter a probabilidade do evento topo $(P(c))$, o procedimento para o caso da porta "E" (Equações de (2.26) a (2.29)) pode ser repetido para a porta "OU”. Para este caso, considerando as probabilidades apresentadas nas Equações (2.30) a (2.33):

$$
P(c, A, B)=P(a) P(b)+P(\neg a) P(b)+P(a) P(\neg b)
$$

Como os eventos $A$ e $B$ não são mutuamente exclusivos, há probabilidade de intersecção, e:

$$
P(b)=P(a) P(b)+P(\neg a) P(b)
$$

e:

$$
P(a) P(\neg b)=P(a)(1-P(b))=P(a)-P(a) P(b)
$$

de onde conclui-se:

$$
P(c, A, B)=P(a)+P(b)-P(a) P(b)
$$

Lembrando-se que,

$$
P(C, A, B)=\sum_{a, b, c} P(C \mid A, B) P(A) P(B)=1
$$

chega-se a:

$$
P(c)=P(a)+P(b)-P(a) P(b)
$$

O resultado apresentado na Equação (2.39) é o esperado para o evento $C$ da Árvore de Falhas da Figura 12(b) quando os eventos $A$ e $B$ são ligados por uma porta “OU” (sendo os eventos básicos independentes).

Agora, para terminar as conversões propostas, falta a árvore contendo a porta "OU Exclusivo". Para este caso faz-se necessária uma mudança na topologia da Rede Bayesiana que representará a Árvore de Falhas, conforme apresentado na 
Figura 14. Sendo assim, considere-se a árvore da Figura 12(c). Desta árvore extraise que as TPC para a rede equivalente devem ser baseadas nos dados apresentados nas Equações de (2.40) a (2.45).

$$
\begin{gathered}
P(c \mid a, b)=0 \\
P(c \mid \neg a, b)=1 \\
P(c \mid a, \neg b)=1 \\
P(c \mid \neg a, \neg b)=0 \\
P(b \mid a)=0 \\
P(b \mid \neg a)=\frac{P(b)}{P(\neg a)}
\end{gathered}
$$

A referida mudança na topologia se deve à dependência condicional entre os eventos $A$ e $B$. Deve-se notar que é necessário apenas um arco entre estes eventos (de outra maneira a rede deixaria de ser um DAG).

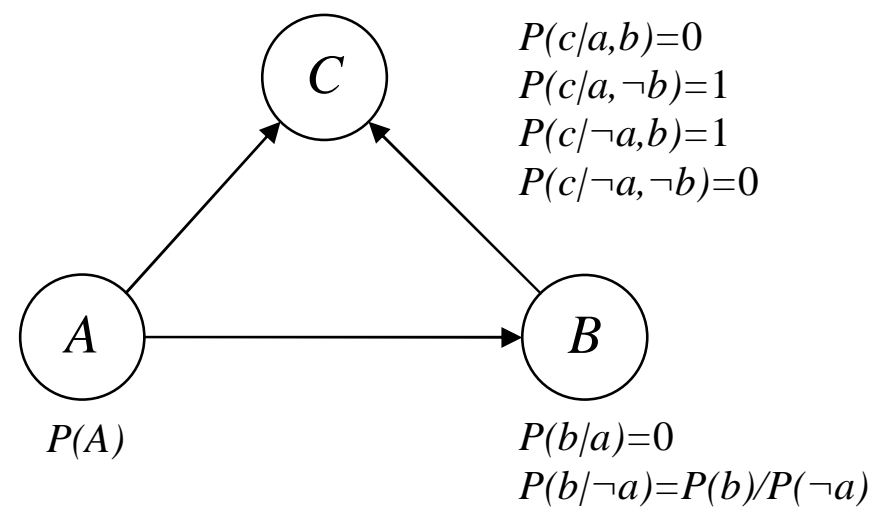

Figura 14 - Rede obtida da Árvore com Porta "OU Exclusivo"

Para obter a probabilidade do evento topo $(P(c))$, o procedimento para o caso da porta "E" (Equações de (2.26) a (2.29)) também pode ser repetido para a porta "OU Exclusivo", ou seja:

$$
P(c)=\frac{P(c, A, B)}{P(C, A, B)}
$$

onde, de (2.8): 


$$
P(c, A, B)=\sum_{a, b} P(c \mid A, B) P(B \mid A) P(A)
$$

e, considerando as probabilidades apresentadas nas Equações (2.40) a (2.45):

$$
P(c, A, B)=P(a)+P(b)
$$

Lembrando-se que,

$$
P(C, A, B)=\sum_{a, b, c} P(C \mid A, B) P(A) P(B)=1
$$

chega-se a:

$$
P(c)=P(a)+P(b)
$$

O resultado obtido (Equação (2.50)) é o esperado para o evento $C$ da Árvore de Falhas da Figura 12(c), onde os eventos $A$ e $B$ são ligados por uma porta "OU Exclusivo" (sendo os eventos básicos mutuamente exclusivos). O mesmo resultado seria obtido se o arco entre $A$ e $B$ na rede da Figura 14 fosse direcionado de $B$ para A.

Como conclusão, pode-se dizer que as Árvores de Falhas e as correspondentes Redes Bayesianas representam os mesmos domínios. As idéias básicas desenvolvidas aqui serão aplicadas no estudo de caso para agregar as informações apresentadas no trabalho anterior (Maturana e Martins, 2008), então condensadas em Árvores de Falhas.

Para encerrar o capítulo de fundamentos teóricos, na próxima seção serão considerados alguns pontos sobre a modelagem de sistemas por meio das Redes Bayesianas.

\subsection{MODELAGEM POR MEIO DE REDES BAYESIANAS}

Com as Redes Bayesianas é possível sanar os seguintes problemas vivenciados durante a modelagem com métodos convencionais (que trabalham diretamente com a conjunção de probabilidades do domínio):

- Dificuldade de representação dos domínios com muitas variáveis;

- Necessidade de um grande número de probabilidades para a representação de um domínio;

- Probabilidades não intuitivas nas representações convencionais; 
- Dificuldade para se fazer inferência partindo das representações convencionais.

Outra vantagem das Redes Bayesianas é a possibilidade de trabalhar com redes dinâmicas (dynamic networks). A rede dinâmica, por definição, é uma rede que possui nós influenciados por estados anteriores das variáveis do domínio (no instante $t$ alguns nós são influenciados pelos estados de nós no instante $t-1, t-2, t$ $3, \ldots)$. Como exemplo, tem-se a rede da Figura 15 que apresenta nós influenciados por outros da mesma rede, mas em tempo distinto.

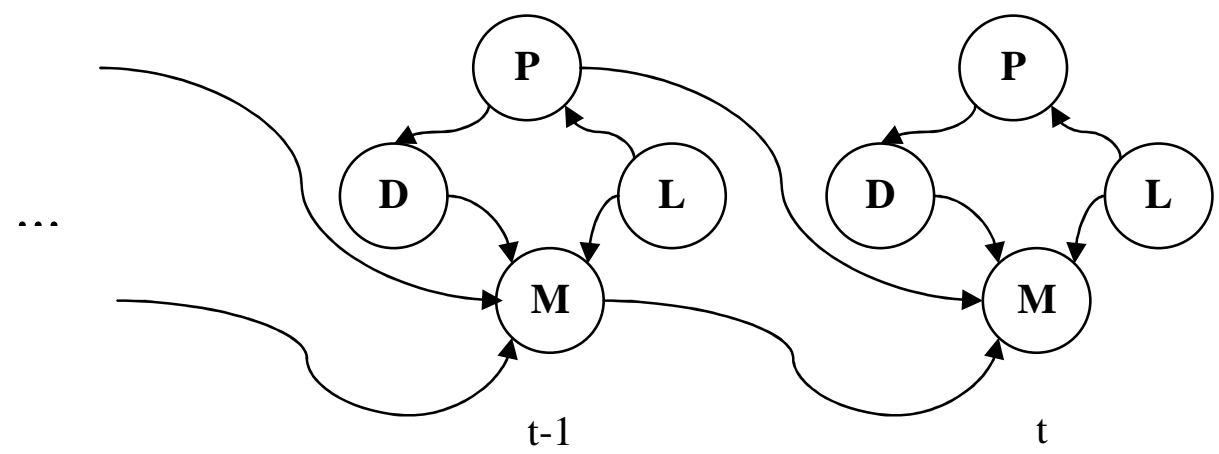

Figura 15 - Exemplo de rede dinâmica

Ainda em relação às redes dinâmicas, existem técnicas para estimar o "limite superior" em Redes Bayesianas, ou seja, fazer o tempo tender a infinito, para estimar as probabilidades das variáveis de redes com este tipo de característica (o método de inferência aproximada, apresentado no tópico 2.2.2.4, é um exemplo do que pode ser feito).

De acordo com Russell e Norvig (2003), o procedimento geral para a construção de uma Rede Bayesiana deve ser de acordo com os passos a seguir:

- Escolher o conjunto de variáveis $X_{i}$ que descrevem o domínio;

- Escolher a ordenação para as variáveis;

- Enquanto existirem variáveis:

- Selecionar uma variável $X_{i}$ e adicionar um nó na rede para ela;

- Definir os pais $\left(X_{i}\right)$ como o conjunto mínimo de nós já existentes na rede para as quais a propriedade de dependência condicional se verifique, ou seja, o conjunto dos nós cujos estados influenciam nos estados do nó $X_{i}$; 


\section{○ Definir a TPC para $X_{i}$.}

Uma vez que cada nó apenas se liga a nós definidos anteriormente, este método garante que a rede seja acíclica.

\subsubsection{PROCEDIMENTO PARA A CONSTRUÇÃO DE REDES BAYESIANAS NA ANÁLISE DE CONFIABILIDADE}

São as relações de dependência condicional entre as variáveis que devem guiar a construção da topologia da rede. Deve-se garantir que todos os nós que

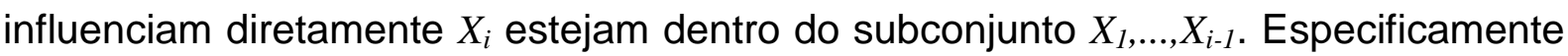
na modelagem para análise de confiabilidade, o processo de construção de uma rede que represente a contento um determinado domínio pode seguir o procedimento abaixo (Beldford e Cooke, 2001):

- Deve-se fazer a listagem de todas as variáveis, começando com os objetivos da análise;

- Devem ser levantados todos os fatores secundários que impactam as variáveis listadas no primeiro passo (neste ponto já é possível fazer uma análise qualitativa do impacto dos fatores levantados, olhando para os fatores e determinando caminhos pelos quais suas influências possam ser quebradas ou ao menos reduzidas);

- Os diferentes fatores devem ser descritos em termos precisos: os estados das variáveis devem ser determinados (se são exclusivos ou exaustivos $^{8}$ );

- Construção do modelo qualitativo (DAG): os fatores de influência devem ser ordenados. Freqüentemente esta ordenação se dá de forma natural, como resultado do tempo ou do fluxo de informação. De forma geral pode-se seguir o seguinte procedimento, em forma de questionamentos, para a ordenação e desenho da rede:

○ $O$ valor de $X_{1}$ influencia $X_{2}$ ?

- O valor de $X_{1}$ e $X_{2}$ influenciam $X_{3}$ ? Se sim, o conhecimento do valor de $X_{1}$ torna irrelevante o valor de $X_{2}$ para $X_{3}$ ?, ou, o conhecimento de $X_{2}$ torna o valor de $X_{1}$ irrelevante para $X_{3}$ ?

\footnotetext{
${ }^{8}$ Os nós exclusivos são os que apresentam apenas um estado e os exaustivos ocorrem em mais de um estado Aplicação de Redes Bayesianas na Análise da Contribuição da Falha Humana em Acidentes de Colisão - 42
} 
A resposta positiva para estes questionamentos determinam os arcos que devem existir entre os nós, além de influenciar no preenchimento da TPC que alimentará determinado nó. A aplicação desta técnica no caso analisado pode ser considerada como exemplo;

- Quantificação: devem ser preenchidas as tabelas de probabilidades condicionais. Isto geralmente é feito mediante a consulta da opinião de especialistas. Deve-se considerar a hipótese de análise da confiabilidade da opinião destes especialistas, ou ao menos um estudo de quão conservadoras podem ser suas respostas.

É interessante notar que este procedimento incorpora os princípios estabelecidos no procedimento geral apresentado anteriormente.

O próximo capítulo apresenta uma metodologia para a HRA via Redes Bayesianas e subsídios para a modelagem do fator humano na operação do navio. 


\section{METODOLOGIA PARA HRA VIA REDES BAYESIANAS}

Para facilitar a apresentação do que foi desenvolvido, este capítulo está dividido em três tópicos. O primeiro descreve de forma geral uma metodologia baseada em trabalho de outros autores para realizar a HRA por meio das Redes Bayesianas. Para apoiar esta metodologia, o segundo tópico traz um modelo para representação do elemento humano em sistemas complexos e, considerando as necessidades do estudo de caso (próximo capítulo), enumera os fatores que podem influenciar o desempenho humano e auxilia na integração entre os PSF - MOF, fatores internos, fatores ambientais e habilidades - e as ações humanas e suas conseqüências em uma única rede. Por fim, no terceiro tópico, são feitas considerações sobre a integração das Redes Bayesianas Dinâmicas com a Árvore de Falhas que representa o desencadeamento dos eventos perigosos.

\subsection{METODOLOGIA}

A fim de atingir o objetivo principal deste trabalho, buscou-se uma metodologia que englobe os principais estágios para a realização da HRA (ver item 2.1) e considere o emprego das Redes Bayesianas como ferramenta para a modelagem do fator humano.

Swain e Guttman (1983) apresentaram um procedimento com quatro fases para realização da HRA por meio da THERP (apresentado em resumo em Maturana e Martins, 2008). De maneira semelhante, um procedimento proposto recentemente para integrar as Redes Bayesianas na HRA (Droguett e Menêzes, 2007) inclui os seguintes passos:

- Passo 1 - Familiarização: com o procedimento a ser modelado;

- Passo 2 - Análise de tarefas: para a determinação da seqüência de atividades da tarefa;

- Passo 3 - Construção da Rede Bayesiana Dinâmica: que representa a seqüência de atividades da tarefa;

- Passo 4 - Erros humanos: identificação dos prováveis erros humanos nas atividades levantadas no passo 2;

- Passo 5 - Fatores de Desempenho: identificação dos fatores de 
desempenho relevantes com base no passo anterior;

- Passo 6 - Construção das Redes Bayesianas dos fatores de desempenho: para cada atividade (ou operador responsável pela atividade);

- Passo 7 - Integração das redes desenvolvidas: nos passos anteriores (Dinâmica e dos Fatores de Desempenho);

- Passo 8 - Análise dos resultados: partindo de evidências empíricas ou subjetivas.

A aglutinação destes procedimentos (Swain e Guttman (1983) e Droguett e Menêzes (2007)) com os pontos apresentados no capítulo anterior, resultou em uma metodologia em quatro fases para realizar a HRA por meio das Redes Bayesianas. A Figura 16 representa este procedimento.

\begin{tabular}{|c|c|c|c|}
\hline $\begin{array}{c}\text { FASE } 1 \\
\text { Familiarização }\end{array}$ & $\begin{array}{c}\text { FASE } 2 \\
\text { Análise Qualitativa }\end{array}$ & $\begin{array}{c}\text { FASE } 3 \\
\text { Análise Quantitativa }\end{array}$ & $\begin{array}{c}\text { FASE } 4 \\
\text { Incorporação }\end{array}$ \\
\hline $\begin{array}{l}\text { - Juntar informações; } \\
\text { - Visita à Planta; } \\
\text { - Revisar informações e } \\
\text { processos dados por } \\
\text { especialistas; }\end{array}$ & $\begin{array}{l}\text { - Determinar o } \\
\text { Desempenho } \\
\text { Requerido; } \\
\text { - Análise de Tarefas; } \\
\text { - Encontrar os possíveis } \\
\text { erros humanos na } \\
\text { execução das Tarefas; } \\
\text { - Desenvolver a } \\
\text { topologia das Redes } \\
\text { Dinâmicas das } \\
\text { Tarefas; } \\
\text { - Definir os Fatores de } \\
\text { Desempenho } \\
\text { relevantes para a boa } \\
\text { execução das Tarefas e } \\
\text { sua interdependência; } \\
\text { - Desenvolver a } \\
\text { topologia das Redes } \\
\text { dos Fatores de } \\
\text { Desempenho; }\end{array}$ & $\begin{array}{l}\text { - Integrar as Redes dos } \\
\text { Fatores de } \\
\text { Desempenho à Rede } \\
\text { Dinâmica da Tarefa, } \\
\text { considerando a } \\
\text { interdependência entre } \\
\text { elas; } \\
\text { - Promover o } \\
\text { preenchimento das } \\
\text { TPC; } \\
\text { - Determinar } \\
\text { Probabilidades de } \\
\text { Falha ou Sucesso da } \\
\text { Tarefa; } \\
\text { - Determinar os Efeitos } \\
\text { dos Fatores de } \\
\text { Revisão. }\end{array}$ & $\begin{array}{l}\text { - Análise do modelo - } \\
\text { que pode incluir a } \\
\text { análise de } \\
\text { sensibilidades das } \\
\text { probabilidades dos nós } \\
\text { em relação às TPC, } \\
\text { considerações sobre a } \\
\text { opinião dos } \\
\text { especialistas no } \\
\text { preenchimento das } \\
\text { TPC, etc.; } \\
\text { - Análise com apoio do } \\
\text { modelo - pode incluir } \\
\text { o levantamento de } \\
\text { cenários de acidentes, } \\
\text { dadas evidências; a } \\
\text { verificação de quais } \\
\text { fatores mais impactam } \\
\text { num determinado } \\
\text { cenário, etc.; } \\
\text { Incorporar Resultados } \\
\text { na Análise do Sistema. }\end{array}$ \\
\hline
\end{tabular}

Figura 16 - Metodologia para realização da HRA por meio das Redes Bayesianas

Neste procedimento, a primeira fase trata da familiarização com o sistema que será analisado e do agrupamento do máximo de informações a seu respeito - a visita à planta e o estudo do que já foi publicado sobre o assunto são atividades recomendadas para esta fase. A segunda se refere à análise qualitativa do elemento humano; incluindo a análise das tarefas, determinação do desempenho requerido em cada atividade e o desenvolvimento da topologia das Redes Bayesianas que modelam o sistema. Na terceira etapa, fazem-se as associações de probabilidades 
às TPC, conforme descrito no tópico referente aos passos para aplicação das Redes Bayesianas nos estudos de confiabilidade (capítulo anterior); além disto, devem ser considerados os efeitos dos eventuais fatores de revisão (quando o erro pode ser corrigido por outra pessoa, ou pelo próprio executor: pode-se estudar, por exemplo, a influência do acréscimo de um passo de revisão na probabilidade de sucesso na execução da tarefa). A última etapa pode considerar a incorporação do fator humano no estudo da confiabilidade do sistema como um todo (incluindo o maquinário); pode-se realizar análise de sensibilidade para verificar o impacto de alterações no fator humano para o sistema, ou ainda um estudo sobre o preenchimento das TPC.

\subsection{FATORES HUMANOS NA OPERAÇÃO DO NAVIO}

Para garantir que um sistema complexo, como o navio, atenda a todas as funções a ele atribuídas é necessário que, durante a fase de projeto, todas estas funções sejam analisadas a luz da tecnologia disponível, desempenho desejado, custo de pessoal, complexidade das tarefas, etc. Depois desta análise deve ser definido se estas funções ficarão a cargo de pessoas ou de equipamentos. Mas mesmo neste último caso o fator humano estará presente, por exemplo, na necessidade do fornecimento de informação e na tomada de decisão. Na verdade, existe a tendência de que os operadores não realizem tarefas físicas, tais como erguer e carregar pesos, e passem às atividades de análise e tomada de decisão, por exemplo.

Para realizar suas funções, os operadores precisam utilizar os recursos disponibilizados, coletando e interpretando as informações disponíveis (com base em sua experiência e treinamento) e, por fim, tomando a decisão de agir ou não sobre o sistema conforme seja apropriado. Dependendo do nível de complexidade e previsibilidade da situação, treinamento e experiência do indivíduo, o comportamento pode ser rotineiro ou baseado em regras, ou pode ser que a tarefa exija maior criatividade, pesquisa e análise. A maneira de interação com os equipamentos varia com as características da pessoa, as qualidades físicas do ambiente de trabalho, treinamento a respeito do sistema a ser operado, fatores organizacionais tais como horas de trabalho, e atitudes moldadas pela cultura organizacional. É provável que os operadores de uma parte do sistema partilhem de características de perfil (idade, grupo sócio-econômico, treinamento, experiência, 
nível de aptidão, etc.) e este perfil faça com que suas ações sejam mais previsíveis. Estas interdependências podem ser sintetizadas pela Figura 17 (baseada em Webb e Lamoureux (2003)).

Para uma classe de sistemas, como o navio, e para uma dada função, como a operação de guinada, a tecnologia disponível permite diferentes soluções que propiciam diferenças significativas na operação de navio para navio. Alguns navios podem permitir a guinada feita da ponte, de onde o timoneiro tem visão total sobre os arredores. Em outros o timoneiro fica em compartimento separado, onde recebe ordens verbais sem ver para onde o navio se dirige. Em navios pequenos pode ocorrer de o capitão acumular a função de timoneiro, por exemplo. Há casos em que o timoneiro também controla o sistema propulsivo.

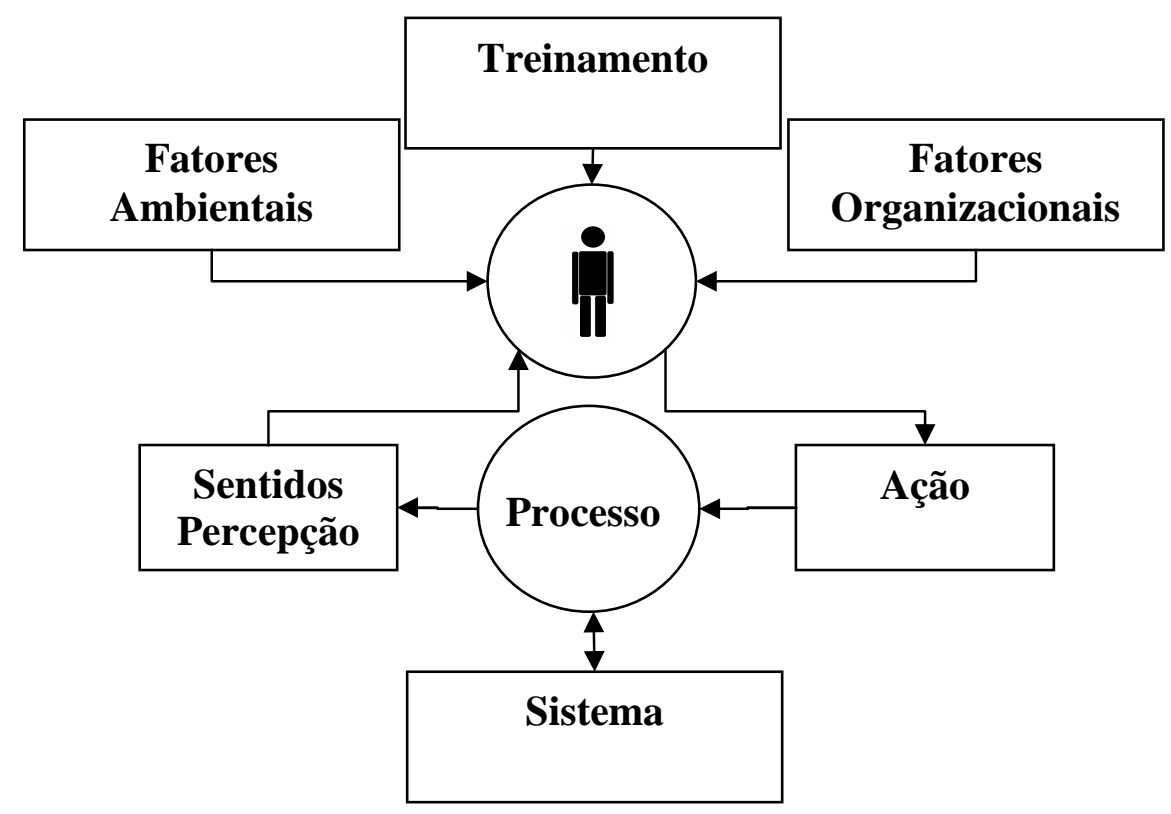

Figura 17 - Modelagem dos fatores que influenciam o desempenho humano

Assim, para cada caso devem ser levantadas as características do sistema, representar os perfis dos operadores, fatores de forma, comportamento, atividades cognitivas realizadas, erros e conseqüências. De posse destas informações é possível levantar os fatores (PSF) que influenciam cada operador (ou que mais influenciam). De qualquer maneira, é útil desenvolver um modelo genérico de influência que incorpore os PSF mais significativos na operação do sistema que está sendo analisado, deixando para um segundo passo o detalhamento caso a caso.

Com base em Mosleh e Chang (2004), Droguett e Menezes (2007), Maturana 
e Martins (2008), Swain e Guttman (1983) e IMO (2002), foi desenvolvido um modelo genérico para aplicação no estudo de caso (diagrama apresentado na Figura 18). Este modelo representa a influência entre os fatores que determinam o desempenho de um operador (PSF). Foram considerados, para a sua construção, quatro grupos de fatores: 1) MOF; 2) Fatores Internos (ao operador, como fadiga, inteligência, etc.); 3) Fatores Ambientais; e 4) Habilidades Requeridas (para a execução das tarefas). O detalhamento de cada um destes fatores é apresentado nos sub-tópicos mais adiante.

Neste diagrama, considerou-se que a execução da tarefa depende da situação das habilidades requeridas do operador. E que os estados destas habilidades dependerá dos fatores ambientais e dos fatores internos do operador. Em outras palavras, considerou-se que os fatores ambientais atrapalham a execução da tarefa (influenciando nos sentidos, por exemplo), e que os fatores internos influenciam no desempenho do operador (fadiga, por exemplo), na medida em que indisponibilizam as habilidades necessárias para que o operador realize a tarefa.

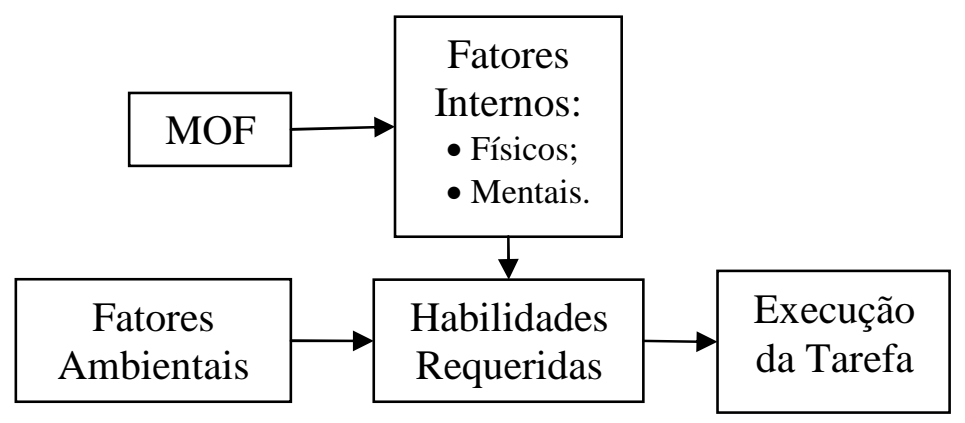

Figura 18 - Rede Genérica para Fatores de Desempenho

Como observado na Figura 18, os fatores externos ao operador foram divididos entre MOF e fatores ambientais. Considerou-se que os fatores relativos a treinamento, à organização e gerenciais (agrupados nos MOF) influenciam diretamente os fatores físicos e mentais (incluindo os relativos à memória), ou seja, considerou-se, por simplicidade, que quando o operador chega para a execução da tarefa os MOF já estão definidos, e que o único grupo que o operador traz em si, passível de mudança de estado, são os fatores internos. Assim, as influências dos MOF ocorrem durante a vida do operador e não numa tarefa específica. Porém, os 
fatores ambientais estão presentes durante a realização das tarefas.

\subsubsection{MOF}

No caso de empresas de navegação, a tripulação é grandemente influenciada por fatores tais como: políticas, procedimentos e decisões dos gestores. Para cumprir as regulamentações da IMO (IMO, 2002b) estas questões devem ser levadas em conta pelo operador do navio ao se elaborar um SMS (Safety Management System). Fatores que envolvem grandes riscos precisam ser identificados e medidas de correção devem ser adotadas para estes fatores. Para tanto o primeiro passo é identificar os MOF críticos. De acordo com IMO (2002b), os principais MOF envolvidos na operação do navio são os apresentados na Tabela 10.

As relações entre os MOF e os fatores internos estão apresentadas no tópico relativo a estes últimos, a seguir.

Tabela $10-$ MOF

\begin{tabular}{|c|c|}
\hline A & Carga de Trabalho \\
\hline B & Formalização \\
\hline C & Coordenação do Trabalho \\
\hline D & Cultura Organizacional \\
\hline E & Prêmios, reconhecimentos, benefícios \\
\hline F & Recursos Físicos \\
\hline G & Qualidade de Vida \\
\hline H & Avaliação de Rendimento \\
\hline J & Programas da Companhia \\
\hline K & Seleção de Pessoal \\
\hline L & Rotatividade de Pessoal \\
\hline M & Atitudes de Supervisores, Sindicatos, Agências Reguladoras, etc. \\
\hline N & Tempo \\
\hline O & Aprendizado Organizacional \\
\hline P & Comunicação oral ou escrita \\
\hline
\end{tabular}

\subsubsection{FATORES INTERNOS}

Os PSF relacionados na Tabela 11 são uma compilação dos apresentados em Swain e Guttman (1983), Chang e Mosleh (2007b), Droguett e Menezes (2007) e Maturana e Martins (2008). Seguindo o modelo proposto (Figura 18), estes fatores internos foram relacionados aos MOF listados na Tabela 10. Isto foi feito de acordo com o julgamento do autor deste trabalho, considerando os MOF mais influentes para cada fator interno. 
É importante ressaltar que nem todos os MOF relacionados na Tabela 11 precisam ser considerados quando determinado fator interno for associado ao executor de uma tarefa, na aplicação desta tabela. Devem-se considerar as características do operador antes de definir quais MOF devem ser adicionados às redes a serem desenvolvidas.

Outra questão importante é a inter-relação entre os fatores internos. Estas inter-relações serão tratadas caso a caso na implementação (no próximo capítulo).

\begin{tabular}{|c|c|c|c|c|c|}
\hline \multicolumn{2}{|r|}{ Físicos } & \multirow{2}{*}{$\begin{array}{c}\text { MOF } \\
\text { Relacionado } \\
\mathrm{A}, \mathrm{B}, \mathrm{G}, \mathrm{H}, \mathrm{M} \\
\end{array}$} & \multicolumn{2}{|r|}{ Mentais } & \multirow{2}{*}{$\begin{array}{c}\text { MOF } \\
\text { Relacionado } \\
\mathrm{A}, \mathrm{C}, \mathrm{E}, \mathrm{F}, \mathrm{G}, \mathrm{H}, \mathrm{I}, \mathrm{M} \\
\end{array}$} \\
\hline 1 & Fadiga & & 15 & Estado Emocional & \\
\hline 2 & Dor e Desconforto & $\mathrm{A}, \mathrm{B}, \mathrm{F}, \mathrm{M}$ & 16 & $\begin{array}{c}\text { Velocidade na Realização } \\
\text { da Tarefa }\end{array}$ & $\mathrm{B}, \mathrm{C}, \mathrm{F}, \mathrm{H}, \mathrm{M}$ \\
\hline 3 & Falta de Exercícios Físicos & $A, D, I, G$ & 17 & Criticalidade da Tarefa & $\mathrm{J}, \mathrm{L}, \mathrm{O}$ \\
\hline 4 & Qualidade do Sono & $A, C, G$ & 18 & $\begin{array}{l}\text { Atitudes baseadas na } \\
\text { influência de grupos ou } \\
\text { outras pessoas }\end{array}$ & $\mathrm{B}, \mathrm{C}, \mathrm{D}, \mathrm{H}, \mathrm{I}, \mathrm{J}, \mathrm{M}, \mathrm{P}$ \\
\hline 5 & Condição Física & $A, B, G, J$ & 19 & Identificação com a equipe & $\mathrm{C}, \mathrm{D}, \mathrm{I}, \mathrm{J}, \mathrm{K}, \mathrm{L}, \mathrm{M}$ \\
\hline \multicolumn{2}{|c|}{ Relativos ao Estresse } & & 20 & $\begin{array}{l}\text { Personalidade e } \\
\text { Inteligência }\end{array}$ & $J$ \\
\hline 6 & Duração do Estresse & $A, B, C, D, F, G, L, M, P$ & 21 & Motivação e Atitude & $\mathrm{A}, \mathrm{C}, \mathrm{D}, \mathrm{E}, \mathrm{F}, \mathrm{G}, \mathrm{H}, \mathrm{I}$ \\
\hline 7 & Velocidade da Tarefa & $\mathrm{B}, \mathrm{C}, \mathrm{F}, \mathrm{H}, \mathrm{M}$ & & & \\
\hline 8 & $\begin{array}{l}\text { Riscos na Execução da } \\
\text { Tarefa }\end{array}$ & $\mathrm{C}, \mathrm{D}, \mathrm{H}, \mathrm{O}$ & & Memória & \\
\hline 9 & $\begin{array}{l}\text { Tratamento dispensado à } \\
\text { falha (perda de emprego) }\end{array}$ & $\mathrm{D}, \mathrm{H}$ & 22 & Conhecimento das Normas & $B, J, L$ \\
\hline 10 & Trabalho Monótono & $\mathrm{B}, \mathrm{C}, \mathrm{I}, \mathrm{J}, \mathrm{M}$ & 23 & Experiência e Treinamento & $\mathrm{B}, \mathrm{D}, \mathrm{J}, \mathrm{K}, \mathrm{L}$ \\
\hline 11 & Longos períodos sem ação & $\mathrm{A}, \mathrm{B}, \mathrm{C}, \mathrm{K}, \mathrm{M}$ & 24 & Habilidade & $\mathrm{H}, \mathrm{J}, \mathrm{L}$ \\
\hline 12 & Distrações & $\mathrm{C}, \mathrm{G}, \mathrm{J}, \mathrm{L}, \mathrm{M}, \mathrm{N}$ & 25 & Controle Motor & $\mathrm{J}, \mathrm{K}, \mathrm{L}$ \\
\hline 13 & Falta de Avisos & $\mathrm{C}, \mathrm{D}, \mathrm{O}$ & 26 & $\begin{array}{c}\text { Estado atual da Prática } \\
\text { (Memórias) }\end{array}$ & $\mathrm{C}, \mathrm{K}, \mathrm{L}, \mathrm{M}$ \\
\hline 14 & $\begin{array}{l}\text { Conflitos a respeito dos } \\
\text { motivos da obtenção do } \\
\text { melhor resultado }\end{array}$ & $\mathrm{C}, \mathrm{E}, \mathrm{G}, \mathrm{H}, \mathrm{I}, \mathrm{L}, \mathrm{M}$ & & & \\
\hline
\end{tabular}

\subsubsection{FATORES AMBIENTAIS}

A Tabela 12 lista os fatores ambientais considerados possíveis para o caso do navio apresentado no estudo de caso, levantados durante a visita ao navio (Maturana e Martins, 2008). Neste grupo foram alocados tanto os fatores relativos ao clima em alto mar como os relativos ao ambiente interno ao navio (é antinatural supor uma sala de máquinas sem vibração, ruídos, etc.).

Nesta tabela os fatores ambientais não estão apresentados por ordem de importância ou de incidência. Outro ponto importante é que para cada tarefa pode haver a presença de um ou de vários destes fatores. Para o modelo considerado, eles foram relacionados às habilidades (Tabela 13) exigidas em operações de navios, considerando o quanto podem influenciar em seu estado. 
Tabela 12 - Fatores Ambientais

\begin{tabular}{|c|c|}
\hline $\boldsymbol{\alpha}$ & Temperatura \\
\hline $\boldsymbol{\beta}$ & Umidade \\
\hline $\boldsymbol{\chi}$ & Insuficiência de Oxigênio \\
\hline $\boldsymbol{\delta}$ & Luminosidade \\
\hline $\boldsymbol{\varepsilon}$ & Ruído \\
\hline $\boldsymbol{\phi}$ & Vibração \\
\hline $\boldsymbol{\gamma}$ & Limpeza \\
\hline $\boldsymbol{\eta}$ & Visibilidade \\
\hline $\boldsymbol{\varphi}$ & Correnteza \\
\hline $\boldsymbol{\kappa}$ & Tempestades \\
\hline $\boldsymbol{\lambda}$ & Ventos \\
\hline $\boldsymbol{\mu}$ & Ondas \\
\hline
\end{tabular}

\subsubsection{LISTA DE HABILIDADES}

A tabela a seguir apresenta uma relação das principais habilidades requeridas para a execução de operações dentro do navio. Para tanto, foram consideradas as tarefas relacionadas ao evento de colisão, listadas em Maturana e Martins (2008) da atividade de monitoramento do radar, por exemplo, se extraíram as habilidades de percepção e concentração, necessárias para o seu bom desempenho.

Tabela 13 - Habilidades

\begin{tabular}{|c|c|c|c|}
\hline \multirow{2}{*}{ Descrição } & \multicolumn{2}{c|}{ PSF Relacionados } & Ambientais \\
\cline { 3 - 4 } & Interpretações & Internos & Todos \\
\hline II & Cálculos & $1,2,3,4,5,6,7,11,16,20,21$ & Todos \\
\hline III & Concentração & $1,2,3,4,5,6,7,16,20,21,24,26$ & Todos \\
\hline IV & Conhecimento de procedimentos & $1,2,3,4,5,6,7,8,9,10,11,12,13,14,15,16,17,20,21$ & Todos \\
\hline V & Memória de longo e curto prazo & $13,15,23,26$ & Todos \\
\hline VI & Resistência Física & $1,2,3,4,5,6,7,11,15,16,21$ & Todos \\
\hline VII & Controle motor & $1,2,3,4,5,6,11,15,20,23,24,25,26$ & Todos \\
\hline VIII & Equipe e comunicação & $8,9,14,15,16,18,19,20,21,24$ & Todos \\
\hline IX & Freqüência e Repetitividade & $6,7,10,11,16,24$ & Todos \\
\hline X & Percepção & $1,2,3,4,5,6,15,20,21$ & Todos \\
\hline XI & Planejamento & $6,7,9,15,16,20,24$ & Todos \\
\hline XII & Liderança & $9,15,17,19,20,21,24$ & Todos \\
\hline XIII & Criatividade & $8,9,10,15,16.20,21$ & Todos \\
\hline XIV & Flexibilidade & $9,15,16,19,20,21$ & Todos \\
\hline XV & Empatia & $14,15,19,20,21$ & \\
\hline
\end{tabular}

De acordo com o proposto na Figura 18, a Tabela 13 correlaciona os fatores internos (representados pelos números; ver Tabela 11) e os fatores ambientais que, no âmbito do navio, podem afetar as habilidades listadas. Esta associação foi feita 
de acordo com o julgamento do autor deste trabalho, levando em consideração a análise de tarefas realizada em trabalho anterior (Maturana e Martins, 2008) naquele trabalho esta informação foi importante para definir os estados dos operadores e, por conseguinte, os valores das HEP associadas à execução das atividades dentro do navio.

Nesta tabela, considerou-se que todos os fatores ambientais (listados na Tabela 12) podem, de alguma forma, afetar os as habilidades listadas. Obviamente, no desenvolvimento da rede devem-se considerar apenas os que podem estar presentes e sejam significantes.

Como cada habilidade pode, direta ou indiretamente, ser afetada por quase todos os fatores internos, decidiu-se por excluir nesta tabela os fatores que afetam indiretamente o rendimento, deixando apenas os diretamente relacionados. Por exemplo, para o caso da habilidade I-Interpretação poderia ser associado o fator 26 Estado atual desta prática, já que a interpretação pode exigir memória (conhecimento prévio que embase as conclusões). No entanto, o fator 26 foi associado à habilidade V-Memória de longo e curto prazo. Desta forma, para uma tarefa que exija interpretação e memória devem-se selecionar as habilidades I e $\mathbf{V}$, e na rede o fator $\mathbf{2 6}$ será ligado apenas à habilidade V. Assim, pode-se considerar a hipótese de colocar um arco de influência partindo da habilidade $\mathbf{V}$ e ligando-a a habilidade $\mathbf{I}$.

Conforme observado anteriormente, um acidente pode estar relacionado a diversas tarefas realizadas dentro do navio. Na verdade, se espera que uma seqüência de falhas, ou combinações delas, leve a um evento catastrófico. No trabalho anterior, as seqüências consideradas mais prováveis foram agregadas por meio de uma Árvore de Falhas. A seguir serão considerados alguns pontos sobre o aproveitamento destas informações neste trabalho.

\subsection{INTEGRAÇÃO DAS REDES BAYESIANAS COM A ÁRVORE DE FALHAS}

Conforme observado previamente, o caso a ser estudado já foi explorado em trabalho anterior (Maturana e Martins, 2008). Trata-se da análise quantitativa da contribuição do erro humano em acidentes de colisão. No trabalho anterior foram empregadas as Árvores de Eventos para obter as HEP para alimentar uma Árvore 
de Falhas - esta árvore foi empregada para representar o desencadeamento dos eventos, ou seja, das conseqüências dos erros humanos. $\mathrm{Na}$ árvore desenvolvida os eventos básicos alimentados pelas HEP são erros das ações humanas; as Árvores de Eventos, no entanto, tornaram difícil e pouco natural a consideração dos PSF.

Um dos objetivos do estudo de caso (apresentado no próximo capítulo) é verificar como as Redes Bayesianas se comportam neste papel de modelar o fator humano. E, como o desencadeamento dos eventos que trazem perigo à operação do navio já foram representados a contento naquele trabalho, a árvore gerada será aproveitada neste estudo de caso. Assim, o que será feito no próximo capítulo é a alimentação da Árvore de Falhas com os estados dos nós que representarão as atividades realizadas pelos operadores (responsáveis pelas tarefas associadas a seus eventos básicos). Para cada evento básico será desenvolvida uma Rede Bayesiana Dinâmica da tarefa associada, agregando os fatores de desempenho (fatores internos, MOF, ambientais e habilidades requeridas) a cada atividade da tarefa. A Figura 19 apresenta uma ilustração destas idéias.

A Árvore de Falhas que representa os desencadeamentos dos eventos perigosos será transformada numa Rede Bayesiana - empregando os conceitos apresentados no tópico 2.2.3. Sendo assim, o resultado da modelagem será uma grande rede ${ }^{9}$ concatenando tanto esta árvore quanto as redes dinâmicas das tarefas. Isto permitirá fazer inferências que levam em consideração a probabilidade de colisão do navio (evento topo da Árvore de Falhas).

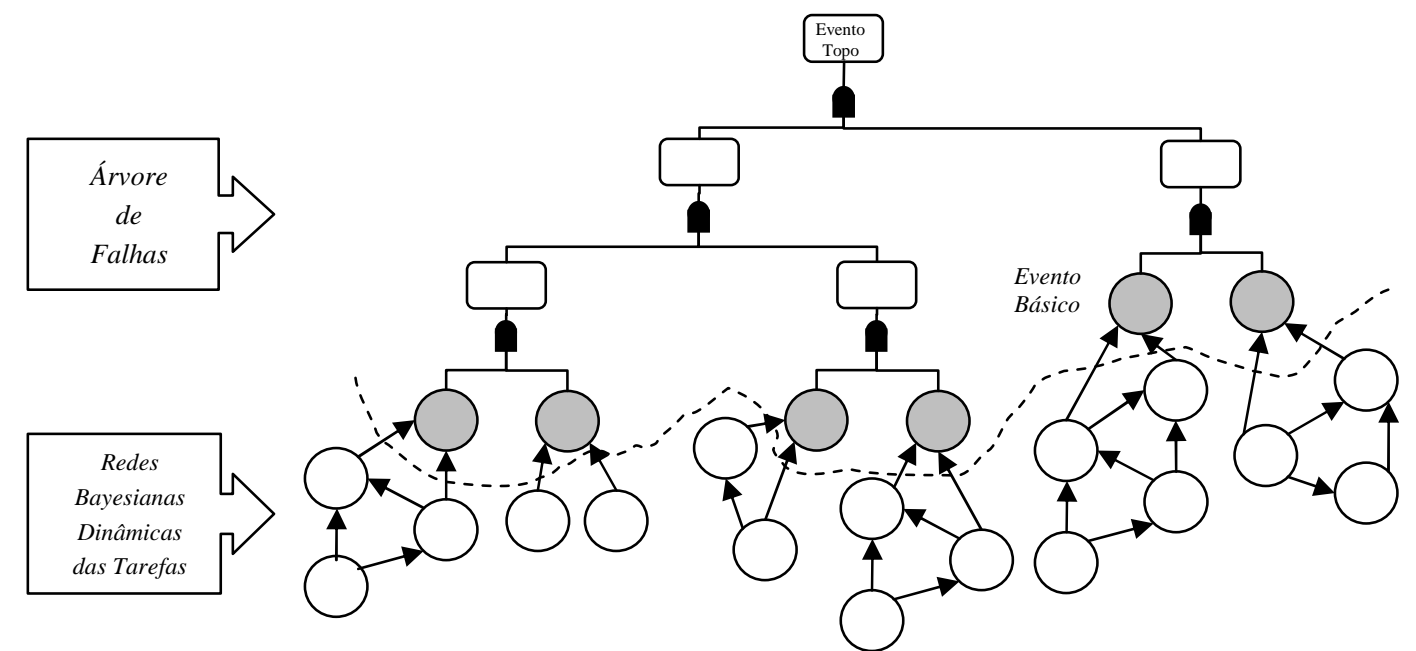

Figura 19 - llustração da integração Árvore de Falhas-Redes Bayesianas

${ }^{9}$ No texto subseqüente esta rede será referida como rede integrada Aplicação de Redes Bayesianas na Análise da Contribuição da Falha Humana em Acidentes de Colisão - 53 


\section{APLICAÇÃO AO ESTUDO DA COLISÃO}

Este estudo de caso foi desenvolvido com objetivo de verificar o potencial das Redes Bayesianas na modelagem do fator humano em sistemas complexos. Optouse por modelar a operação de um navio petroleiro, operando na costa brasileira, focando as atividades relacionadas ao evento de colisão. Esta escolha considerou a realização de trabalho anterior (Maturana e Martins, 2008) em que o mesmo sistema é analisado por meio de Árvores de Falhas e de Eventos - o que permite a comparação entre estas diferentes ferramentas.

De maneira geral, procurou-se seguir os passos propostos no capítulo 2.1, quando foi feita a descrição inicial da HRA. No entanto, as atividades do passo 1 (Identificação de Perigos) e as duas iniciais do passo 2 (Análise Detalhada das Tarefas Críticas e Análise do Erro Humano), que deram origem à Árvore de Falhas e às estruturas das Árvores de Eventos no trabalho anterior (Maturana e Martins, 2008) - e, portanto, já estavam prontas -, foram aproveitadas diretamente, restando apenas a atividade de Quantificação (passo 2) e o passo 3 (Opções de Controle de Risco). Assim, para verificar a influência do fator humano no acidente de colisão a modelagem do sistema se deu pela execução das seguintes atividades: 1) A Árvore de Falhas do trabalho anterior foi transformada em uma Rede Bayesiana (a Rede dos Eventos Perigosos); 2) Foram elaboradas as Redes Bayesianas Dinâmicas para as tarefas associadas aos eventos básicos da Árvore de Falhas (tendo como apoio as Árvores de Eventos do trabalho anterior); 3) Foram geradas as Redes Bayesianas dos fatores de desempenho para cada atividade das tarefas. Com a topologia destas redes em mãos e não tendo sido possível nova consulta a especialistas, os dados quantitativos do trabalho anterior foram aproveitados para balizar o preenchimento das TPC das Redes Bayesianas para as atividades desempenhadas no navio.

Sendo assim, neste capítulo são apresentadas as redes desenvolvidas para modelar a operação do navio e os desencadeamentos dos eventos que podem leválo a colidir. Também apresenta a técnica utilizada para o preenchimento das TPC e que possibilitou a quantificação do fator humano em termos de probabilidade de colisão. Antes, no entanto, é apresentada a descrição do sistema em estudo e são considerados alguns pontos sobre os dados utilizados neste trabalho. Em relação à análise do modelo obtido, foi desenvolvido o próximo capítulo - com considerações 
quantitativas sobre os efeitos das mudanças nos MOF e comparações com os resultados alcançados no trabalho anterior.

Conforme comentado, para o trabalho com as Redes Bayesianas foi utilizado o programa Netica ${ }^{\mathrm{TM}}$ (Norsys Software Corp., 1996), disponibilizado pelo LabRiscoUSP. Desta forma, todas as figuras representando as redes foram obtidas por meio deste programa.

\subsection{DESCRIÇÃO DO SISTEMA E APROVEITAMENTO DE DADOS QUANTITATIVOS}

O sistema modelado refere-se a um navio SUEZMAX com posicionamento dinâmico utilizado em operações de alívio de unidades de produção do tipo Floating Production System and Offloading (FPSO). A operação foi modelada considerando a rota entre a unidade de produção (Bacia de Campos) e o terminal portuário (São Sebastião).

Como parte primordial na familiarização com o sistema, foi feito um levantamento de campo, com visita ao navio e observação de seu ciclo operacional (ida e volta das unidades de produção I e II, ver Figura 20). Objetivando uma base de conhecimento mais precisa e completa, durante esta visita também foram feitas entrevistas com a tripulação (entrevista formal com o comandante e informais com o restante da tripulação durante os quartos - período de serviço de um tripulante). Isto foi feito devido à carga de trabalho e aos horários dos quartos e folgas que impossibilitaram o isolamento dos tripulantes para entrevistas formais. A Tabela 14 apresenta a configuração da tripulação no momento da visita.

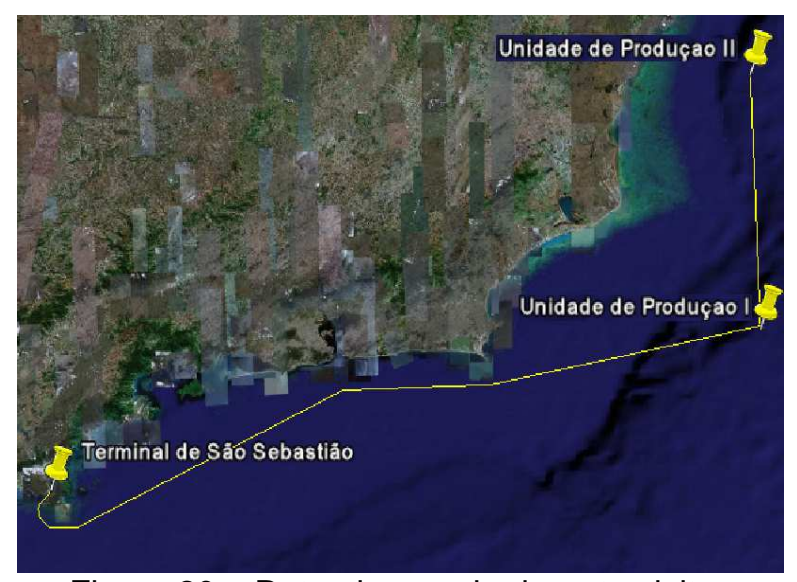

Figura 20 - Rota observada durante visita

Durante a entrevista, o comandante foi indagado sobre questões envolvendo os desencadeamentos de eventos perigosos e o histórico de falhas operacionais no 
navio. Também foi coletada sua opinião sobre o relacionamento dos tripulantes e características essenciais para execução de suas tarefas. Apesar do caráter formal e do questionário preparado antecipadamente, outras questões surgiram durante a entrevista e todas as questões foram respondidas de forma aberta pelo oficial.

Tabela 14 - Distribuição da Tripulação

\begin{tabular}{|c|c|c|c|c|}
\hline & Náutica & Máquinas & Convés & Total \\
\hline \multirow{4}{*}{ Oficiais } & \multicolumn{3}{|c|}{ Comandante } & \multirow{4}{*}{11} \\
\hline & Imediato & Chefe de Máquinas & & \\
\hline & 1응icial de Náutica & 1 Oficial de Máquinas & & \\
\hline & $\begin{array}{l}2^{\circ} \text { Oficial de Náutica } \\
\text { (3 pessoas) }\end{array}$ & $\begin{array}{l}\text { 20 Oficial de Máquinas } \\
\text { (3 pessoas) }\end{array}$ & & \\
\hline \multirow{4}{*}{ Suboficiais } & \multirow{4}{*}{$\begin{array}{l}\text { Praticante de Náutica } \\
\text { (2 pessoas) }\end{array}$} & $\begin{array}{l}\text { Praticante de Máquinas } \\
\text { (2 pessoas) }\end{array}$ & \multirow{4}{*}{ Contramestre } & \multirow{4}{*}{8} \\
\hline & & Mecânico & & \\
\hline & & Eletricista & & \\
\hline & & Bombeador & & \\
\hline \multirow[t]{2}{*}{ Guarnição } & & Marinheiro de Máquinas & $\begin{array}{c}\text { Marinheiro de Convés } \\
\text { (2 pessoas) }\end{array}$ & \multirow[t]{2}{*}{5} \\
\hline & & Moço de Máquinas & Moço de Convés & \\
\hline \multirow{2}{*}{ Serviço } & \multicolumn{3}{|c|}{ Cozinheiro (2 pessoas) } & \multirow{2}{*}{3} \\
\hline & \multicolumn{3}{|c|}{ Taifeiro } & \\
\hline Total & 7 & 12 & 4 & 27 \\
\hline
\end{tabular}

Em relação aos tripulantes, foram feitas perguntas e coletadas informações sobre a operação dos sistemas do navio e, individualmente, sobre questões pessoais (envolvendo qualidade de vida, recursos disponibilizados pela empresa, problemas familiares, etc.) que poderiam influenciar no seu rendimento no trabalho. Mesmo informalmente, foi possível coletar suas impressões sobre a liderança da empresa e satisfação pessoal.

Durante esta visita ao navio - considerando as observações e as informações obtidas por meio das entrevistas - todas as tarefas relacionadas à operação foram listadas e comparadas com os procedimentos estabelecidos nos manuais da empresa. Com isto verificou-se que por diferentes razões (instruções de operação ou de segurança apagadas, cobertas por sujeira ou ausentes e excesso de confiança do operador em sua experiência, por exemplo) haviam discrepâncias entre o praticado no navio e os procedimentos estabelecidos. Assim, os procedimentos escritos foram considerados como base para a modelagem, mas foram as evidências encontradas a bordo que determinaram os desencadeamentos de eventos perigosos e o seqüenciamento definitivo das tarefas (no trabalho anterior 
estas diferenças foram utilizadas para determinar o valor das HEP nas Árvores de Eventos).

Foram considerados os procedimentos para navegação tanto em águas restritas quanto em águas abertas. Para cada tarefa foram verificados: 1) Os objetivos e descrição da tarefa; 2) Sinais de início e fim da tarefa; 3) Momento em que deve ser realizada; 4) Materiais disponíveis para a execução da tarefa; 5) Se eram tarefas executadas rotineiramente; 6) Características exigidas do pessoal (requisitos de percepção e antecipação); 7) Memória requerida (informações da memória do operador); 8) Problemas de manipulação (manivelas, botões, etc.); 9) Prováveis erros cometidos e em quais momentos; 10) Se existe a possibilidade do erro ser detectado e corrigido; 11) Condições ambientais (temperatura, barulho, vibração, umidade, etc.). Além disto, para cada operador foram feitas observações sobre: 1) A preparação que recebeu para realizar a tarefa; 2) Tempo de descanso e trabalhando; 3) Se possuía outras responsabilidades.

No trabalho anterior (Maturana e Martins, 2008) estes dados, juntamente com os encontrados em Brown et al. (1996, 1997 e 1998), Bigano e Sheehan (1997) e Rawson et al.(1998) sobre a questão de colisão de navios petroleiros, foram utilizados para gerar a Árvore de Falhas e as Árvores de Eventos. Quanto aos dados quantitativos, sua disponibilidade na análise da confiabilidade humana é escassa, se não inexistente, para o caso da operação de navios. Seguindo o que foi proposto por outros autores (IMO, 2002a; Brown e Golay, 1997; Bigano e Sheehan, 1997), no trabalho anterior os dados necessários para a realização da THERP foram obtidos em bibliografia referente ao setor nuclear (Gertman e Blackman, 1993; Swain e Guttman, 1983). Porém, para o uso dos dados apresentados em Gertman e Blackman (1993) e Swain e Guttman (1983) foi necessário fazer associações entre as atividades desenvolvidas no navio e aquelas que são apresentadas para as plantas nucleares. Obviamente existem diferenças entre os dois casos, mas assumindo que as tarefas sejam semelhantes, considerou-se que as probabilidades de erros humanos apresentam a mesma ordem de grandeza, ou seja, acredita-se que os dados conseguidos no setor nuclear sejam uma boa estimativa inicial para 0 setor naval. As opiniões coletadas durante a visita também foram utilizadas para a realização quantitativa do trabalho anterior (Maturana e Martins, 2008) - estes dados ajudaram a definir os PSF significativos para cada atividade e, com isto, determinar 
suas HEP com apoio das tabelas apresentadas por Gertman e Blackman (1993) e Swain e Guttman (1983) (ver item 2.1.1.2). Nesta dissertação, os dados quantitativos do trabalho anterior foram aproveitados para balizar o preenchimento das TPC das Redes Bayesianas para as atividades desempenhadas no navio. Isto porque não foram consultados especialistas e não foram encontradas outras fontes para ajudar na execução desta tarefa. Mais adiante o aproveitamento destes dados será detalhado (item 4.5).

\subsection{DESENCADEAMENTO DOS EVENTOS PERIGOSOS}

Conforme comentado acima, com a análise das tarefas foi possível relacionar as tarefas e o evento de colisão por meio do desencadeamento de eventos perigosos, ou seja, montagem de cenários de acidente. Durante a visita ao navio, estes desencadeamentos foram apresentados ao comandante do navio que fez um julgamento de quais seriam os mais prováveis.

No trabalho anterior, antes da visita ao navio, foram levantadas árvores relativas à colisão definidas por outros autores para outras operações (Brown e Golay, 1997; Bigano e Sheehan, 1997). Estas Árvores de Falha preliminares foram comparadas com o conjunto de desencadeamentos de eventos perigosos citados no parágrafo anterior, o que deu origem à Árvore de Falha final para o evento de colisão, apresentada na Figura 21. Partindo desta Árvore de Falhas, foi possível o desenvolvimento de uma Rede Bayesiana com o mesmo valor de representação do domínio. A Rede Bayesiana obtida está apresentada na Figura 22.

Para a elaboração da rede da Figura 22 foram observados os princípios estabelecidos no capítulo anterior a respeito da conversão de Árvore de Falhas em Rede Bayesiana. Os números apresentados para os estados dos nós serão mais bem compreendidos com a leitura do próximo tópico e do capítulo relativo à análise do modelo obtido (onde todas as redes foram integradas; incluindo as redes dinâmicas das tarefas e as redes dos fatores de desempenho, com o intuito de quantificar o erro humano em termos de probabilidade de colisão). Ressalta-se que na Figura 21 os valores estão representados em notação científica, enquanto na Figura 22 as probabilidades estão representadas em percentagem.

Em relação à Figura 22, os nós que possuem somente arcos que "saem" representam os eventos básicos (da árvore da Figura 21). A cada nó de evento 
básico foram associadas tarefas que, se mal executadas, podem gerar o evento básico em questão. A seguir é feita uma consideração sobre estas tarefas.

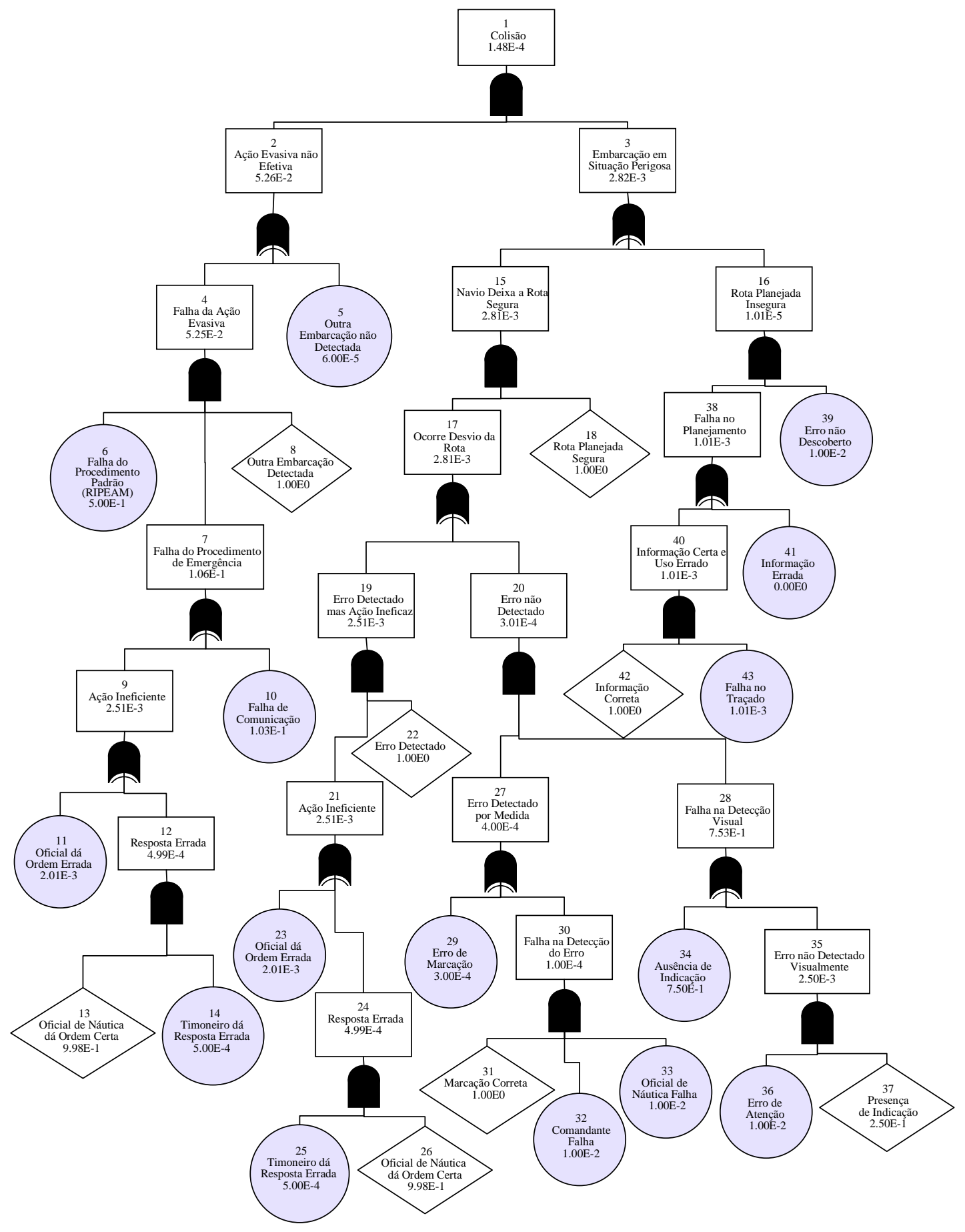

Figura 21 - Árvore de Falhas para Colisão 


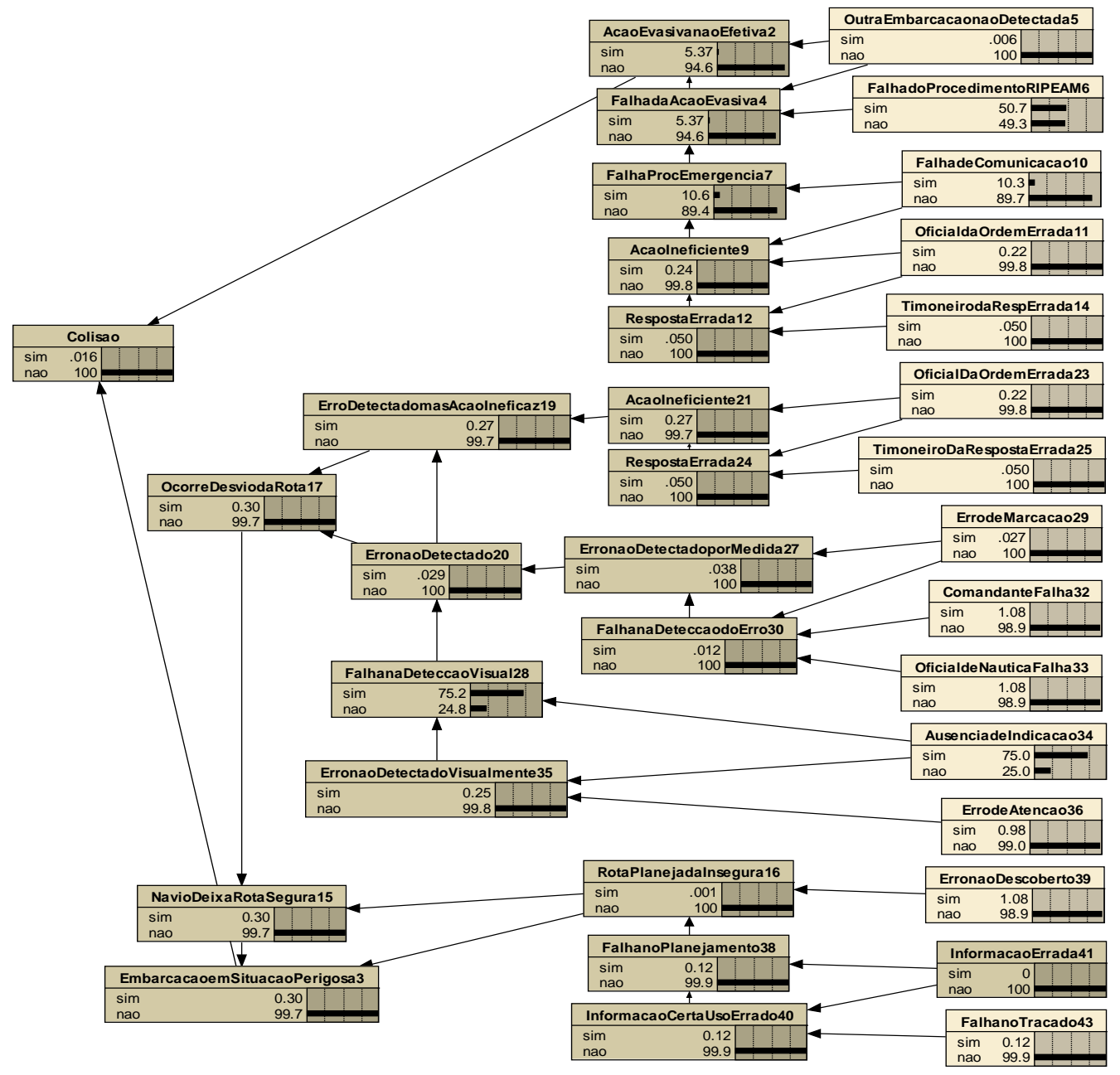

Figura 22 - Rede Bayesiana para o desencadeamento de eventos perigosos

\subsection{REDES BAYESIANAS DINÂMICAS DAS TAREFAS}

Para obter as atividades relacionadas aos eventos básicos da Árvore de Falhas (ou as tarefas relacionadas ao evento de colisão, conforme Figura 21) recorreu-se às Árvores de Eventos já desenvolvidas (Maturana e Martins, 2008). Na Tabela 15 abaixo são apresentados os eventos básicos e as atividades retiradas das Árvores de Eventos mencionadas. Estas atividades estão numeradas na ordem em que ocorrem.

Partindo destes eventos e considerando as Árvores de Eventos do trabalho anterior, foram desenvolvidas as Redes Bayesianas Dinâmicas das tarefas (dado que cada evento básico se origina na falha de execução de alguma tarefa). Nota-se que só é possível desenvolver uma rede dinâmica para tarefas que apresentam mais de uma atividade. A seguir são apresentadas as redes para estas tarefas. Antes, no entanto, salienta-se que nestas redes foram incluídos nós para os eventos básicos 
que podem ser fruto de falhas na execução das atividades e que foram considerados dois estados para cada nó. A numeração dos eventos respeita a apresentada na Figura 21.

Tabela 15 - Eventos Básicos e atividades relacionadas

\begin{tabular}{|c|c|c|}
\hline \multicolumn{2}{|r|}{ Evento } & Atividade \\
\hline \multirow{3}{*}{5} & \multirow{3}{*}{ Outra Embarcação não Detectada } & 1-Detectar Outra Embarcação por Radar \\
\hline & & 2-Detectar Outra Embarcação Visualmente \\
\hline & & 3-Detectar Outra Embarcação por Alarme \\
\hline 6 & Falha do Procedimento RIPEAM & 1-Falha do Procedimento RIPEAM \\
\hline \multirow{5}{*}{10} & \multirow{5}{*}{ Falha de Comunicação } & 1-Decidir Fazer Contato por Rádio \\
\hline & & 2-Conseguir Fazer Contato \\
\hline & & 3-Entender Interlocutor \\
\hline & & 4-Decidir Fazer Contato por Outro Meio \\
\hline & & 5-Entender Interlocutor \\
\hline \multirow{3}{*}{11} & \multirow{3}{*}{ Oficial dá Ordem Errada } & 1-Entende Corretamente \\
\hline & & 2-Tomada de Decisão \\
\hline & & 3-Detecção do Erro \\
\hline 14 & Timoneiro dá Resposta Errada & 1-Resposta Errada \\
\hline \multirow{3}{*}{23} & \multirow{3}{*}{ Oficial dá Ordem Errada } & 1-Entende Corretamente \\
\hline & & 2-Tomada de Decisão \\
\hline & & 3-Detecção do Erro \\
\hline 25 & Timoneiro dá Resposta Errada & 1-Resposta Errada \\
\hline \multirow{6}{*}{29} & \multirow{6}{*}{ Erro de Marcação } & 1-Checagem de Equipamento \\
\hline & & 2-Falha Material \\
\hline & & 3-Respeito dos Intervalos \\
\hline & & 4-Leitura de posição \\
\hline & & 5-Marcação na Carta Náutica \\
\hline & & 6-Comandante Detecta o Erro \\
\hline 32 & Capitão Falha & 1-Capitão Falha \\
\hline 33 & ON Falha & 1-ON Falha \\
\hline 34 & Ausência de Indicação & 1-Ausência de Indicação \\
\hline 36 & Erro de Atenção & 1-Erro de Atenção \\
\hline 39 & Erro não Descoberto & 1-Erro não Descoberto \\
\hline 41 & Informação Errada & 1-Informação Errada \\
\hline \multirow{11}{*}{43} & \multirow{11}{*}{ Falha no Traçado } & 1-Atualização das Publicações \\
\hline & & 2-Leitura das Informações \\
\hline & & 3-Estabelecimento da Profundidade Mínima \\
\hline & & 4-Leitura da Profundidade \\
\hline & & 5-Identificar Áreas Restritas \\
\hline & & 6-Traçar Áreas Restritas \\
\hline & & 7-Traçar Rumos Sucessivos \\
\hline & & 8-Identificar Way-Points \\
\hline & & 9-Escolha dos Pontos \\
\hline & & 10-Revisão da Rota ON \\
\hline & & 11-detecção de Falha Comandante \\
\hline
\end{tabular}

\subsubsection{EVENTO 5-OUTRA EMBARCAÇÃO NÃO DETECTADA}

Durante a operação de navegação, o monitoramento do tráfego é realizado por dois meios: visual e eletrônico. O meio eletrônico (RADAR) tem um alcance maior que o visual, portanto foi colocado em primeira posição no desencadeamento cronológico das atividades. Se a detecção por meio eletrônico falhar, o próximo passo é a detecção visual, e se esta também falhar, os equipamentos de detecção eletrônica são dotados de alarmes sonoros de proximidade e de rumo de colisão.

Para o desenvolvimento da rede considerou-se que a falha na detecção ocorrerá somente se houver falha na detecção por alarme. Para isto considerou-se que se houver a detecção visual então será certa a detecção por alarme (dado que a 
concentração do operador deve aumentar; além disto, foram desconsideradas falhas nos equipamentos). E também que se houver a detecção por radar será certa a detecção visual. Estas considerações simplificaram as relações de dependência e permitiram tabelas de probabilidades condicionais mais simples - que serão vistas mais adiante, depois de serem discutidos os fatores de desempenho. A rede desenvolvida está apresentada na Figura 23.

\begin{tabular}{|c|c|c|c|}
\hline DetectarPorRadar & DectarVisualmente & DetectarPorAlarme & OutraEmbarcacaonaoDetectada5 \\
\hline $\operatorname{sim} \quad 99.9$ & $\operatorname{sim} 100$ & 100 & $\operatorname{sim}$ \\
\hline nao $\quad 0.10$ & nao $0+$ & nao $0+$ & nao \\
\hline
\end{tabular}

Figura 23 - Rede Bayesiana Dinâmica para a tarefa de monitoramento do tráfego

Na Figura 23 o nó em tom mais escuro representa o evento básico e os demais são os nós para as atividades da tarefa. As probabilidades apresentadas nesta rede serão discutidas no tópico sobre a integração das redes dos fatores de desempenho com as redes dinâmicas (este padrão também será seguido para as demais tarefas).

\subsubsection{EVENTO 10-FALHA DE COMUNICAÇÃO}

A operação do rádio é feita com apoio de checklist. Consideraram-se dois meios de comunicação entre duas embarcações separadas por uma distância da ordem do alcance da visão: o rádio é o meio privilegiado e o código Morse visual, usando sinal luminoso, o meio secundário.

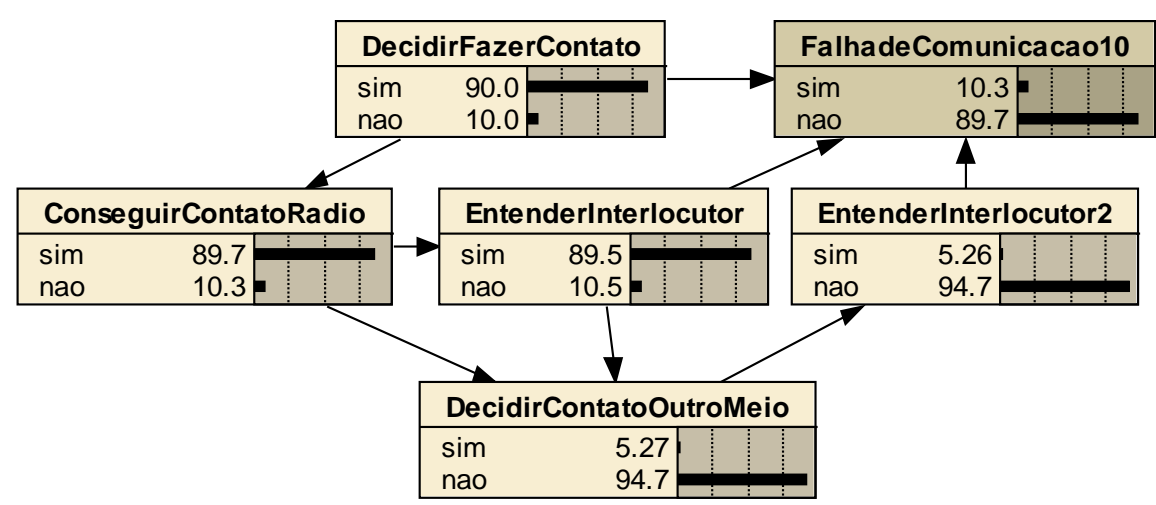

Figura 24 - Rede Bayesiana Dinâmica para a tarefa de comunicação

A Rede Bayesiana Dinâmica para a tarefa de comunicação está apresentada na Figura 24. Nesta rede foram consideradas atividades para conseguir fazer contato (manipulação de equipamentos) e entender o interlocutor (na comunicação 
propriamente dita). Considerou-se a possibilidade de falha na comunicação se houver falha na decisão de fazer contato ou falha no entendimento (insucesso nos dois meios de comunicação disponíveis).

\subsubsection{EVENTO 11-OFICIAL DÁ ORDEM ERRADA}

Para a ordem dos oficiais considerou a necessidade de duas etapas. A primeira consistindo em compreender o que está acontecendo, sendo essencial para o processo decisório, e a segunda, denominada tomada de decisão, consistindo em escolher entre as soluções existentes. A simplicidade desta representação é justificada pela necessidade de resposta em curto espaço de tempo, já que a complexidade na operação de um navio petroleiro dificulta a geração de respostas coerentes neste curto espaço de tempo, de forma que todas as ações possíveis são estudadas previamente. Em outras palavras, não fosse o tempo escasso, poderia ser incluído um passo intermediário de pesquisa e raciocínio para gerar soluções.

Considerou-se que a ordem do oficial será falha se a decisão for errada e a revisão desta decisão também for imperfeita. Assim a rede desenvolvida ganhou as características apresentadas na Figura 25.

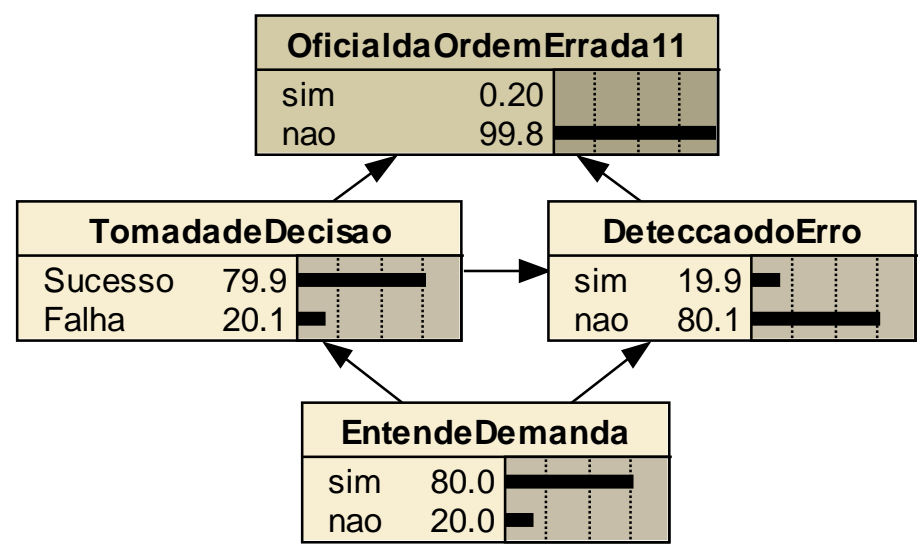

Figura 25 - Rede Bayesiana Dinâmica para ordem dos oficiais

\subsubsection{EVENTO 23-OFICIAL DÁ ORDEM ERRADA}

A construção desta rede seguiu os mesmos princípios apresentados no item anterior (Evento 11-Oficial dá Ordem Errada) e o resultado é idêntico.

\subsubsection{EVENTO 29-ERRO DE MARCAÇÃO}

A rede relacionada a este evento é na verdade a composição de outras duas: uma para o processo de marcação e outra para o estado do equipamento de GPS 
(Global Positioning System).

A marcação na carta náutica segue um procedimento escrito, que define inclusive os intervalos de marcação. A leitura de posição consiste em ler e recordar informações obtidas de displays enquanto a marcação se refere à plotagem da posição na carta náutica.

A parte da rede relacionada aos equipamentos se resume a atividade de checagem destes equipamentos (foi incluído um nó para falha de equipamento, o que não é o foco deste trabalho).

Considerou-se a possibilidade de erro de marcação se houver falha de equipamento (inspeção incorreta acarretando em falha material imprevista ou regulagem incorreta) ou na marcação da carta náutica (ocasionada por leitura incorreta do equipamento, intervalo muito grande entre as marcações e marcação do ponto em coordenada diferente da obtida no equipamento) somada à falha na revisão do comandante. A rede dinâmica está apresentada na Figura 26.

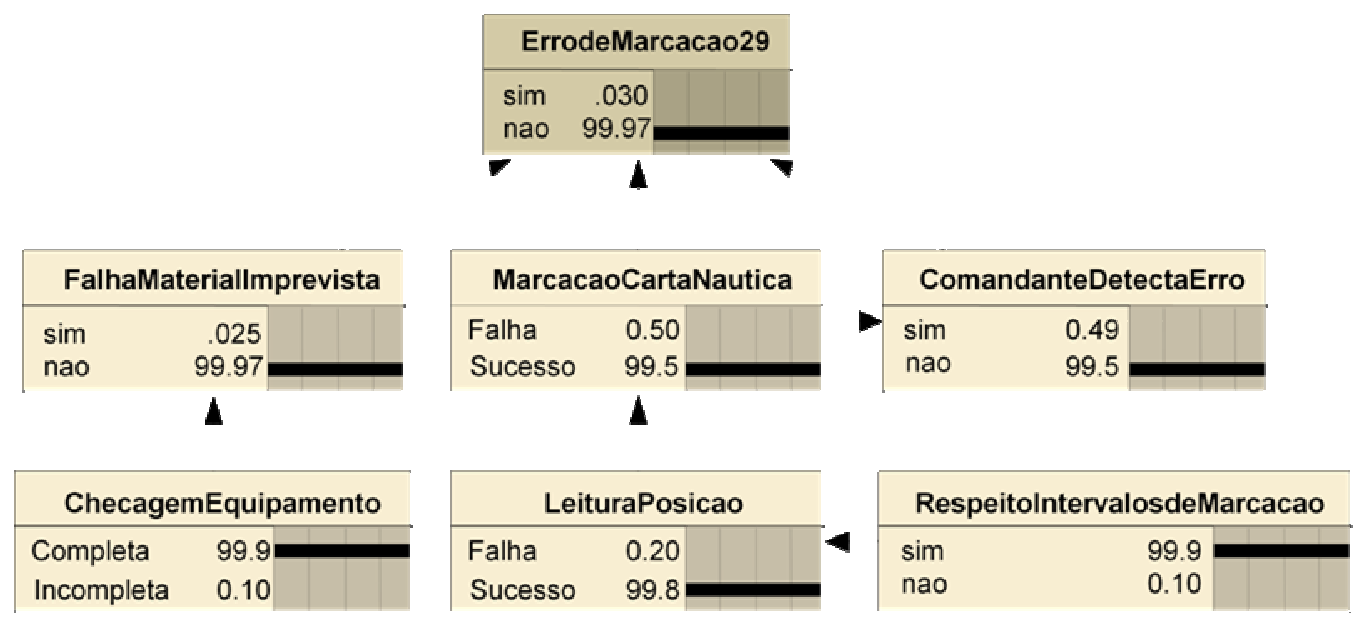

Figura 26 - Rede Bayesiana Dinâmica para a tarefa de marcação de posição

\subsubsection{EVENTO 43-FALHA NO TRAÇADO}

O planejamento da rota é efetuado pelo $1^{\circ}$ Oficial de Náutica ( $\left.1^{\circ} \mathrm{ON}\right)$. Ele também é responsável pela atualização das publicações tais como cartas náuticas, roteiros de informações sobre as regiões de navegação, lista de faróis e bóias cegas. Estas atualizações chegam a cada duas semanas por meios eletrônicos e papel. A cada seis meses, a Autoridade Marítima apresenta uma lista de todas as correções feitas nos últimos seis meses e a cada ano uma lista de todas as 
correções já efetuadas.

A atividade de traçado da rota consiste em utilizar as informações disponíveis sobre o meio ambiente e o navio para determinar o caminho seguro mais curto entre a origem e o destino da embarcação. Assim, a leitura das cartas náuticas e a definição da profundidade mínima para a navegação são atividades essenciais nesta tarefa, pois com estas informações é possível identificar e traçar as áreas restritas para a circulação do navio e determinar o caminho que reúne as características acima (definido na carta por rumos sucessivos, ou seja, pelo conjunto de retas que formam a rota).

Além do traçado da rota, são marcados os pontos de mudança de rumo (os Way-Points) e os pontos de referência (que servem para o monitoramento da rota). Depois de traçada, a rota é submetida ao comandante para aprovação.

Para o desenvolvimento da rede considerou-se a possibilidade de falha no traçado se houver falha na atualização das publicações, na revisão da rota feita pelo Oficial de Náutica e pelo Comandante. Estas considerações e o desencadeamento das atividades deram origem à rede apresentada na Figura 27.

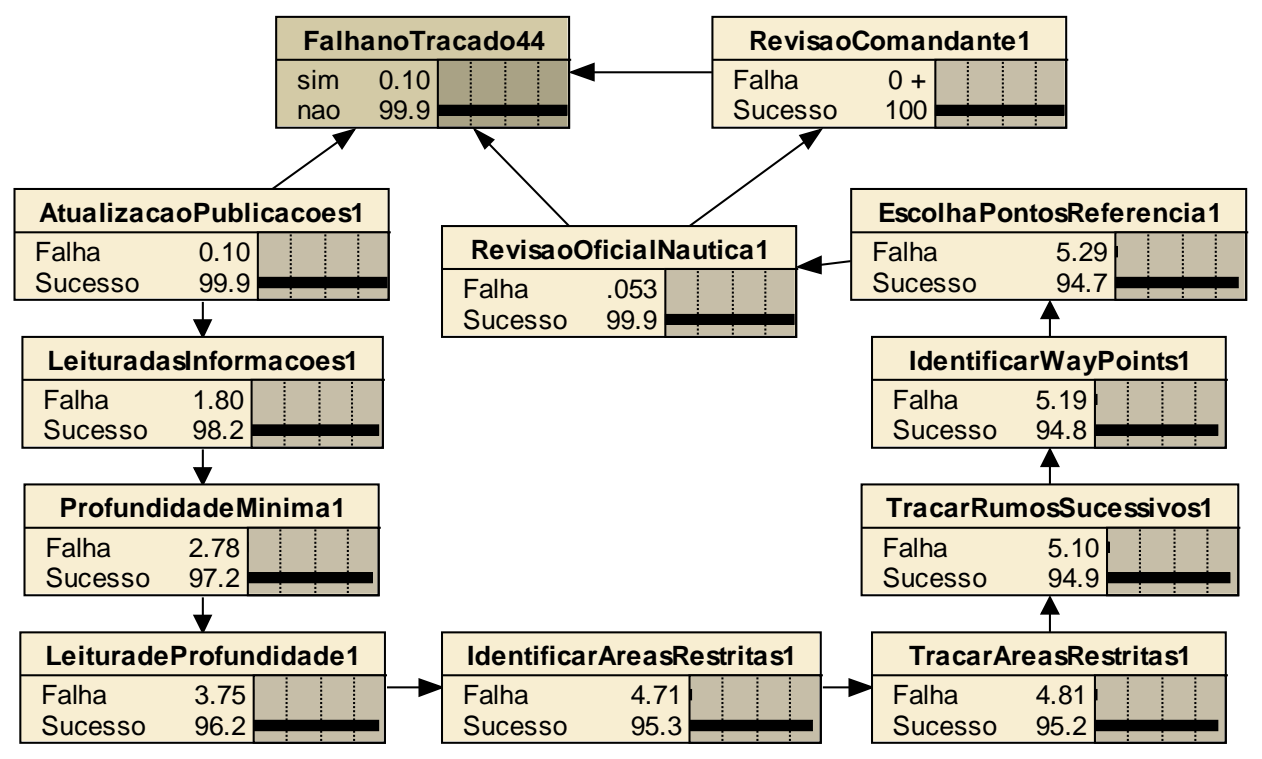

Figura 27 - Rede Bayesiana Dinâmica para a tarefa de traçado da rota

\subsection{REDES BAYESIANAS DOS FATORES DE DESEMPENHO}

Neste tópico foram levantados os fatores de desempenho (relacionados às tarefas do tópico anterior) e as redes para estes fatores. Primeiramente, as 
habilidades consideradas essenciais para a realização de cada atividade são relacionadas e, em seguida, a rede genérica para os fatores de desempenho conforme apresentada no capítulo anterior (Figura 18) - é aplicada para obterem-se as Redes Bayesianas para representar os fatores que mais influenciam a execução das atividades relacionadas ao evento de colisão.

Como será observado mais adiante, alguns fatores discriminados para determinada tarefa são ligados a várias atividades desta tarefa. Isto porque as atividades são executadas pela mesma pessoa, ou ainda porque o fator está disponível para mais de um operador (este é o caso, por exemplo, de fatores ambientais para tarefas executadas em um mesmo compartimento e com diferença pequena de tempo).

\subsubsection{LISTA DE HABILIDADES RELACIONADAS ÀS ATIVIDADES}

$\mathrm{Na}$ Tabela 15 é possível verificar as atividades relacionadas aos eventos básicos da Árvore de Falhas (Figura 21). Com base nas habilidades listadas na Tabela 13 (identificadas por números romanos), foi possível desenvolver a Tabela 16. Esta tabela apresenta as habilidades consideradas essenciais para a boa execução das atividades ligadas ao evento de colisão.

Para os eventos básicos 34 e 41 (Ausência de Indicação e Informação Errada, respectivamente) não foram associadas habilidades. Para o caso do evento 34 isto se dá porque este não é um evento gerado pela ação humana, mas depende da posição do navio na rota. Já para o evento 41, a tarefa de fornecer informação correta depende de agentes externos à operação (Autoridade Marítima) cuja ação não foi modelada.

A Tabela 16 foi utilizada no desenvolvimento da topologia das redes para os fatores de desempenho. Como exemplo, a seguir será apresentado o desenvolvimento da rede completa para a atividade de monitoramento do tráfego.

\subsubsection{REDE DOS FATORES DE DESEMPENHO PARA MONITORAMENTO DO TRÁFEGO}

Para ilustrar a criação da topologia das redes dos fatores de desempenho, será tomado o exemplo do evento básico "5 - Outra Embarcação não Detectada". Para tanto, será apresentada a análise individual das atividades desta tarefa. 
Para a Atividade "5-1: Detectar Outra Embarcação por Radar" a Tabela 17 apresenta as habilidades requeridas e os fatores de desempenho internos relacionados (escolhidos entre os apresentados na Tabela 11, conforme se julgaram mais influentes). Além dos MOF (escolhidos com apoio da Tabela 10) e dos fatores ambientais (Tabela 12) relacionados a estes fatores de desempenho.

Tabela 16 - Habilidades relacionadas às atividades

\begin{tabular}{|c|c|c|}
\hline \multicolumn{2}{|r|}{ Descrição } & Habilidades Requeridas \\
\hline $5-1$ & Detectar Outra Embarcação por Radar & III,X \\
\hline $5-2$ & Detectar Outra Embarcação Visualmente & III,X \\
\hline $5-3$ & Detectar Outra Embarcação por Alarme & III,X \\
\hline 6-1 & Seguir o Procedimento RIPEAM & IV,VIII,X \\
\hline $10-1$ & Decidir Fazer Contato por Rádio & I,IV,VIII \\
\hline $10-2$ & Conseguir Fazer Contato & III,IV,VII \\
\hline $10-3$ & Entender o Interlocutor & III,X \\
\hline $10-4$ & Decidir Fazer Contato por Outro Meio & I,IV,XIV \\
\hline $10-5$ & Entender o Interlocutor & III,X \\
\hline $11-1$ & Entender Corretamente & III,X \\
\hline $11-2$ & Tomar Decisão & I,XI,XIV \\
\hline $11-3$ & Detectar erro & III,VIII,X \\
\hline 14-1 & Responder Corretamente & III,VII,VIII \\
\hline 23-1 & Entender Corretamente & III,X \\
\hline 23-2 & Tomar Decisão & I,XI,XIV \\
\hline 23-3 & Detectar Erro & III,X,VIII \\
\hline $25-1$ & Responder Corretamente & III,VII,VIII \\
\hline $29-1$ & Checar Equipamentos & III,IV,X \\
\hline $29-3$ & Respeitar Intervalos de Marcação & IX \\
\hline $29-4$ & Ler Posição & III,X \\
\hline $29-5$ & Marcar a Carta Náutica & III,VII \\
\hline $29-6$ & Detectar o Erro (Comandante) & III,VIII,X \\
\hline $32-1$ & Detectar Erro (Comandante) & III,VIII,X \\
\hline $33-1$ & Detectar o Erro (ON) & III,VIII,X \\
\hline $36-1$ & Monitorar o tráfego & III,VI,X \\
\hline $39-1$ & Revisar Rota & III,VIII,X \\
\hline 43-1 & Atualizar as Publicações & III,VI,X \\
\hline 43-2 & Ler as Informações & III \\
\hline $43-3$ & Estabelecer a Profundidade Mínima & II,III,X \\
\hline 43-4 & Ler a Profundidade na Carta & III \\
\hline 43-5 & Identificar Áreas Restritas & III \\
\hline 43-6 & Traçar Áreas Restritas & III,VII \\
\hline 43-7 & Traçar Rumos Sucessivos & III,VII \\
\hline 43-8 & Identificar Way-points & III,VII \\
\hline 43-9 & Escolher os Pontos de Referência & $\mathrm{I}, \mathrm{IV}, \mathrm{X}$ \\
\hline 43-10 & Revisar a Rota (ON) & III,VIII,X \\
\hline 43-11 & Revisar a Rota (Comandante) & III,VIII,X \\
\hline
\end{tabular}

Neste ponto é interessante relembrar que nem todos os PSF listados nas tabelas do item 3.2 precisaram ser associados às habilidades consideradas para esta atividade. Naquelas tabelas a associação foi feita de maneira geral, para um navio e tripulação qualquer, localizando as relações mais prováveis entre os PSF. No caso do fator interno 4 - Qualidade do Sono, por exemplo, a Tabela 11 associa também o MOF G - Qualidade de Vida, mas na modelagem este MOF não foi relacionado a este fator interno. A qualidade de vida está relacionada a diversos 
fatores: um indivíduo, por exemplo, pode não ter boa qualidade de vida porque está preocupado (com o pagamento no final do mês, ou com problemas com a justiça ou de saúde na família, ou com a educação dos filhos, etc.) ou não desfrutar de boa saúde (sedentarismo, falta de acompanhamento médico, alimentação, etc.). De forma que diversos fatores estão agrupados no MOF G - Qualidade de Vida. Não foi observada nas entrevistas e visita a presença de dificuldades neste quesito, em relação a preocupações, que possam influenciar significativamente a concentração (esta habilidade está mais relacionada às faculdades mentais que às físicas) do pessoal envolvido com o monitoramente do tráfego. Em contrapartida observou-se a presença de sedentarismo e, assim, para o fator interno 5 - Condição Física da habilidade $X$ - Percepção, foi mantida a associação deste MOF.

Tabela 17 - Fatores de desempenho para monitoramento com RADAR

\begin{tabular}{|c|c|c|c|}
\hline Habilidades Requeridas & \multicolumn{2}{|c|}{ PSF } & MOF \\
\hline \multirow{4}{*}{ III - Concentração } & \multirow{4}{*}{ Internos } & $\begin{array}{l}4 \text { - Qualidade do } \\
\text { Sono }\end{array}$ & A - Carga de Trabalho \\
\hline & & $\begin{array}{l}10-\text { Trabalho } \\
\text { Monótono }\end{array}$ & C - Coordenação do Trabalho \\
\hline & & \multirow{2}{*}{12 - Distrações } & C - Coordenação do Trabalho \\
\hline & & & F - Recursos Físicos \\
\hline \multirow{6}{*}{ X - Percepção } & \multirow{4}{*}{ Internos } & $\begin{array}{l}4 \text { - Qualidade do } \\
\text { Sono }\end{array}$ & A - Carga de Trabalho \\
\hline & & & A - Carga de Trabalho \\
\hline & & 5 - Condição Física & G - Qualidade de Vida \\
\hline & & & J - Seleção de Pessoal \\
\hline & Ambientais & $\kappa$ - Tempestades & \\
\hline & & $\mu$ - Ondas & \\
\hline
\end{tabular}

Outro ponto a ser ressaltado é a complexidade da rede final se as mínimas influências forem consideradas. Assim, cabe ao analista um estudo cuidadoso para eliminar na modelagem os fatores que são secundários. Na Tabela 13, por exemplo, verifica-se que muitos outros PSF (fatores internos) foram associados às habilidades III - Concentração e $X$ - Percepção, mas com as observações feitas em campo foi possível agrupar na modelagem aqueles com maior impacto para as pessoas envolvidas na operação. A visita à planta tornou-se, portanto, fundamental na determinação dos fatores que não podem ser ignorados. O mesmo pode ser concluído em relação aos fatores ambientais.

Dando seqüência à modelagem, os fatores de desempenho para a atividade "5-2: Detectar Outra Embarcação Visualmente" são muito semelhantes aos encontrados para a atividade precedente. A diferença está na influência dos fatores 
ambientais. Para este caso adota-se a influência da visibilidade e ignoram-se ondas e tempestade.

Para o caso da Atividade "5-3: Detectar Outra Embarcação por Alarme" os fatores também são semelhantes aos da atividade inicial. Mas aqui não foi considerada a influência de fatores ambientais.

Com o apoio da Tabela 17 e do descrito acima foi possível desenvolver a topologia da Rede Bayesiana para os fatores que influenciam no desempenho das atividades da tarefa de monitoramento do tráfego. A rede integrada obtida está apresentada na Figura 28.

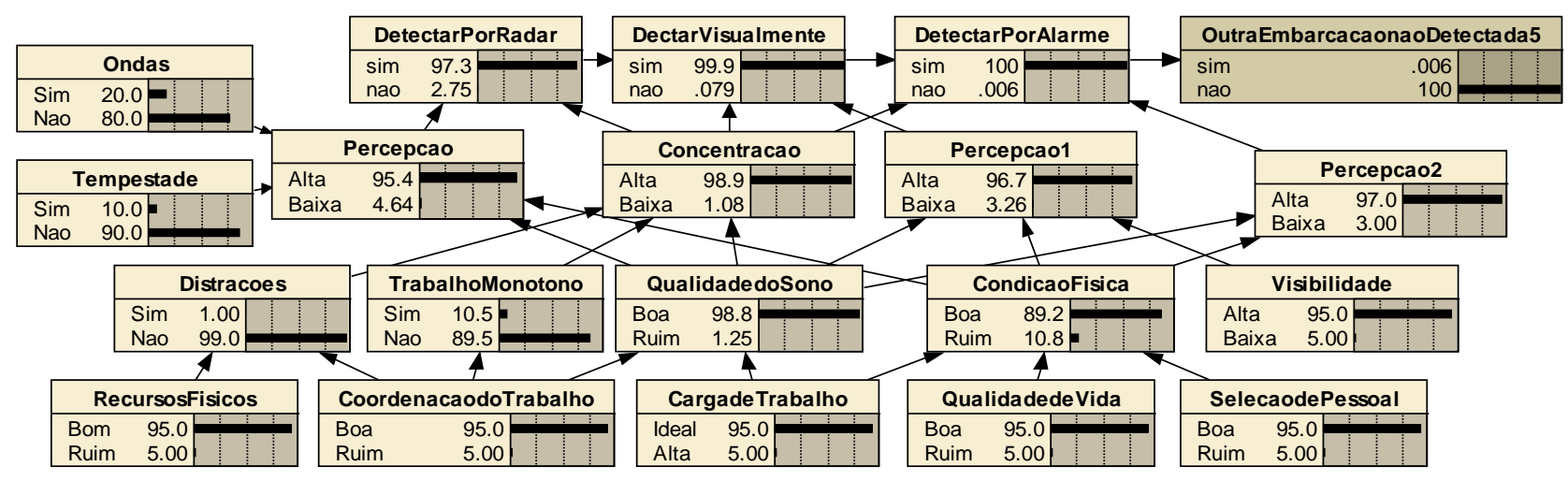

Figura 28 - Rede dos Fatores de Desempenho para Monitoramento do Tráfego

Como pode ser visto na Figura 28, não há repetição dos MOF e fatores internos para o operador. No entanto, para a habilidade de percepção, foram gerados nós específicos para cada atividade. Isto porque, apesar de classificadas sobre a mesma nomenclatura, esta habilidade apresentou natureza diferente para cada atividade - da esquerda para a direita, conforme apresentadas na Figura 28: visual para as duas primeiras, com exigências diferentes de interpretação, e auditiva para a última.

No Apêndice A estão apresentadas tabelas semelhantes à Tabela 17 para as demais tarefas, o que permite a reconstrução das redes consideradas nos tópicos seguintes. A seguir será considerado o preenchimento das TPC das redes desenvolvidas.

\subsection{PREENCHIMENTO DAS TABELAS DE PROBABILIDADES CONDICIONAIS}

Para viabilizar o estudo de caso, a obtenção das TPC se deu pelo emprego 
de dois procedimentos complementares: o primeiro objetivou o estabelecimento de valores iniciais de acordo com a opinião das pessoas envolvidas neste trabalho (foi estabelecido um critério de preenchimento que considera os estados dos nós pais) e o segundo consistiu do aproveitamento das probabilidades estimadas anteriormente (Maturana e Martins, 2008) para os eventos básicos da Árvore de Falhas através da aplicação da THERP, aproveitando, indiretamente, os dados obtidos de banco de dados do setor nuclear (ver item 4.1).

Em uma condição adequada as probabilidades condicionais deveriam ser obtidas a partir de banco de dados ou da opinião de especialistas, por exemplo. Porém, como salientado anteriormente, existe escassez de dados para o caso da indústria naval e a coleta de informações de especialistas não é um procedimento trivial, demandando tempo e recursos financeiros indisponíveis para o período de execução deste trabalho. Além disto, a obtenção indireta dos dados quantitativos necessários para preenchimento das TPC não inviabiliza a verificação do potencial da metodologia e técnica que estão sendo estudadas, e que é o objetivo principal deste trabalho (ver item 1.1). Ademais, a utilização da opinião de especialistas ou banco de dados exige a verificação do quão adequadas e empregáveis são as probabilidades obtidas (Droguett e Menêzes, 2007), o que seria justificado na necessidade de determinação quantitativa da probabilidade de colisão. Neste trabalho, no entanto, foram modelados apenas os eventos ligados à operação do navio e, assim, as probabilidades dos eventos modelados seriam mais bem avaliadas se fatores tais como manutenção, falha de equipamentos, atuação de pessoas e organismos externos à tripulação e a empresa de navegação, etc., fossem considerados com melhor detalhe.

As opiniões coletadas durante a visita também foram utilizadas para a realização quantitativa do trabalho anterior (Maturana e Martins, 2008) - estes dados ajudaram a definir os PSF significativos para cada atividade e, com isto, determinar seus HEP com apoio das tabelas apresentadas por Gertman e Blackman (1993) e Swain e Guttman (1983) (ver item 2.1.1.2). Nesta dissertação, o aproveitamento dos dados do trabalho anterior se baseou na hipótese não validada de que os resultados obtidos naquela ocasião para as probabilidades dos eventos básicos da Árvore de Falhas são realistas. Assim, com apoio destes dados, foi desenvolvido um procedimento para balizar o preenchimento das TPC das Redes Bayesianas para os 
fatores de desempenho relacionados às atividades desempenhadas no navio (não quantificados no trabalho anterior).

Os nós que representam as atividades das tarefas ligadas aos eventos básicos não passaram pelo segundo procedimento (proposto no primeiro parágrafo deste tópico). Isto porque o erro em determinada atividade pode inviabilizar o sucesso na atividade subseqüente (para tarefas compostas por múltiplas atividades; por serem organizadas numa seqüência cronológica). Por conta disto, antes de apresentar o procedimento para a obtenção das probabilidades iniciais em função dos nós pais (item 4.5.2), serão discutidos alguns pontos sobre a obtenção das TPC para o caso das atividades (item 4.5.1). Posteriormente, será apresentado o procedimento para ajustagem da probabilidade inicial (item 4.5.3).

\subsubsection{NÓS DAS ATIVIDADES}

Cada evento básico da Árvore de Falhas é gerado pelo erro na execução de determinada tarefa ou de um conjunto delas (erro de leitura e de revisão do comandante gerando erro de marcação, por exemplo). Na elaboração das árvores dinâmicas para os eventos básicos, estas tarefas foram decompostas em suas atividades, e a cada atividade se associou um conjunto de habilidades requeridas para sua boa execução (ver item 4.4.1). Estes pontos devem ser levados em consideração para entender o preenchimento das TPC das atividades. Como exemplo, na Figura 28 verifica-se que a atividade "5-2: Detectar Outra Embarcação Visualmente" é precedida pela atividade "5-1: Detectar Outra Embarcação por Radar", sendo que no item 4.3.1 definiu-se que se houver sucesso na detecção por radar será certa a detecção visual. O preenchimento da TPC para este último caso deve considerar então o estado do nó de atividade precedente (detecção por alarme) e os estados dos nós de habilidades. A Tabela 18 apresenta o resultado final para o preenchimento desta TPC.

Desta tabela, verifica-se que se houver sucesso no nó precedente (DetectarPorRadar) então o estado Sim será certo. Em contrapartida, se houver falha, as probabilidades dos estados dependerão dos estados dos nós para as habilidades. Estas probabilidades foram obtidas de maneira análoga a apresentada a seguir para os nós das habilidades e dos fatores internos em relação a seus nós pais. 
Tabela 18 - TPC para o nó DectarVisualmente

\begin{tabular}{|c|c|c|c|c|}
\hline Sim & Não & DetectarPorRadar & Concentração & Percepcao1 \\
\hline 1 & 0 & Sim & Alta & Alta \\
\hline 1 & 0 & Sim & Alta & Baixa \\
\hline 1 & 0 & Sim & Baixa & Alta \\
\hline 1 & 0 & Sim & Baixa & Baixa \\
\hline 1 & 0 & Não & Alta & Alta \\
\hline 0.7 & 0.3 & Não & Alta & Baixa \\
\hline 0.7 & 0.3 & Não & Baixa & Alta \\
\hline 0.4 & 0.6 & Não & & Baixa \\
\hline
\end{tabular}

\subsubsection{PROBABILIDADES CONDICIONAIS INICIAIS}

Para a obtenção das probabilidades iniciais foi estabelecida uma regra empregada em todos os nós relativos a habilidades e fatores internos. As probabilidades obtidas por esta regra foram submetidas a ajustamento (ver item 4.5.3) a fim de que os mesmos valores para as probabilidades dos eventos básicos estimados em trabalho anterior fossem observados na rede que integra as redes dos fatores de desempenho, as redes dinâmicas das tarefas e a rede dos desencadeamentos dos eventos perigosos, conforme mencionado anteriormente.

A regra estabelecida consiste em considerar em $40 \%$ a probabilidade de estado positivo do nó, dado que todos os nós pais apresentam estados negativos; da mesma forma, se arbitrou a probabilidade de 100\% para o estado positivo do nó, dado que todos os nós pais apresentam estados positivos. E, para o estado positivo do nó, dadas as demais combinações de estados dos nós pais, as probabilidades condicionais iniciais foram obtidas pela interpolação neste intervalo $([0.4 ; 1])$, determinada pela quantidade de nós pais em estado positivo (lembrando que foram assumidos dois estados para cada nó). Por exemplo, para um nó (A) com dois pais (B e C) a TPC seria a apresentada na Tabela 19.

Tabela 19 - TPC para o nó (A)

\begin{tabular}{|c|c|c|c|}
\hline \multicolumn{2}{|c|}{ Estados dos Nós Pais } & \multicolumn{2}{c|}{$\boldsymbol{P}(\boldsymbol{A} \mid \boldsymbol{B}, \boldsymbol{C})$} \\
\hline B & C & Positivo & Negativo \\
\hline Positivo & Positivo & $\mathbf{1}$ & $\mathbf{0}$ \\
\hline Positivo & Negativo & $\mathbf{0 . 7}$ & $\mathbf{0 . 3}$ \\
\hline Negativo & Positivo & $\mathbf{0 . 7}$ & $\mathbf{0 . 3}$ \\
\hline Negativo & Negativo & $\mathbf{0 . 4}$ & $\mathbf{0 . 6}$ \\
\hline
\end{tabular}

Neste ponto é importante explicitar que foram considerados dois estados para cada nó, um positivo e outro negativo. Por exemplo, num nó que represente distração foram definidos os estados sim e não, sendo que o estado não é positivo (porque a distração é algo negativo para a execução da tarefa). Já para um nó que represente concentração foram definidos os estados baixa e alta, sendo que o 
estado alta é positivo. Assim, não se deve confundir a nomenclatura do nó com sua contribuição negativa ou positiva para a probabilidade associada à boa execução da tarefa (o estado positivo é o que, tendo aumentada sua probabilidade, faz diminuir a probabilidade de ocorrência do evento básico da rede).

A seguir se apresenta a ajustagem das TPC iniciais às probabilidades conhecidas para os eventos básicos.

\subsubsection{AJUSTAGEM DAS PROBABILIDADES INICIAIS}

A ajustagem das TPC foi feita com apoio dos resultados obtidos em trabalho anterior, pela aplicação da THERP, para os eventos básicos da Árvore de Falhas (Maturana e Martins, 2008). Neste processo procuraram-se, em princípio, dois objetivos. O primeiro foi popular as TPC de forma que os resultados obtidos no trabalho anterior para os eventos básicos fossem mantidos. E o segundo foi manter as diferenças relativas entre as probabilidades das TPC iniciais. Por exemplo, se uma TPC apresentar as mesmas probabilidades do conjunto $\{25 \%, 50 \%$ e $75 \%\}$ para seu estado positivo - sendo $25 \%$ o valor mínimo e $75 \%$ o valor máximo, portanto - e depois do ajuste a TPC apresentar 40\% como valor mínimo 80\% como valor máximo, então, por interpolação, a outra probabilidade para seu estado positivo será $60 \%$.

O primeiro objetivo representa uma forma de calibrar, ou julgar, a realidade das suposições iniciais; permitindo, ainda, a obtenção dos valores a serem adotados - para isto foi suposto que os dados obtidos em trabalho anterior são realistas. Já o segundo é uma forma de manter a distribuição relativa inicial entre as probabilidades - assim, considera-se que os valores iniciais, mesmo não sendo exatos, trazem a experiência do especialista que os definiu.

Sendo assim, para ajustar as probabilidades das TPC foram utilizados dois artifícios. O primeiro consistiu da utilização de um fator a multiplicado a cada probabilidade condicional inicial associada ao estado positivo do nó (sendo este multiplicador o mesmo para todos os nós da rede ligada a determinado evento básico, excetuando-se os nós para as atividades das tarefas compostas por múltiplas atividades) - os valores para o estado negativo foram ajustados de forma que a soma das probabilidades fosse igual a 100\% para uma mesma linha da TPC (daqui por diante isto fica implícito e as manipulações consideradas no texto que se 
segue consideram as probabilidades para o estado positivo do nó). Desta forma, com o valor de a podendo ser diminuído a valores próximos de zero, pode-se obter quaisquer valores para a probabilidade máxima da tabela (inferiores ao máximo da TPC inicial, ou $\alpha=1$ ).

O segundo artifício foi o estreitamento ou alargamento do intervalo em que se distribuíram as probabilidades condicionais. Esta ação se deu pela atribuição de um valor $\beta$ para o valor mínimo do intervalo (lembrando que inicialmente foi atribuído o intervalo [40\%;100\%]).

O primeiro artifício ou o alargamento do intervalo (uma das alternativas do segundo artifício) podem ser empregados quando a probabilidade de ocorrência do evento básico (que pode contribuir para a colisão), pela utilização das TPC iniciais, se apresenta maior do que a procurada. Já o estreitamento do intervalo, proposto no segundo artifício, pode ser empregado quando ocorre o contrário. Neste trabalho, para simplificar a busca, no primeiro caso foram experimentados valores para $\alpha$ até que a probabilidade ideal para o evento básico (encontrada no trabalho anterior, que foi utilizada como referência) fosse encontrada. Para tanto, o valor de a foi reduzido paulatinamente - partindo-se de 1. No segundo caso, com o mesmo objetivo e de forma similar, o valor de $\beta$ foi alterado. Mas desta vez, partindo de $40 \%$, o valor de $\beta$ foi incrementado.

Para ilustrar o que foi descrito, será tomado o exemplo do evento 6 - Falha no Procedimento Padrão (RIPEAM), composto de uma tarefa com atividade única. A Rede Bayesiana que reúne a atividade, as habilidades, fatores internos e MOF a este evento está apresentada na Figura 29 (No Apêndice A estão apresentadas as tabelas que auxiliaram na composição desta rede).

Nota-se que para a rede da Figura 29 não foram considerados nós para fatores ambientais, já que para este caso seus efeitos foram considerados secundários. Para a mesma rede, os MOF foram modelados com dois estados. Assumiu-se o valor de 95\% para o estado positivo (este padrão foi assumido para todos os MOF).

Para esta rede (Figura 29), a probabilidade do evento básico 6 - Falha no Procedimento Padrão (RIPEAM) varia em função de $\alpha$ e de $\beta$ (trabalhando com as TPC iniciais preenchidas de acordo com item 4.5.2) conforme o apresentado no 
gráfico da Figura 30. Os dados plotados na Figura 30 foram obtidos de um programa desenvolvido com auxílio do Octave (software livre - ver Eaton et al., 2008), observando os princípios determinados nos parágrafos iniciais deste tópico.

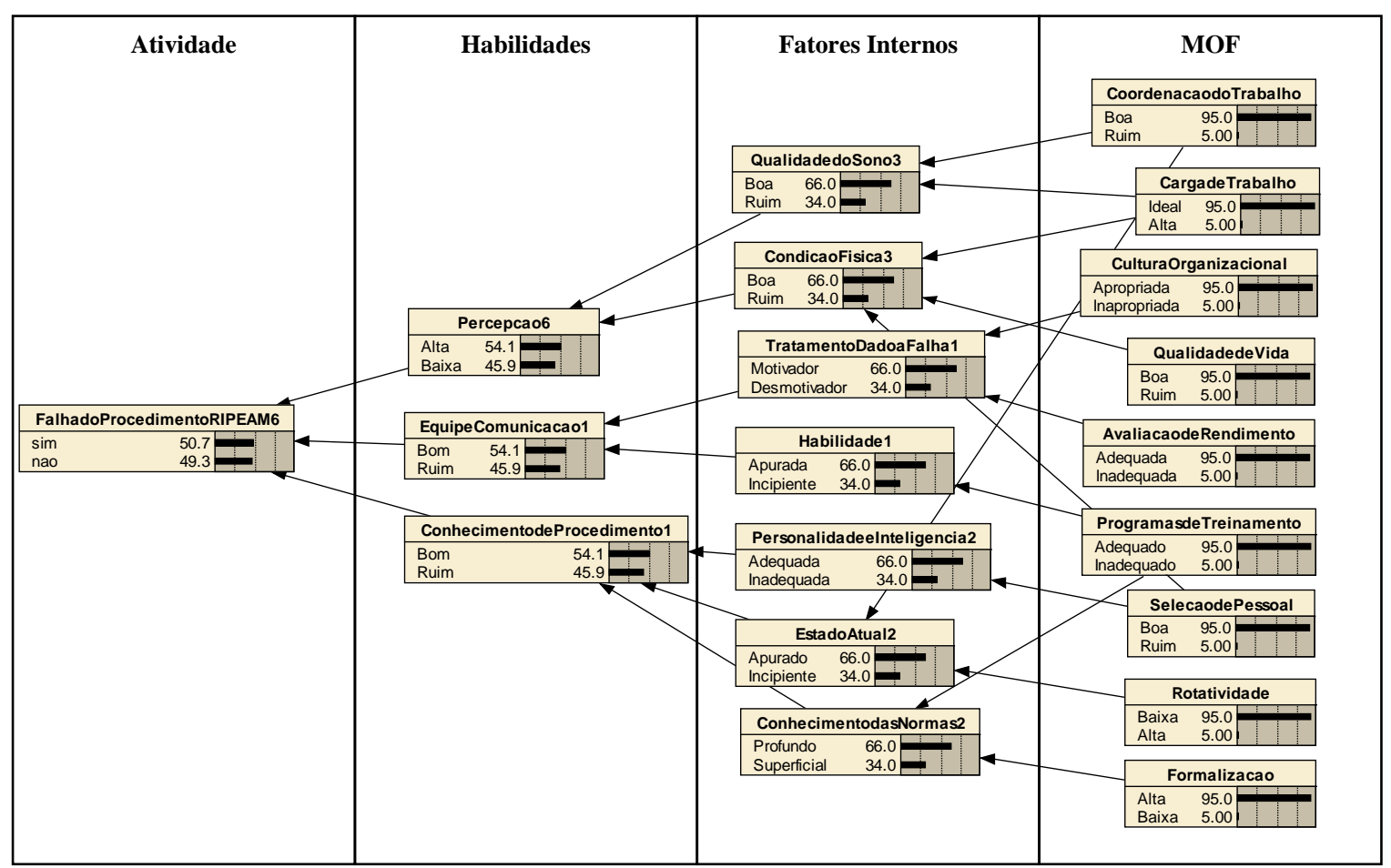

Figura 29 - Rede para o evento 6 - Falha no Procedimento Padrão (RIPEAM)

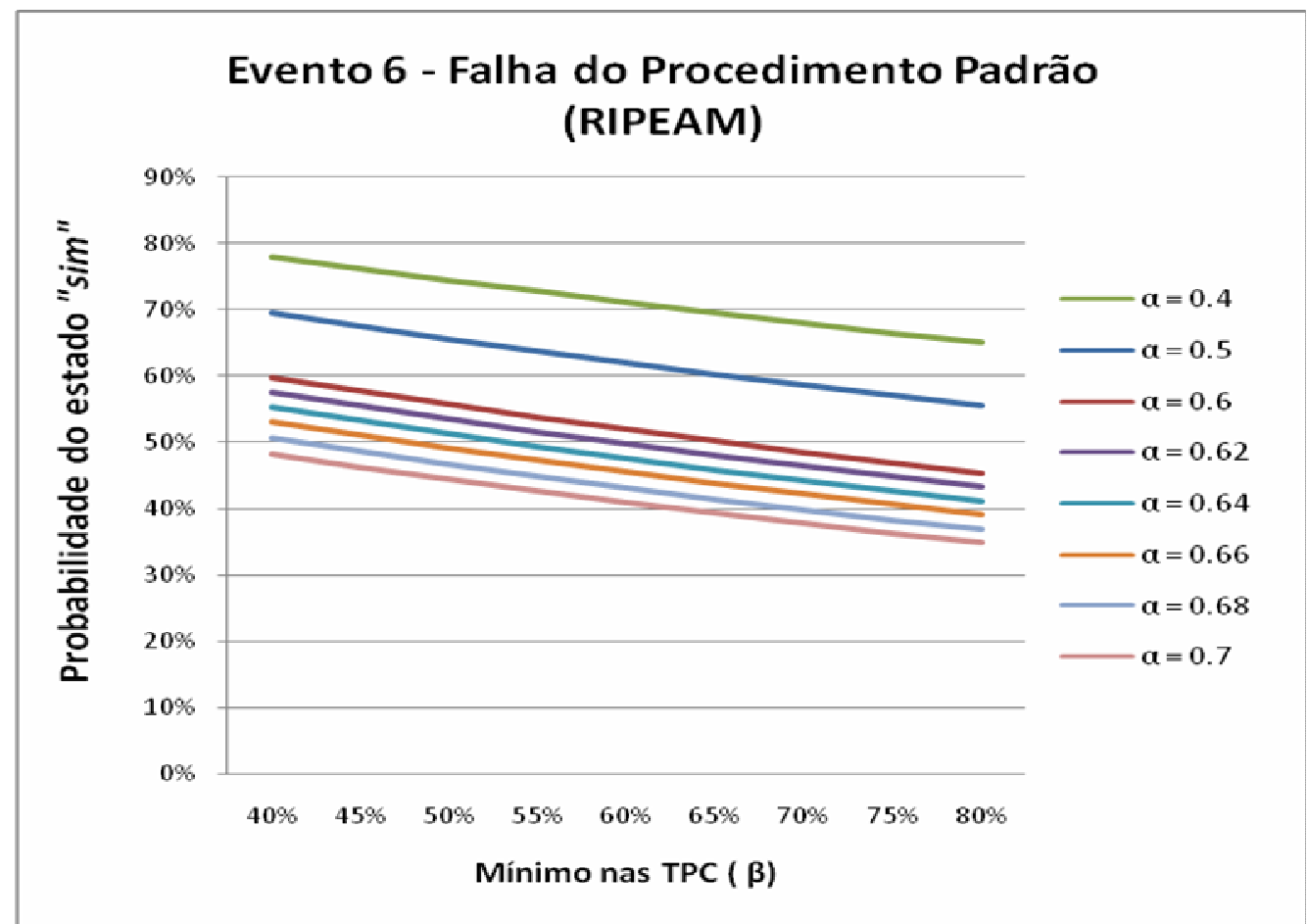

Figura 30 - Variação da probabilidade do evento 6 em função de $\alpha$ e $\beta$ 
De acordo com o descrito anteriormente e com o apoio do gráfico da Figura 30 , pode-se verificar que o valor de $\alpha$ a ser utilizado se aproxima de 0.68 , mantendose $\beta$ em $40 \%$. O que dará $50,72 \%$ de probabilidade para ocorrência do referido evento básico. Muito próxima dos $50 \%$ procurados (resultado encontrado em Maturana e Martins (2008) para o mesmo evento).

Para compreender o gráfico acima é importante não confundir a nomenclatura do estado sim com a sua natureza (o evento modelado é o de falha no procedimento, ou seja, se ocorre ou não ocorre a falha). Este é um estado negativo do nó, ou seja, é um estado que tendo sua probabilidade aumentada faz com que a probabilidade de colisão aumente também. Assim, o aumento generalizado das probabilidades dos estados positivos dos nós para os PSF ligados a este evento gera uma diminuição na probabilidade do estado sim, como pode ser observado pelo estreitamento ocasionado pelo aumento de $\beta$.

Se fosse mantido a igual a 0.68 e a probabilidade buscada em $50 \%$, ○ $\beta$ necessário seria de $41,79 \%$. A Figura 31 apresenta todos os pares $(\alpha, \beta)$ possíveis para se encontrar a probabilidade de $50 \%$ no evento básico estudado (dentro dos intervalos propostos na Figura 30).

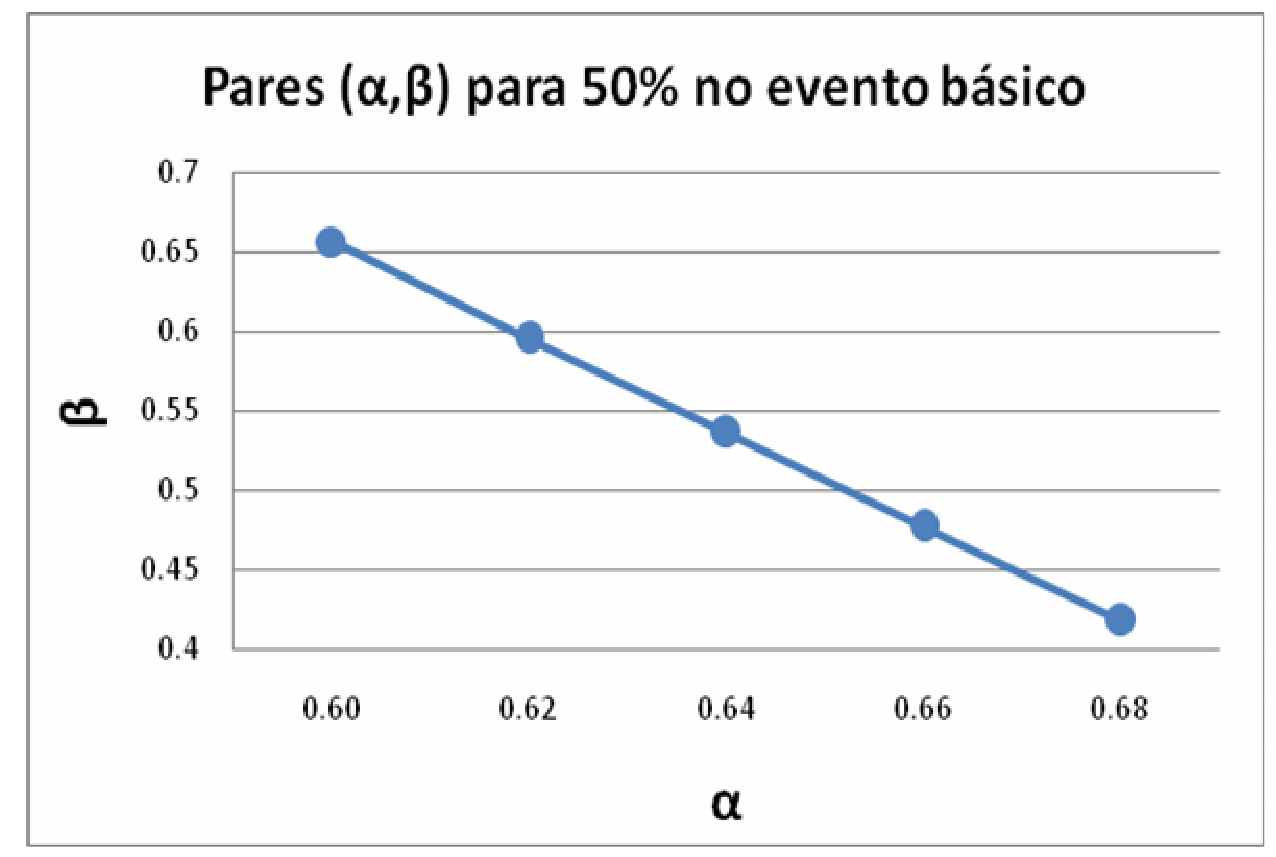

Figura 31 - Pares de $\alpha$ e $\beta$ possíveis para se encontrar $50 \%$ no Evento 6

Sendo assim, para a rede da Figura 29 as TPC finais escolhidas e as iniciais estão apresentadas nas 11 tabelas a seguir (da Tabela 20 até a Tabela 30). 
Tabela 20 - TPC para o nó Falha do Procedimento Padrão (RIPEAM)

\begin{tabular}{|c|c|c|c|c|c|c|}
\hline \multirow{2}{*}{ Percepção 6 } & \multirow{2}{*}{$\begin{array}{c}\text { Equipe } \\
\text { Comunicação 1 }\end{array}$} & \multirow{2}{*}{$\begin{array}{c}\text { Conhecimento de } \\
\text { Procedimento 1 }\end{array}$} & \multicolumn{2}{|c|}{ Finais } & \multicolumn{2}{c|}{ Iniciais } \\
\cline { 4 - 7 } & Sim & Não & Sim & Não \\
\hline Alta & Bom & Bom & 0.320 & 0.680 & 0.000 & 1.000 \\
\hline Alta & Bom & Ruim & 0.456 & 0.544 & 0.200 & 0.800 \\
\hline Alta & Ruim & Bom & 0.456 & 0.544 & 0.200 & 0.800 \\
\hline Alta & Ruim & Ruim & 0.592 & 0.408 & 0.400 & 0.600 \\
\hline Baixa & Bom & Bom & 0.456 & 0.544 & 0.200 & 0.800 \\
\hline Baixa & Bom & Ruim & 0.592 & 0.408 & 0.400 & 0.600 \\
\hline Baixa & Ruim & Bom & 0.592 & 0.408 & 0.400 & 0.600 \\
\hline Baixa & Ruim & Ruim & 0.728 & 0.272 & 0.600 & 0.400 \\
\hline
\end{tabular}

Tabela 21 - TPC para o nó Percepção 6

\begin{tabular}{|c|c|c|c|c|c|}
\hline \multirow{2}{*}{ Qualidade do Sono 3 } & \multirow{2}{*}{ Condição Física 3 } & \multicolumn{2}{|c|}{ Finais } & \multicolumn{2}{c|}{ Iniciais } \\
\cline { 3 - 6 } & & Alta & Baixa & Alta & Baixa \\
\hline Boa & Boa & 0.680 & 0.320 & 1.000 & 0.000 \\
\hline Boa & Ruim & 0.476 & 0.524 & 0.700 & 0.300 \\
\hline Ruim & Boa & 0.476 & 0.524 & 0.700 & 0.300 \\
\hline Ruim & Ruim & 0.272 & 0.728 & 0.400 & 0.600 \\
\hline
\end{tabular}

Tabela 22 - TPC para o nó Equipe e Comunicação 1

\begin{tabular}{|c|c|c|c|c|c|}
\hline \multirow{2}{*}{ Tratamento Dado a Falha 1 } & \multirow{2}{*}{ Habilidade 1 } & \multicolumn{2}{|c|}{ Finais } & \multicolumn{2}{c|}{ Iniciais } \\
\cline { 3 - 6 } & & Bom & Ruim & Bom & Ruim \\
\hline Motivador & Apurada & 0.680 & 0.320 & 1.000 & 0.000 \\
\hline Motivador & Incipiente & 0.476 & 0.524 & 0.700 & 0.300 \\
\hline Desmotivador & Apurada & 0.476 & 0.524 & 0.700 & 0.300 \\
\hline Desmotivador & Incipiente & 0.272 & 0.728 & 0.400 & 0.600 \\
\hline
\end{tabular}

Tabela 23 - TPC para o nó Conhecimento de Procedimento 1

\begin{tabular}{|c|c|c|c|c|c|c|}
\hline \multirow{2}{*}{$\begin{array}{c}\text { Personalidade e } \\
\text { Inteligência 2 }\end{array}$} & Estado Atual 2 & \multirow{2}{*}{$\begin{array}{c}\text { Conhecimento das } \\
\text { Normas 2 }\end{array}$} & \multicolumn{2}{|c|}{ Finais } & \multicolumn{2}{c|}{ Iniciais } \\
\cline { 4 - 7 } & & Bom & Ruim & Bom & Ruim \\
\hline Adequada & Apurado & Profundo & 0.320 & 0.680 & 1.000 & 0.000 \\
\hline Adequada & Apurado & Superficial & 0.456 & 0.544 & 0.800 & 0.200 \\
\hline Adequada & Incipiente & Profundo & 0.456 & 0.544 & 0.800 & 0.200 \\
\hline Adequada & Incipiente & Superficial & 0.592 & 0.408 & 0.600 & 0.400 \\
\hline Inadequada & Apurado & Profundo & 0.456 & 0.544 & 0.800 & 0.200 \\
\hline Inadequada & Apurado & Superficial & 0.592 & 0.408 & 0.600 & 0.400 \\
\hline Inadequada & Incipiente & Profundo & 0.592 & 0.408 & 0.600 & 0.400 \\
\hline Inadequada & Incipiente & Superficial & 0.728 & 0.272 & 0.400 & 0.600 \\
\hline
\end{tabular}

Tabela 24 - TPC para o nó Qualidade do Sono 3

\begin{tabular}{|c|c|c|c|c|c|}
\hline \multirow{2}{*}{ Coordenação do Trabalho } & \multirow{2}{*}{ Carga de Trabalho } & \multicolumn{2}{|c|}{ Finais } & \multicolumn{2}{c|}{ Iniciais } \\
\cline { 3 - 6 } & & Boa & Ruim & Boa & Ruim \\
\hline Boa & Ideal & 0.680 & 0.320 & 1.000 & 0.000 \\
\hline Boa & Alta & 0.476 & 0.524 & 0.700 & 0.300 \\
\hline Ruim & Ideal & 0.476 & 0.524 & 0.700 & 0.300 \\
\hline Ruim & Alta & 0.272 & 0.728 & 0.400 & 0.600 \\
\hline
\end{tabular}

Tabela 25 - TPC para o nó Tratamento Dado a Falha 1

\begin{tabular}{|c|c|c|c|c|c|}
\hline \multirow{2}{*}{$\begin{array}{c}\text { Cultura } \\
\text { Organizacional }\end{array}$} & \multirow{2}{*}{$\begin{array}{c}\text { Avaliação de } \\
\text { Rendimento }\end{array}$} & \multicolumn{2}{|c|}{ Finais } & \multicolumn{2}{c|}{ Iniciais } \\
\cline { 3 - 6 } & & Motivador & Desmotivador & Motivador & Desmotivador \\
\hline Apropriada & Adequada & 0.680 & 0.320 & 1.000 & 0.000 \\
\hline Apropriada & Inadequada & 0.476 & 0.524 & 0.700 & 0.300 \\
\hline Inapropriada & Adequada & 0.476 & 0.524 & 0.700 & 0.300 \\
\hline Inapropriada & Inadequada & 0.272 & 0.728 & 0.400 & 0.600 \\
\hline
\end{tabular}

Tabela 26 - TPC para o nó Habilidade 1

\begin{tabular}{|c|c|c|c|c|}
\hline \multirow{2}{*}{ Programas de treinamento } & \multicolumn{2}{|c|}{ Final } & \multicolumn{2}{c|}{ Inicial } \\
\cline { 2 - 5 } & Apurada & Incipiente & Apurada & Incipiente \\
\hline Adequado & 0.680 & 0.320 & 1.000 & 0.000 \\
\hline Inadequado & 0.272 & 0.728 & 0.400 & 0.600 \\
\hline
\end{tabular}

Aplicação de Redes Bayesianas na Análise da Contribuição da Falha Humana em Acidentes de Colisão - 77 
Tabela 27 - TPC para o nó Condição Física 3

\begin{tabular}{|c|c|c|c|c|c|c|}
\hline \multirow{2}{*}{$\begin{array}{c}\text { Carga de } \\
\text { Trabalho }\end{array}$} & \multirow{2}{*}{ Qualidade de Vida } & \multirow{2}{*}{ Seleção de Pessoal } & \multicolumn{2}{|c|}{ Finais } & \multicolumn{2}{c|}{ Iniciais } \\
\cline { 4 - 7 } & & & Boa & Ruim & Boa & Ruim \\
\hline Ideal & Boa & Boa & 0.320 & 0.680 & 0.000 & 1.000 \\
\hline Ideal & Boa & Ruim & 0.456 & 0.544 & 0.200 & 0.800 \\
\hline Ideal & Ruim & Boa & 0.456 & 0.544 & 0.200 & 0.800 \\
\hline Ideal & Ruim & Ruim & 0.592 & 0.408 & 0.400 & 0.600 \\
\hline Alta & Boa & Boa & 0.456 & 0.544 & 0.200 & 0.800 \\
\hline Alta & Boa & Ruim & 0.592 & 0.408 & 0.400 & 0.600 \\
\hline Alta & Ruim & Boa & 0.592 & 0.408 & 0.400 & 0.600 \\
\hline Alta & Ruim & Ruim & 0.728 & 0.272 & 0.600 & 0.400 \\
\hline
\end{tabular}

Tabela 28 - TPC para o nó Personalidade e Inteligência 2

\begin{tabular}{|c|c|c|c|c|}
\hline \multirow{2}{*}{ Seleção de Pessoal } & \multicolumn{2}{|c|}{ Final } & \multicolumn{2}{c|}{ Inicial } \\
\cline { 2 - 5 } & Adequada & Inadequada & Adequada & Inadequada \\
\hline Boa & 0.680 & 0.320 & 1.000 & 0.000 \\
\hline Ruim & 0.272 & 0.728 & 0.400 & 0.600 \\
\hline
\end{tabular}

Tabela 29 - TPC para o nó Estado Atual 2

\begin{tabular}{|c|c|c|c|c|c|}
\hline \multirow{2}{*}{$\begin{array}{c}\text { Coordenação do } \\
\text { Trabalho }\end{array}$} & \multirow{2}{*}{ Rotatividade } & \multicolumn{2}{|c|}{ Finais } & \multicolumn{2}{c|}{ Iniciais } \\
\cline { 3 - 5 } & & Apurado & Incipiente & Apurado & Incipiente \\
\hline Boa & Baixa & 0.680 & 0.320 & 1.000 & 0.000 \\
\hline Boa & Alta & 0.476 & 0.524 & 0.700 & 0.300 \\
\hline Ruim & Baixa & 0.476 & 0.524 & 0.700 & 0.300 \\
\hline Ruim & Alta & 0.272 & 0.728 & 0.400 & 0.600 \\
\hline
\end{tabular}

Tabela 30 - TPC para o nó Conhecimento das Normas 2

\begin{tabular}{|c|c|c|c|c|c|}
\hline \multirow{2}{*}{$\begin{array}{c}\text { Programas de } \\
\text { Treinamento }\end{array}$} & \multirow{2}{*}{ Formalização } & \multicolumn{2}{|c|}{ Finais } & \multicolumn{2}{c|}{ Iniciais } \\
\cline { 3 - 5 } & & Profundo & Superficial & Profundo & Superficial \\
\hline Adequado & Alta & 0.680 & 0.320 & 1.000 & 0.000 \\
\hline Adequado & Baixa & 0.476 & 0.524 & 0.700 & 0.300 \\
\hline Inadequado & Alta & 0.476 & 0.524 & 0.700 & 0.300 \\
\hline Inadequado & Baixa & 0.272 & 0.728 & 0.400 & 0.600 \\
\hline
\end{tabular}

Ainda segundo o gráfico da Figura 30, é possível obter a probabilidade igual a $50 \%$ para o evento estudado com quaisquer dos valores de alfa testados (exceto para 0.4 e 0.5) variando-se o valor de beta entre $40 \%$ e $80 \%$. Conforme comentado adiante, isto não foi feito porque tornaria a busca mais complexa. Além disto, não foi trabalhado nenhum mecanismo que justifique a escolha de quaisquer pares de $\alpha$ e $\beta$.

Para concluir este tópico, poder-se-ia atribuir a diferença entre os valores iniciais e os ajustados nas TPC a erros no estabelecimento dos dados iniciais (visto no tópico anterior) ou, por outro lado, a fatores considerados secundários na modelagem da topologia da rede (influência de habilidades, fatores ambientais, MOF, etc.). Não podendo ser ignoradas possíveis deficiências dos valores utilizados como referência (os valores assumidos para as probabilidades dos eventos básicos, obtidos por meio da THERP). Neste trabalho não são feitas considerações a respeito destes pontos. Isto porque os dados iniciais para as TPC não foram obtidos da opinião de especialistas ou de banco de dados, mas reúnem apenas as expectativas 
do autor.

Resultados semelhantes aos apresentados para o evento 6 - Falha no Procedimento Padrão (RIPEAM) foram obtidos para os demais eventos básicos da rede. Utilizando os princípios apontados acima e com auxílio do Octave (software livre - ver Eaton et al., 2008), foi elaborado um programa de busca dos a e $\beta$ que ajustam as TPC dos PSF a fim de que sejam obtidas as probabilidades requeridas para os eventos básicos (próximas às do trabalho anterior - Maturana e Martins, 2008). O programa elaborado, no entanto, demonstrou-se lento em seu propósito, de forma que a busca não foi refinada, ou seja, para este trabalho as probabilidades consideradas atendem apenas aproximadamente este requisito (para o caso do evento 6, por exemplo, as TPC ajustadas permitiram a probabilidade de $50,72 \%$ para o estado Sim, enquanto o esperado era $50 \%$ - a Tabela 31 , que será melhor detalhada no próximo capítulo, apresenta os resultados obtidos para cada evento básico, e a Figura 21 apresenta os resultados do trabalho anterior). No Apêndice B foram incluídas as redes com as respectivas TPC associadas aos demais eventos básicos da Figura 21. 


\section{ANÁLISE DO MODELO}

Este capítulo tem por objetivo principal ajudar a compreender o potencial da metodologia proposta, apresentando algumas informações que podem ser extraídas do modelo desenvolvido e sua significância.

Com a junção das redes modeladas no capítulo anterior (para Árvore de Falhas, redes dinâmicas das tarefas e redes dos fatores de desempenho) é possível fazer inferências em relação a todos os nós envolvidos - sendo que cada nó desta rede integrada pode representar um evento, a execução de uma atividade, uma habilidade, um PSF interno (físico ou mental), um fator ambiental ou um MOF. Com objetivo de levantar os pontos na operação do navio que são críticos em relação ao risco de colisão, neste capítulo serão feitas algumas considerações sobre os estados destes nós e sobre como eles se relacionam. Isto será feito em quatro etapas:

1. Análise dos eventos básicos, dado o evento topo: inicialmente será feita uma análise quantitativa dos eventos básicos (geradores de eventos perigosos) no contexto das seqüências de eventos que podem levar ao acidente de colisão;

2. Análise das atividades: em seguida, serão feitas algumas considerações sobre as atividades desenvolvidas no navio, isolando-as por meio de suposições sobre a evidência do evento de colisão e comparando os resultados alcançados desta forma (por meio das Redes Bayesianas) com os apresentados em trabalho anterior (Maturana e Martins, 2008);

3. Análise dos fatores internos e habilidades requeridas: nesta etapa serão considerados os efeitos dos fatores internos e habilidades sobre a execução das atividades; serão feitas inferências sobre as tarefas sinalizadas como críticas nas etapas anteriores, tais como: 1) havendo falha na atividade, encontrar as probabilidades para os possíveis estados das habilidades; 2) dado que foram observadas certas condições do operador (fadiga, reclamações sobre sono, etc.), encontrar a chance de execução errônea da atividade; 3) se houver erro em atividade precedente, encontrar a chance de erro em outra atividade da mesma tarefa; 
4. Análise dos MOF: serão apresentadas algumas formas para identificar os fatores gerenciais e organizacionais - considerados no modelo que são importantes e devem ser analisados com maior cuidado para a redução das chances de acidente na operação.

Os resultados obtidos nestas quatro etapas apresentam-se a seguir.

\subsection{ANÁLISE DOS EVENTOS BÁSICOS, DADO O EVENTO TOPO}

Conforme apontado na modelagem (capítulo anterior), as probabilidades dos estados dos eventos básicos da Árvore de Falhas (Figura 21) foram obtidas de trabalho anterior. Inicialmente, pretendeu-se que as TPC dos PSF das redes dos fatores de desempenho fossem ajustadas para que as probabilidades destes eventos nas redes fossem iguais, sem considerar, no entanto, a evidência de colisão ou de "não colisão" (ver item 4.5.3). Para simplificar a busca, optou-se por não refiná-la, de forma que os resultados alcançados na ajustagem foram apenas aproximações dos resultados pretendidos (assim, os resultados da Figura 21 diferem dos apresentados aqui, apesar de serem próximos). As probabilidades associadas aos estados dos eventos básicos, considerando as evidências de colisão ou de "não colisão" e a ausência de evidência, utilizando estes resultados aproximados (apresentados no Apêndice B), estão apontadas na Tabela 31.

Tabela 31 - Probabilidades associadas aos eventos básicos

\begin{tabular}{|c|l|c|c|c|c|}
\hline \multicolumn{2}{|c|}{ Evento } & Estado & $\begin{array}{c}\text { Colisão } \\
\text { sim }\end{array}$ & $\begin{array}{c}\text { Colisão } \\
\text { não }\end{array}$ & $\begin{array}{c}\text { Nenhuma } \\
\text { Evidência }\end{array}$ \\
\hline 34 & Ausência de Indicação & $\operatorname{sim}$ & $7,98 \mathrm{E}-01$ & $7,50 \mathrm{E}-01$ & $7,50 \mathrm{E}-01$ \\
\hline 6 & Falha do Procedimento RIPEAM & $\operatorname{sim}$ & $9,98 \mathrm{E}-01$ & $5,07 \mathrm{E}-01$ & $5,07 \mathrm{E}-01$ \\
\hline 10 & Falha de Comunicação & $\operatorname{sim}$ & $9,53 \mathrm{E}-01$ & $1,03 \mathrm{E}-01$ & $1,03 \mathrm{E}-01$ \\
\hline 39 & Erro não Descoberto & $\operatorname{sim}$ & $6,65 \mathrm{E}-02$ & $1,08 \mathrm{E}-02$ & $1,08 \mathrm{E}-02$ \\
\hline 32 & Capitão Falha & $\operatorname{sim}$ & $1,77 \mathrm{E}-01$ & $1,08 \mathrm{E}-02$ & $1,08 \mathrm{E}-02$ \\
\hline 33 & ON Falha & $\operatorname{sim}$ & $1,77 \mathrm{E}-01$ & $1,08 \mathrm{E}-02$ & $1,08 \mathrm{E}-02$ \\
\hline 36 & Erro de Atenção & $\operatorname{sim}$ & $3,71 \mathrm{E}-02$ & $9,81 \mathrm{E}-03$ & $9,81 \mathrm{E}-03$ \\
\hline 23 & Oficial dá Ordem Errada & $\operatorname{sim}$ & $6,08 \mathrm{E}-01$ & $2,03 \mathrm{E}-03$ & $2,17 \mathrm{E}-03$ \\
\hline 11 & Oficial dá Ordem Errada & $\operatorname{sim}$ & $3,86 \mathrm{E}-02$ & $2,16 \mathrm{E}-03$ & $2,17 \mathrm{E}-03$ \\
\hline 43 & Falha no Traçado & $\operatorname{sim}$ & $2,80 \mathrm{E}-02$ & $1,22 \mathrm{E}-03$ & $1,23 \mathrm{E}-03$ \\
\hline 25 & Timoneiro dá Resposta Errada & $\operatorname{sim}$ & $1,65 \mathrm{E}-01$ & $4,61 \mathrm{E}-04$ & $4,99 \mathrm{E}-04$ \\
\hline 14 & Timoneiro dá Resposta Errada & $\operatorname{sim}$ & $1,28 \mathrm{E}-02$ & $4,96 \mathrm{E}-04$ & $4,99 \mathrm{E}-04$ \\
\hline 29 & Erro de Marcação & $\operatorname{sim}$ & $6,64 \mathrm{E}-02$ & $2,50 \mathrm{E}-04$ & $2,65 \mathrm{E}-04$ \\
\hline 5 & Outra Embarcação não Detectada & $\operatorname{sim}$ & $4,33 \mathrm{E}-03$ & $6,19 \mathrm{E}-05$ & $6,29 \mathrm{E}-05$ \\
\hline 41 & Informação Errada & $\operatorname{sim}$ & $0,00 \mathrm{E}+00$ & $0,00 \mathrm{E}+00$ & $0,00 \mathrm{E}+00$ \\
\hline
\end{tabular}

Os resultados da Tabela 31 foram obtidos da Rede Bayesiana integrada dos eventos e fatores humanos, modelada com auxílio do Netica ${ }^{\mathrm{TM}} 4.08$ (ver Norsys Software Corp., 1996). 
Com a evidência de colisão, foram obtidos novos valores para as probabilidades dos eventos básicos que foram substituídos na Árvore de Falhas original (Figura 21). Isto gerou uma probabilidade de ocorrência do evento topo de $66,58 \%$, que está associada à ocorrência de um dos desencadeamentos de eventos representado pela Árvore de Falhas. Os 33,42\% restantes devem ser associados a seqüências não modeladas - incluindo falhas de equipamentos e erros humanos considerados secundários. Este resultado vai ao encontro do que é esperado, ou seja, de que $80 \%$ da falha na indústria naval é causada pelo erro humano (Webb e Lamoureux, 2003), o que auxilia a concluir que os eventos considerados secundários somariam $13,42 \%$ e outros considerados não humanos, os $20 \%$ restantes. É importante ressaltar que alguns eventos considerados não humanos poderiam ser classificados como humanos - por exemplo, na falha de equipamento, poderia ser estudada a possibilidade de erro de projeto ou ainda dos conceitos empregados na sua elaboração (por exemplo, na escolha de materiais ou mesmo inexistência de material adequado para determinado componente). No entanto, neste trabalho são considerados apenas os erros relacionados à operação do navio.

O cálculo da probabilidade do evento topo (Colisão) da Árvore de Falhas considerada (Figura 21) é feito de maneira direta, utilizando as portas lógicas apresentadas, em função dos eventos básicos. De outra forma, o cálculo da probabilidade do evento topo pode ser efetuado em função das probabilidades dos eventos que não são básicos. Assim, para simplificar a explanação seguinte, o cálculo da probabilidade de colisão (para a árvore da Figura 21) pode ser feito em função dos fatores apresentados na Tabela 32.

Tabela 32 - Correlação entre fatores e eventos da árvore de falhas

\begin{tabular}{|c|c|c|}
\hline Fator & Evento & $\begin{array}{c}\text { Quantidade de } \\
\text { possibilidades }\end{array}$ \\
\hline A & 18-Sucesso no traçado da rota & 3 \\
\hline B & 22-Deteç̧ão por marcação & 6 \\
\hline C & 22-Deteção ambos & 3 \\
\hline D & 22-Sucesso na detecção visual & 2 \\
\hline E & 21-Ação ineficiente na correção da rota & 2 \\
\hline F & 20-Falha na detecção visual e por marcação & 4 \\
\hline G & 16-Falha no traçado da rota & 2 \\
\hline H & 2-Ação evasiva não efetiva & 4 \\
\hline
\end{tabular}

Nesta tabela, cada fator (primeira coluna) representa a probabilidade de ocorrência do evento apresentado na segunda coluna (numerado conforme Figura 21) - a terceira coluna será explicada mais adiante. Observa-se que o evento 22 foi 
discretizado em suas três possibilidades: 1) Detecção por marcação; 2) Detecção por marcação e visual (ambos); e 3) Deteç̧ão visual. Esta discretização auxilia no entendimento dos desencadeamentos que levam ao evento topo da Árvore de Falhas.

Assim, conforme o apresentado, a probabilidade de colisão fica calculada na Equação (5.1).

$$
P(\text { Colisão })=\{A *[(B+C+D) * E+F]+G\} * H
$$

As probabilidades dos eventos apresentados na Tabela 32 podem ser calculadas em função dos eventos básicos. As equações abaixo representam os resultados obtidos desta forma.

$$
\begin{gathered}
A=(\neg 41 * \neg 43+\neg 41 * 43 * \neg 39+41 * \neg 39) \\
B=[\neg 29 *(32 * \neg 33+\neg 32 * 33+\neg 32 * \neg 33)] *(\neg 34 * 36+34) \\
C=(\neg 34 * \neg 36) *(\neg 29 *(32 * \neg 33+\neg 32 * 33+\neg 32 * \neg 33)) \\
D=(\neg 34 * \neg 36) *(29 *+\neg 29 * 32 * 33) \\
E=(25 * \neg 23+23) \\
F=(\neg 34 * 36+34) *(29 *+\neg 29 * 32 * 33) \\
G=(\neg 41 * 43 * 39+41 * 39) \\
H=\{5+\neg 5 * 6 *[10+\neg 10 *(11+\neg 11 * 14)]\}
\end{gathered}
$$

Nestas equações ((5.2) a (5.9)), os números em negrito representam os eventos básicos da Árvore de Falhas, numerados conforme Figura 21, e o sinal "ᄀ"é aplicado na negação do evento que precede. Na Figura 21, alguns eventos já foram definidos como a negação de eventos básicos (como o evento 42 em relação ao 41 , por exemplo), confundindo-se aqui com os estados de negação destes eventos básicos mas sem prejuízo para o cálculo proposto nestas equações ((5.1) a (5.9)).

De acordo com as equações acima ((5.1) a (5.9)), verifica-se que a probabilidade do evento topo pode ser definida pela somatória de diversas parcelas (aplicando a propriedade distributiva da multiplicação em relação à soma). Do estudo mais detalhado destas parcelas, percebe-se que cada uma representa um desencadeamento de eventos e que a probabilidade final é a somatória de um conjunto de possibilidades de desencadeamentos que podem levar o navio a colidir. 
A terceira coluna da Tabela 32 ajuda a compreender a quantidade de maneiras em que cada evento representado pode ocorrer, calculada em função do número de parcelas possíveis nas Equações (5.2) a (5.9) (após aplicação da propriedade distributiva). Desta forma, a Tabela 32 e a Equação (5.1) permitem concluir que a Árvore de Falhas (Figura 21) representa 320 associações possíveis que determinam desencadeamentos de eventos que, de acordo com esta árvore, podem levar à colisão da embarcação. Estes desencadeamentos foram estudados com o intuito de se verificar o mais provável, dada a evidência de colisão.

A Figura 32 representa graficamente, de maneira condensada, todos os desencadeamentos modelados pela Árvore de Falhas. Nesta figura, os eventos básicos são representados por círculos e os demais, colocados para facilitar a compreensão, por retângulos. Para a compreensão desta figura, o parágrafo a seguir apresenta algumas explicações.

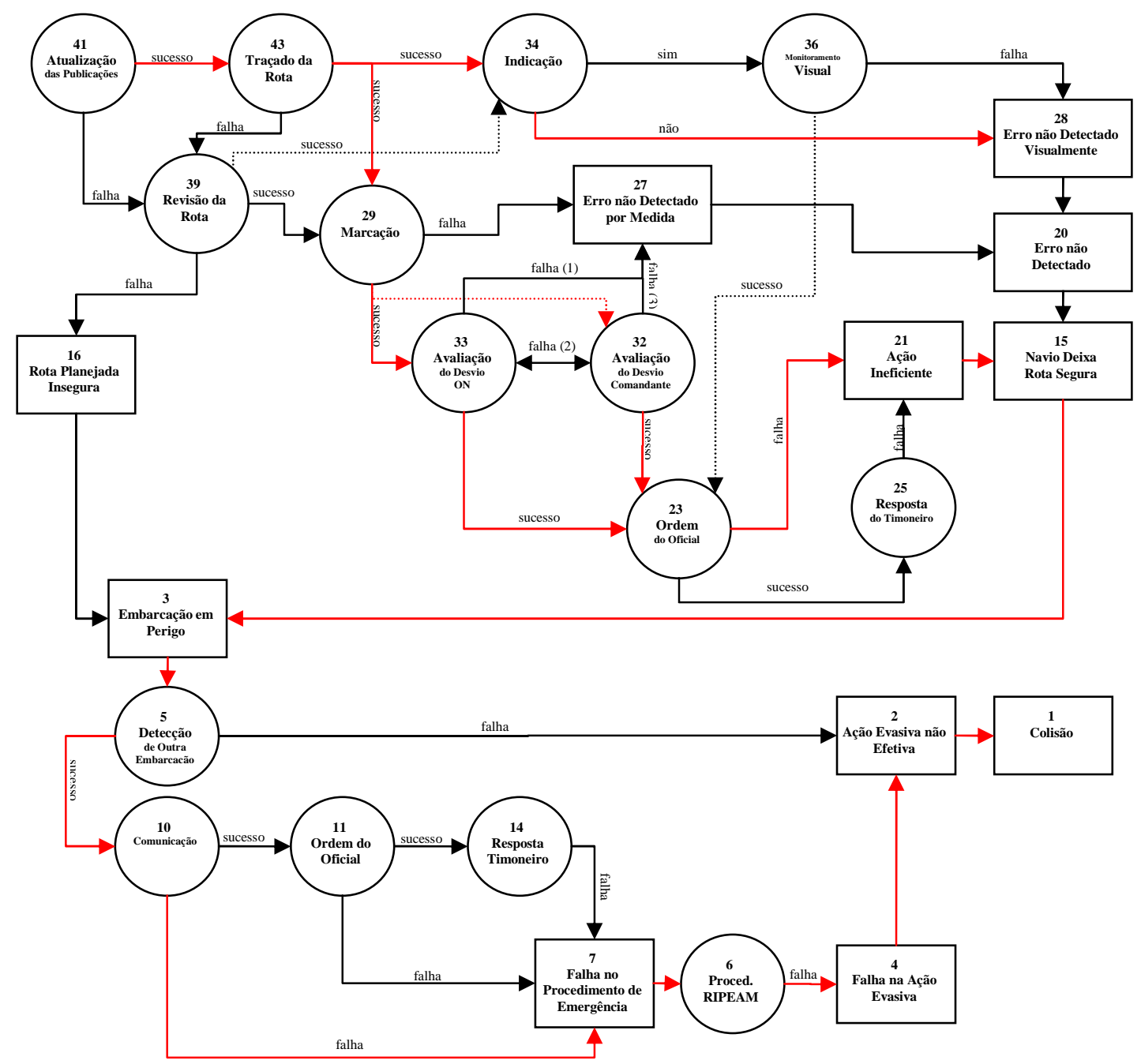

Figura 32 - Diagrama dos desencadeamentos modelados na Figura 21 
Um ponto importante da Figura 32 é que em certos eventos são representados dois caminhos para sucesso ou dois para falha. No caso dos eventos 32 e 33, por exemplo, existem dois caminhos para falha (identificados por falha(1), falha(2) e falha(3)) - os caminhos falha(1) e falha(3) devem ser utilizados apenas quando houver falha em ambas as tarefas (associadas aos eventos 32 e 33, ligandoos ao evento 27; isto porque, de acordo com a Árvore de Falhas, os eventos 32 e 33 devem falhar para que haja falha na análise dos dados sobre marcação na carta e , havendo sucesso em um dos dois ou em ambos, ocorre sucesso na avaliação do erro de posição); e o caminho falha(2) deve ser utilizado quando houver falha em uma das duas tarefas, no sentido da tarefa em que houve falha para a que foi bem sucedida. Também existem alguns eventos que somente ocorrem quando ocorre uma associação de outros eventos - o evento 20 somente ocorrerá se ocorrerem os eventos 27 e 28; isto porque o evento 20 representa a falha na detecção do erro de posição, que representa a falha na detecção visual e na detecção por marcação na carta náutica (considerados independentes na Árvore de Falhas).

No diagrama da Figura 32, o caminho em vermelho foi determinado como mais provável $(28,26 \%)$ pela multiplicação das probabilidades dos eventos envolvidos, dada a evidência de colisão. Os eventos que o compõe estão reproduzidos na tabela abaixo, juntamente com as probabilidades associadas.

Tabela 33 - Desencadeamento mais provável

\begin{tabular}{|c|c|c|c|c|c|c|c|c|c|c|c|c|c|c|c|c|c|c|c|c|c|c|c|c|c|c|c|}
\hline 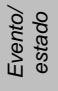 & $\bar{\nabla}$ & 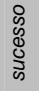 & $\mathscr{7}$ & 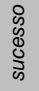 & ని & 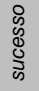 & ల్ల & 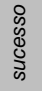 & ભ్ల & 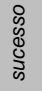 & ले & ஐ̊̊ి & $\stackrel{\Re}{N}$ & 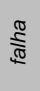 & $\bar{\sim}$ & $\stackrel{20}{\leftarrow}$ & $m$ & in & 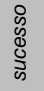 & ? & $\underset{\mathbb{\mathbb { N }}}{\mathbb{\Phi}}$ & $\wedge$ & 0 & $\stackrel{\mathbb{\pi}}{\frac{\pi}{\pi}}$ & $\forall$ & $\sim$ & - \\
\hline 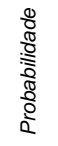 & & 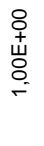 & & $\begin{array}{l}\bar{o} \\
\text { 定 } \\
\text { N } \\
\sigma^{\circ}\end{array}$ & & 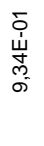 & & 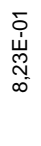 & & 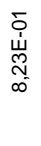 & & $\begin{array}{l}\bar{o} \\
\text { 山े } \\
\text { o } \\
\stackrel{2}{N}\end{array}$ & & $\begin{array}{l}\overline{0} \\
\stackrel{\dot{u}}{ } \\
\infty \\
0 \\
0 \\
0\end{array}$ & & & & & 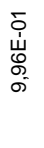 & & $\begin{array}{l}\overline{0} \\
\text { 山े } \\
\tilde{~} \\
0 \\
\sigma\end{array}$ & & & $\begin{array}{l}\overline{0} \\
\text { 山े } \\
\infty \\
o \\
\sigma\end{array}$ & & & $\begin{array}{l}\text { むे } \\
\text { ஸ્ } \\
\text { : }\end{array}$ \\
\hline
\end{tabular}

Verifica-se que neste desencadeamento houve falha nas tarefas 23, 10 e 6. No evento básico 34 também houve resultado negativo devido à ausência de indicação visual (o que ocorre em 75\% da rota, segundo a Árvore de Falhas original, mas que na evidência de colisão aumentou para 79,8\% de probabilidade), mas este caso não se constitui erro da tripulação. Nota-se, da Tabela 32, que estes também estão entre os eventos mais prováveis, dada a evidência de colisão. Nestas circunstâncias, eles serão estudados com mais detalhes no tópico referente à análise dos fatores de desempenho e habilidades requeridas.

$\mathrm{Na}$ Tabela 34 estão apresentados outros desencadeamentos que 
apresentaram probabilidade de ocorrência superior a 1\%, dada a evidência de colisão. Nesta tabela, os desencadeamentos com as características descritas estão representados pelos eventos básicos que os compõem, organizados em colunas. Ao final de cada coluna está apresentada a probabilidade de o desencadeamento ter ocorrido, dada a evidência de colisão. Nota-se que a somatória destas probabilidades é de $31,78 \%$ e que, somada à probabilidade do desencadeamento apresentado na Tabela 33, compõe mais de $60 \%$ das probabilidades dos desencadeamentos representados na Figura 21, dada a evidência de colisão.

Tabela 34 - Desencadeamentos com probabilidade maior que 1\%

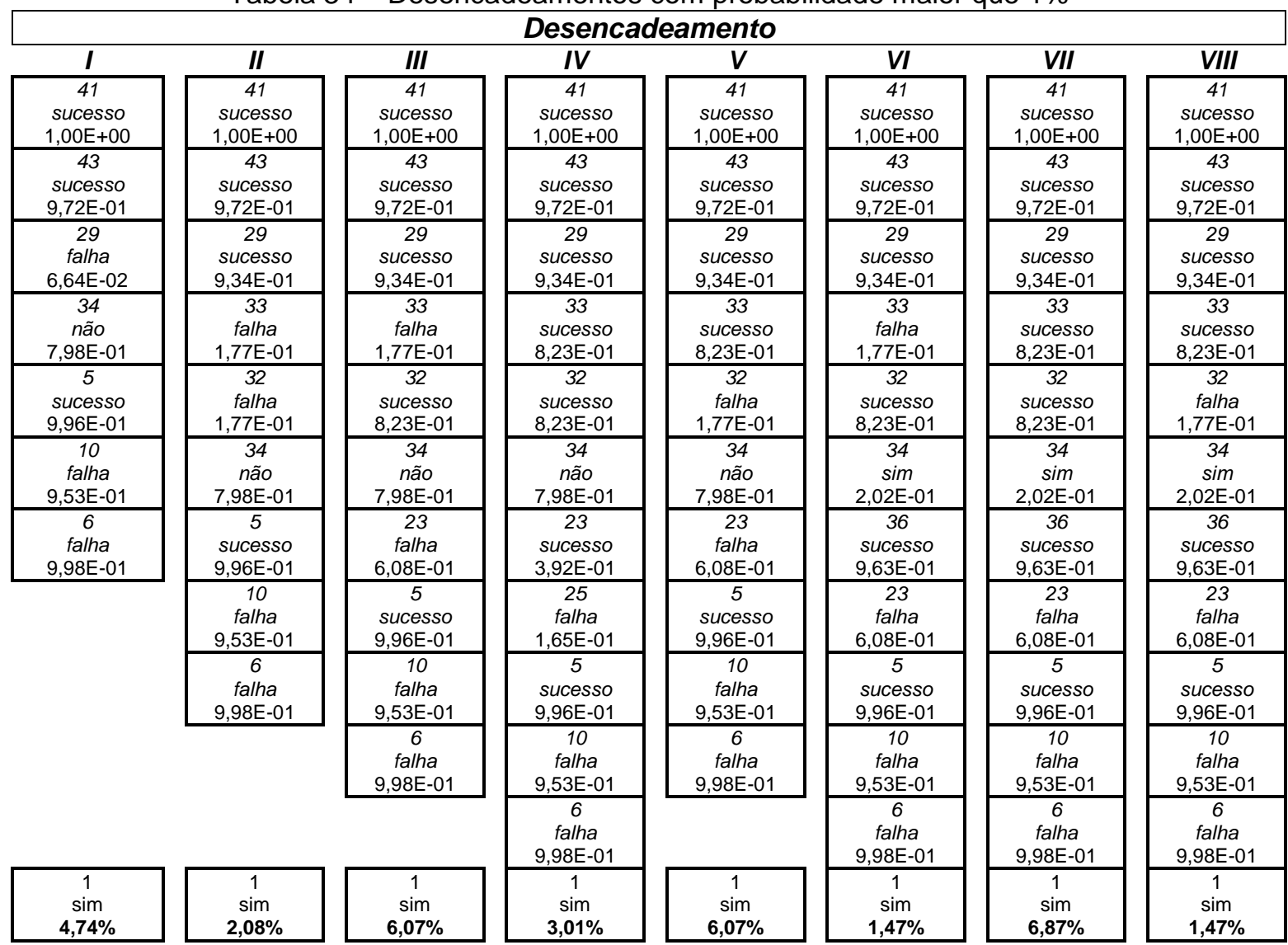

Nesta tabela, nota-se falha nas tarefas 6 e 10 para todos desencadeamentos (o que já era esperado para a tarefa 6 , já que o procedimento RIPEAM é o último recurso para evitar o acidente), e na 23 para a maioria deles, o que reforça a escolha destas tarefas para análise dos fatores de desempenho e habilidades requeridas (ver item 5.3).

A seguir serão consideradas as probabilidades das atividades das tarefas, dada a evidência de colisão. 


\subsection{ANÁLISE DAS ATIVIDADES}

Para iniciar a análise quantitativa das atividades realizadas na operação do navio e que se relacionam ao evento de colisão, foi elaborada a Tabela 35 , onde estão inseridas as probabilidades de erro nas atividades, sem evidência de colisão e com evidência de colisão. As atividades foram ordenadas de acordo com o aumento observado na probabilidade de erro, dada a evidência de colisão, e em negrito e sombreadas estão as atividades que apresentaram probabilidade de erro maior que $10 \%$, na evidência de colisão. Ressalta-se que estes números foram obtidos da rede integrada modelada conforme capítulo anterior.

Tabela 35 - Probabilidades para as atividades

\begin{tabular}{|c|c|c|c|c|c|}
\hline Tarefa & Atividade & Estado & $\begin{array}{c}\text { Sem } \\
\text { evidência } \\
\text { de colisão }\end{array}$ & $\begin{array}{c}\text { Com } \\
\text { evidência } \\
\text { de colisão }\end{array}$ & $\begin{array}{c}\text { Aumento da } \\
\text { probabilidade de } \\
\text { erro }\end{array}$ \\
\hline 25 & TimoneiroDaRespostaErrada25 & $\operatorname{sim}$ & $4,99 \mathrm{E}-04$ & $1,65 \mathrm{E}-01$ & $32962 \%$ \\
\hline 5 & DetectarPorAlarme & não & $6,29 \mathrm{E}-05$ & $4,33 \mathrm{E}-03$ & $6777 \%$ \\
\hline 29 & ChecagemEquipamento & Incompleta & $1,00 \mathrm{E}-03$ & $6,53 \mathrm{E}-02$ & $6404 \%$ \\
\hline 23 & EntendeDemanda1 & กล̃o & $9,81 \mathrm{E}-03$ & $5,86 \mathrm{E}-01$ & $5868 \%$ \\
\hline 23 & TomadadeDecisao1 & falha & $1,45 \mathrm{E}-02$ & $6,22 \mathrm{E}-01$ & $4202 \%$ \\
\hline 43 & RevisaoComandante1 & falha & $1,90 \mathrm{E}-07$ & $6,85 \mathrm{E}-06$ & $3511 \%$ \\
\hline 14 & TimoneirodaRespErrada14 & $\operatorname{sim}$ & $4,99 \mathrm{E}-04$ & $1,28 \mathrm{E}-02$ & $2474 \%$ \\
\hline 5 & DectarVisualmente & não & $2,18 \mathrm{E}-04$ & $5,16 \mathrm{E}-03$ & $2270 \%$ \\
\hline 43 & AtualizacaoPublicacoes1 & falha & $1,23 \mathrm{E}-03$ & $2,80 \mathrm{E}-02$ & $2184 \%$ \\
\hline 32 & ComandanteFalha32 & $\operatorname{sim}$ & $1,08 \mathrm{E}-02$ & $1,77 \mathrm{E}-01$ & $1537 \%$ \\
\hline 33 & OficialdeNauticaFalha33 & $\operatorname{sim}$ & $1,08 \mathrm{E}-02$ & $1,77 \mathrm{E}-01$ & $1537 \%$ \\
\hline 43 & LeituradasInformacoes1 & falha & $2,21 \mathrm{E}-03$ & $3,20 \mathrm{E}-02$ & $1345 \%$ \\
\hline 43 & RevisaoOficialNautica1 & falha & $2,91 \mathrm{E}-05$ & $3,53 \mathrm{E}-04$ & $1113 \%$ \\
\hline 43 & ProfundidadeMinima1 & falha & $3,05 \mathrm{E}-03$ & $3,54 \mathrm{E}-02$ & $1062 \%$ \\
\hline 43 & LeituradeProfundidade1 & falha & $3,36 \mathrm{E}-03$ & $3,66 \mathrm{E}-02$ & $991 \%$ \\
\hline 43 & IdentificarAreasRestritas1 & falha & $3,48 \mathrm{E}-03$ & $3,71 \mathrm{E}-02$ & $967 \%$ \\
\hline 43 & TracarAreasRestritas1 & falha & 4,07E-03 & $3,96 \mathrm{E}-02$ & $874 \%$ \\
\hline 43 & TracarRumosSucessivos1 & falha & $4,48 \mathrm{E}-03$ & 4,14E-02 & $824 \%$ \\
\hline 43 & IdentificarWayPoints1 & falha & $4,76 \mathrm{E}-03$ & $4,26 \mathrm{E}-02$ & $794 \%$ \\
\hline 10 & DecidirFazerContato & não & $7,30 \mathrm{E}-02$ & $6,21 \mathrm{E}-01$ & $751 \%$ \\
\hline 43 & EscolhaPontosReferencia1 & falha & $5,79 \mathrm{E}-03$ & $4,59 \mathrm{E}-02$ & $692 \%$ \\
\hline 29 & RespeitolntervalosdeMarcacao & não & $1,00 \mathrm{E}-03$ & $7,40 \mathrm{E}-03$ & $637 \%$ \\
\hline 29 & LeituraPosicao & falha & $1,96 \mathrm{E}-03$ & $1,37 \mathrm{E}-02$ & $595 \%$ \\
\hline 29 & MarcacaoCartaNautica & falha & $2,76 \mathrm{E}-03$ & $1,87 \mathrm{E}-02$ & $578 \%$ \\
\hline 39 & ErronãoDescoberto39 & $\operatorname{sim}$ & $1,08 \mathrm{E}-02$ & $6,65 \mathrm{E}-02$ & $516 \%$ \\
\hline 10 & ConseguirContatoRadio & não & 1,37E-01 & $7,82 \mathrm{E}-01$ & $473 \%$ \\
\hline 11 & EntendeDemanda & não & $9,81 \mathrm{E}-03$ & $5,58 \mathrm{E}-02$ & $469 \%$ \\
\hline 10 & EntenderInterlocutor & กล̃o & $1,95 \mathrm{E}-01$ & $9,60 \mathrm{E}-01$ & $393 \%$ \\
\hline 11 & TomadadeDecisao & falha & $1,45 \mathrm{E}-02$ & $6,91 \mathrm{E}-02$ & $377 \%$ \\
\hline 36 & ErrodeAtencao36 & $\operatorname{sim}$ & $9,81 \mathrm{E}-03$ & $3,71 \mathrm{E}-02$ & $278 \%$ \\
\hline 5 & DetectarPorRadar & não & $3,93 \mathrm{E}-03$ & $1,19 \mathrm{E}-02$ & $203 \%$ \\
\hline 6 & FalhadoProcedimentoRIPEAM6 & $\operatorname{sim}$ & 5,07E-01 & 9,98E-01 & $97 \%$ \\
\hline 23 & DeteccaodoErro1 & não & $9,88 \mathrm{E}-01$ & $9,85 \mathrm{E}-01$ & $0 \%$ \\
\hline 29 & ComandanteDetectaErro & não & 9,97E-01 & $9,85 \mathrm{E}-01$ & $-1 \%$ \\
\hline 11 & DeteccaodoErro & não & $9,88 \mathrm{E}-01$ & $9,70 \mathrm{E}-01$ & $-2 \%$ \\
\hline 10 & EntenderInterlocutor2 & não & $8,55 \mathrm{E}-01$ & $5,54 \mathrm{E}-01$ & $-35 \%$ \\
\hline 10 & DecidirContatoOutroMeio & กล̃o & $8,28 \mathrm{E}-01$ & $2,59 \mathrm{E}-01$ & $-69 \%$ \\
\hline
\end{tabular}
$\mathrm{Na}$ Tabela
35 ,
verifica-se
que
certas
atividades

("TimoneiroDaRespostaErrada25", por exemplo), que antes da evidência de colisão tinham probabilidades baixas (4,99E-04), passaram a altas probabilidades após a 
evidência (1,65E-01). Por outro lado, algumas atividades tiveram suas probabilidades reduzidas na evidência de colisão (as cinco últimas da tabela). Esta redução pode ser compreendida pela análise da modelagem da rede; para exemplificar será tomada a atividade "DecidirContatoOutroMeio" (última da tabela). Nesta atividade, a probabilidade do estado não, sem evidência de colisão, é de 82,8\% e com evidência passou a 25,9\% - uma redução de 69\% na probabilidade. Esta redução se justifica pelo fato de o estado não agregar também a hipótese de não execução da atividade. Quando existe a evidência de colisão, aumentam as chances de a atividade ter sido executada (com ou sem erro) e o número apresentado para a probabilidade de o estado ser não se aproxima mais da probabilidade de erro na execução da atividade.

Um resultado mais próximo da probabilidade de erro na atividade, dado que foi necessário executá-la, pode ser observado na Tabela 36.

Tabela 36 - Probabilidades para as atividades, dadas as atividades precedentes

\begin{tabular}{|c|c|c|c|c|c|c|c|c|c|}
\hline \multirow{3}{*}{$\frac{\text { Tarefa }}{5}$} & \multirow{2}{*}{$\begin{array}{c}\text { Atividade } \\
\text { DectarVisualmente }\end{array}$} & \multirow{2}{*}{$\begin{array}{c}\text { Estado } \\
\text { não }\end{array}$} & \multirow{2}{*}{$\begin{array}{c}\text { Sem } \\
\text { evidência } \\
\text { de colisão }\end{array}$} & \multirow{2}{*}{$\begin{array}{c}\text { Com } \\
\text { evidência } \\
\text { de colisão }\end{array}$} & \multirow{2}{*}{$\begin{array}{c}\text { Aumento } \\
683 \% \\
\end{array}$} & \multicolumn{4}{|c|}{ Evidências nas atividades precedentes } \\
\hline & & & & & & DectarporRadar & falha & & \\
\hline & DetectarPorAlarme & กล̃o & $2,89 \mathrm{E}-01$ & $8,38 \mathrm{E}-01$ & $190 \%$ & DectarVisualmente & falha & DetectarPorRadar & falha \\
\hline \multirow{4}{*}{10} & Entenderlnterlocutor & não & $6,73 \mathrm{E}-02$ & $8,16 \mathrm{E}-01$ & $1113 \%$ & ConseguirContatoRadio & $\operatorname{sim}$ & & \\
\hline & ConseguirContatoRadio & não & $6,86 \mathrm{E}-02$ & $4,25 \mathrm{E}-01$ & $519 \%$ & DecidirFazerContato & $\operatorname{sim}$ & & \\
\hline & EntenderInterlocutor2 & กão & $2,18 \mathrm{E}-01$ & $9,73 \mathrm{E}-01$ & $346 \%$ & ConseguirContatoRadio & $\operatorname{sim}$ & DecidirContatoOutroMeio & $\operatorname{sim}$ \\
\hline & DecidirContatoOutroMeio & não & $1,39 \mathrm{E}-01$ & $2,25 \mathrm{E}-01$ & $61 \%$ & ConseguirContatoRadio & não & & \\
\hline \multirow{3}{*}{11} & \multirow{2}{*}{ DeteccaodoErro } & não & $1,98 \mathrm{E}-02$ & $1,40 \mathrm{E}-01$ & $604 \%$ & EntendeDemanda & $\operatorname{sim}$ & TomadadeDecisao & falha \\
\hline & & não & 2,11E-01 & $6,59 \mathrm{E}-01$ & $212 \%$ & EntendeDemanda & não & & \\
\hline & TomadadeDecisao & falha & $4,70 \mathrm{E}-03$ & $1,40 \mathrm{E}-02$ & $198 \%$ & EntendeDemanda & $\operatorname{sim}$ & & \\
\hline \multirow{3}{*}{23} & TomadadeDecisao1 & falha & $4,70 \mathrm{E}-03$ & $8,85 \mathrm{E}-02$ & $1783 \%$ & EntendeDemanda1 & $\operatorname{sim}$ & & \\
\hline & \multirow{2}{*}{ DeteccaodoErro1 } & não & $1,98 \mathrm{E}-02$ & $8,51 \mathrm{E}-01$ & $4191 \%$ & EntendeDemanda1 & $\operatorname{sim}$ & TomadadeDecisao 1 & falha \\
\hline & & não & 2,11E-01 & $9,85 \mathrm{E}-01$ & $366 \%$ & EntendeDemanda1 & não & & \\
\hline \multirow{2}{*}{29} & ComandanteDetectaErro & não & $5,23 E-03$ & $2,16 \mathrm{E}-01$ & $4030 \%$ & MarcacaoCartaNautica & falha & & \\
\hline & MarcacaoCartaNautica & falha & 7,93E-04 & $5,10 \mathrm{E}-03$ & $544 \%$ & LeituraPosicao & sucesso & & \\
\hline \multirow{10}{*}{43} & IdentificarWayPoints1 & falha & $2,87 \mathrm{E}-04$ & $1,27 \mathrm{E}-03$ & $340 \%$ & TracarRumosSucessivos1 & sucesso & & \\
\hline & TracarRumosSucessivos1 & falha & $4,11 \mathrm{E}-04$ & $1,81 \mathrm{E}-03$ & $340 \%$ & TracarAreasRestritas1 & sucesso & & \\
\hline & TracarAreasRestritas1 & falha & $5,87 \mathrm{E}-04$ & $2,58 \mathrm{E}-03$ & $339 \%$ & IdentificarAreasRestritas1 & sucesso & & \\
\hline & ProfundidadeMinima1 & falha & $8,35 \mathrm{E}-04$ & $3,51 \mathrm{E}-03$ & $320 \%$ & LeituradasInformacoes1 & sucesso & & \\
\hline & LeituradasInformacoes1 & falha & $9,89 \mathrm{E}-04$ & $4,12 \mathrm{E}-03$ & $316 \%$ & AtualizacaoPublicacoes1 & sucesso & & \\
\hline & IdentificarAreasRestritas1 & falha & $1,25 \mathrm{E}-04$ & $5,19 \mathrm{E}-04$ & $316 \%$ & LeituradeProfundidade1 & sucesso & & \\
\hline & LeituradeProfundidade1 & falha & $3,12 \mathrm{E}-04$ & $1,30 \mathrm{E}-03$ & $316 \%$ & ProfundidadeMinima1 & sucesso & & \\
\hline & EscolhaPontosReferencia1 & falha & $1,04 \mathrm{E}-03$ & $3,45 \mathrm{E}-03$ & $233 \%$ & IdentificarWayPoints1 & sucesso & & \\
\hline & RevisaoComandante1 & falha & $6,52 \mathrm{E}-03$ & $1,94 \mathrm{E}-02$ & $198 \%$ & RevisaoOficialNautica1 & falha & & \\
\hline & RevisaoOficialNautica1 & falha & $5,02 \mathrm{E}-03$ & $7,70 \mathrm{E}-03$ & $53 \%$ & EscolhaPontosReferencia1 & falha & & \\
\hline
\end{tabular}

Nesta tabela, são apresentadas as probabilidades de erros nas atividades, considerando as evidências dos estados dos nós de atividades precedentes da mesma tarefa, para duas condições: 1) Sem evidência de colisão (nenhuma evidência a respeito de colisão); e 2) Com evidência de colisão. Ressalta-se que nesta tabela estão representadas apenas as atividades que são precedidas por nós 
de atividades. Além disto, os dados apresentados representam a probabilidade de erro nas atividades, dado que não foram observadas evidências sobre os PSF. Nesta tabela, a quinta coluna (denominada Aumento) refere-se ao aumento observado nas probabilidades de erros das atividades se for observado o evento de colisão. As atividades discriminadas (por negrito e sombreamento) referem-se às que apresentaram probabilidade de erro maior que $10 \%$ na evidência de colisão.

Com estes resultados já é possível determinar em quais atividades despender os esforços iniciais para a redução da probabilidade de ocorrência de colisão (verifica-se, por exemplo, que as tarefas 10 e 23 possuem atividades que se destacam entre as com maiores chances de erro e que, além disto, no item 5.1 estas tarefas compunham o desencadeamento mais provável, na evidência de colisão), definindo ações para a redução da freqüência dos erros nestas atividades, mitigação de seus efeitos, aliviando as circunstâncias em que ocorrem e/ou reduzindo suas conseqüências, obtendo-se, assim, uma série de opções de controle de risco, a serem aplicadas ao sistema - treinamento da tripulação; mudanças de layout ou ergonômicas; especificação de informações a serem disponibilizadas e desenvolvimento de procedimentos de emergência. No próximo tópico, no entanto, estas atividades serão mais bem estudadas em relação à influência dos PSF, o que pode auxiliar na definição destas opções de controle de risco. Antes, para encerrar este tópico, serão apresentados alguns pontos sobre a obtenção das probabilidades de erro com apoio das Redes Bayesianas em um breve exercício de comparação com os resultados alcançados no trabalho anterior (Maturana e Martins, 2008).

Numa Rede Bayesiana, para conseguir as probabilidades de um nó independentemente dos demais, são necessárias evidências a respeito de todos os nós que formam o Markov Blanket (ver item 2.2.1.5). Portanto, no caso modelado, para determinar a probabilidade de erro em uma atividade, independentemente das demais da rede, seriam necessárias evidências a respeito da tarefa e das habilidades as quais se relaciona, além das referidas evidências sobre os estados das atividades precedentes (da mesma tarefa). Na ausência de outras evidências, as probabilidades de erro para cada atividade, dados os estados dos nós pais, ou seja, para cada combinação dos estados das atividades precedentes (quando existem) e habilidades, formam as TPC das atividades, que consideram sua necessidade de execução. O Apêndice B apresenta todas as TPC consideradas na modelagem. 
No trabalho anterior (Maturana e Martins, 2008), para definir as probabilidades de erro nas atividades, foram determinadas as HEP que foram alteradas por PSF, de acordo com o observado em campo e, além disto, foi considerada independência em relação às outras atividades. Desta forma, foram apresentadas as probabilidades de erro na execução da atividade, dado que houve a necessidade de sua execução.

Observa-se que a situação descrita no parágrafo anterior se assemelha mais às condições apresentadas na Tabela 36 que na Tabela 35. Com objetivo de verificar os efeitos das considerações assumidas a respeito dos nós precedentes das atividades, e lembrando que foi assumido hipoteticamente que os resultados utilizados no trabalho anterior reproduzem a realidade, foi desenvolvida a Tabela 37 apresentando os resultados do trabalho anterior comparados com os apresentados nestas tabelas (Tabela 35 e Tabela 36). Esta comparação permite verificar que não houve equívocos na manipulação dos dados do trabalho anterior capazes de alterar significativamente os resultados esperados (comparação com a Tabela 36), conforme será comentado mais adiante. Além disto, permite confrontar os resultados dos dois processos (Árvores Binárias e Redes Bayesianas) verificando o impacto da não consideração da dinâmica e dependências do sistema, ou seja, das limitações na representação de contexto no trabalho anterior (comparação com a Tabela 35).

$\mathrm{Na}$ Tabela 37, a sexta e a oitava coluna, denominadas Diferença, referem-se à diferença entre as probabilidades observadas no trabalho anterior para cada atividade e as observadas na Tabela 35 e Tabela 36, respectivamente.

Conforme explicado no capítulo anterior, o preenchimento das TPC considerou somente as probabilidades associadas aos eventos básicos da Árvore de Falhas e não considerou as probabilidades de erro específicas das atividades ligadas a estes eventos (que podem ser vistas em Maturana e Martins, 2008) - as informações retiradas das Árvores de Eventos também ajudaram na elaboração da topologia das redes dinâmicas das tarefas (ver item 4.3) -. Assim, verifica-se na Tabela 37 que, de maneira geral, os dados oriundos da Tabela 36 se aproximam mais dos dados utilizados no trabalho anterior do que os da Tabela 35. Para a atividade "DeteccaodoErro" (da tarefa 11), por exemplo, a probabilidade para o estado não é de $1 \%$ (obtida do trabalho anterior), enquanto a probabilidade deste 
estado, sem evidência do nó anterior é de 98,8\% (Tabela 35), e de aproximadamente $2 \%$, se forem observados erros nas atividades precedentes (Tabela 36). Em média, o módulo das diferenças entre as probabilidades do trabalho anterior e as obtidas da Tabela 35 para cada atividade, é de 13,7\%; e, considerando os dados da Tabela 36, é de 3,9\%. Esta análise ajuda a compreender que os dados obtidos sem evidência de execução da atividade carregam, além da informação de erro na execução, a informação de que a atividade não foi iniciada - para a atividade "DeteccaodoErro", por exemplo, o estado não também inclui a inexistência da necessidade de detecção.

Tabela 37 - Probabilidades de erro obtidas no trabalho anterior

\begin{tabular}{|c|c|c|c|c|c|c|c|}
\hline Tarefa & Atividade & Estado & Anterior & Tabela 35 & Diferença & Tabela 36 & Diferença \\
\hline 5 & DectarVisualmente & não & $2,00 \mathrm{E}-02$ & $2,18 \mathrm{E}-04$ & $-1,98 \mathrm{E}-02$ & $5,54 \mathrm{E}-02$ & $3,54 \mathrm{E}-02$ \\
\hline 5 & DetectarPorAlarme & não & $1,00 \mathrm{E}-01$ & $6,29 E-05$ & $-9,99 \mathrm{E}-02$ & $2,89 \mathrm{E}-01$ & $1,89 \mathrm{E}-01$ \\
\hline 5 & DetectarPorRadar & não & $3,00 \mathrm{E}-03$ & $3,93 \mathrm{E}-03$ & $9,30 \mathrm{E}-04$ & - & - \\
\hline 6 & FalhadoProcedimentoRIPEAM6 & $\operatorname{sim}$ & $5,00 \mathrm{E}-01$ & $5,07 E-01$ & $7,00 \mathrm{E}-03$ & - & - \\
\hline 10 & ConseguirContatoRadio & não & $3,00 \mathrm{E}-03$ & $1,37 \mathrm{E}-01$ & $1,34 \mathrm{E}-01$ & $6,86 \mathrm{E}-02$ & $6,56 \mathrm{E}-02$ \\
\hline 10 & DecidirContatoOutroMeio & não & $5,00 \mathrm{E}-01$ & $8,28 \mathrm{E}-01$ & $3,28 \mathrm{E}-01$ & $1,39 \mathrm{E}-01$ & $-3,61 \mathrm{E}-01$ \\
\hline 10 & DecidirFazerContato & não & $1,00 \mathrm{E}-01$ & $7,30 \mathrm{E}-02$ & $-2,70 \mathrm{E}-02$ & - & - \\
\hline 10 & EntenderInterlocutor & não & $3,00 \mathrm{E}-03$ & $1,95 \mathrm{E}-01$ & $1,92 \mathrm{E}-01$ & $6,73 \mathrm{E}-02$ & $6,43 \mathrm{E}-02$ \\
\hline 10 & EntenderInterlocutor2 & não & $1,00 \mathrm{E}-03$ & $8,55 \mathrm{E}-01$ & $8,54 \mathrm{E}-01$ & $2,18 \mathrm{E}-01$ & $2,17 \mathrm{E}-01$ \\
\hline 11 & DeteccaodoErro & não & $1,00 \mathrm{E}-02$ & $9,88 \mathrm{E}-01$ & $9,78 \mathrm{E}-01$ & $1,98 \mathrm{E}-02$ & $9,80 \mathrm{E}-03$ \\
\hline 11 & EntendeDemanda & não & $2,00 \mathrm{E}-01$ & $9,81 \mathrm{E}-03$ & $-1,90 \mathrm{E}-01$ & - & - \\
\hline 11 & TomadadeDecisao & falha & $1,00 \mathrm{E}-03$ & $1,45 \mathrm{E}-02$ & $1,35 \mathrm{E}-02$ & $4,70 \mathrm{E}-03$ & $3,70 \mathrm{E}-03$ \\
\hline 14 & TimoneirodaRespErrada14 & $\operatorname{sim}$ & $5,00 \mathrm{E}-04$ & $4,99 \mathrm{E}-04$ & $-1,00 \mathrm{E}-06$ & - & - \\
\hline 23 & DeteccaodoErro1 & não & $1,00 \mathrm{E}-02$ & $9,88 \mathrm{E}-01$ & $9,78 \mathrm{E}-01$ & $1,98 \mathrm{E}-02$ & $9,80 \mathrm{E}-03$ \\
\hline 23 & EntendeDemanda1 & não & $2,00 \mathrm{E}-01$ & $9,81 \mathrm{E}-03$ & $-1,90 \mathrm{E}-01$ & - & - \\
\hline 23 & TomadadeDecisao1 & falha & $1,00 \mathrm{E}-03$ & $1,45 \mathrm{E}-02$ & $1,35 \mathrm{E}-02$ & 4,70E-03 & $3,70 \mathrm{E}-03$ \\
\hline 25 & TimoneiroDaRespostaErrada25 & $\operatorname{sim}$ & $5,00 \mathrm{E}-04$ & 4,99E-04 & $-1,00 \mathrm{E}-06$ & - & - \\
\hline 29 & ChecagemEquipamento & $\begin{array}{c}\text { Incomplet } \\
a\end{array}$ & $1,00 \mathrm{E}-03$ & $1,00 \mathrm{E}-03$ & $0,00 \mathrm{E}+00$ & - & - \\
\hline 29 & ComandanteDetectaErro & não & $1,00 \mathrm{E}-02$ & 9,97E-01 & $9,87 \mathrm{E}-01$ & $5,23 \mathrm{E}-03$ & $-4,77 \mathrm{E}-03$ \\
\hline 29 & LeituraPosicao & falha & $1,00 \mathrm{E}-03$ & $1,96 \mathrm{E}-03$ & $9,60 \mathrm{E}-04$ & $9,60 \mathrm{E}-04$ & $-4,00 \mathrm{E}-05$ \\
\hline 29 & MarcacaoCartaNautica & falha & $3,00 \mathrm{E}-03$ & $2,76 \mathrm{E}-03$ & $-2,40 \mathrm{E}-04$ & $7,93 \mathrm{E}-04$ & $-2,21 \mathrm{E}-03$ \\
\hline 29 & RespeitolntervalosdeMarcacao & não & $1,00 \mathrm{E}-03$ & $1,00 \mathrm{E}-03$ & $0,00 \mathrm{E}+00$ & - & - \\
\hline 32 & ComandanteFalha32 & $\operatorname{sim}$ & $1,00 \mathrm{E}-02$ & $1,08 \mathrm{E}-02$ & $8,00 \mathrm{E}-04$ & - & - \\
\hline 33 & OficialdeNauticaFalha33 & $\operatorname{sim}$ & $1,00 \mathrm{E}-02$ & $1,08 \mathrm{E}-02$ & $8,00 \mathrm{E}-04$ & - & - \\
\hline 36 & ErrodeAtencao36 & $\operatorname{sim}$ & $1,00 \mathrm{E}-02$ & $9,81 \mathrm{E}-03$ & $-1,90 \mathrm{E}-04$ & - & - \\
\hline 39 & ErronãoDescoberto39 & $\operatorname{sim}$ & $1,00 \mathrm{E}-02$ & $1,08 \mathrm{E}-02$ & $8,00 \mathrm{E}-04$ & - & - \\
\hline 43 & AtualizacaoPublicacoes1 & falha & $1,00 \mathrm{E}-03$ & $1,23 \mathrm{E}-03$ & $2,30 \mathrm{E}-04$ & - & - \\
\hline 43 & EscolhaPontosReferencia1 & falha & $1,00 \mathrm{E}-03$ & $5,79 \mathrm{E}-03$ & 4,79E-03 & $1,04 \mathrm{E}-03$ & $4,00 \mathrm{E}-05$ \\
\hline 43 & IdentificarAreasRestritas1 & falha & $1,00 \mathrm{E}-02$ & $3,48 \mathrm{E}-03$ & $-6,52 \mathrm{E}-03$ & $1,25 \mathrm{E}-04$ & $-9,88 \mathrm{E}-03$ \\
\hline 43 & IdentificarWayPoints1 & falha & $1,00 \mathrm{E}-03$ & $4,76 \mathrm{E}-03$ & $3,76 \mathrm{E}-03$ & $2,87 \mathrm{E}-04$ & $-7,13 \mathrm{E}-04$ \\
\hline 43 & LeituradasInformacoes1 & falha & $1,70 \mathrm{E}-02$ & $2,21 \mathrm{E}-03$ & $-1,48 \mathrm{E}-02$ & $9,89 \mathrm{E}-04$ & $-1,60 \mathrm{E}-02$ \\
\hline 43 & LeituradeProfundidade1 & falha & $1,00 \mathrm{E}-02$ & $3,36 \mathrm{E}-03$ & $-6,64 \mathrm{E}-03$ & $3,12 \mathrm{E}-04$ & $-9,69 E-03$ \\
\hline 43 & ProfundidadeMinima1 & falha & $1,00 \mathrm{E}-02$ & $3,05 \mathrm{E}-03$ & $-6,95 \mathrm{E}-03$ & $8,35 \mathrm{E}-04$ & $-9,17 E-03$ \\
\hline 43 & RevisaoComandante1 & falha & $1,00 \mathrm{E}-02$ & $1,90 \mathrm{E}-07$ & $-1,00 \mathrm{E}-02$ & $6,52 \mathrm{E}-03$ & $-3,48 \mathrm{E}-03$ \\
\hline 43 & RevisaoOficialNautica1 & falha & $1,00 \mathrm{E}-02$ & $2,91 \mathrm{E}-05$ & $-9,97 \mathrm{E}-03$ & $5,02 \mathrm{E}-03$ & $-4,98 \mathrm{E}-03$ \\
\hline 43 & TracarAreasRestritas1 & falha & $1,00 \mathrm{E}-03$ & $4,07 E-03$ & $3,07 E-03$ & $5,87 \mathrm{E}-04$ & $-4,13 \mathrm{E}-04$ \\
\hline 43 & TracarRumosSucessivos1 & falha & $3,00 \mathrm{E}-03$ & $4,48 \mathrm{E}-03$ & $1,48 \mathrm{E}-03$ & $4,11 \mathrm{E}-04$ & $-2,59 \mathrm{E}-03$ \\
\hline
\end{tabular}

Assim, de maneira geral e sem objetivo de validação, os resultados alcançados por meio das Redes Bayesianas estão coerentes com o esperado, já que a modelagem se pautou pelo aproveitamento dos resultados do trabalho anterior 
(Maturana e Martins. 2008) obtidos por meio da THERP. Em outras palavras, ressalta-se que nesta análise aqueles dados estão sendo utilizados apenas para uma comparação geral, já que os dados obtidos da rede integrada consideram dependências não modeladas no trabalho anterior. Além disto, para se processar a comparação foi necessário definir condições específicas para os nós pais das atividades, para tornar as circunstâncias mais semelhantes ao modelado naquele trabalho. De qualquer modo, o apresentado acima ajuda a compreender uma diferença importante entre modelar via Redes Bayesianas e modelar via Árvores Binárias. Pelo apresentado, verifica-se que a utilização das Redes Bayesianas obriga o analista a uma consideração contextual do erro, ou seja, a uma consideração completa dos fatores que influenciam na execução da atividade. $E$ isto ocorre tanto na fase de modelagem quanto na de análise do modelo, para compreensão dos resultados obtidos.

Voltando à seqüência proposta para este capítulo, no próximo tópico serão apresentados os resultados da análise do erro humano considerando os estados dos PSF.

\subsection{ANÁLISE DOS FATORES INTERNOS E HABILIDADES}

A rede formada pela integração da rede dos desencadeamentos de eventos perigosos, redes dinâmicas das tarefas e redes dos fatores de desempenho possui 263 nós, dos quais 24 são para eventos perigosos, 40 para atividades, 12 para os MOF e 187 para habilidades, fatores internos e ambientais. Como a análise detalhada de cada condição (combinação de estados dos nós) da rede é inviável, para a análise dos PSF (exceto os MOF, que serão vistos no próximo tópico) foram escolhidas as atividades que se destacaram nos tópicos precedentes. Além disto, nos apêndices estão apresentados subsídios para a reconstrução da rede integrada, o que permite ao interessado a verificação das condições não consideradas.

No item 5.1 foram levantados os desencadeamentos de eventos mais prováveis, dada a evidência de colisão. Especificamente para o desencadeamento mais provável, as tarefas que apresentaram estado de falha foram ${ }^{10}$ (ver Tabela 33):

\section{- 6 - Procedimento RIPEAM;}

\footnotetext{
${ }^{10}$ A título de comparação, estas tarefas também foram selecionadas como críticas no trabalho anterior (ver Maturana e Martins, 2008), utilizando um método diferente do apresentado aqui.
} 
- 10 - Comunicação;

- 23 - Ordem do Oficial.

Considerando o apresentado no item 5.2, as atividades que compõem estas tarefas também podem ser isoladas entre as mais passíveis de erro. Na Tabela $35 \mathrm{e}$ na Tabela 36, elas foram discriminadas (em negrito) entre as atividades que apresentaram probabilidade de erro maior que $10 \%$, dada a evidência de colisão.

Sendo assim, para a tarefa 6-Procedimento RIPEAM, foram obtidos os dados apresentados na Tabela 38.

Tabela 38 - Análise dos PSF para a Tarefa 6-Procedimento RIPEAM

\begin{tabular}{|c|c|c|c|c|c|c|}
\hline \multicolumn{4}{|c|}{ Falha no procedimento, dado o estado do PSF } & \multirow{2}{*}{\multicolumn{3}{|c|}{$\begin{array}{c}\text { Estado do PSF, dada a falha } \\
\text { no procedimento }\end{array}$}} \\
\hline \multirow{2}{*}{ Sem evidência } & \multirow{2}{*}{ Estado } & \multirow{2}{*}{$\begin{array}{c}\text { Probabilidade } \\
\text { de Falha } \\
5,0722 \mathrm{E}-01\end{array}$} & \multirow{2}{*}{ Diferença } & & & \\
\hline & & & & & Evidência & \\
\hline \multicolumn{4}{|c|}{ Com evidência } & evidência & de Falha & Diterença \\
\hline \multicolumn{7}{|c|}{ Habilidades } \\
\hline ConhecimentodeProcedimento1 & Ruim & $5,8089 \mathrm{E}-01$ & $14,52 \%$ & $4,5888 \mathrm{E}-01$ & $5,2553 \mathrm{E}-01$ & $14,52 \%$ \\
\hline Percepcao6 & Baixa & $5,8085 \mathrm{E}-01$ & $14,52 \%$ & 4,5888E-01 & $5,2550 \mathrm{E}-01$ & $14,52 \%$ \\
\hline EquipeComunicacao1 & Ruim & $5,8085 \mathrm{E}-01$ & $14,52 \%$ & $4,5888 \mathrm{E}-01$ & $5,2549 \mathrm{E}-01$ & $14,52 \%$ \\
\hline \multicolumn{7}{|c|}{ Fatores Internos } \\
\hline CondicaoFisica3 & Ruim & $5,2577 \mathrm{E}-01$ & $3,66 \%$ & $3,4040 \mathrm{E}-01$ & $3,5285 \mathrm{E}-01$ & $3,66 \%$ \\
\hline Habilidade1 & Incipiente & $5,2574 \mathrm{E}-01$ & $3,65 \%$ & $3,4040 \mathrm{E}-01$ & $3,5283 \mathrm{E}-01$ & $3,65 \%$ \\
\hline QualidadedoSono3 & Ruim & $5,2574 \mathrm{E}-01$ & $3,65 \%$ & $3,4040 \mathrm{E}-01$ & $3,5283 \mathrm{E}-01$ & $3,65 \%$ \\
\hline TratamentoDadoaFalha1 & Desmotivador & $5,2552 \mathrm{E}-01$ & $3,61 \%$ & $3,4040 \mathrm{E}-01$ & $3,5268 \mathrm{E}-01$ & $3,61 \%$ \\
\hline ConhecimentodasNormas2 & Superficial & $5,1975 \mathrm{E}-01$ & $2,47 \%$ & $3,4040 \mathrm{E}-01$ & $3,4880 \mathrm{E}-01$ & $2,47 \%$ \\
\hline Personalidadeelnteligencia2 & Inadequada & $5,1964 \mathrm{E}-01$ & $2,45 \%$ & $3,4040 \mathrm{E}-01$ & $3,4873 \mathrm{E}-01$ & $2,45 \%$ \\
\hline EstadoAtual2 & Incipiente & $5,1959 \mathrm{E}-01$ & $2,44 \%$ & $3,4040 \mathrm{E}-01$ & $3,4870 \mathrm{E}-01$ & $2,44 \%$ \\
\hline
\end{tabular}

Nesta tabela (Tabela 38) estão apresentadas as inferências feitas para obter dois tipos de probabilidade: 1) A probabilidade de falha na tarefa, dado o estado de determinado PSF (habilidade ou fator interno); e 2) A probabilidade do estado negativo do PSF, dado a falha na tarefa. Ela também apresenta a comparação entre estas probabilidades e aquelas apresentadas pelos nós sem as referidas evidências - as colunas Diferença sintetizam estes dados. Verifica-se que estas colunas apresentam resultados iguais para um mesmo PSF. O entendimento desta igualdade pode ser alcançado por uma análise das probabilidades associadas aos nós em cada circunstância e do método de cálculo dos dados apresentados nas colunas Diferença. Para exemplificar, tome-se inicialmente a Equação (5.10), baseada na Equação (2.1):

$$
P(\text { tarefa } \mid p s f)=\frac{P(\text { tarefa }, p s f)}{P(p s f)}
$$


onde tarefa refere-se ao estado de falha do nó para a tarefa, e psf refere-se ao estado negativo de um nó qualquer para habilidade ou para fator interno.

O cálculo da diferença entre a probabilidade sem evidência e a probabilidade, dada a evidência do PSF, foi feito segundo a Equação (5.11):

$$
\text { Diferença }=\frac{P(\text { tarefa } \mid p s f)-P(\text { tarefa })}{P(\text { tarefa })}
$$

que, considerando a Equação (5.10), pode ser manipulada para gerar a Equação (5.12):

$$
\text { Diferença }=\frac{P(\text { tarefa }, p s f)}{P(\text { tarefa }) * P(p s f)}-1
$$

O procedimento acima pode ser repetido para a verificação da probabilidade do estado negativo do PSF, dada a evidência de erro na atividade. Para este caso, tome-se a Equação (5.13), que emprega as mesmas variáveis da Equação (5.10):

$$
P(p s f \mid \text { tarefa })=\frac{P(\text { tarefa }, p s f)}{P(\text { tarefa })}
$$

O cálculo da diferença entre a probabilidade sem evidência e a probabilidade, dada a evidência de erro na atividade, foi feito segundo a Equação (5.14):

$$
\text { Diferença }=\frac{P(p s f \mid \text { tarefa })-P(p s f)}{P(p s f)}
$$

que, considerando a Equação (5.13), pode ser manipulada para gerar o mesmo resultado apresentado na Equação (5.12).

Daqui por diante, a demonstração acima será utilizada para apoiar a idéia de que se o cálculo da diferença for feito considerando a probabilidade do estado do PSF, dada evidência de falha na tarefa (ou atividade), será encontrado o mesmo resultado do cálculo que considera a probabilidade de falha na tarefa (ou atividade), dado o estado do PSF.

Os PSF que apresentam diferenças maiores na Tabela 38 são os mais críticos para a atividade, ou seja, são os que sendo melhorados representam um ganho maior em termos de segurança operacional. No caso do fator interno CondicaoFisica3, por exemplo, se for observado o estado Boa ao invés de Ruim, a probabilidade de falha na tarefa cai 5,35\%, para 4,98E-01. A figura a seguir ilustra as quedas obtidas, dado este ou os demais fatores internos da Tabela 38. 


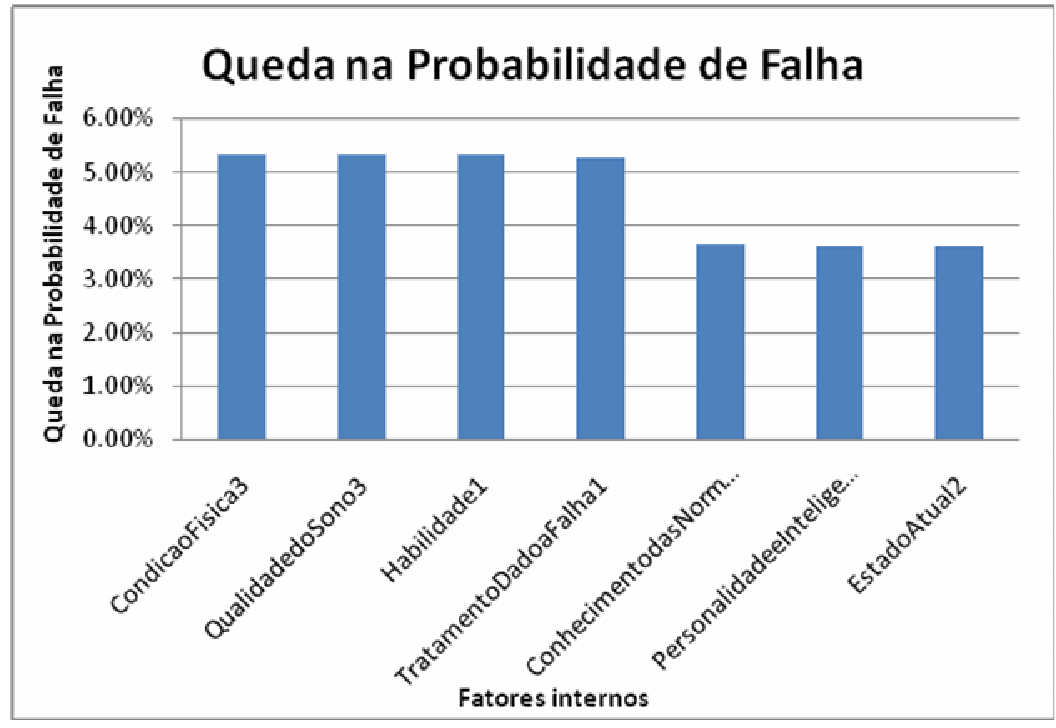

Figura 33 - Queda na probabilidade de falha

Um gráfico semelhante poderia ser elaborado para as habilidades, mas isto não foi feito porque as consideradas na Tabela 38 apresentaram resultados muito semelhantes entre si em relação ao critério abordado no parágrafo anterior (em torno de $23,42 \%)$.

Para as atividades da tarefa 10-Comunicação, foram obtidos os dados apresentados da Tabela 39 a Tabela 43. Nestas tabelas estão apresentadas as inferências feitas para obter as probabilidades dos estados negativos dos PSF (habilidades e fatores internos), dada o erro na execução da atividade (ou decisão de não prosseguir com a comunicação). Elas também apresentam a comparação entre estas probabilidades e aquelas apresentadas pelos nós sem as referidas evidências - as colunas Diferença sintetizam estes dados. Na Tabela 41 e na Tabela 43, além das evidências citadas, a primeira linha da segunda coluna apresenta outras evidências referentes aos estados dos nós das atividades precedentes. Estas evidências foram consideradas a fim de que a análise dos PSF ligados à determinada atividade incorpore a necessidade de sua execução (ver item 5.2).

Os resultados apresentados nestas tabelas foram ordenados em função das colunas Diferença. Assim, os fatores apresentados nas primeiras posições são os mais críticos em relação à possibilidade de erro na execução das atividades. Da Tabela 43, por exemplo, a evidência do estado Ruim para o fator QualidadedoSono2 é pior que do que a evidência do estado Ruim para o fator CondicaoFisica2, visto que a probabilidade de erro na atividade aumentará quatro vezes mais para o 
primeiro caso do que para o segundo (81,40\% e 19,49\%, respectivamente).

Tabela 39 - Análise dos PSF para a atividade DecidirFazerContato

\begin{tabular}{|c|c|c|c|c|}
\hline DecidirFazerContato & Sem evidência & PSF, dado o erro na atividade \\
\hline não & $7,30 \mathrm{E}-02$ & Sem evidência & Erro & Diferença \\
\hline \multicolumn{5}{|c|}{ Habilidades } \\
\hline ConhecimentodeProcedimento & Ruim & $1,22 \mathrm{E}-01$ & $4,25 \mathrm{E}-01$ & $248,60 \%$ \\
\hline Interpretacao & Lenta & $1,24 \mathrm{E}-01$ & $4,29 \mathrm{E}-01$ & $247,08 \%$ \\
\hline EquipeComunicacao & Ruim & $1,19 \mathrm{E}-01$ & $4,09 \mathrm{E}-01$ & $242,20 \%$ \\
\hline \multicolumn{5}{|c|}{ Fatores Internos } \\
\hline PersonalidadeeInteligencia & Inadequado & $9,80 \mathrm{E}-02$ & $1,89 \mathrm{E}-01$ & $93,12 \%$ \\
\hline Habilidade & Incipiente & $8,85 \mathrm{E}-02$ & $1,54 \mathrm{E}-01$ & $74,36 \%$ \\
\hline TratamentoDadoaFalha & Desmotivador & $8,80 \mathrm{E}-02$ & $1,50 \mathrm{E}-01$ & $69,97 \%$ \\
\hline ConhecimentodasNormas & Superficial & $8,80 \mathrm{E}-02$ & $1,35 \mathrm{E}-01$ & $53,67 \%$ \\
\hline MotivacaoeAtitude & Baixa & $8,80 \mathrm{E}-02$ & $1,31 \mathrm{E}-01$ & $49,15 \%$ \\
\hline Fadiga & Sim & $9,80 \mathrm{E}-02$ & $1,45 \mathrm{E}-01$ & $48,44 \%$ \\
\hline EstadoAtual & Incipiente & $8,80 \mathrm{E}-02$ & $1,29 \mathrm{E}-01$ & $47,06 \%$ \\
\hline
\end{tabular}

Tabela 40 - Análise dos PSF para a atividade ConseguirContatoRadio

\begin{tabular}{|c|c|c|c|c|}
\hline $\begin{array}{c}\text { ConseguirContatoRadi } \\
0\end{array}$ & Sem evidência & \multicolumn{3}{|c|}{ PSF, dado o erro na atividade } \\
\hline Não & $1,37 \mathrm{E}-01$ & Sem evidência & Erro & Diferença \\
\hline \multicolumn{5}{|c|}{ Habilidades } \\
\hline EquipeComunicacao & Ruim & $1,19 \mathrm{E}-01$ & $3,82 \mathrm{E}-01$ & $220,22 \%$ \\
\hline ConhecimentodeProcedimento2 & Ruim & $1,22 \mathrm{E}-01$ & $2,70 \mathrm{E}-01$ & $121,91 \%$ \\
\hline Concentracao2 & Baixa & $1,25 \mathrm{E}-01$ & $2,75 \mathrm{E}-01$ & $119,97 \%$ \\
\hline \multicolumn{5}{|c|}{ Fatores Internos } \\
\hline Habilidade & Incipiente & $8,85 \mathrm{E}-02$ & $1,48 \mathrm{E}-01$ & $67,76 \%$ \\
\hline TratamentoDadoaFalha & Desmotivador & $8,80 \mathrm{E}-02$ & $1,44 \mathrm{E}-01$ & $63,65 \%$ \\
\hline QualidadedoSono2 & Ruim & $9,80 \mathrm{E}-02$ & $1,37 \mathrm{E}-01$ & $39,45 \%$ \\
\hline Distracoes2 & Sim & $9,80 \mathrm{E}-02$ & $1,35 \mathrm{E}-01$ & $37,61 \%$ \\
\hline ConhecimentodasNormas1 & Superficial & $8,80 \mathrm{E}-02$ & $1,16 \mathrm{E}-01$ & $31,29 \%$ \\
\hline PersonalidadeeInteligencia1 & Inadequada & $9,80 \mathrm{E}-02$ & $1,28 \mathrm{E}-01$ & $30,59 \%$ \\
\hline EstadoAtual1 & Incipiente & $8,80 \mathrm{E}-02$ & $1,13 \mathrm{E}-01$ & $28,61 \%$ \\
\hline
\end{tabular}

Tabela 41 - Análise dos PSF para a atividade DecidirContatoOutroMeio

\begin{tabular}{|c|c|c|c|c|}
\hline DecidirContatoOutroMeio & $\begin{array}{l}\text { Dado estado "Não" para } \\
\text { ConseguirContatoRadio }\end{array}$ & \multicolumn{3}{|c|}{ PSF, dado o erro na atividade } \\
\hline Não & $1,39 \mathrm{E}-01$ & Sem evidência & Erro & Diferença \\
\hline \multicolumn{5}{|c|}{ Habilidades } \\
\hline Flexibilidade & Baixa & $1,46 \mathrm{E}-01$ & $3,43 \mathrm{E}-01$ & $135,11 \%$ \\
\hline Interpretacao & Lenta & $2,76 \mathrm{E}-01$ & 5,57E-01 & $101,78 \%$ \\
\hline ConhecimentodeProcedimento & Ruim & $2,74 \mathrm{E}-01$ & $5,45 \mathrm{E}-01$ & $98,92 \%$ \\
\hline \multicolumn{5}{|c|}{ Fatores Internos } \\
\hline Personalidadeelnteligencia & Inadequada & $1,47 \mathrm{E}-01$ & $2,66 \mathrm{E}-01$ & $81,18 \%$ \\
\hline MotivacaoeAtitude & Baixa & $1,11 \mathrm{E}-01$ & $1,73 \mathrm{E}-01$ & $55,91 \%$ \\
\hline Fadiga & $\operatorname{sim}$ & $1,23 \mathrm{E}-01$ & $1,63 \mathrm{E}-01$ & $32,72 \%$ \\
\hline EstadoAtual & Incipiente & $1,13 \mathrm{E}-01$ & $1,46 \mathrm{E}-01$ & $28,82 \%$ \\
\hline ConhecimentodasNormas & Superficial & $1,16 \mathrm{E}-01$ & $1,48 \mathrm{E}-01$ & $27,70 \%$ \\
\hline TratamentoDadoaFalha & Desmotivador & $1,44 \mathrm{E}-01$ & $1,50 \mathrm{E}-01$ & $3,81 \%$ \\
\hline
\end{tabular}

Tabela 42 - Análise dos PSF para a atividade EntenderInterlocutor

\begin{tabular}{|c|c|c|c|c|}
\hline $\begin{array}{c}\text { Entenderlnterlocuto } \\
r\end{array}$ & Sem evidência & \multicolumn{2}{|c|}{ PSF, dado o erro na atividade } \\
\hline Não & $1,95 \mathrm{E}-01$ & Sem evidência & Erro & Diferença \\
\hline \multicolumn{5}{|c|}{ Habilidades } \\
\hline Concentracao2 & Baixa & $1,25 \mathrm{E}-01$ & $3,52 \mathrm{E}-01$ & $181,99 \%$ \\
\hline Percepcao7 & Baixa & $1,25 \mathrm{E}-01$ & $2,85 \mathrm{E}-01$ & $127,97 \%$ \\
\hline \multicolumn{5}{|c}{ Fatores Internos } \\
\hline
\end{tabular}




\begin{tabular}{|c|c|c|c|c|} 
QualidadedoSono2 & Ruim & $9,80 \mathrm{E}-02$ & $1,84 \mathrm{E}-01$ & $87,46 \%$ \\
\hline Distracoes2 & Sim & $9,80 \mathrm{E}-02$ & $1,52 \mathrm{E}-01$ & $54,95 \%$ \\
\hline CondicaoFisica2 & Ruim & $9,84 \mathrm{E}-02$ & $1,37 \mathrm{E}-01$ & $38,98 \%$ \\
\hline
\end{tabular}

Tabela 43 - Análise dos PSF para a atividade EntenderInterlocutor2

\begin{tabular}{|c|c|c|c|c|}
\hline $\begin{array}{c}\text { Entenderlnterlocutor } \\
2\end{array}$ & $\begin{array}{l}\text { Dado o estado "Não" para } \\
\text { DecidirContatoOutroMeio }\end{array}$ & \multicolumn{3}{|c|}{ PSF, dado o erro na atividade } \\
\hline Não & $1,57 \mathrm{E}-01$ & Sem evidência & Erro & Diferença \\
\hline \multicolumn{5}{|c|}{ Habilidades } \\
\hline Percepcao8 & Baixa & $1,60 \mathrm{E}-01$ & 4,30E-01 & $169,74 \%$ \\
\hline Concentracao2 & Baixo & $3,65 \mathrm{E}-01$ & $8,22 \mathrm{E}-01$ & $125,12 \%$ \\
\hline \multicolumn{5}{|c|}{ Fatores Internos e Ambientais } \\
\hline QualidadedoSono2 & Ruim & $1,88 \mathrm{E}-01$ & $3,40 \mathrm{E}-01$ & $81,40 \%$ \\
\hline Distracoes2 & Sim & 1,55E-01 & 2,57E-01 & $66,36 \%$ \\
\hline Visibilidade2 & Baixa & $1,50 \mathrm{E}-01$ & $1,96 \mathrm{E}-01$ & $30,33 \%$ \\
\hline CondicaoFisica2 & Ruim & 1,37E-01 & $1,64 \mathrm{E}-01$ & $19,49 \%$ \\
\hline
\end{tabular}

O procedimento apresentado para a tarefa 10-Comunicação foi repetido para a tarefa 23-Oficial dá Ordem Errada, e a Tabela 44, a Tabela 45 e a Tabela 46 apresentam os resultados obtidos.

Tabela 44 - Análise dos PSF para a atividade EntendeDemanda $1^{11}$

\begin{tabular}{|c|c|c|c|c|}
\hline EntendeDemanda1 & Sem evidência & PSF, dado o erro na atividade \\
\hline Não & $9,81 \mathrm{E}-03$ & Sem evidência & Erro & Diferença \\
\hline \multicolumn{5}{|c|}{ Habilidades } \\
\hline Concentracao5 & Baixa & $8,00 \mathrm{E}-03$ & $2,69 \mathrm{E}-01$ & $3261,63 \%$ \\
\hline Percepcao10 & Baixa & $2,47 \mathrm{E}-02$ & $7,80 \mathrm{E}-01$ & $3055,41 \%$ \\
\hline \multicolumn{5}{|c|}{ Fatores Internos e Ambientais } \\
\hline QualidadedoSono6 & Ruim & $2,00 \mathrm{E}-02$ & $2,36 \mathrm{E}-01$ & $1077,80 \%$ \\
\hline Distracoes5 & Sim & $2,00 \mathrm{E}-02$ & $1,59 \mathrm{E}-01$ & $695,40 \%$ \\
\hline Condicaofisica6 & Ruim & $1,96 \mathrm{E}-02$ & $1,10 \mathrm{E}-01$ & $460,24 \%$ \\
\hline Visibilidade4 & Baixa & $1,50 \mathrm{E}-01$ & $6,58 \mathrm{E}-01$ & $338,71 \%$ \\
\hline
\end{tabular}

Tabela 45 - Análise dos PSF para a atividade TomadadeDecisao1

\begin{tabular}{|c|c|c|c|c|}
\hline $\begin{array}{c}\text { TomadadeDecisao } \\
1\end{array}$ & Sem evidência & PSF, dado o erro na atividade \\
\hline Falha & $1,45 \mathrm{E}-02$ & Sem evidência & Erro & Diferença \\
\hline \multicolumn{5}{|c|}{ Habilidades } \\
\hline Interpretacao2 & Lenta & $7,83 \mathrm{E}-03$ & $1,35 \mathrm{E}-01$ & $1621,43 \%$ \\
\hline Flexibilidade2 & Baixa & $7,81 \mathrm{E}-03$ & $1,33 \mathrm{E}-01$ & $1599,86 \%$ \\
\hline Planejamento1 & Inadequado & $8,00 \mathrm{E}-03$ & $1,32 \mathrm{E}-01$ & $1545,38 \%$ \\
\hline \multicolumn{5}{|c|}{ Fatores Internos e Ambientais } \\
\hline Personalidadeelnteligencia4 & Inadequada & $2,00 \mathrm{E}-02$ & $1,50 \mathrm{E}-01$ & $648,80 \%$ \\
\hline MotivacaoeAtitude2 & Baixa & $2,00 \mathrm{E}-02$ & $1,09 \mathrm{E}-01$ & $445,50 \%$ \\
\hline Fadiga3 & Sim & $2,00 \mathrm{E}-02$ & $7,78 \mathrm{E}-02$ & $289,21 \%$ \\
\hline Habilidade4 & Incipiente & $2,00 \mathrm{E}-02$ & $7,37 \mathrm{E}-02$ & $268,27 \%$ \\
\hline TratamentoDadoaFalha4 & Desmotivador & $2,00 \mathrm{E}-02$ & $5,50 \mathrm{E}-02$ & $174,90 \%$ \\
\hline
\end{tabular}

Desta maneira, ficam evidenciados os PSF que mais influenciam nas probabilidades de falha nas atividades discriminadas inicialmente.

\footnotetext{
${ }^{11}$ Aqui foi utilizada a nomenclatura empregada no Netica ${ }^{\mathrm{TM}}$ e no Apêndice B, na Tabela 15 a nomenclatura para esta atividade é Entende Corretamente.
}

Aplicação de Redes Bayesianas na Análise da Contribuição da Falha Humana em Acidentes de Colisão - 97 
Com estes resultados é possível delinear ações para reduzir as chances do acidente em estudo (colisão). No contexto dos passos previstos na HRA, este delineamento poderia ser o ponto inicial para o passo 3 - Opções de Controle de Risco (ver item 2.1).

Tabela 46 - Análise dos PSF para a atividade DeteccaodoErro1

\begin{tabular}{|c|c|c|c|c|}
\hline DeteccaodoErro1 & $\begin{array}{c}\text { Dado o estado "Não" para } \\
\text { EntendeDemanda1 e "Falha" para } \\
\text { TomadadeDecisao1 }\end{array}$ & \multicolumn{3}{|c|}{ PSF, dado o erro na atividade } \\
\hline Não & $1,98 \mathrm{E}-02$ & Sem evidência & Erro & Diferença \\
\hline \multicolumn{5}{|c|}{ Habilidades } \\
\hline Concentracao5 & Baixa & $9,58 \mathrm{E}-03$ & 1,09E-01 & $1032,48 \%$ \\
\hline Percepcao10 & Baixa & $2,64 \mathrm{E}-02$ & $2,86 \mathrm{E}-01$ & $983,74 \%$ \\
\hline EquipeComunicacao4 & Ruim & $6,31 \mathrm{E}-02$ & $6,52 \mathrm{E}-01$ & $933,48 \%$ \\
\hline \multicolumn{5}{|c|}{ Fatores Internos e Ambientais } \\
\hline QualidadedoSono6 & Ruim & $4,64 \mathrm{E}-02$ & $1,44 \mathrm{E}-01$ & $209,79 \%$ \\
\hline Distracoes5 & $\operatorname{sim}$ & $1,86 \mathrm{E}-02$ & $5,02 \mathrm{E}-02$ & $169,57 \%$ \\
\hline TratamentoDadoaFalha4 & Desmotivador & $1,29 \mathrm{E}-01$ & $3,04 \mathrm{E}-01$ & $136,04 \%$ \\
\hline Habilidade4 & Incipiente & $1,87 \mathrm{E}-01$ & 4,34E-01 & $132,45 \%$ \\
\hline Visibilidade4 & Baixa & $1,45 \mathrm{E}-01$ & $2,65 \mathrm{E}-01$ & $83,11 \%$ \\
\hline CondicaoFisica6 & Ruim & $8,52 \mathrm{E}-02$ & 1,31E-01 & $53,70 \%$ \\
\hline
\end{tabular}

A título de ilustração, pode-se tomar o exemplo do fator interno Qualidade do Sono - este PSF aparece muitas vezes como o fator mais impactante (ou como um dos mais impactantes) nas probabilidades de erro das atividades analisadas nas tabelas acima (ver Tabela 38, Tabela 40, Tabela 42, Tabela 43, Tabela 44 e Tabela 46). Algumas alternativas para atenuar o impacto deste fator podem ser: 1) melhorar o conforto das acomodações da tripulação; 2) enrijecer as regras relativas ao período entre quartos (estabelecendo um período fixo de repouso obrigatório); 3) elaborar um programa de conscientização sobre a importância do sono; 4) etc. Ressalta-se, no entanto, que de maneira geral ações isoladas apresentarão resultados isolados. No caso da atividade analisada na Tabela 46, por exemplo, as ações conjuntas de aumentar a qualidade do sono e de aumentar as distrações não se anulam, mas geram apenas uma pequena diferença na probabilidade de erro na atividade. Assim, o ideal é considerar ações para todos os PSF que se destacaram na análise.

\subsection{ANÁLISE DOS MOF}

Tendo a rede elaborada (conforme capítulo anterior) foi possível discriminar os MOF que mais influenciam na determinação da probabilidade da colisão. Isto foi feito partindo da elaboração do gráfico da probabilidade de colisão em função dos 
MOF. Na verdade, foi elaborada uma curva para cada MOF presente na rede. Sendo assim, foi gerado o gráfico apresentado na Figura 34.

Nesta figura algumas curvas se sobrepõem a outras. As curvas para "Avaliação de Rendimento" e "Cultura Organizacional" são coincidentes; já as curvas para "Formalização", "Programas da Companhia" e "Prêmios, Reconhecimento e Benefícios" são visualmente coincidentes nesta figura.

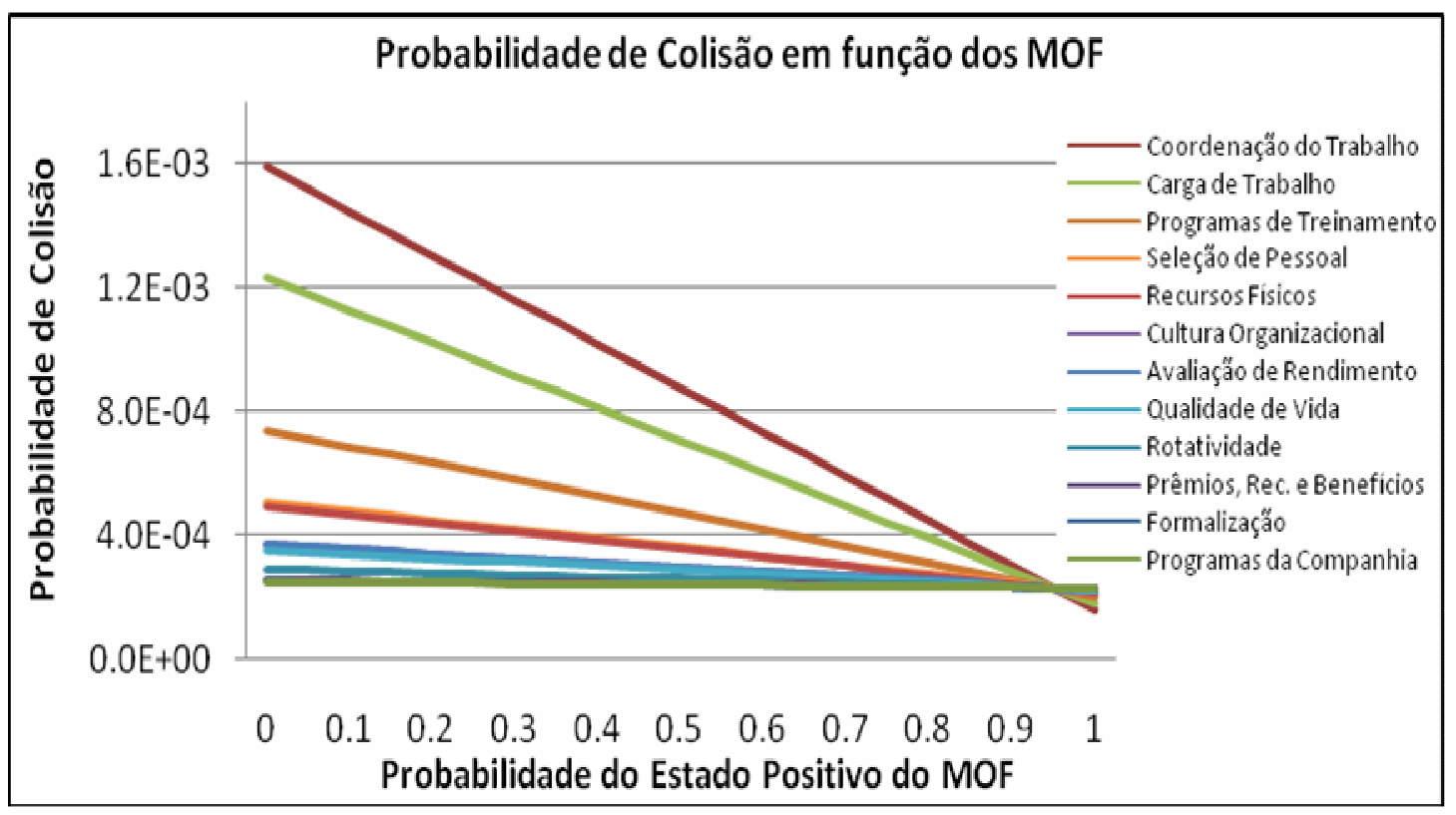

Figura 34 - Probabilidade de Colisão em Função dos MOF

Para a obtenção dos dados apresentados neste gráfico variaram-se as probabilidades associadas aos estados dos MOF. Isto foi feito para cada MOF mantendo-se inalteradas as probabilidades dos demais (95\% para os estados positivos - aqueles que tendo suas probabilidades aumentadas geram uma redução na probabilidade de colisão - e $5 \%$ para os negativos).

Neste ponto pode ser ressaltado que, na rede modelada, as probabilidades associadas aos MOF possuem relação linear com a probabilidade de ocorrência do evento topo da Árvore de Falhas (colisão). Esta propriedade pode ser verificada considerando-se o método de cálculo direto apresentado no item 2.2.2.1.

Com auxílio deste gráfico (Figura 34) foi definida a Tabela 47 com os MOF que se destacaram, em ordem decrescente. O critério escolhido foi o valor da probabilidade de colisão quando a probabilidade do estado positivo do MOF é baixa (para "Avaliação de Rendimento" e "Cultura Organizacional" a ordenação foi alfabética, já que as curvas são coincidentes). 
Os MOF apresentados nas primeiras posições são aqueles que, sendo trabalhados, podem representar ganhos mais evidentes em termos de segurança operacional, ou seja, diminuem mais a probabilidade de colisão. De outra forma, são os MOF que, sendo ignorados, podem contribuir de forma mais significativa para o aumento do risco de colisão.

\begin{tabular}{|c|c|}
\hline \multicolumn{2}{|r|}{ Ordenação dos MOF } \\
\hline 10 & Coordenação do Trabalho \\
\hline 20 & Carga de Trabalho \\
\hline 3음 & Programas de Treinamento \\
\hline 40 & Seleção de Pessoal \\
\hline 5o & Recursos Físicos \\
\hline 60 & Avaliação de Rendimento \\
\hline 70 & Cultura Organizacional \\
\hline 80 & Qualidade de Vida \\
\hline 9음 & Rotatividade \\
\hline 10 은 & Prêmios, Reconhecimento e Benefícios \\
\hline 11 음 & Formalização \\
\hline 120 & Programas da Companhia \\
\hline
\end{tabular}

Outra maneira de levantar a lista acima (Tabela 47) é, tendo a rede, supor a evidência de colisão e calcular as probabilidades dos MOF. Isto foi feito para a rede modelada e foram alcançados os valores apresentados na Figura 35. Nesta figura foram colocadas as probabilidades para os estados negativos e positivos dos MOF (como foram definidos apenas dois estados, sua soma deve ser 1).

Como observado nesta Figura 35, os MOF puderam ser ordenados da mesma maneira que anteriormente (Tabela 47). Os MOF com menores probabilidades para os estados positivos, dada a evidência de colisão, são também os que mais afetam a probabilidade de colisão levantada pelo método anterior (conforme esperado, já que as relações entre a probabilidade de colisão e as dos MOF são lineares, e os valores iniciais assumidos para cada MOF são iguais a 95\%). 


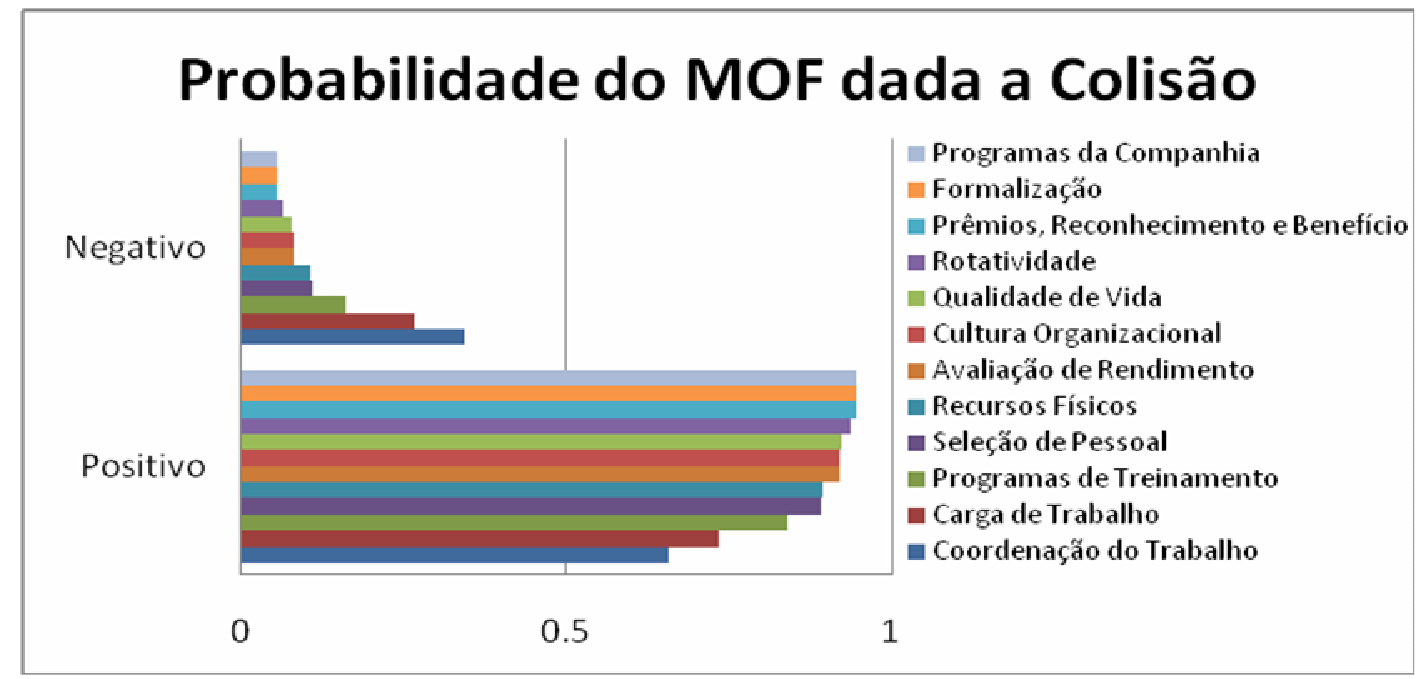

Figura 35 - Probabilidade do MOF, dada uma evidência de Colisão

Uma constatação importante é que, quando o MOF está relacionado a um grande número de fatores internos na rede, e considerando o método de cálculo direto da probabilidade de um evento negativo (evento de colisão, por exemplo) dado um MOF, uma quantidade maior de fatores da multiplicação (ver Equação (2.8)) é influenciada pelo estado deste MOF (por conta das muitas dependências) e, conseqüentemente, se o estado considerado do MOF for negativo as probabilidades dos fatores internos, dado o estado negativo do MOF, aparecerão com maior freqüência no cálculo. Para a rede modelada, e considerando a ordem dos MOF apresentada na Tabela 47, foi elaborada a Figura 36 abaixo. Nesta figura apresentase a quantidade de arcos existentes a partir de cada MOF.

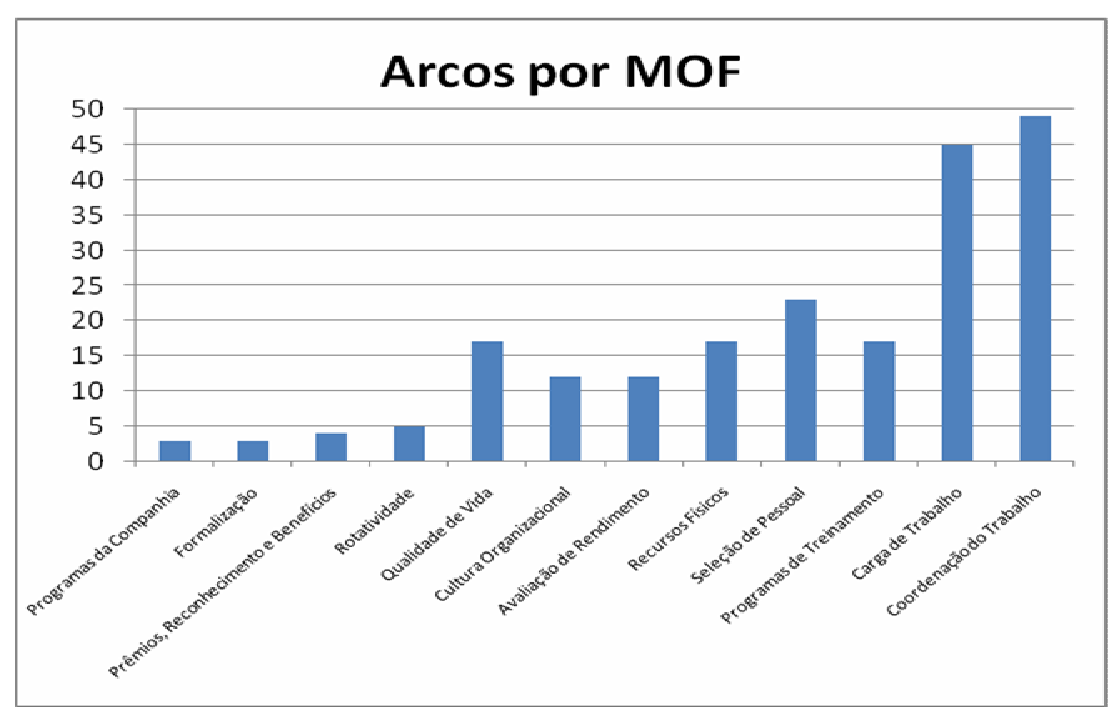

Figura 36 - Quantidade de arcos para cada MOF 
Desta figura e com apoio do descrito nos parágrafos anteriores, verifica-se a tendência de os MOF com maior quantidade de arcos influenciarem mais na probabilidade de colisão. Desta forma, logo após a elaboração da topologia da rede já é possível ter uma idéia qualitativa de quais serão os MOF discriminados pela aplicação dos métodos quantitativos acima.

Feitas estas considerações, ficam determinados os MOF que apresentam maior potencial para redução na probabilidade de colisão. 


\section{CONCLUSÕES E RECOMENDAÇÕES PARA TRABALHOS FUTUROS}

Tipicamente, os fatores humanos são a origem da maior parte das incertezas ao se aplicar a FSA (IMO, 2002). Ao longo das últimas décadas, muitas técnicas dedicadas a HRA foram desenvolvidas com intuito de melhorar o entendimento destes fatores e diminuir estas incertezas para, com isto, ajudar a identificar riscos específicos e permitir conjeturar modos para a redução destes riscos. O estudo de algumas destas técnicas, classificadas entre técnicas de $1^{\underline{a}}$ e de $2^{\underline{a}}$ geração, permitiu levantar pontos fortes e fracos a respeito da representação do fator humano alcançada por sua aplicação. Apesar de seus méritos, elas não permitem, de forma direta, a representação das dependências entre os elementos humanos incorporados ao sistema a ser analisado e, além disto, tornam difícil a representação dinâmica das atividades humanas, de forma que muita informação sobre o sistema deve ser desconsiderada para possibilitar uma análise quantitativa. As Redes Bayesianas vêm sendo propostas a fim de superar estas limitações e melhorar a representação do contexto em que as ações humanas se desenvolvem (Droguett e Menezes, 2007; Lampis e Andrews, 2008).

Com o estudo de caso, foi possível explorar o potencial das Redes Bayesianas como instrumento na HRA e foi possível apresentar sua aplicação na modelagem do fator humano - o que permitiu investigar os aspectos práticos do trabalho com esta ferramenta. O estudo de caso foi realizado em duas etapas: modelagem dos fatores humanos relacionados ao evento de colisão de um navio tanque, e análise deste modelo para identificar os fatores críticos em relação a este evento. A modelagem foi feita por meio da aplicação de uma metodologia baseada em técnicas existentes e nas características das Redes Bayesianas, considerando os resultados apresentados em Maturana e Martins (2008). A rede integrada obtida na etapa de modelagem foi submetida a uma série de suposições a respeito dos seus estados, resultando no levantamento dos fatores que devem receber maior atenção para melhorar a aplicação dos recursos da companhia numa cultura de redução de risco.

Durante a modelagem, verificou-se que as Redes Bayesianas permitem grande detalhamento dos fatores que influenciam a execução das tarefas e que para sua boa aplicação, entretanto, é necessário um conhecimento do sistema que 
permita determinar com segurança o que pode e o que não pode ser ignorado nesta fase. Para este trabalho foi desenvolvido um modelo genérico de dependência entre os PSF e as atividades com base em suposições contextuais sobre possíveis erros.

A modelagem dos desencadeamentos dos eventos perigosos (que podem levar o navio a colidir) se deu por meio do aproveitamento das informações da Árvore de Falhas apresentada em Maturana e Martins (2008), o que permitiu utilizar as probabilidades dos seus eventos básicos como referência para popular as TPC dos nós das redes dinâmicas das tarefas e, diferentemente do trabalho anterior, foi possível integrar estes desencadeamentos com as atividades realizadas no navio e os PSF num mesmo modelo quantitativo, considerando as dependências entre os eventos resultantes da ação humana e seus condicionantes. Partindo deste modelo, foram encontrados atividades e fatores críticos em relação ao evento de colisão e que poderiam pautar a incorporação de melhoramentos - tais como mudanças de procedimentos, ergonômicas, disponibilidade de equipamentos, etc. - para remover ou reduzir as oportunidades de erros e de acidentes, aumentando a segurança operacional. É importante enfatizar, no entanto, que a implementação bem sucedida destas ações está sujeita à cultura de risco de cada setor específico e que vem se desenvolvendo recentemente na indústria naval.

Os resultados para o isolamento das tarefas críticas foram próximos aos alcançados no trabalho anterior (Maturana e Martins, 2008). Isto se justifica no parágrafo acima, em relação ao aproveitamento dos dados quantitativos e qualitativos. Mas, diferentemente daquele trabalho, foram isoladas atividades específicas destas tarefas para estudar os PSF (habilidades, fatores internos e ambientais) que as influenciam e destacá-los em relação ao impacto na probabilidade de erro - com estes dados é possível concluir quais habilidades e características pessoais precisam ser treinadas ou buscadas para a tripulação do navio. Dentre as tarefas consideradas críticas durante a análise, as que se destacaram foram as seguintes: 6 - Procedimento RIPEAM, 10 - Comunicação e 23 - Ordem do Oficial.

Além disto, foi possível concluir quais MOF podem ser trabalhados com prioridade para um efetivo ganho na segurança operacional ou, de outra forma, quais poderiam ser ignorados sem incorrer em grandes incrementos no risco de 
colisão. Dentre os MOF analisados, os três considerados mais críticos para aumentar as chances de acidente foram os seguintes: Coordenação do Trabalho, Carga de Trabalho e Programas de Treinamento.

A modelagem dos PSF feita de maneira geral, considerando um modelo genérico de relacionamento entre os fatores, pode ter contribuído para que relações importantes tenham sido descartadas. Assim, para melhorar os resultados obtidos, deve ser considerado um aprofundamento na avaliação dos PSF. Por outro lado, pode ser considerado o incremento na quantidade de PSF analisados e o estudo do impacto da consideração discreta de variáveis que, na realidade, são contínuas.

Outro ponto que pode ser melhorado é a representação dos desencadeamentos dos eventos perigosos. A modelagem feita com aproveitamento das informações disponibilizadas em uma Árvore de Falhas limitou a representação temporal de ocorrência destes eventos, já que a precedência na execução das tarefas não é detectada pela Árvore de Falhas. A Figura 32 poderia ser utilizada com ponto de partida para esta modelagem.

Nem todos os fatores humanos relacionados ao sistema estudado foram considerados na modelagem. O estudo de caso tratou somente das atividades realizadas por operadores (isto é, tripulação do navio e pessoal de terra com quem eles se relacionam, em um navio já na fase operacional). Por exemplo, fatores relacionados ao projeto do navio - ligados a erros de projetos, que também são humanos - não foram considerados profundamente e os erros relacionados às decisões dos gerentes e administradores da empresa foram considerados apenas indiretamente, através dos MOF. Assim, entre as propostas para continuação desta pesquisa, poderia ser examinada a expansão da modelagem do sistema considerando a fase de projeto, o gerenciamento, os períodos de manutenção, etc., e sua influência sobre a fase operacional do navio.

Outro ponto que poderia ser considerado para incremento desta pesquisa, é o método de preenchimento das TPC. Poderiam ser consultadas as opiniões de especialistas para popular as TPC e assim obter as probabilidades de colisão e de falhas nas tarefas com base nestas opiniões - ressaltando-se que os resultados seriam mais robustos se as áreas listadas no parágrafo anterior fossem mais bem detalhadas -, utilizando um procedimento de coleta e organização da informação 
que considere o trabalho com as Redes Bayesianas. Por outro lado, pode ser proveitoso um estudo sobre o aproveitamento das bases de dados oriundos de outras técnicas.

Ainda entre as propostas para trabalhos futuros, pode ser incluído o estudo da operação de alívio da plataforma (offload, não considerada neste trabalho) que demonstrou boa dependência do elemento humano, com os agravantes da interação entre as tripulações e da proximidade das unidades envolvidas neste procedimento (navio e plataforma). 


\section{REFERÊNCIAS}

Beldford, T.; Cooke, R., (2001), "Probabilistic Risk Analysis: Foundations and Methods", Cambridge University Press. 1st edition.

Chang, Y. H.; Mosleh, A., (2007), "Cognitive Modeling and Dynamic Probabilistic Simulation of Operating Crew Response to Complex System Accidents. Part 1: Overview of the IDAC Model", Reliability Engineering and System Safety, v.92, p.997-1013.

Chang, Y. H.; Mosleh, A., (2007b), "Cognitive Modeling and Dynamic Probabilistic Simulation of Operating Crew Response to Complex System Accidents. Part 2: IDAC Performance Influencing Factors Model", Reliability Engineering and System Safety, v.92, p.1014-1040.

Chang, Y. H.; Mosleh, A., (2007c), "Cognitive Modeling and Dynamic Probabilistic Simulation of Operating Crew Response to Complex System Accidents. Part 3: IDAC Operator Response Model", Reliability Engineering and System Safety, v.92, p.10411060.

Chang, Y. H.; Mosleh, A., (2007d), "Cognitive Modeling and Dynamic Probabilistic Simulation of Operating Crew Response to Complex System Accidents. Part 4: IDAC Causal Model of Operator Problem-solving Response", Reliability Engineering and System Safety, v.92, p.1061-1075.

Chang, Y. H.; Mosleh, A., (2007e), "Cognitive Modeling and Dynamic Probabilistic Simulation of Operating Crew Response to Complex System Accidents. Part 5: Dynamic Probabilistic Simulation of the IDAC Model", Reliability Engineering and System Safety, v.92, p.1076-1101.

Charniak, E., (1991), "Bayesian Network without Tears”. IA Magazine, USA.

Droguett, E.; Menêzes, R., (2007), "Análise de Confiabilidade Humana via redes Bayesianas: uma Aplicação à Manutenção de Linhas de Transmissão", Revista Produção, v.17, n.1, p.162-185.

Eaton, J.; Bateman, D.; Hauberg, S., (2008) "GNU Octave Manual Version 3", Disponível em: http://www.network-theory.co.uk/docs/octave3 (Acessado em 15/06/2009).

Eleye-Datubo, A.; Wall, A.; Wang ,J., (2008), "Marine and Offshore Safety Assessment by Incorporative Risk Modeling in a Fuzzy-Bayesian Network of an Induced Mass Assignment Paradigm", Risk Analysis, v. 28, n.1, p. 95-112. 
General Accounting Office, (1980), "Three Mile Island: The Most Studied Nuclear Accident In History", Report of the Comptroller General to the U.S. Congress, EMD80-109.

Gertman, I.; Blackman S., (1993), "Human Reliability Analysis and Safety Analysis Data Handbook", New York, Johnwiley \& Sons, Inc.

Hollnagel, E. (1998) "Cognitive reliability and error analysis method: CREAM" Elsevier Science.

Hollnagel, E., (2005), "Human Reliability Assessment in Context", Nuclear Engineering and Technology, vol.37 no.2.

IAEA, (1992), "Procedures for Conducting Probabilistic Safety Assessment of Nuclear Power Plants (Level 1): A Safety Practice", Safety Series, No. 50-P-4, Vienna: International Atomic Energy Agency.

IAEA, (1995), "Procedures for Conducting Probabilistic Safety Assessment of Nuclear Power Plants (Level 2): Accident Progression, Containment Analysis and Estimation of Accident Source Terms", Safety Series, No. 50-P-8, Vienna: International Atomic Energy Agency.

IMO, (2002), "Guidelines for Formal Safety Assessment for use in the IMO rulemaking process", Maritime Safety Committee and Marine Environment Protection Committee, London.

IMO, (2002b), "International Safety Management Code (ISM Code)", London.

Kirwan, B. (1994), "A Guide to Practical Human Reliability Assessment”, CPC Press.

Lampis, M., Andrews, J. D., (2008), "Bayesian Belief Networks for System Fault Diagnostics", Department of Aeronautical and Automotive Engineering, Loughborough University, U.K. Wiley InterScience.

Marques, R. L., Dutra, I., (2006), "Redes Bayesianas: o que são, para que servem, algoritmos e exemplos de aplicações". Coppe Sistemas - UFRJ. Disponível em: http://www.cos.ufrj.br/ ines/courses/cos740/leila/cos740/Bayesianas.pdf (acessado em 25/09/2008).

Martins, M.; Goyano, F., (2007), "Preliminary Hazard Analysis of fire systems of tankers", ISOPE-2007.

Maturana, M. C.; Martins, M. R., (2008), "Análise da Falha Humana em Acidentes de Colisão", 22ª Congresso de Nacional de Transporte Aquaviário, Construção Naval e Offshore - Sobena 2008, p. 1-15. 
Mosleh, A.; Chang, Y. H., (2004), "Model-based Human Reliability Analysis: Prospects and Requirements", Reliability Engineering and System Safety, v.83, p.241-253.

Norsys Software Corp., (1996), "Application for Belief Networks and Influence Diagrams", User's Guide, Vancouver, BC, Canada. Disponível em: http://www.norsys.com (acessado em 06/06/2008).

NUREG/CR-6350, (1996), "A Technique for Human Error Analysis: ATHEANA", Nuclear Regulatory Commission, Washington, DC.

NUREG-0492 (1981), "Fault Tree Handbook", U. S. Nuclear Regulatory Commission, Washington, DC.

NUREG-1880 (2007), "ATHEANA User's Guide”, U. S. Nuclear Regulatory Commission, Washington, DC.

NUREG-75/014 (1975), "Reactor Safety Study: An Assessment of Accident Risks in US Commercial Nuclear power Plants", U. S. Nuclear Regulatory Commission, Washington, DC.

Pear, J., (1988), "Probabilistic Reasoning in Intelligent Systems: Network of Plausive Inference", Morgan Kaufmann, San Mateo, California, USA.

Russell, S. J., Norvig, P. (2003) "Artificial Intelligence - A Modern Approach", Second Edition, Prentice Hall, New Jersey, USA.

Salmon, P., Stanton, N.A., Walker, G. (2003), "Human Factors Design Methods Review". Defence Technology Centre. Disponível em: http://www.hfidtc.com/pdf/reports/Human\%20Factors\%20design\%20methods\%20revi ew.pdf (acessado em 15/06/2009).

Swain, A.; Guttman, H., (1983), "Handbook of Human Reliability Analysis with Emphasis on Nuclear Power Plant Applications", Albuquerque: Sandia National Laboratories.

Webb, R. D. G., Lamoureux, T. M. (2003), "Human Reliability and Ship Stability", Department of National Defense, Toronto, Ontario, Canada. Disponível em: http://pubs.rddc-drdc.gc.ca/BASIS/pcandid/www/engpub/DDW?W\%3DAUTHOR +\%3D+'Lamoureux\%2C+T.M.'\%26M\%3D2\%26K\%3D521120\%26U\%3D1 (acessado em 05/12/2008). 


\section{APÊNDICE A: TABELAS COMPLEMENTARES PARA OS FATORES DE DESEMPENHO}

Neste tópico são apresentadas as tabelas utilizadas para a geração das redes dos fatores de desempenho. As atividades a que se relacionam são indicadas pelo número do evento e pelo número da atividade (ver Tabela 16).

Tabela 48 - Atividade 6-1: Falha do Procedimento RIPEAM

\begin{tabular}{|c|c|c|c|}
\hline Habilidades Requeridas & & PSF & MOF \\
\hline \multirow{5}{*}{$\begin{array}{l}\text { IV - Conhecimento de } \\
\text { Procedimento }\end{array}$} & \multirow{5}{*}{ Internos } & 20 - Personalidade e Inteligência & J-Seleção de Pessoal \\
\hline & & \multirow{2}{*}{22 - Conhecimento das Normas } & B - Formalização \\
\hline & & & $\mathrm{L}-$ Proqramas de treinamento \\
\hline & & \multirow{2}{*}{$\begin{array}{l}26 \text { - Estado atual desta prática } \\
\text { (Memórias) }\end{array}$} & C - Coordenação do Trabalho \\
\hline & & & K - Rotatividade de Pessoal \\
\hline \multirow{2}{*}{ VIII - Equipe e Comunicação } & \multirow[b]{2}{*}{ Internos } & \multirow{2}{*}{$\begin{array}{l}9 \text { - Tratamento dispensado à falha } \\
\text { (perda de empreao) } \\
24 \text { - Habilidade }\end{array}$} & D - Cultura Organizacional \\
\hline & & & H - Avaliacão de Rendimento \\
\hline \multirow{3}{*}{ X - Percepção } & \multirow{3}{*}{ Internos } & 4 - Qualidade do Sono & A - Carga de Trabalho \\
\hline & & \multirow[b]{2}{*}{5 - Condição Física } & C - Coordenacão do Trabalho \\
\hline & & & G - Qualidade de Vida \\
\hline
\end{tabular}

Tabela 49 - Atividade 10-1: Decidir Fazer Contato por Rádio

\begin{tabular}{|c|c|c|c|}
\hline Habilidades Requeridas & & PSF & MOF \\
\hline \multirow{5}{*}{ I - Interpretações } & \multirow{5}{*}{ Internos } & \multirow{2}{*}{1 - Fadiga } & A - Carga de Trabalho \\
\hline & & & I-Programas da Companhia \\
\hline & & 20 - Personalidade e Inteligência & J-Seleção de Pessoal \\
\hline & & \multirow[b]{2}{*}{21 - Motivação e Atitude } & A - Carga de Trabalho \\
\hline & & & $\begin{array}{l}\text { E - Prêmios, Reconhecimentos } \\
\text { e Benefícios }\end{array}$ \\
\hline \multirow{5}{*}{$\begin{array}{l}\text { IV - Conhecimento de } \\
\text { Procedimento }\end{array}$} & \multirow{5}{*}{ Internos } & 20 - Personalidade e Inteligência & J-Seleção de Pessoal \\
\hline & & \multirow{2}{*}{22 - Conhecimento das Normas } & B - Formalização \\
\hline & & & $\mathrm{L}$-Programas de treinamento \\
\hline & & \multirow{2}{*}{$\begin{array}{l}26 \text { - Estado atual desta prática } \\
\text { (Memórias) }\end{array}$} & C - Coordenação do Trabalho \\
\hline & & & $\mathrm{K}$ - Rotatividade de Pessoal \\
\hline \multirow{3}{*}{ VIII - Equipe e Comunicação } & \multirow{3}{*}{ Internos } & \multirow{3}{*}{$\begin{array}{l}9 \text { - Tratamento dispensado à falha } \\
\text { (perda de emprego) } \\
24-\text { Habilidade }\end{array}$} & D - Cultura Organizacional \\
\hline & & & $\mathrm{H}-$ Avaliação de Rendimento \\
\hline & & & $\mathrm{L}$ - Programas de treinamento \\
\hline
\end{tabular}

Tabela 50 - Atividade 10-2: Conseguir Fazer Contato

\begin{tabular}{|c|c|c|c|}
\hline Habilidades Requeridas & & PSF & MOF \\
\hline \multirow{4}{*}{ III - Concentração } & \multirow{4}{*}{ Internos } & \multirow{2}{*}{4 - Qualidade do Sono } & A - Carga de Trabalho \\
\hline & & & C - Coordenação do Trabalho \\
\hline & & \multirow{2}{*}{12 - Distrações } & C - Coordenação do Trabalho \\
\hline & & & F-Recursos Físicos \\
\hline \multirow{5}{*}{$\begin{array}{l}\text { IV - Conhecimento de } \\
\text { Procedimento }\end{array}$} & \multirow{5}{*}{ Internos } & 20 - Personalidade e Inteligência & J-Seleção de Pessoal \\
\hline & & \multirow{2}{*}{22 - Conhecimento das Normas } & B - Formalização \\
\hline & & & $\mathrm{L}-$ Programas de treinamento \\
\hline & & \multirow{2}{*}{$\begin{array}{l}26 \text { - Estado atual desta prática } \\
\text { (Memórias) }\end{array}$} & C - Coordenação do Trabalho \\
\hline & & & $\mathrm{K}$ - Rotatividade de Pessoal \\
\hline \multirow{3}{*}{ VIII - Equipe e Comunicação } & \multirow{3}{*}{ Internos } & \multirow{3}{*}{$\begin{array}{l}\text { 9- Tratamento dispensado à falha } \\
\text { (perda de emprego) } \\
24 \text { - Habilidade }\end{array}$} & $\mathrm{D}$ - Cultura Organizacional \\
\hline & & & $\mathrm{H}-$ Avaliação de Rendimento \\
\hline & & & $\mathrm{L}-$ Programas de treinamento \\
\hline
\end{tabular}

Tabela 51 - Atividade 10-3: Entender Interlocutor

\begin{tabular}{|c|c|c|c|}
\hline Habilidades Requeridas & & PSF & MOF \\
\hline \multirow{4}{*}{ III - Concentração } & \multirow{4}{*}{ Internos } & \multirow{2}{*}{4 - Qualidade do Sono } & A - Carga de Trabalho \\
\hline & & & C-Coordenação do Trabalho \\
\hline & & \multirow{2}{*}{12 - Distrações } & C - Coordenação do Trabalho \\
\hline & & & F-Recursos Físicos \\
\hline \multirow{5}{*}{ X - Percepção } & \multirow{5}{*}{ Internos } & \multirow{2}{*}{4 - Qualidade do Sono } & A - Carga de Trabalho \\
\hline & & & C - Coordenação do Trabalho \\
\hline & & \multirow{3}{*}{5 - Condição Física } & A - Carga de Trabalho \\
\hline & & & G-Qualidade de Vida \\
\hline & & & J - Seleção de Pessoal \\
\hline
\end{tabular}


Tabela 52 - Atividade 10-4: Decidir Fazer Contato por Outro Meio

\begin{tabular}{|c|c|c|c|}
\hline Habilidades Requeridas & & PSF & MOF \\
\hline \multirow{5}{*}{ I - Interpretações } & \multirow{5}{*}{ Internos } & \multirow{2}{*}{1 - Fadiga } & A - Carga de Trabalho \\
\hline & & & I-Programas da Companhia \\
\hline & & 20 - Personalidade e Inteligência & J-Seleção de Pessoal \\
\hline & & \multirow[b]{2}{*}{21 - Motivação e Atitude } & A - Carga de Trabalho \\
\hline & & & $\begin{array}{l}\text { E - Prêmios, Reconhecimentos } \\
\text { e Benefícios }\end{array}$ \\
\hline \multirow{5}{*}{$\begin{array}{l}\text { IV - Conhecimento de } \\
\text { Procedimento }\end{array}$} & \multirow{5}{*}{ Internos } & 20 - Personalidade e Inteligência & J-Seleção de Pessoal \\
\hline & & \multirow{2}{*}{22 - Conhecimento das Normas } & B - Formalização \\
\hline & & & $\mathrm{L}-$ Programas de treinamento \\
\hline & & \multirow{2}{*}{$\begin{array}{l}26 \text { - Estado atual desta prática } \\
\text { (Memórias) }\end{array}$} & C - Coordenação do Trabalho \\
\hline & & & K - Rotatividade de Pessoal \\
\hline \multirow{5}{*}{ XIV - Flexibilidade } & \multirow{5}{*}{ Internos } & \multirow{2}{*}{$\begin{array}{l}9 \text { - Tratamento dispensado à falha } \\
\text { (perda de emprego) }\end{array}$} & D - Cultura Organizacional \\
\hline & & & $\mathrm{H}-$ Avaliação de Rendimento \\
\hline & & 20 - Personalidade e Inteligência & J-Seleção de Pessoal \\
\hline & & \multirow[b]{2}{*}{21 - Motivação e Atitude } & A - Carga de Trabalho \\
\hline & & & $\begin{array}{l}\text { E-Prêmios, Reconhecimentos } \\
\text { e Benefícios }\end{array}$ \\
\hline
\end{tabular}

Tabela 53 - Atividade 10-5: Entender Interlocutor

\begin{tabular}{|c|c|c|c|}
\hline Habilidades Requeridas & & PSF & MOF \\
\hline \multirow{4}{*}{ III - Concentração } & \multirow{4}{*}{ Internos } & \multirow{2}{*}{4 - Qualidade do Sono } & A - Carga de Trabalho \\
\hline & & & C - Coordenação do Trabalho \\
\hline & & \multirow{2}{*}{12 - Distrações } & C - Coordenação do Trabalho \\
\hline & & & F-Recursos Físicos \\
\hline \multirow{5}{*}{ X - Percepção } & \multirow{4}{*}{ Internos } & \multirow[t]{2}{*}{4 - Qualidade do Sono } & A - Carga de Trabalho \\
\hline & & & C - Coordenação do Trabalho \\
\hline & & \multirow{2}{*}{5 - Condição Física } & G-Qualidade de Vida \\
\hline & & & J-Seleção de Pessoal \\
\hline & Ambientais & $\eta$ - Visibilidade & \\
\hline
\end{tabular}

Tabela 54 - Atividade 11-1: Entende Corretamente

\begin{tabular}{|c|c|c|c|}
\hline Habilidades Requeridas & & PSF & MOF \\
\hline \multirow{4}{*}{ III - Concentração } & \multirow{4}{*}{ Internos } & \multirow{2}{*}{4 - Qualidade do Sono } & A - Carga de Trabalho \\
\hline & & & C - Coordenação do Trabalho \\
\hline & & \multirow{2}{*}{12 - Distrações } & C - Coordenação do Trabalho \\
\hline & & & F-Recursos Físicos \\
\hline \multirow{6}{*}{ X - Percepção } & \multirow{5}{*}{ Internos } & \multirow{2}{*}{4 - Qualidade do Sono } & A - Carga de Trabalho \\
\hline & & & C - Coordenação do Trabalho \\
\hline & & \multirow{3}{*}{5 - Condição Física } & A - Carga de Trabalho \\
\hline & & & G - Qualidade de Vida \\
\hline & & & J-Seleção de Pessoal \\
\hline & Ambientais & $\eta$-Visibilidade & \\
\hline
\end{tabular}

Tabela 55 - Atividade 11-2: Tomada de Decisão

\begin{tabular}{|c|c|c|c|}
\hline Habilidades Requeridas & & PSF & MOF \\
\hline \multirow{5}{*}{ I - Interpretações } & \multirow{5}{*}{ Internos } & \multirow{2}{*}{1 - Fadiga } & A - Carga de Trabalho \\
\hline & & & I-Programas da Companhia \\
\hline & & 20 - Personalidade e Inteligência & J-Seleção de Pessoal \\
\hline & & \multirow[b]{2}{*}{21 - Motivação e Atitude } & A - Carga de Trabalho \\
\hline & & & $\begin{array}{l}\text { E - Prêmios, Reconhecimentos } \\
\text { e Benefícios }\end{array}$ \\
\hline \multirow{4}{*}{$\mathrm{XI}$ - Planejamento } & \multirow{4}{*}{ Internos } & 20 - Personalidade e Inteligência & J-Seleção de Pessoal \\
\hline & & \multirow{3}{*}{24 - Habilidade } & $\mathrm{H}-$ Avaliação de Rendimento \\
\hline & & & $\mathrm{J}$-Seleção de Pessoal \\
\hline & & & $\mathrm{L}$ - Programas de Treinamento \\
\hline \multirow{5}{*}{ XIV - Flexibilidade } & \multirow{5}{*}{ Internos } & \multirow{2}{*}{$\begin{array}{l}\text { 9- Tratamento dispensado à falha } \\
\text { (perda de emprego) }\end{array}$} & D - Cultura Organizacional \\
\hline & & & $\mathrm{H}-$ Avaliação de Rendimento \\
\hline & & 20 - Personalidade e Inteligência & J-Seleção de Pessoal \\
\hline & & \multirow[b]{2}{*}{21 - Motivação e Atitude } & A - Carga de Trabalho \\
\hline & & & $\begin{array}{l}\text { E - Prêmios, Reconhecimentos } \\
\text { e Benefícios }\end{array}$ \\
\hline
\end{tabular}


Tabela 56 - Atividade 11-3: Detecção do Erro

\begin{tabular}{|c|c|c|c|}
\hline Habilidades Requeridas & & PSF & MOF \\
\hline \multirow{4}{*}{ III - Concentração } & \multirow{4}{*}{ Internos } & \multirow{2}{*}{4 - Qualidade do Sono } & A - Carga de Trabalho \\
\hline & & & C - Coordenação do Trabalho \\
\hline & & \multirow{2}{*}{12 - Distrações } & C-Coordenação do Trabalho \\
\hline & & & F-Recursos Físicos \\
\hline \multirow{5}{*}{ X - Percepção } & \multirow{5}{*}{ Internos } & \multirow{2}{*}{4 - Qualidade do Sono } & A - Carga de Trabalho \\
\hline & & & C - Coordenação do Trabalho \\
\hline & & \multirow{3}{*}{5 - Condição Física } & A - Carga de Trabalho \\
\hline & & & G-Qualidade de Vida \\
\hline & & & $\mathrm{J}$-Seleção de Pessoal \\
\hline \multirow{3}{*}{ VIII - Equipe e Comunicação } & \multirow{3}{*}{ Internos } & \multirow{3}{*}{$\begin{array}{l}\text { 9- Tratamento dispensado à falha } \\
\text { (perda de emprego) } \\
24 \text { - Habilidade }\end{array}$} & D - Cultura Organizacional \\
\hline & & & $\mathrm{H}-$ Avaliação de Rendimento \\
\hline & & & $\mathrm{L}-$ Programas de treinamento \\
\hline
\end{tabular}

Tabela 57 - Atividade 14-1: Resposta Errada

\begin{tabular}{|c|c|c|c|}
\hline Habilidades Requeridas & & PSF & MOF \\
\hline \multirow{4}{*}{ III - Concentração } & \multirow{4}{*}{ Internos } & \multirow{2}{*}{4 - Qualidade do Sono } & A - Carga de Trabalho \\
\hline & & & C - Coordenação do Trabalho \\
\hline & & \multirow{2}{*}{12 - Distrações } & C - Coordenação do Trabalho \\
\hline & & & F-Recursos Físicos \\
\hline \multirow{8}{*}{ VII - Controle Motor } & \multirow{8}{*}{ Internos } & \multirow{2}{*}{1 - Fadiga } & A - Carga de Trabalho \\
\hline & & & C - Coordenação do Trabalho \\
\hline & & \multirow{3}{*}{5 - Condição Física } & A - Carga de Trabalho \\
\hline & & & G-Qualidade de Vida \\
\hline & & & J-Seleção de Pessoal \\
\hline & & \multirow{3}{*}{24 - Habilidade } & $\mathrm{H}-$ Avaliação de Rendimento \\
\hline & & & $\mathrm{L}-$ Programas de treinamento \\
\hline & & & $\mathrm{J}$-Seleção de Pessoal \\
\hline \multirow{3}{*}{ VIII - Equipe e Comunicação } & \multirow{3}{*}{ Internos } & \multirow{3}{*}{$\begin{array}{l}\text { 9- Tratamento dispensado à falha } \\
\text { (perda de emprego) } \\
24 \text { - Habilidade }\end{array}$} & D - Cultura Organizacional \\
\hline & & & $\mathrm{H}$ - Avaliação de Rendimento \\
\hline & & & $\mathrm{L}$ - Programas de treinamento \\
\hline
\end{tabular}

Tabela 58 - Atividade 23-1: Entende Corretamente

\begin{tabular}{|c|c|c|c|}
\hline Habilidades Requeridas & & PSF & MOF \\
\hline \multirow{4}{*}{ III - Concentração } & \multirow{4}{*}{ Internos } & \multirow{2}{*}{4 - Qualidade do Sono } & A - Carga de Trabalho \\
\hline & & & C - Coordenação do Trabalho \\
\hline & & \multirow{2}{*}{12 - Distrações } & C - Coordenação do Trabalho \\
\hline & & & F-Recursos Físicos \\
\hline \multirow{6}{*}{ X - Percepção } & \multirow{5}{*}{ Internos } & \multirow{2}{*}{4 - Qualidade do Sono } & A - Carga de Trabalho \\
\hline & & & C - Coordenação do Trabalho \\
\hline & & \multirow{3}{*}{5 - Condição Física } & A - Carga de Trabalho \\
\hline & & & G-Qualidade de Vida \\
\hline & & & $\mathrm{J}$-Seleção de Pessoal \\
\hline & Ambientais & $\eta$-Visibilidade & \\
\hline
\end{tabular}

Tabela 59 - Atividade 23-2: Tomada de Decisão

\begin{tabular}{|c|c|c|c|}
\hline Habilidades Requeridas & & PSF & MOF \\
\hline \multirow{5}{*}{ I - Interpretações } & \multirow{5}{*}{ Internos } & \multirow{2}{*}{1 - Fadiga } & A - Carga de Trabalho \\
\hline & & & I-Programas da Companhia \\
\hline & & 20 - Personalidade e Inteligência & J-Seleção de Pessoal \\
\hline & & \multirow[b]{2}{*}{21 - Motivação e Atitude } & A - Carga de Trabalho \\
\hline & & & $\begin{array}{l}\text { E - Prêmios, Reconhecimentos } \\
\text { e Benefícios }\end{array}$ \\
\hline \multirow{4}{*}{$\mathrm{XI}$ - Planejamento } & \multirow{4}{*}{ Internos } & 20 - Personalidade e Inteligência & J-Seleção de Pessoal \\
\hline & & \multirow{3}{*}{24 - Habilidade } & $\mathrm{H}-$ Avaliação de Rendimento \\
\hline & & & $\mathrm{J}$-Seleção de Pessoal \\
\hline & & & L-Programas de Treinamento \\
\hline \multirow{5}{*}{ XIV - Flexibilidade } & \multirow{5}{*}{ Internos } & \multirow{2}{*}{$\begin{array}{l}\text { 9- Tratamento dispensado à falha } \\
\text { (perda de emprego) }\end{array}$} & D - Cultura Organizacional \\
\hline & & & $\mathrm{H}$ - Avaliação de Rendimento \\
\hline & & 20 - Personalidade e Inteligência & J - Seleção de Pessoal \\
\hline & & \multirow[b]{2}{*}{21 - Motivação e Atitude } & A - Carga de Trabalho \\
\hline & & & $\begin{array}{l}\text { E - Prêmios, Reconhecimentos } \\
\text { e Benefícios }\end{array}$ \\
\hline
\end{tabular}


Tabela 60 - Atividade 23-3: Detecção do Erro

\begin{tabular}{|c|c|c|c|}
\hline Habilidades Requeridas & \multicolumn{2}{|c|}{ PSF } & MOF \\
\hline \multirow{4}{*}{ III - Concentração } & \multirow{4}{*}{ Internos } & \multirow{2}{*}{4 - Qualidade do Sono } & A - Carga de Trabalho \\
\hline & & & C - Coordenação do Trabalho \\
\hline & & \multirow{2}{*}{12 - Distrações } & C - Coordenação do Trabalho \\
\hline & & & F-Recursos Físicos \\
\hline \multirow{5}{*}{ X - Percepção } & \multirow{5}{*}{ Internos } & \multirow{2}{*}{4 - Qualidade do Sono } & A - Carga de Trabalho \\
\hline & & & C - Coordenação do Trabalho \\
\hline & & \multirow{3}{*}{5 - Condição Física } & A - Carga de Trabalho \\
\hline & & & G - Qualidade de Vida \\
\hline & & & $\mathrm{J}$-Seleção de Pessoal \\
\hline \multirow{3}{*}{ VIII - Equipe e Comunicação } & \multirow{3}{*}{ Internos } & \multirow{3}{*}{$\begin{array}{l}\text { 9- Tratamento dispensado à falha } \\
\text { (perda de emprego) } \\
24 \text { - Habilidade }\end{array}$} & D - Cultura Organizacional \\
\hline & & & $\mathrm{H}-$ Avaliação de Rendimento \\
\hline & & & $\mathrm{L}-$ Programas de treinamento \\
\hline
\end{tabular}

Tabela 61 - Atividade 25-1: Resposta Errada

\begin{tabular}{|c|c|c|c|}
\hline Habilidades Requeridas & & PSF & MOF \\
\hline \multirow{4}{*}{ III - Concentração } & \multirow{4}{*}{ Internos } & \multirow{2}{*}{4 - Qualidade do Sono } & A - Carga de Trabalho \\
\hline & & & C - Coordenação do Trabalho \\
\hline & & \multirow{2}{*}{12 - Distrações } & C - Coordenação do Trabalho \\
\hline & & & F-Recursos Físicos \\
\hline \multirow{8}{*}{ VII - Controle Motor } & \multirow{8}{*}{ Internos } & \multirow{2}{*}{1 - Fadiga } & A - Carga de Trabalho \\
\hline & & & C - Coordenação do Trabalho \\
\hline & & \multirow{3}{*}{5 - Condição Física } & A - Carga de Trabalho \\
\hline & & & G-Qualidade de Vida \\
\hline & & & J-Seleção de Pessoal \\
\hline & & \multirow{3}{*}{24 - Habilidade } & $\mathrm{H}-$ Avaliação de Rendimento \\
\hline & & & $\mathrm{L}$ - Programas de treinamento \\
\hline & & & $\mathrm{J}$-Seleção de Pessoal \\
\hline \multirow{3}{*}{ VIII - Equipe e Comunicação } & \multirow{3}{*}{ Internos } & \multirow{3}{*}{$\begin{array}{l}\text { 9- Tratamento dispensado à falha } \\
\text { (perda de emprego) } \\
24 \text { - Habilidade }\end{array}$} & D - Cultura Organizacional \\
\hline & & & $\mathrm{H}$ - Avaliação de Rendimento \\
\hline & & & $\mathrm{L}$ - Programas de treinamento \\
\hline
\end{tabular}

Tabela 62 - Atividade 29-1: Checagem de Equipamento

\begin{tabular}{|c|c|c|c|}
\hline Habilidades Requeridas & & PSF & MOF \\
\hline \multirow{5}{*}{ III - Concentração } & \multirow{5}{*}{ Internos } & \multirow{2}{*}{4 - Qualidade do Sono } & A - Carga de Trabalho \\
\hline & & & C - Coordenação do Trabalho \\
\hline & & 10 - Trabalho Monótono & C - Coordenação do Trabalho \\
\hline & & \multirow{2}{*}{12 - Distrações } & C - Coordenação do Trabalho \\
\hline & & & F-Recursos Físicos \\
\hline \multirow{2}{*}{$\begin{array}{l}\text { IV - Conhecimento dos } \\
\text { Procedimentos }\end{array}$} & \multirow{2}{*}{ Internos } & \multirow{2}{*}{23 - Experiência e Treinamento } & $\mathrm{K}$ - Rotatividade de Pessoal \\
\hline & & & $\mathrm{L}-$ Programas de Treinamento \\
\hline \multirow{5}{*}{ X - Percepção } & \multirow{5}{*}{ Internos } & \multirow{2}{*}{4 - Qualidade do Sono } & A - Carga de Trabalho \\
\hline & & & C - Coordenação do Trabalho \\
\hline & & \multirow{3}{*}{5 - Condição Física } & A - Carga de Trabalho \\
\hline & & & G-Qualidade de Vida \\
\hline & & & $\mathrm{J}$-Seleção de Pessoal \\
\hline
\end{tabular}

Tabela 63 - Atividade 29-3: Respeito dos Intervalos

\begin{tabular}{|l|l|l|l|}
\hline Habilidades Requeridas & \multicolumn{1}{|c|}{ PSF } & \multicolumn{1}{c|}{ MOF } \\
\hline \multirow{4}{*}{ IX - Frequência e Repetitividade } & \multirow{4}{*}{ Internos } & $4-$ Qualidade do Sono & A - Carga de Trabalho \\
\cline { 3 - 4 } & & C - Coordenação do Trabalho \\
\cline { 3 - 4 } & & 10-Trabalho Monótono & C - Coordenação do Trabalho \\
\cline { 3 - 4 } & & C - Distrações & F - Coordenação do Trabalho \\
\cline { 3 - 4 } & &
\end{tabular}

Tabela 64 - Atividade 29-4: Leitura de posição

\begin{tabular}{|c|c|c|c|}
\hline Habilidades Requeridas & & PSF & MOF \\
\hline \multirow{5}{*}{ III - Concentração } & \multirow{5}{*}{ Internos } & \multirow{2}{*}{4 - Qualidade do Sono } & A - Carga de Trabalho \\
\hline & & & C - Coordenação do Trabalho \\
\hline & & 10 - Trabalho Monótono & C - Coordenação do Trabalho \\
\hline & & \multirow{2}{*}{12 - Distrações } & C - Coordenação do Trabalho \\
\hline & & & F-Recursos Físicos \\
\hline \multirow{5}{*}{ X - Percepção } & \multirow{5}{*}{ Internos } & \multirow{2}{*}{4 - Qualidade do Sono } & A - Carga de Trabalho \\
\hline & & & C - Coordenação do Trabalho \\
\hline & & \multirow{3}{*}{5 - Condição Física } & A - Carga de Trabalho \\
\hline & & & G - Qualidade de Vida \\
\hline & & & $\mathrm{J}$-Seleção de Pessoal \\
\hline
\end{tabular}


Tabela 65 - Atividade 29-5: Marcação na Carta Náutica

\begin{tabular}{|c|c|c|c|}
\hline Habilidades Requeridas & & PSF & MOF \\
\hline \multirow{5}{*}{ III - Concentração } & \multirow{5}{*}{ Internos } & \multirow{2}{*}{4 - Qualidade do Sono } & A - Carga de Trabalho \\
\hline & & & C - Coordenação do Trabalho \\
\hline & & 10 - Trabalho Monótono & C - Coordenação do Trabalho \\
\hline & & \multirow{2}{*}{12 - Distrações } & C - Coordenação do Trabalho \\
\hline & & & F-Recursos Físicos \\
\hline \multirow{5}{*}{ VII - Controle Motor } & \multirow{5}{*}{ Internos } & \multirow{2}{*}{4 - Qualidade do Sono } & A - Carga de Trabalho \\
\hline & & & C - Coordenação do Trabalho \\
\hline & & \multirow{3}{*}{5 - Condição Física } & A - Carga de Trabalho \\
\hline & & & G - Qualidade de Vida \\
\hline & & & J-Seleção de Pessoal \\
\hline
\end{tabular}

Tabela 66 - Atividade 29-6: Comandante Detecta o Erro

\begin{tabular}{|c|c|c|c|}
\hline Habilidades Requeridas & & PSF & MOF \\
\hline \multirow{5}{*}{ III - Concentração } & \multirow{5}{*}{ Internos } & \multirow{2}{*}{4 - Qualidade do Sono } & A - Carga de Trabalho \\
\hline & & & C - Coordenação do Trabalho \\
\hline & & 10 - Trabalho Monótono & C - Coordenação do Trabalho \\
\hline & & \multirow{2}{*}{12 - Distrações } & C-Coordenação do Trabalho \\
\hline & & & F-Recursos Físicos \\
\hline \multirow{5}{*}{ X - Percepção } & \multirow{5}{*}{ Internos } & \multirow{2}{*}{4 - Qualidade do Sono } & A - Carga de Trabalho \\
\hline & & & C - Coordenação do Trabalho \\
\hline & & \multirow{3}{*}{5 - Condição Física } & A - Carga de Trabalho \\
\hline & & & G - Qualidade de Vida \\
\hline & & & J-Seleção de Pessoal \\
\hline \multirow{3}{*}{ VIII - Equipe e Comunicação } & \multirow{3}{*}{ Internos } & \multirow{3}{*}{$\begin{array}{l}\text { 9- Tratamento dispensado à falha } \\
\text { (perda de emprego) } \\
24 \text { - Habilidade }\end{array}$} & D - Cultura Organizacional \\
\hline & & & $\mathrm{H}-$ Avaliação de Rendimento \\
\hline & & & $\mathrm{L}$ - Programas de treinamento \\
\hline
\end{tabular}

Tabela 67 - Atividade 32-1: Capitão Falha

\begin{tabular}{|c|c|c|c|}
\hline Habilidades Requeridas & \multicolumn{2}{|c|}{ PSF } & MOF \\
\hline \multirow{5}{*}{ III - Concentração } & \multirow{5}{*}{ Internos } & \multirow{2}{*}{4 - Qualidade do Sono } & A - Carga de Trabalho \\
\hline & & & C - Coordenação do Trabalho \\
\hline & & 10 - Trabalho Monótono & C-Coordenação do Trabalho \\
\hline & & \multirow{2}{*}{12 - Distrações } & C - Coordenação do Trabalho \\
\hline & & & F-Recursos Físicos \\
\hline \multirow{5}{*}{ X - Percepção } & \multirow{5}{*}{ Internos } & \multirow{2}{*}{4 - Qualidade do Sono } & A - Carga de Trabalho \\
\hline & & & C - Coordenação do Trabalho \\
\hline & & \multirow{3}{*}{5 - Condição Física } & A - Carga de Trabalho \\
\hline & & & G - Qualidade de Vida \\
\hline & & & $\mathrm{J}$-Seleção de Pessoal \\
\hline \multirow{3}{*}{ VIII - Equipe e Comunicação } & \multirow{3}{*}{ Internos } & \multirow{3}{*}{$\begin{array}{l}\text { 9- Tratamento dispensado à falha } \\
\text { (perda de emprego) } \\
24 \text { - Habilidade }\end{array}$} & $\mathrm{D}$ - Cultura Organizacional \\
\hline & & & $\mathrm{H}$ - Avaliação de Rendimento \\
\hline & & & $\mathrm{L}-$ Programas de treinamento \\
\hline
\end{tabular}

\begin{tabular}{|c|c|c|c|}
\hline & \\
\hline Habilidades Requeridas & & PSF & MOF \\
\hline \multirow{5}{*}{ III - Concentração } & \multirow{5}{*}{ Internos } & \multirow{2}{*}{4 - Qualidade do Sono } & A - Carga de Trabalho \\
\hline & & & C - Coordenação do Trabalho \\
\hline & & 10 - Trabalho Monótono & C - Coordenação do Trabalho \\
\hline & & \multirow{2}{*}{12 - Distrações } & C - Coordenação do Trabalho \\
\hline & & & F-Recursos Físicos \\
\hline \multirow{5}{*}{ X - Percepção } & \multirow{5}{*}{ Internos } & \multirow{2}{*}{4 - Qualidade do Sono } & A - Carga de Trabalho \\
\hline & & & C - Coordenação do Trabalho \\
\hline & & \multirow{3}{*}{5 - Condição Física } & A-Carga de Trabalho \\
\hline & & & G-Qualidade de Vida \\
\hline & & & J-Seleção de Pessoal \\
\hline \multirow{3}{*}{ VIII - Equipe e Comunicação } & \multirow{3}{*}{ Internos } & \multirow{3}{*}{$\begin{array}{l}9-\text { Tratamento dispensado à falha } \\
\text { (perda de emprego) } \\
24 \text { - Habilidade }\end{array}$} & D - Cultura Organizacional \\
\hline & & & $\mathrm{H}-$ Avaliação de Rendimento \\
\hline & & & $\mathrm{L}$ - Programas de treinamento \\
\hline
\end{tabular}


Tabela 69 - Atividade 36-1: Erro de Atenção

\begin{tabular}{|c|c|c|c|}
\hline Habilidades Requeridas & & PSF & MOF \\
\hline \multirow{5}{*}{ III - Concentração } & \multirow{5}{*}{ Internos } & \multirow{2}{*}{4 - Qualidade do Sono } & A - Carga de Trabalho \\
\hline & & & C - Coordenação do Trabalho \\
\hline & & 10 - Trabalho Monótono & C-Coordenação do Trabalho \\
\hline & & \multirow{2}{*}{12 - Distrações } & C - Coordenação do Trabalho \\
\hline & & & F-Recursos Físicos \\
\hline \multirow{2}{*}{ VI - Resistência Física } & \multirow{2}{*}{ Internos } & \multirow{2}{*}{1 - Fadiga } & A - Carga de Trabalho \\
\hline & & & C - Coordenação do Trabalho \\
\hline \multirow{6}{*}{ X - Percepção } & \multirow{5}{*}{ Internos } & \multirow{2}{*}{4 - Qualidade do Sono } & A - Carga de Trabalho \\
\hline & & & C-Coordenação do Trabalho \\
\hline & & \multirow{3}{*}{5 - Condição Física } & A - Carga de Trabalho \\
\hline & & & G - Qualidade de Vida \\
\hline & & & $\mathrm{J}$-Seleção de Pessoal \\
\hline & Ambientais & $\eta$-Visibilidade & \\
\hline
\end{tabular}

Tabela 70 - Atividade 39-1: Erro não Descoberto

\begin{tabular}{|c|c|c|c|}
\hline Habilidades Requeridas & & PSF & MOF \\
\hline \multirow{5}{*}{ III - Concentração } & \multirow{5}{*}{ Internos } & \multirow{2}{*}{4 - Qualidade do Sono } & A - Carga de Trabalho \\
\hline & & & C - Coordenação do Trabalho \\
\hline & & 10 - Trabalho Monótono & C-Coordenação do Trabalho \\
\hline & & \multirow{2}{*}{12 - Distrações } & C-Coordenação do Trabalho \\
\hline & & & F-Recursos Físicos \\
\hline \multirow{5}{*}{ X - Percepção } & \multirow{5}{*}{ Internos } & \multirow{2}{*}{4 - Qualidade do Sono } & A - Carga de Trabalho \\
\hline & & & C - Coordenação do Trabalho \\
\hline & & \multirow{3}{*}{5 - Condição Física } & A - Carga de Trabalho \\
\hline & & & G - Qualidade de Vida \\
\hline & & & $\mathrm{J}$-Seleção de Pessoal \\
\hline \multirow{3}{*}{ VIII - Equipe e Comunicação } & \multirow{3}{*}{ Internos } & \multirow{3}{*}{$\begin{array}{l}\text { 9- Tratamento dispensado à falha } \\
\text { (perda de emprego) } \\
24 \text { - Habilidade }\end{array}$} & D - Cultura Organizacional \\
\hline & & & $\mathrm{H}$ - Avaliação de Rendimento \\
\hline & & & $\mathrm{L}$ - Programas de treinamento \\
\hline
\end{tabular}

Tabela 71 - Atividade 43-1: Atualização das Publicações

\begin{tabular}{|c|c|c|c|}
\hline Habilidades Requeridas & & PSF & MOF \\
\hline \multirow{5}{*}{ III - Concentração } & \multirow{5}{*}{ Internos } & \multirow{2}{*}{4 - Qualidade do Sono } & A - Carga de Trabalho \\
\hline & & & C - Coordenação do Trabalho \\
\hline & & 10 - Trabalho Monótono & C - Coordenação do Trabalho \\
\hline & & \multirow{2}{*}{12 - Distrações } & C - Coordenação do Trabalho \\
\hline & & & F-Recursos Físicos \\
\hline \multirow{2}{*}{ VI - Resistência Física } & \multirow{2}{*}{ Internos } & \multirow{2}{*}{1 - Fadiga } & A - Carga de Trabalho \\
\hline & & & C-Coordenação do Trabalho \\
\hline \multirow{5}{*}{ X - Percepção } & \multirow{5}{*}{ Internos } & \multirow{2}{*}{4 - Qualidade do Sono } & A - Carga de Trabalho \\
\hline & & & C - Coordenação do Trabalho \\
\hline & & \multirow{3}{*}{5 - Condição Física } & A - Carga de Trabalho \\
\hline & & & G - Qualidade de Vida \\
\hline & & & $\mathrm{J}$-Seleção de Pessoal \\
\hline
\end{tabular}

Tabela 72 - Atividade 43-2: Leitura das Informações

\begin{tabular}{|l|l|l|l|}
\hline Habilidades Requeridas & \multicolumn{1}{|c|}{ PSF } & \multicolumn{1}{c|}{ MOF } \\
\hline \multirow{4}{*}{ III - Concentração } & \multirow{4}{*}{ Internos } & \multirow{2}{*}{ - Qualidade do Sono } & A - Carga de Trabalho \\
\cline { 3 - 4 } & & C - Coordenação do Trabalho \\
\cline { 3 - 4 } & & \multirow{2}{*}{ 12 - Trabalho Monótono } & C - Coordenação do Trabalho \\
\cline { 3 - 4 } & & C - Coordenação do Trabalho \\
\cline { 3 - 4 } & & F - Recursos Físicos \\
\hline
\end{tabular}

Tabela 73 - Atividade 43-3: Estabelecimento da Profundidade Mínima

\begin{tabular}{|c|c|c|c|}
\hline Habilidades Requeridas & & PSF & MOF \\
\hline \multirow{3}{*}{ II - Cálculo } & \multirow{3}{*}{ Internos } & \multirow{2}{*}{4 - Qualidade do Sono } & A - Carga de Trabalho \\
\hline & & & C-Coordenação do Trabalho \\
\hline & & 20 - Personalidade e Inteligência & J-Seleção de Pessoal \\
\hline \multirow{5}{*}{ III - Concentração } & \multirow{5}{*}{ Internos } & \multirow{2}{*}{4 - Qualidade do Sono } & A - Carga de Trabalho \\
\hline & & & C-Coordenação do Trabalho \\
\hline & & 10 - Trabalho Monótono & C - Coordenação do Trabalho \\
\hline & & \multirow{2}{*}{12 - Distrações } & C - Coordenação do Trabalho \\
\hline & & & F-Recursos Físicos \\
\hline \multirow{5}{*}{ X - Percepção } & \multirow{5}{*}{ Internos } & \multirow{2}{*}{4 - Qualidade do Sono } & A - Carga de Trabalho \\
\hline & & & C-Coordenação do Trabalho \\
\hline & & \multirow{3}{*}{5 - Condição Física } & A - Carga de Trabalho \\
\hline & & & G-Qualidade de Vida \\
\hline & & & J-Seleção de Pessoal \\
\hline
\end{tabular}

Aplicação de Redes Bayesianas na Análise da Contribuição da Falha Humana em Acidentes de Colisão - 115 
Tabela 74 - Atividade 43-4: Leitura da Profundidade

\begin{tabular}{|l|l|l|l|}
\hline Habilidades Requeridas & \multicolumn{1}{|c|}{ PSF } & \multicolumn{1}{c|}{ MOF } \\
\hline \multirow{4}{*}{ III - Concentração } & \multirow{4}{*}{ Internos } & 4 - Qualidade do Sono & A - Carga de Trabalho \\
\cline { 3 - 4 } & & C - Coordenação do Trabalho \\
\cline { 3 - 4 } & & 12 - Trabalho Monótono & C - Coordenação do Trabalho \\
\cline { 3 - 4 } & & C - Coordenação do Trabalho \\
\cline { 3 - 4 } & & F - Recursos Físicos \\
\hline
\end{tabular}

Tabela 75 - Atividade 43-5: Identificar Áreas Restritas

\begin{tabular}{|l|l|l|l|}
\hline Habilidades Requeridas & \multicolumn{1}{|c|}{ PSF } & \multicolumn{1}{c|}{ MOF } \\
\hline \multirow{4}{*}{ III - Concentração } & \multirow{4}{*}{ Internos } & 4 - Qualidade do Sono & A - Carga de Trabalho \\
\cline { 3 - 4 } & & C - Coordenação do Trabalho \\
\cline { 3 - 4 } & & 12 - Trabalho Monótono & C - Coordenação do Trabalho \\
\cline { 3 - 4 } & & C - Coordenação do Trabalho \\
\cline { 3 - 4 } & & F - Recursos Físicos \\
\hline
\end{tabular}

Tabela 76 - Atividade 43-6: Traçar Áreas Restritas

\begin{tabular}{|c|c|c|c|}
\hline Habilidades Requeridas & & PSF & MOF \\
\hline \multirow{5}{*}{ III - Concentração } & \multirow{5}{*}{ Internos } & \multirow{2}{*}{4 - Qualidade do Sono } & A - Carga de Trabalho \\
\hline & & & C - Coordenação do Trabalho \\
\hline & & 10 - Trabalho Monótono & C - Coordenação do Trabalho \\
\hline & & \multirow{2}{*}{12 - Distrações } & C-Coordenação do Trabalho \\
\hline & & & F - Recursos Físicos \\
\hline \multirow{5}{*}{ VII - Controle Motor } & \multirow{5}{*}{ Internos } & \multirow{2}{*}{4 - Qualidade do Sono } & A - Carga de Trabalho \\
\hline & & & C - Coordenação do Trabalho \\
\hline & & \multirow{3}{*}{5 - Condição Física } & A - Carga de Trabalho \\
\hline & & & G-Qualidade de Vida \\
\hline & & & $\mathrm{J}$-Seleção de Pessoal \\
\hline
\end{tabular}

Tabela 77 - Atividade 43-7: Traçar Rumos Sucessivos

\begin{tabular}{|c|c|c|c|}
\hline Habilidades Requeridas & & PSF & MOF \\
\hline \multirow{5}{*}{ III - Concentração } & \multirow{5}{*}{ Internos } & \multirow{2}{*}{4 - Qualidade do Sono } & A - Carga de Trabalho \\
\hline & & & C - Coordenação do Trabalho \\
\hline & & 10 - Trabalho Monótono & C - Coordenação do Trabalho \\
\hline & & \multirow{2}{*}{12 - Distrações } & C - Coordenação do Trabalho \\
\hline & & & F-Recursos Físicos \\
\hline \multirow{5}{*}{ VII - Controle Motor } & \multirow{5}{*}{ Internos } & \multirow{2}{*}{4 - Qualidade do Sono } & A - Carga de Trabalho \\
\hline & & & C - Coordenação do Trabalho \\
\hline & & \multirow{3}{*}{5 - Condição Física } & A - Carga de Trabalho \\
\hline & & & G - Qualidade de Vida \\
\hline & & & J-Seleção de Pessoal \\
\hline
\end{tabular}

Tabela 78 - Atividade 43-8: Identificar Way-Points

\begin{tabular}{|c|c|c|c|}
\hline Habilidades Requeridas & & PSF & MOF \\
\hline \multirow{5}{*}{ III - Concentração } & \multirow{5}{*}{ Internos } & \multirow{2}{*}{4 - Qualidade do Sono } & A - Carga de Trabalho \\
\hline & & & C - Coordenação do Trabalho \\
\hline & & 10 - Trabalho Monótono & C - Coordenação do Trabalho \\
\hline & & \multirow{2}{*}{12 - Distrações } & C - Coordenação do Trabalho \\
\hline & & & F-Recursos Físicos \\
\hline \multirow{5}{*}{ VII - Controle Motor } & \multirow{5}{*}{ Internos } & \multirow{2}{*}{4 - Qualidade do Sono } & A - Carga de Trabalho \\
\hline & & & C - Coordenação do Trabalho \\
\hline & & \multirow{3}{*}{5 - Condição Física } & A - Carga de Trabalho \\
\hline & & & G - Qualidade de Vida \\
\hline & & & $\mathrm{J}$-Seleção de Pessoal \\
\hline
\end{tabular}

Tabela 79 - Atividade 43-9: Escolha dos Pontos

\begin{tabular}{|c|c|c|c|}
\hline Habilidades Requeridas & & PSF & MOF \\
\hline \multirow{5}{*}{ I - Interpretações } & \multirow{5}{*}{ Internos } & \multirow{2}{*}{1 - Fadiga } & A - Carga de Trabalho \\
\hline & & & I-Programas da Companhia \\
\hline & & 20 - Personalidade e Inteligência & $\mathrm{J}$-Seleção de Pessoal \\
\hline & & \multirow[b]{2}{*}{21 - Motivação e Atitude } & A - Carga de Trabalho \\
\hline & & & $\begin{array}{l}\text { E - Prêmios, Reconhecimentos } \\
\text { e Benefícios }\end{array}$ \\
\hline \multirow{2}{*}{$\begin{array}{l}\mathrm{IV} \text { - Conhecimento dos } \\
\text { Procedimentos }\end{array}$} & \multirow{2}{*}{ Internos } & \multirow{2}{*}{23 - Experiência e Treinamento } & K-Rotatividade de Pessoal \\
\hline & & & $\mathrm{L}$ - Programas de Treinamento \\
\hline \multirow{5}{*}{ X - Percepção } & \multirow{5}{*}{ Internos } & \multirow{2}{*}{4 - Qualidade do Sono } & A - Carga de Trabalho \\
\hline & & & C - Coordenação do Trabalho \\
\hline & & \multirow{3}{*}{5 - Condição Física } & A - Carga de Trabalho \\
\hline & & & G-Qualidade de Vida \\
\hline & & & J-Seleção de Pessoal \\
\hline
\end{tabular}

Aplicação de Redes Bayesianas na Análise da Contribuição da Falha Humana em Acidentes de Colisão - 116 
Departamento de Engenharia Naval e Oceânica

Escola Politécnica da USP

Tabela 80 - Atividade 43-10: Revisão da Rota ON

\begin{tabular}{|c|c|c|c|}
\hline Habilidades Requeridas & & PSF & MOF \\
\hline \multirow{5}{*}{ III - Concentração } & \multirow{5}{*}{ Internos } & \multirow{2}{*}{4 - Qualidade do Sono } & A - Carga de Trabalho \\
\hline & & & C - Coordenação do Trabalho \\
\hline & & 10 - Trabalho Monótono & C - Coordenação do Trabalho \\
\hline & & \multirow{2}{*}{12 - Distrações } & C - Coordenação do Trabalho \\
\hline & & & F-Recursos Físicos \\
\hline \multirow{5}{*}{ X - Percepção } & \multirow{5}{*}{ Internos } & \multirow{2}{*}{4 - Qualidade do Sono } & A - Carga de Trabalho \\
\hline & & & C - Coordenação do Trabalho \\
\hline & & \multirow{3}{*}{5 - Condição Física } & A - Carga de Trabalho \\
\hline & & & G - Qualidade de Vida \\
\hline & & & $\mathrm{J}$-Seleção de Pessoal \\
\hline \multirow{3}{*}{ VIII - Equipe e Comunicação } & \multirow{3}{*}{ Internos } & \multirow{3}{*}{$\begin{array}{l}\text { 9- Tratamento dispensado à falha } \\
\text { (perda de emprego) } \\
24 \text { - Habilidade }\end{array}$} & D - Cultura Organizacional \\
\hline & & & $\mathrm{H}$ - Avaliação de Rendimento \\
\hline & & & $\mathrm{L}-$ Programas de treinamento \\
\hline
\end{tabular}

Tabela 81 - Atividade 43-11: Detecção de Falha Comandante

\begin{tabular}{|c|c|c|c|}
\hline Habilidades Requeridas & & PSF & MOF \\
\hline \multirow{5}{*}{ III - Concentração } & \multirow{5}{*}{ Internos } & \multirow{2}{*}{4 - Qualidade do Sono } & A - Carga de Trabalho \\
\hline & & & C - Coordenação do Trabalho \\
\hline & & 10 - Trabalho Monótono & C - Coordenação do Trabalho \\
\hline & & \multirow{2}{*}{12 - Distrações } & C - Coordenação do Trabalho \\
\hline & & & F-Recursos Físicos \\
\hline \multirow{5}{*}{ X - Percepção } & \multirow{5}{*}{ Internos } & \multirow{2}{*}{4 - Qualidade do Sono } & A - Carga de Trabalho \\
\hline & & & C - Coordenação do Trabalho \\
\hline & & \multirow{3}{*}{5 - Condição Física } & A - Carga de Trabalho \\
\hline & & & G-Qualidade de Vida \\
\hline & & & $\mathrm{J}$-Seleção de Pessoal \\
\hline \multirow{3}{*}{ VIII - Equipe e Comunicação } & \multirow{3}{*}{ Internos } & \multirow{3}{*}{$\begin{array}{l}9 \text { - Tratamento dispensado à falha } \\
\text { (perda de emprego) } \\
24 \text { - Habilidade }\end{array}$} & D - Cultura Organizacional \\
\hline & & & $\mathrm{H}-$ Avaliação de Rendimento \\
\hline & & & $\mathrm{L}-$ Programas de treinamento \\
\hline
\end{tabular}




\section{APÊNDICE B: REDES BAYESIANAS DINÂMICAS E REDES DOS FATORES DE DESEMPENHO}

Neste apêndice, estão apresentadas as redes dinâmicas das tarefas integradas ao evento básico e às redes dos fatores de desempenho. Além da topologia estão apresentadas as TPC obtidas depois da ajustagem de seus valores de acordo com o item 4.5.3. Não foram repetidas aqui as redes já apresentadas ao longo do texto. Além disto, os eventos para os quais não foram assumidos nós filhos (34 e 41) já estão bem descritos na Figura 22 (a justificativa para os valores empregados nestes eventos encontra-se em Maturana e Martins (2008)).

Os eventos listados na Tabela 82 não foram repetidos neste apêndice. Esta tabela também apresenta justificativas para as exclusões.

Tabela 82 - Eventos não apresentados no Apêndice

\begin{tabular}{|c|c|}
\hline Evento não apresentado & Evento semelhante \\
\hline 6-Falha do Procedimento RIPEAM & Evento abordado no texto (ver item sobre o preenchimento das TPC). \\
\hline 23-Oficial dá Ordem Errada & Modelagem idêntica à do evento 11. \\
\hline 25-Timoneiro dá Resposta Errada & Modelagem idêntica à do evento 14. \\
\hline 33-ON Falha & Modelagem idêntica à do evento 32. \\
\hline 39-Erro Não Descoberto & Modelagem idêntica à do evento 32. \\
\hline
\end{tabular}

De maneira geral, os nós apresentados nas redes estão agrupados (em atividades, habilidades, etc.) de acordo com a Figura 29.

Neste apêndice, as TPC se apresentam após as figuras às quais se relacionam.

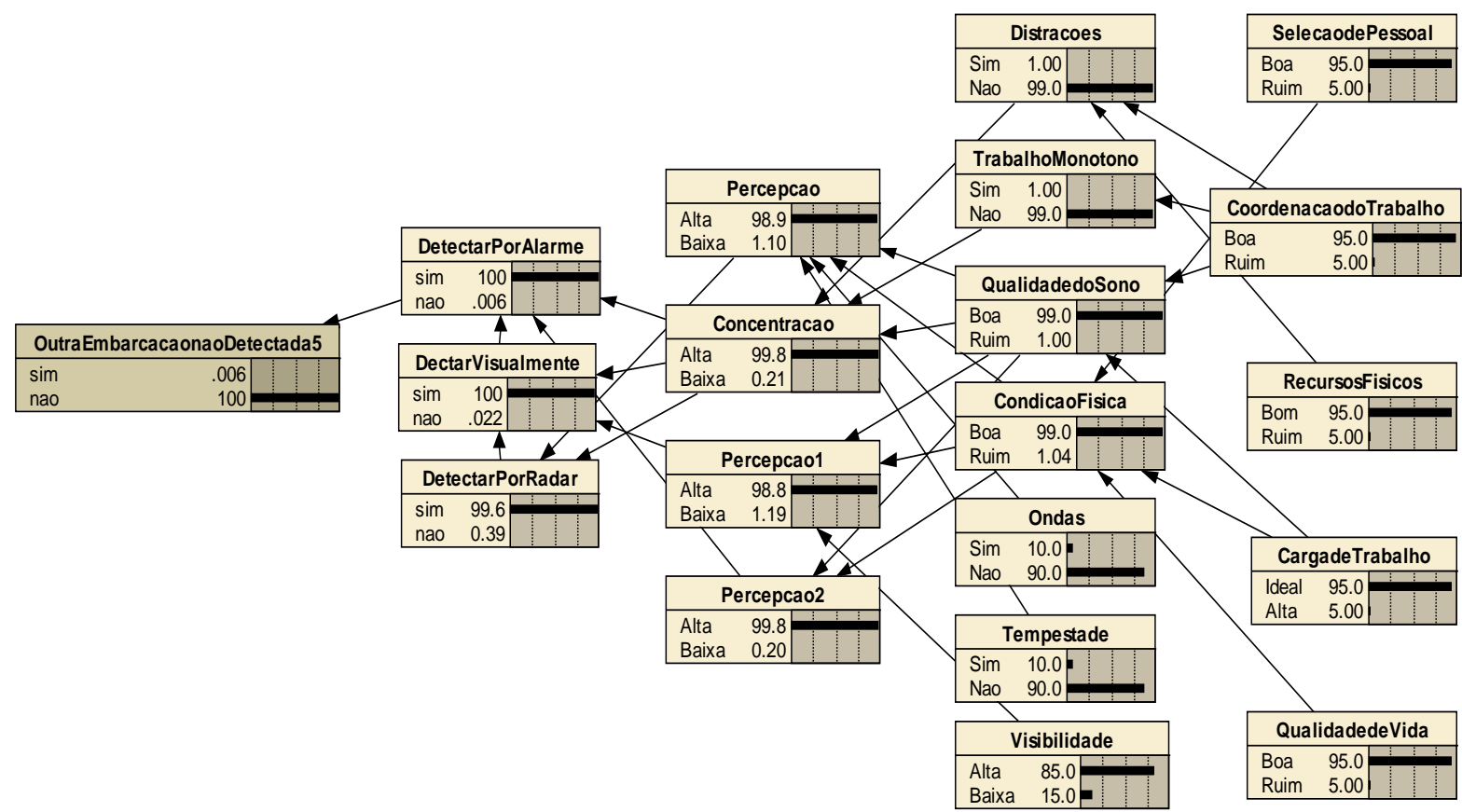

Figura 37 - Rede para o evento 5 - Outra Embarcação Não Detectada 
Tabela 83 - TPC para o nó Percepção

\begin{tabular}{|c|c|c|c|c|c|}
\hline Alta & Baixa & QualidadedoSono & Condicaofisica & Ondas & Tempestade \\
\hline 0.90 & 0.10 & Boa & Boa & Sim & Sim \\
\hline 0.95 & 0.05 & Boa & Boa & Sim & Não \\
\hline 0.95 & 0.05 & Boa & Boa & Não & Sim \\
\hline 1.00 & 0.00 & Boa & Boa & Não & Não \\
\hline 0.85 & 0.15 & Boa & Ruim & Sim & Sim \\
\hline 0.90 & 0.10 & Boa & Ruim & Sim & Não \\
\hline 0.90 & 0.10 & Boa & Ruim & Não & Sim \\
\hline 0.95 & 0.05 & Boa & Ruim & Não & Não \\
\hline 0.85 & 0.15 & Ruim & Boa & Sim & Sim \\
\hline 0.90 & 0.10 & Ruim & Boa & Sim & Não \\
\hline 0.90 & 0.10 & Ruim & Boa & Não & Sim \\
\hline 0.95 & 0.05 & Ruim & Boa & Não & Não \\
\hline 0.80 & 0.20 & Ruim & Ruim & Sim & Sim \\
\hline 0.85 & 0.15 & Ruim & Ruim & Sim & Não \\
\hline 0.85 & 0.15 & Ruim & Ruim & Não & Sim \\
\hline 0.90 & 0.10 & Ruim & Ruim & Não & Não \\
\hline
\end{tabular}

Tabela 84 - TPC para o nó Concentração

\begin{tabular}{|c|c|c|c|c|}
\hline Alta & Baixa & QualidadedoSono & Distrações & TrabalhoMonotono \\
\hline 0.87 & 0.13 & Boa & Sim & Sim \\
\hline 0.93 & 0.07 & Boa & Sim & Não \\
\hline 0.93 & 0.07 & Boa & Não & Sim \\
\hline 1.00 & 0.00 & Boa & Não & Não \\
\hline 0.80 & 0.20 & Ruim & Sim & Sim \\
\hline 0.87 & 0.13 & Ruim & Sim & Não \\
\hline 0.87 & 0.13 & Ruim & Não & Sim \\
\hline 0.93 & 0.07 & Ruim & Não & Não \\
\hline
\end{tabular}

Tabela 85 - TPC para o nó Percepcao1

\begin{tabular}{|c|c|c|c|c|}
\hline Alta & Baixa & QualidadedoSono & CondicaoFisica & Visibilidade \\
\hline 1.00 & 0.00 & Boa & Boa & Alta \\
\hline 0.93 & 0.07 & Boa & Boa & Baixa \\
\hline 0.93 & 0.07 & Boa & Ruim & Alta \\
\hline 0.87 & 0.13 & Boa & Ruim & Baixa \\
\hline 0.93 & 0.07 & Ruim & Boa & Alta \\
\hline 0.87 & 0.13 & Ruim & Boa & Baixa \\
\hline 0.87 & 0.13 & Ruim & Ruim & Alta \\
\hline 0.80 & 0.20 & Ruim & Ruim & Baixa \\
\hline
\end{tabular}

Tabela 86 - TPC para o nó Percepcao2

\begin{tabular}{|c|c|c|c|}
\hline Alta & Baixa & QualidadedoSono & CondicaoFisica \\
\hline 1.00 & 0.00 & Boa & Boa \\
\hline 0.90 & 0.10 & Boa & Ruim \\
\hline 0.90 & 0.10 & Ruim & Boa \\
\hline 0.80 & 0.20 & Ruim & Ruim \\
\hline
\end{tabular}

Tabela 87 - TPC para o nó DectarVisualmente

\begin{tabular}{|c|c|c|c|c|}
\hline Sim & Não & DetectarPorRadar & Concentração & Percepcao1 \\
\hline 1.00 & 0.00 & Sim & Alta & Alta \\
\hline 1.00 & 0.00 & Sim & Alta & Baixa \\
\hline 1.00 & 0.00 & Sim & Baixa & Alta \\
\hline 1.00 & 0.00 & Sim & Baixa & Baixa \\
\hline 1.00 & 0.00 & Não & Alta & Alta \\
\hline 0.70 & 0.30 & Não & Alta & Baixa \\
\hline 0.70 & 0.30 & Não & Baixa & Alta \\
\hline 0.40 & 0.60 & Não & Baixa & Baixa \\
\hline
\end{tabular}

Tabela 88 - TPC para o nó DetectarPorRadar

\begin{tabular}{|c|c|c|c|}
\hline Sim & Não & Percepção & Concentração \\
\hline 1.00 & 0.00 & Alta & Alta \\
\hline 0.70 & 0.30 & Alta & Baixa \\
\hline 0.70 & 0.30 & Baixa & Alta \\
\hline 0.40 & 0.60 & Baixa & Baixa \\
\hline
\end{tabular}

Tabela 89 - TPC para o nó DetectarPorAlarme

\begin{tabular}{|c|c|c|c|c|}
\hline Sim & Não & DectarVisualmente & Concentração & Percepcao2 \\
\hline 1.00 & 0.00 & Sim & Alta & Alta \\
\hline 1.00 & 0.00 & Sim & Alta & Baixa \\
\hline 1.00 & 0.00 & Sim & Baixa & Alta \\
\hline 1.00 & 0.00 & Sim & Baixa & Baixa \\
\hline 1.00 & 0.00 & Não & Alta & Alta \\
\hline 0.70 & 0.30 & Não & Alta & Baixa \\
\hline 0.70 & 0.30 & Não & Baixa & Alta \\
\hline 0.40 & 0.60 & Não & Baixa & Baixa \\
\hline
\end{tabular}


Tabela 90 - TPC para o nó OutraEmbarcacaoNãoDetectada5

\begin{tabular}{|c|c|}
\hline & DetectarPorAlarme \\
\hline Sim & Não \\
\hline Não & Sim \\
\hline
\end{tabular}

Tabela 91 - TPC para o nó Distrações

\begin{tabular}{|c|c|c|c|}
\hline Sim & Não & RecursosFisicos & CoordenacaodoTrabalho \\
\hline 0.00 & 1.00 & Bom & Boa \\
\hline 0.10 & 0.90 & Bom & Ruim \\
\hline 0.10 & 0.90 & Ruim & Boa \\
\hline 0.20 & 0.80 & Ruim & Ruim \\
\hline
\end{tabular}

Tabela 92 - TPC para o nó TrabalhoMonotono

\begin{tabular}{|c|c|c|}
\hline Sim & Não & CoordenacaodoTrabalho \\
\hline 0.00 & 1.00 & Boa \\
\hline 0.20 & 0.80 & Ruim \\
\hline
\end{tabular}

Tabela 93 - TPC para o nó QualidadedoSono

\begin{tabular}{|c|c|c|c|}
\hline Boa & Ruim & CoordenacaodoTrabalho & CargadeTrabalho \\
\hline 1.00 & 0.00 & Boa & Ideal \\
\hline 0.90 & 0.10 & Boa & Alta \\
\hline 0.90 & 0.10 & Ruim & Ideal \\
\hline 0.80 & 0.20 & Ruim & Alta \\
\hline
\end{tabular}

Tabela 94 - TPC para o nó CondicaoFisica

\begin{tabular}{|c|c|c|c|c|}
\hline Boa & Ruim & CargadeTrabalho & QualidadedeVida & SelecaodePessoal \\
\hline 1.00 & 0.00 & Ideal & Boa & Boa \\
\hline 0.93 & 0.07 & Ideal & Boa & Ruim \\
\hline 0.93 & 0.07 & Ideal & Ruim & Boa \\
\hline 0.87 & 0.13 & Ideal & Ruim & Ruim \\
\hline 0.93 & 0.07 & Alta & Boa & Boa \\
\hline 0.87 & 0.13 & Alta & Boa & Ruim \\
\hline 0.87 & 0.13 & Alta & Ruim & Boa \\
\hline 0.80 & 0.20 & Alta & Ruim & Ruim \\
\hline
\end{tabular}

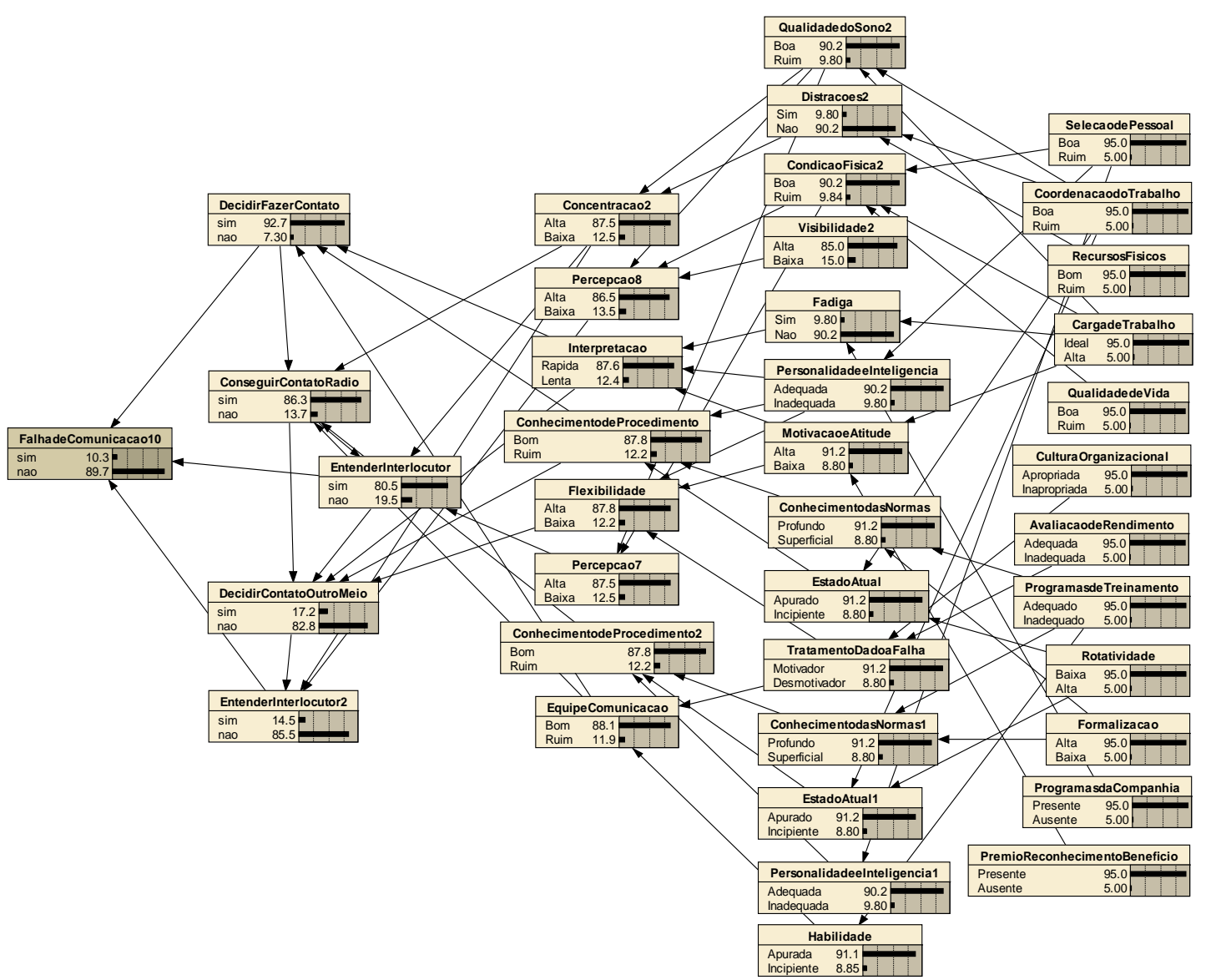

Figura 38 - Rede para o evento 10 - Falha de Comunicação 
Tabela 95 - TPC para o nó QualidadedoSono2

\begin{tabular}{|c|c|c|c|}
\hline Boa & Ruim & CoordenacaodoTrabalho & CargadeTrabalho \\
\hline 0.93 & 0.07 & Boa & Ideal \\
\hline 0.65 & 0.35 & Boa & Alta \\
\hline 0.65 & 0.35 & Ruim & Ideal \\
\hline 0.37 & 0.63 & Ruim & Alta \\
\hline
\end{tabular}

Tabela 96 - TPC para o nó Distracoes2

\begin{tabular}{|c|c|c|c|}
\hline Sim & Não & CoordenacaodoTrabalho & RecursosFisicos \\
\hline 0.07 & 0.93 & Boa & Bom \\
\hline 0.35 & 0.65 & Boa & Ruim \\
\hline 0.35 & 0.65 & Ruim & Bom \\
\hline 0.63 & 0.37 & Ruim & Ruim \\
\hline
\end{tabular}

Tabela 97 - TPC para o nó CondicaoFisica2

\begin{tabular}{|c|c|c|c|c|}
\hline Boa & Ruim & CargadeTrabalho & SelecaodePessoal & QualidadedeVida \\
\hline 0.93 & 0.07 & Ideal & Boa & Boa \\
\hline 0.74 & 0.26 & Ideal & Boa & Ruim \\
\hline 0.74 & 0.26 & Ideal & Ruim & Boa \\
\hline 0.56 & 0.44 & Ideal & Ruim & Ruim \\
\hline 0.74 & 0.26 & Alta & Boa & Boa \\
\hline 0.56 & 0.44 & Alta & Boa & Ruim \\
\hline 0.56 & 0.44 & Alta & Ruim & Boa \\
\hline 0.37 & 0.63 & Alta & Ruim & Ruim \\
\hline
\end{tabular}

Tabela 98 - TPC para o nó Fadiga

\begin{tabular}{|c|c|c|c|}
\hline Sim & Não & CargadeTrabalho & ProgramasdaCompanhia \\
\hline 0.07 & 0.93 & Ideal & Presente \\
\hline 0.35 & 0.65 & Ideal & Ausente \\
\hline 0.35 & 0.65 & Alta & Presente \\
\hline 0.63 & 0.37 & Alta & Ausente \\
\hline
\end{tabular}

Tabela 99 - TPC para o nó Personalidadeelnteligencia

\begin{tabular}{|c|c|c|}
\hline Adequada & Inadequada & SelecaodePessoal \\
\hline 0.93 & 0.07 & Boa \\
\hline 0.37 & 0.63 & Ruim \\
\hline
\end{tabular}

Tabela 100 - TPC para o nó MotivacaoeAtitude

\begin{tabular}{|c|c|c|c|}
\hline Alta & Baixa & CargadeTrabalho & PremioReconhecimentoBeneficio \\
\hline 0.94 & 0.06 & Ideal & Presente \\
\hline 0.66 & 0.34 & Ideal & Ausente \\
\hline 0.66 & 0.34 & Alta & Presente \\
\hline 0.37 & 0.63 & Alta & Ausente \\
\hline
\end{tabular}

Tabela 101 - TPC para o nó ConhecimentodasNormas \begin{tabular}{|l|l|l|l|}
\hline Profundo & Superficial & Formalização & ProgramasdeTreinamento \\
\hline
\end{tabular}

\begin{tabular}{|c|c|c|c|}
\hline 0.94 & 0.06 & Alta & Adequado \\
\hline 0.66 & 0.34 & Alta & Inadequado \\
\hline 0.66 & 0.34 & Baixa & Adequado \\
\hline 0.37 & 0.63 & Baixa & Inadequado \\
\hline
\end{tabular}

Tabela 102 - TPC para o nó EstadoAtual

\begin{tabular}{|c|c|c|c|}
\hline Apurado & Incipiente & CoordenacaodoTrabalho & Rotatividade \\
\hline 0.94 & 0.06 & Boa & Baixa \\
\hline 0.66 & 0.34 & Boa & Alta \\
\hline 0.66 & 0.34 & Ruim & Baixa \\
\hline 0.37 & 0.63 & Ruim & Alta \\
\hline
\end{tabular}

Tabela 103 - TPC para o nó TratamentoDadoaFalha

\begin{tabular}{|c|c|c|c|}
\hline Motivador & Desmotivador & CulturaOrganizacional & AvaliacaodeRendimento \\
\hline 0.94 & 0.06 & Apropriada & Adequada \\
\hline 0.66 & 0.34 & Apropriada & Inadequada \\
\hline 0.66 & 0.34 & Inapropriada & Adequada \\
\hline 0.37 & 0.63 & Inapropriada & Inadequada \\
\hline
\end{tabular}

Tabela 104 - TPC para o nó ConhecimentodasNormas1

\begin{tabular}{|c|c|c|c|}
\hline Profundo & Superficial & Formalização & ProgramasdeTreinamento \\
\hline 0.94 & 0.06 & Alta & Adequado \\
\hline 0.66 & 0.34 & Alta & Inadequado \\
\hline 0.66 & 0.34 & Baixa & Adequado \\
\hline 0.37 & 0.63 & Baixa & Inadequado \\
\hline
\end{tabular}


Tabela 105 - TPC para o nó EstadoAtual1

\begin{tabular}{|c|c|c|c|}
\hline Apurado & Incipiente & CoordenacaodoTrabalho & Rotatividade \\
\hline 0.94 & 0.06 & Boa & Baixa \\
\hline 0.66 & 0.34 & Boa & Alta \\
\hline 0.66 & 0.34 & Ruim & Baixa \\
\hline 0.37 & 0.63 & Ruim & Alta \\
\hline
\end{tabular}

Tabela 106 - TPC para o nó Personalidadeelnteligencia1

\begin{tabular}{|c|c|c|}
\hline Adequada & Inadequada & SelecaodePessoal \\
\hline 0.93 & 0.07 & Boa \\
\hline 0.37 & 0.63 & Ruim \\
\hline
\end{tabular}

Tabela 107 - TPC para o nó Habilidade

\begin{tabular}{|c|c|c|}
\hline Apurada & Incipiente & ProgramasdeTreinamento \\
\hline 0.94 & 0.06 & Adequado \\
\hline 0.37 & 0.63 & Inadequado \\
\hline
\end{tabular}

Tabela 108 - TPC para o nó Concentracao2

\begin{tabular}{|c|c|c|c|}
\hline Alta & Baixa & QualidadedoSono2 & Distracoes2 \\
\hline 0.65 & 0.35 & Boa & Sim \\
\hline 0.93 & 0.07 & Boa & Não \\
\hline 0.37 & 0.63 & Ruim & Sim \\
\hline 0.65 & 0.35 & Ruim & Não \\
\hline
\end{tabular}

Tabela 109 - TPC para o nó Percepcao8

\begin{tabular}{|c|c|c|c|c|}
\hline Alta & Baixa & QualidadedoSono2 & CondicaoFisica2 & Visibilidade2 \\
\hline 0.93 & 0.07 & Boa & Boa & Alta \\
\hline 0.74 & 0.26 & Boa & Boa & Baixa \\
\hline 0.74 & 0.26 & Boa & Ruim & Alta \\
\hline 0.56 & 0.44 & Boa & Ruim & Baixa \\
\hline 0.74 & 0.26 & Ruim & Boa & Alta \\
\hline 0.56 & 0.44 & Ruim & Boa & Baixa \\
\hline 0.56 & 0.44 & Ruim & Ruim & Alta \\
\hline 0.37 & 0.63 & Ruim & Ruim & Baixa \\
\hline
\end{tabular}

Tabela 110 - TPC para o nó ConhecimentodeProcedimento2

\begin{tabular}{|c|c|c|c|c|}
\hline Bom & Ruim & ConhecimentodasNormas1 & EstadoAtual1 & PersonalidadeeInteligencia1 \\
\hline 0.93 & 0.07 & Profundo & Apurado & Adequada \\
\hline 0.74 & 0.26 & Profundo & Apurado & Inadequada \\
\hline 0.74 & 0.26 & Profundo & Incipiente & Adequada \\
\hline 0.56 & 0.44 & Profundo & Incipiente & Inadequada \\
\hline 0.74 & 0.26 & Superficial & Apurado & Adequada \\
\hline 0.56 & 0.44 & Superficial & Apurado & Inadequada \\
\hline 0.56 & 0.44 & Superficial & Incipiente & Adequada \\
\hline 0.37 & 0.63 & Superficial & Incipiente & Inadequada \\
\hline
\end{tabular}

Tabela 111 - TPC para o nó Flexibilidade

\begin{tabular}{|c|c|c|c|c|}
\hline Alta & Baixa & PersonalidadeeInteligencia & MotivacaoeAtitude & TratamentoDadoaFalha \\
\hline 0.93 & 0.07 & Adequada & Alta & Motivador \\
\hline 0.74 & 0.26 & Adequada & Alta & Desmotivador \\
\hline 0.74 & 0.26 & Adequada & Baixa & Motivador \\
\hline 0.56 & 0.44 & Adequada & Baixa & Desmotivador \\
\hline 0.74 & 0.26 & Inadequada & Alta & Motivador \\
\hline 0.56 & 0.44 & Inadequada & Alta & Desmotivador \\
\hline 0.56 & 0.44 & Inadequada & Baixa & Motivador \\
\hline 0.37 & 0.63 & Inadequada & Baixa & Desmotivador \\
\hline
\end{tabular}

Tabela 112 - TPC para o nó ConhecimentodeProcedimento

\begin{tabular}{|c|c|c|c|c|}
\hline Bom & Ruim & PersonalidadeeInteligencia & ConhecimentodasNormas & EstadoAtual \\
\hline 0.93 & 0.07 & Adequada & Profundo & Apurado \\
\hline 0.74 & 0.26 & Adequada & Profundo & Incipiente \\
\hline 0.74 & 0.26 & Adequada & Superficial & Apurado \\
\hline 0.56 & 0.44 & Adequada & Superficial & Incipiente \\
\hline 0.74 & 0.26 & Inadequada & Profundo & Apurado \\
\hline 0.56 & 0.44 & Inadequada & Profundo & Incipiente \\
\hline 0.56 & 0.44 & Inadequada & Superficial & Apurado \\
\hline 0.37 & 0.63 & Inadequada & Superficial & Incipiente \\
\hline
\end{tabular}

Tabela 113 - TPC para o nó EquipeComunicacao

\begin{tabular}{|c|c|c|c|}
\hline Bom & Ruim & TratamentoDadoaFalha & Habilidade \\
\hline 0.93 & 0.07 & Motivador & Apurada \\
\hline 0.65 & 0.35 & Motivador & Incipiente \\
\hline 0.65 & 0.35 & Desmotivador & Apurada \\
\hline 0.37 & 0.63 & Desmotivador & Incipiente \\
\hline
\end{tabular}


Tabela 114 - TPC para o nó Percepcao7

\begin{tabular}{|c|c|c|c|}
\hline Alta & Baixa & QualidadedoSono2 & CondicaoFisica2 \\
\hline 0.93 & 0.07 & Boa & Boa \\
\hline 0.65 & 0.35 & Boa & Ruim \\
\hline 0.65 & 0.35 & Ruim & Boa \\
\hline 0.37 & 0.63 & Ruim & Ruim \\
\hline
\end{tabular}

Tabela 115 - TPC para o nó Interpretação

\begin{tabular}{|c|c|c|c|c|}
\hline Rápida & Lenta & Fadiga & PersonalidadeeInteligencia & MotivacaoeAtitude \\
\hline 0.74 & 0.26 & Sim & Adequada & Alta \\
\hline 0.56 & 0.44 & Sim & Adequada & Baixa \\
\hline 0.56 & 0.44 & Sim & Inadequada & Alta \\
\hline 0.37 & 0.63 & Sim & Inadequada & Baixa \\
\hline 0.93 & 0.07 & Não & Adequada & Baixa \\
\hline 0.74 & 0.26 & Não & Adequada & Alta \\
\hline 0.74 & 0.26 & Não & Inadequada & Baixa \\
\hline 0.56 & 0.44 & Não & Inadequada & \\
\hline
\end{tabular}

Tabela 116 - TPC para o nó EntenderInterlocutor2

\begin{tabular}{|c|c|c|c|c|}
\hline Sim & Não & DecidirContatoOutroMeio & Concentracao2 & Percepcao8 \\
\hline 1.00 & 0.00 & Sim & Alta & Alta \\
\hline 0.70 & 0.30 & Sim & Alta & Baixa \\
\hline 0.70 & 0.30 & Sim & Baixa & Alta \\
\hline 0.40 & 0.60 & Sim & Baixa & Baixa \\
\hline 0.00 & 1.00 & Não & Alta & Alta \\
\hline 0.00 & 1.00 & Não & Alta & Baixa \\
\hline 0.00 & 1.00 & Não & Baixa & Alta \\
\hline 0.00 & 1.00 & Não & Baixa & Baixa \\
\hline
\end{tabular}

Tabela 117 - TPC para o nó DecidirContatoOutroMeio

\begin{tabular}{|c|c|c|c|c|c|c|}
\hline $\begin{array}{l}\mathbf{S i} \\
\mathbf{m}\end{array}$ & $\begin{array}{c}\text { Nã } \\
\text { o }\end{array}$ & $\begin{array}{c}\text { EntenderInterlocuto } \\
\mathbf{r} \\
\end{array}$ & $\begin{array}{c}\text { ConseguirContatoRadi } \\
\text { o } \\
\end{array}$ & $\begin{array}{c}\text { Interpretaçã } \\
\text { o } \\
\end{array}$ & Conhecimento deProcedimento & $\begin{array}{c}\text { Flexibilidad } \\
\text { e }\end{array}$ \\
\hline 0.00 & 1.00 & Sim & Sim & Rápida & Bom & Alta \\
\hline 0.00 & 1.00 & Sim & Sim & Rápida & Bom & Baixa \\
\hline 0.00 & 1.00 & Sim & Sim & Rápida & Ruim & Alta \\
\hline 0.00 & 1.00 & Sim & Sim & Rápida & Ruim & Baixa \\
\hline 0.00 & 1.00 & Sim & Sim & Lenta & Bom & Alta \\
\hline 0.00 & 1.00 & Sim & Sim & Lenta & Bom & Baixa \\
\hline 0.00 & 1.00 & Sim & Sim & Lenta & Ruim & Alta \\
\hline 0.00 & 1.00 & Sim & Sim & Lenta & Ruim & Baixa \\
\hline 0.00 & 1.00 & Sim & Não & Rápida & Bom & Alta \\
\hline 0.00 & 1.00 & Sim & Não & Rápida & Bom & Baixa \\
\hline 0.00 & 1.00 & Sim & Não & Rápida & Ruim & Alta \\
\hline 0.00 & 1.00 & Sim & Não & Rápida & Ruim & Baixa \\
\hline 0.00 & 1.00 & Sim & Não & Lenta & Bom & Alta \\
\hline 0.00 & 1.00 & Sim & Não & Lenta & Bom & Baixa \\
\hline 0.00 & 1.00 & Sim & Não & Lenta & Ruim & Alta \\
\hline 0.00 & 1.00 & Sim & Não & Lenta & Ruim & Baixa \\
\hline 1.00 & 0.00 & Não & Sim & Rápida & Bom & Alta \\
\hline 0.80 & 0.20 & Não & Sim & Rápida & Bom & Baixa \\
\hline 0.80 & 0.20 & Não & Sim & Rápida & Ruim & Alta \\
\hline 0.60 & 0.40 & Não & Sim & Rápida & Ruim & Baixa \\
\hline 0.80 & 0.20 & Não & Sim & Lenta & Bom & Alta \\
\hline 0.60 & 0.40 & Não & Sim & Lenta & Bom & Baixa \\
\hline 0.60 & 0.40 & Não & Sim & Lenta & Ruim & Alta \\
\hline 0.40 & 0.60 & Não & Sim & Lenta & Ruim & Baixa \\
\hline 1.00 & 0.00 & Não & Não & Rápida & Bom & Alta \\
\hline 0.80 & 0.20 & Não & Não & Rápida & Bom & Baixa \\
\hline 0.80 & 0.20 & Não & Não & Rápida & Ruim & Alta \\
\hline 0.60 & 0.40 & Não & Não & Rápida & Ruim & Baixa \\
\hline 0.80 & 0.20 & Não & Não & Lenta & Bom & Alta \\
\hline 0.60 & 0.40 & Não & Não & Lenta & Bom & Baixa \\
\hline 0.60 & 0.40 & Não & Não & Lenta & Ruim & Alta \\
\hline 0.40 & 0.60 & Não & Não & Lenta & Ruim & Baixa \\
\hline
\end{tabular}

Tabela 118 - TPC para o nó DecidirFazerContato

\begin{tabular}{|c|c|c|c|c|}
\hline Sim & Não & Interpretação & ConhecimentodeProcedimento & EquipeComunicacao \\
\hline 1.00 & 0.00 & Rápida & Bom & Bom \\
\hline 0.80 & 0.20 & Rápida & Bom & Ruim \\
\hline 0.80 & 0.20 & Rápida & Ruim & Bom \\
\hline 0.60 & 0.40 & Rápida & Ruim & Ruim \\
\hline 0.80 & 0.20 & Lenta & Bom & Bom \\
\hline 0.60 & 0.40 & Lenta & Bom & Ruim \\
\hline 0.60 & 0.40 & Lenta & Ruim & Bom \\
\hline 0.40 & 0.60 & Lenta & Ruim & Ruim \\
\hline
\end{tabular}


Tabela 119 - TPC para o nó ConseguirContatoRadio

\begin{tabular}{|c|c|c|c|c|c|}
\hline Sim & Não & DecidirFazerContato & EquipeComunicacao & Concentracao2 & ConhecimentodeProcedimento2 \\
\hline 1.00 & 0.00 & Sim & Alta & Bom & Bom \\
\hline 0.80 & 0.20 & Sim & Alta & Bom & Buim \\
\hline 0.80 & 0.20 & Sim & Alta & Ruim & Ruim \\
\hline 0.60 & 0.40 & Sim & Alta & Ruim & Bom \\
\hline 0.80 & 0.20 & Sim & Baixa & Bom & Buim \\
\hline 0.60 & 0.40 & Sim & Baixa & Ruim & Ruim \\
\hline 0.60 & 0.40 & Sim & Baixa & Ruim & Bom \\
\hline 0.40 & 0.06 & Sim & Alta & Bom & Bom \\
\hline 0.00 & 1.00 & Não & Alta & Bom & Ruim \\
\hline 0.00 & 1.00 & Não & Alta & Ruim & Bom \\
\hline 0.00 & 1.00 & Não & Alta & Ruim & Ruim \\
\hline 0.00 & 1.00 & Não & Baixa & Bom & Bom \\
\hline 0.00 & 1.00 & Não & Baixa & Bom & Ruim \\
\hline 0.00 & 1.00 & Não & Baixa & Ruim & \\
\hline 0.00 & 1.00 & Não & Não & & \\
\hline 0.00 & 1.00 & & Ruima & \\
\hline
\end{tabular}

Tabela 120 - TPC para o nó EntenderInterlocutor

\begin{tabular}{|c|c|c|c|c|}
\hline Sim & Não & ConseguirContatoRadio & Concentracao2 & Percepcao7 \\
\hline 1.00 & 0.00 & Sim & Alta & Alta \\
\hline 0.70 & 0.30 & Sim & Alta & Baixa \\
\hline 0.70 & 0.30 & Sim & Baixa & Alta \\
\hline 0.40 & 0.60 & Sim & Baixa & Baixa \\
\hline 0.00 & 1.00 & Não & Alta & Alta \\
\hline 0.00 & 1.00 & Não & Alta & Baixa \\
\hline 0.00 & 1.00 & Não & Baixa & Alta \\
\hline 0.00 & 1.00 & Não & Baixa & Baixa \\
\hline
\end{tabular}

Tabela 121 - TPC para o nó FalhadeComunicacao10

\begin{tabular}{|l|c|c|c|}
\hline & EntenderInterlocutor2 & EntenderInterlocutor & DecidirFazerContato \\
\hline Não & Sim & Sim & Sim \\
\hline Sim & Sim & Sim & Não \\
\hline Não & Sim & Não & Sim \\
\hline Sim & Sim & Não & Não \\
\hline Não & Não & Sim & Sim \\
\hline Sim & Não & Sim & Não \\
\hline Sim & Não & Não & Sim \\
\hline Sim & Não & Não & Não \\
\hline
\end{tabular}

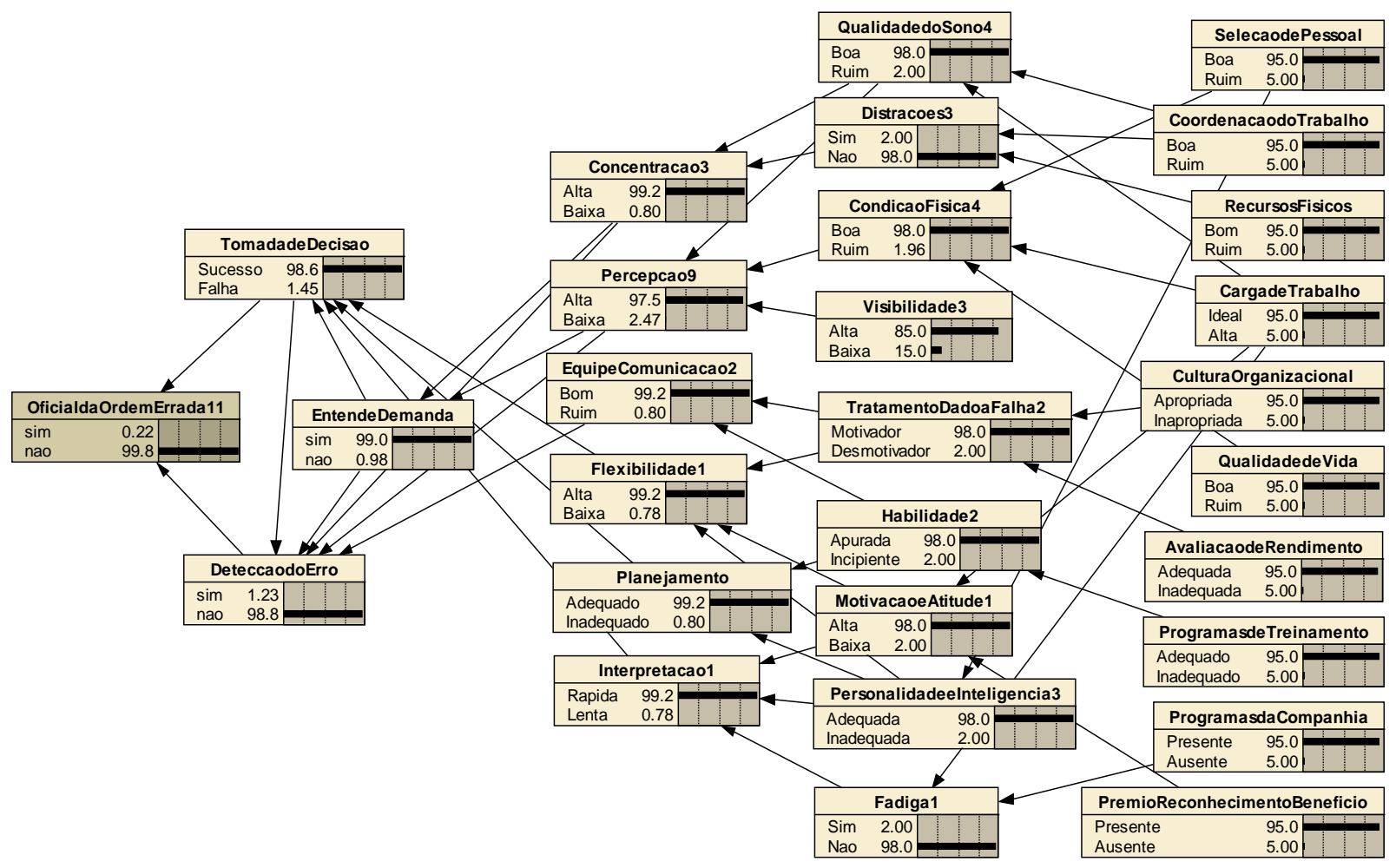


Figura 39 - Rede para o evento 11 - Oficial dá Ordem Errada

Tabela 122 - TPC para o nó Distracoes3

\begin{tabular}{|c|c|c|c|}
\hline Sim & Não & CoordenacaodoTrabalho & RecursosFisicos \\
\hline 0.00 & 1.00 & Boa & Bom \\
\hline 0.20 & 0.80 & Boa & Ruim \\
\hline 0.20 & 0.80 & Ruim & Bom \\
\hline 0.40 & 0.60 & Ruim & Ruim \\
\hline
\end{tabular}

Tabela 123 - TPC para o nó QualidadedoSono4

\begin{tabular}{|c|c|c|c|}
\hline Boa & Ruim & CoordenacaodoTrabalho & CargadeTrabalho \\
\hline 1.00 & 0.00 & Boa & Ideal \\
\hline 0.80 & 0.20 & Boa & Alta \\
\hline 0.80 & 0.20 & Ruim & Ideal \\
\hline 0.60 & 0.40 & Ruim & Alta \\
\hline
\end{tabular}

Tabela 124 - TPC para o nó Fadiga1

\begin{tabular}{|c|c|c|c|}
\hline Sim & Não & CargadeTrabalho & ProgramasdaCompanhia \\
\hline 0.00 & 1.00 & Ideal & Presente \\
\hline 0.20 & 0.80 & Ideal & Ausente \\
\hline 0.20 & 0.80 & Alta & Presente \\
\hline 0.40 & 0.60 & Alta & Ausente \\
\hline
\end{tabular}

Tabela 125 - TPC para o nó CondicaoFisica4

\begin{tabular}{|c|c|c|c|c|}
\hline Boa & Ruim & CargadeTrabalho & QualidadedeVida & SelecaodePessoal \\
\hline 1.00 & 0.00 & Ideal & Boa & Boa \\
\hline 0.87 & 0.13 & Ideal & Boa & Ruim \\
\hline 0.87 & 0.13 & Ideal & Ruim & Boa \\
\hline 0.73 & 0.27 & Ideal & Ruim & Ruim \\
\hline 0.87 & 0.13 & Alta & Boa & Boa \\
\hline 0.73 & 0.27 & Alta & Boa & Ruim \\
\hline 0.73 & 0.27 & Alta & Ruim & Boa \\
\hline 0.60 & 0.40 & Alta & Ruim & Ruim \\
\hline
\end{tabular}

Tabela 126 - TPC para o nó PersonalidadeeInteligencia3

\begin{tabular}{|c|c|c|}
\hline Adequada & Inadequada & SelecaodePessoal \\
\hline 1.00 & 0.00 & Boa \\
\hline 0.60 & 0.40 & Ruim \\
\hline
\end{tabular}

Tabela 127 - TPC para o nó TratamentoDadoaFalha2

\begin{tabular}{|c|c|c|c|}
\hline Motivador & Desmotivador & CulturaOrganizacional & AvaliacaodeRendimento \\
\hline 1.00 & 0.00 & Apropriada & Adequada \\
\hline 0.80 & 0.20 & Apropriada & Inadequada \\
\hline 0.80 & 0.20 & Inapropriada & Adequada \\
\hline 0.60 & 0.40 & Inapropriada & Inadequada \\
\hline
\end{tabular}

Tabela 128 - TPC para o nó Percepcao9

\begin{tabular}{|c|c|c|c|c|}
\hline Alta & Baixa & QualidadedoSono4 & CondicaoFisica4 & Visibilidade3 \\
\hline 1.00 & 0.00 & Boa & Boa & Alta \\
\hline 0.87 & 0.13 & Boa & Boa & Baixa \\
\hline 0.87 & 0.13 & Boa & Ruim & Alta \\
\hline 0.73 & 0.27 & Boa & Ruim & Baixa \\
\hline 0.87 & 0.13 & Ruim & Boa & Alta \\
\hline 0.73 & 0.27 & Ruim & Boa & Baixa \\
\hline 0.73 & 0.27 & Ruim & Ruim & Alta \\
\hline 0.60 & 0.40 & Ruim & Ruim & Baixa \\
\hline
\end{tabular}

Tabela 129 - TPC para o nó Flexibilidade1

\begin{tabular}{|c|c|c|c|c|}
\hline Alta & Baixa & TratamentoDadoaFalha2 & MotivacaoeAtitude1 & PersonalidadeeInteligencia3 \\
\hline 1.00 & 0.00 & Motivador & Alta & Adequada \\
\hline 0.87 & 0.13 & Motivador & Alta & Inadequada \\
\hline 0.87 & 0.13 & Motivador & Baixa & Inadequada \\
\hline 0.73 & 0.27 & Motivador & Baixa & Adequada \\
\hline 0.87 & 0.13 & Desmotivador & Alta & Inadequada \\
\hline 0.73 & 0.27 & Desmotivador & Baixa & Adequada \\
\hline 0.73 & 0.27 & Desmotivador & Baixa & Inadequada \\
\hline 0.60 & 0.40 & Desmotivador &
\end{tabular}

Tabela 130 - TPC para o nó Interpretacao1

\begin{tabular}{|c|c|c|c|c|}
\hline Rápida & Lenta & MotivacaoeAtitude1 & PersonalidadeeInteligencia3 & Fadiga1 \\
\hline 0.87 & 0.13 & Alta & Adequada & Sim \\
\hline 1.00 & 0.00 & Alta & Adequada & Não \\
\hline 0.73 & 0.27 & Alta & Inadequada & Sim \\
\hline 0.87 & 0.13 & Alta & Inadequada & Não \\
\hline 0.73 & 0.27 & Baixa & Adequada & Sim \\
\hline
\end{tabular}




\begin{tabular}{|c|c|c|c|c|}
0.87 & 0.13 & Baixa & Adequada & Não \\
\hline 0.60 & 0.40 & Baixa & Inadequada & Sim \\
\hline 0.73 & 0.27 & Baixa & Inadequada & Não \\
\hline
\end{tabular}

Tabela 131 - TPC para o nó MotivacaoeAtitude1

\begin{tabular}{|c|c|c|c|}
\hline Alta & Baixa & CargadeTrabalho & PremioReconhecimentoBeneficio \\
\hline 1.00 & 0.00 & Ideal & Presente \\
\hline 0.80 & 0.20 & Ideal & Ausente \\
\hline 0.80 & 0.20 & Alta & Presente \\
\hline 0.60 & 0.40 & Alta & Ausente \\
\hline
\end{tabular}

Tabela 132 - TPC para o nó Habilidade2

\begin{tabular}{|c|c|c|}
\hline Apurada & Incipiente & ProgramasdeTreinamento \\
\hline
\end{tabular}

\begin{tabular}{|c|c|c|}
\hline Apurada & Incipiente & ProgramasdeTreinamento \\
\hline 1.00 & 0.00 & Adequado \\
\hline 0.60 & 0.40 & Inadequado \\
\hline
\end{tabular}

Tabela 133 - TPC para o nó Concentracao3

\begin{tabular}{|c|c|c|c|}
\hline Alta & Baixa & QualidadedoSono4 & Distracoes3 \\
\hline 0.80 & 0.20 & Boa & Sim \\
\hline 1.00 & 0.00 & Boa & Não \\
\hline 0.60 & 0.40 & Ruim & Sim \\
\hline 0.80 & 0.20 & Ruim & Não \\
\hline
\end{tabular}

Tabela 134 - TPC para o nó EquipeComunicacao2

\begin{tabular}{|c|c|c|c|}
\hline Bom & Ruim & TratamentoDadoaFalha2 & Habilidade2 \\
\hline 1.00 & 0.00 & Motivador & Apurada \\
\hline 0.80 & 0.20 & Motivador & Incipiente \\
\hline 0.80 & 0.20 & Desmotivador & Apurada \\
\hline 0.60 & 0.40 & Desmotivador & Incipiente \\
\hline
\end{tabular}

Tabela 135 - TPC para o nó Planejamento

\begin{tabular}{|c|c|c|c|}
\hline Adequado & Inadequado & Habilidade2 & PersonalidadeeInteligencia3 \\
\hline 1.00 & 0.00 & Apurada & Adequada \\
\hline 0.80 & 0.20 & Apurada & Inadequada \\
\hline 0.80 & 0.20 & Incipiente & Adequada \\
\hline 0.60 & 0.40 & Incipiente & Inadequada \\
\hline
\end{tabular}

Tabela 136 - TPC para o nó DeteccaodoErro

\begin{tabular}{|c|c|c|c|c|c|c|}
\hline Sim & Não & EntendeDemanda & TomadadeDecisao & Concentracao3 & Percepcao9 & EquipeComunicacao2 \\
\hline 0.00 & 1.00 & $\operatorname{Sim}$ & Sucesso & Alta & Alta & Bom \\
\hline 0.00 & 1.00 & Sim & Sucesso & Alta & Alta & Ruim \\
\hline 0.00 & 1.00 & Sim & Sucesso & Alta & Baixa & Bom \\
\hline 0.00 & 1.00 & Sim & Sucesso & Alta & Baixa & Ruim \\
\hline 0.00 & 1.00 & Sim & Sucesso & Baixa & Alta & Bom \\
\hline 0.00 & 1.00 & Sim & Sucesso & Baixa & Alta & Ruim \\
\hline 0.00 & 1.00 & Sim & Sucesso & Baixa & Baixa & Bom \\
\hline 0.00 & 1.00 & $\operatorname{Sim}$ & Sucesso & Baixa & Baixa & Ruim \\
\hline 1.00 & 0.00 & Sim & Falha & Alta & Alta & Bom \\
\hline 0.80 & 0.20 & Sim & Falha & Alta & Alta & Ruim \\
\hline 0.80 & 0.20 & Sim & Falha & Alta & Baixa & Bom \\
\hline 0.60 & 0.40 & Sim & Falha & Alta & Baixa & Ruim \\
\hline 0.80 & 0.20 & Sim & Falha & Baixa & Alta & Bom \\
\hline 0.60 & 0.40 & Sim & Falha & Baixa & Alta & Ruim \\
\hline 0.60 & 0.40 & Sim & Falha & Baixa & Baixa & Bom \\
\hline 0.40 & 0.60 & Sim & Falha & Baixa & Baixa & Ruim \\
\hline 1.00 & 0.00 & Não & Sucesso & Alta & Alta & Bom \\
\hline 0.80 & 0.20 & Não & Sucesso & Alta & Alta & Ruim \\
\hline 0.80 & 0.20 & Não & Sucesso & Alta & Baixa & Bom \\
\hline 0.60 & 0.40 & Não & Sucesso & Alta & Baixa & Ruim \\
\hline 0.80 & 0.20 & Não & Sucesso & Baixa & Alta & Bom \\
\hline 0.60 & 0.40 & Não & Sucesso & Baixa & Alta & Ruim \\
\hline 0.60 & 0.40 & Não & Sucesso & Baixa & Baixa & Bom \\
\hline 0.40 & 0.60 & Não & Sucesso & Baixa & Baixa & Ruim \\
\hline 1.00 & 0.00 & Não & Falha & Alta & Alta & Bom \\
\hline 0.80 & 0.20 & Não & Falha & Alta & Alta & Ruim \\
\hline 0.80 & 0.20 & Não & Falha & Alta & Baixa & Bom \\
\hline 0.60 & 0.40 & Não & Falha & Alta & Baixa & Ruim \\
\hline 0.80 & 0.20 & Não & Falha & Baixa & Alta & Bom \\
\hline 0.60 & 0.40 & Não & Falha & Baixa & Alta & Ruim \\
\hline 0.60 & 0.40 & Não & Falha & Baixa & Baixa & Bom \\
\hline 0.40 & 0.60 & Não & Falha & Baixa & Baixa & Ruim \\
\hline
\end{tabular}

Tabela 137 - TPC para o nó EntendeDemanda

\begin{tabular}{|c|c|c|c|}
\hline Sim & Não & Concentracao3 & Percepcao9 \\
\hline 1.00 & 0.00 & Alta & Alta \\
\hline 0.70 & 0.30 & Alta & Baixa \\
\hline
\end{tabular}

Aplicação de Redes Bayesianas na Análise da Contribuição da Falha Humana em Acidentes de Colisão - 126 


$$
\begin{array}{|l|l|l|l|}
0.70 & 0.30 & \text { Baixa } & \text { Alta } \\
\hline 0.40 & 0.60 & \text { Baixa } & \text { Baixa } \\
\hline
\end{array}
$$

Tabela 138 - TPC para o nó TomadadeDecisao

\begin{tabular}{|c|c|c|c|c|c|}
\hline Sucesso & Falha & EntendeDemanda & Flexibilidade1 & Planejamento & Interpretacao1 \\
\hline 1.00 & 0.00 & Sim & Alta & Adequado & Rápida \\
\hline 0.80 & 0.20 & Sim & Alta & Adequado & Lenta \\
\hline 0.80 & 0.20 & Sim & Alta & Inadequado & Rápida \\
\hline 0.60 & 0.40 & Sim & Alta & Inadequado & Lenta \\
\hline 0.80 & 0.20 & Sim & Baixa & Adequado & Rápida \\
\hline 0.60 & 0.40 & Sim & Baixa & Adequado & Lenta \\
\hline 0.60 & 0.40 & Sim & Baixa & Inadequado & Rápida \\
\hline 0.40 & 0.60 & Sim & Baixa & Inadequado & Lenta \\
\hline 0.00 & 1.00 & Não & Alta & Adequado & Rápida \\
\hline 0.00 & 1.00 & Não & Alta & Adequado & Lenta \\
\hline 0.00 & 1.00 & Não & Alta & Inadequado & Rápida \\
\hline 0.00 & 1.00 & Não & Alta & Inadequado & Lenta \\
\hline 0.00 & 1.00 & Não & Baixa & Adequado & Rápida \\
\hline 0.00 & 1.00 & Não & Baixa & Adequado & Lenta \\
\hline 0.00 & 1.00 & Não & Baixa & Inadequado & Rápida \\
\hline 0.00 & 1.00 & Não & Baixa & Inadequado & Lenta \\
\hline
\end{tabular}

Tabela 139 - TPC para o nó OficialdaOrdemErrada11

\begin{tabular}{|c|c|c|}
\hline & DeteccaodoErro & TomadadeDecisao \\
\hline Não & Sim & Sucesso \\
\hline Não & Sim & Falha \\
\hline Não & Não & Sucesso \\
\hline Sim & Não & Falha \\
\hline
\end{tabular}

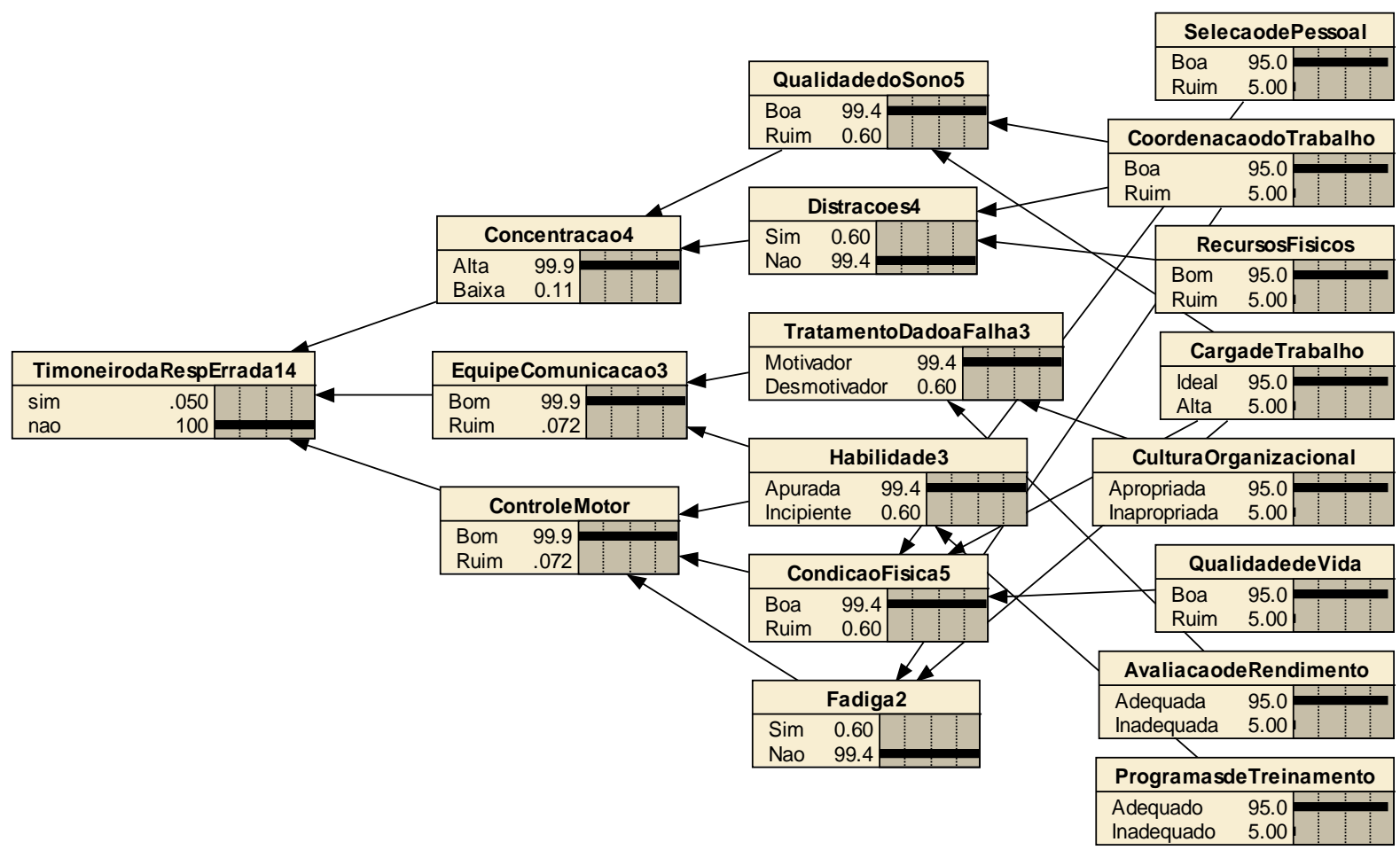

Figura 40 - Rede para o evento 14 - Timoneiro dá Resposta Errada

Tabela 140 - TPC para o nó QualidadedoSono5

\begin{tabular}{|c|c|c|c|}
\hline Boa & Ruim & CargadeTrabalho & CoordenacaodoTrabalho \\
\hline 1.00 & 0.00 & Ideal & Boa \\
\hline 0.94 & 0.06 & Ideal & Ruim \\
\hline 0.94 & 0.06 & Alta & Boa \\
\hline 0.88 & 0.12 & Alta & Ruim \\
\hline
\end{tabular}

Tabela 141 - TPC para o nó Distracoes4

\begin{tabular}{|c|c|c|c|}
\hline Sim & Não & CoordenacaodoTrabalho & RecursosFisicos \\
\hline 0.00 & 1.00 & Boa & Bom \\
\hline 0.06 & 0.94 & Boa & Ruim \\
\hline 0.06 & 0.94 & Ruim & Bom \\
\hline 0.12 & 0.88 & Ruim & Ruim \\
\hline
\end{tabular}

Aplicação de Redes Bayesianas na Análise da Contribuição da Falha Humana em Acidentes de Colisão - 127 
Tabela 142 - TPC para o nó TratamentoDadoaFalha3

\begin{tabular}{|c|c|c|c|}
\hline Motivador & Desmotivador & CulturaOrganizacional & AvaliacaodeRendimento \\
\hline 1.00 & 0.00 & Apropriada & Adequada \\
\hline 0.94 & 0.06 & Apropriada & Inadequada \\
\hline 0.94 & 0.06 & Inapropriada & Adequada \\
\hline 0.88 & 0.12 & Inapropriada & Inadequada \\
\hline
\end{tabular}

Tabela 143 - TPC para o nó Habilidade3

\begin{tabular}{|c|c|c|}
\hline Apurada & Incipiente & ProgramasdeTreinamento \\
\hline 1.00 & 0.00 & Adequado \\
\hline 0.88 & 0.12 & Inadequado \\
\hline
\end{tabular}

Tabela 144 - TPC para o nó CondicaoFisica5

\begin{tabular}{|c|c|c|c|c|}
\hline Boa & Ruim & CargadeTrabalho & QualidadedeVida & SelecaodePessoal \\
\hline 1.00 & 0.00 & Ideal & Boa & Boa \\
\hline 0.96 & 0.04 & Ideal & Boa & Ruim \\
\hline 0.96 & 0.04 & Ideal & Ruim & Boa \\
\hline 0.92 & 0.08 & Ideal & Ruim & Ruim \\
\hline 0.96 & 0.04 & Alta & Boa & Boa \\
\hline 0.92 & 0.08 & Alta & Boa & Ruim \\
\hline 0.92 & 0.08 & Alta & Ruim & Boa \\
\hline 0.88 & 0.12 & Alta & Ruim & Ruim \\
\hline
\end{tabular}

Tabela 145 - TPC para o nó Fadiga2

\begin{tabular}{|l|c|c|c|}
\hline Sim & Não & CargadeTrabalho & CoordenacaodoTrabalho \\
\hline 0.00 & 1.00 & Ideal & Boa \\
\hline 0.06 & 0.94 & Ideal & Boa \\
\hline 0.06 & 0.94 & Alta & Ruim \\
\hline 0.12 & 0.88 & Alta & Ruim \\
\hline
\end{tabular}

Tabela 146 - TPC para o nó EquipeComunicacao3

\begin{tabular}{|c|c|c|c|}
\hline Bom & Ruim & TratamentoDadoaFalha3 & Habilidade3 \\
\hline 1.00 & 0.00 & Motivador & Apurada \\
\hline 0.94 & 0.06 & Motivador & Incipiente \\
\hline 0.94 & 0.06 & Desmotivador & Apurada \\
\hline 0.88 & 0.12 & Desmotivador & Incipiente \\
\hline
\end{tabular}

Tabela 147 - TPC para o nó ControleMotor

\begin{tabular}{|c|c|c|c|c|}
\hline Bom & Ruim & Habilidade3 & CondicaoFisica5 & Fadiga2 \\
\hline 0.96 & 0.04 & Apurada & Boa & Sim \\
\hline 1.00 & 0.00 & Apurada & Boa & Não \\
\hline 0.92 & 0.08 & Apurada & Ruim & Sim \\
\hline 0.96 & 0.04 & Apurada & Ruim & Não \\
\hline 0.92 & 0.08 & Incipiente & Boa & Sim \\
\hline 0.96 & 0.04 & Incipiente & Boa & Não \\
\hline 0.88 & 0.12 & Incipiente & Ruim & Sim \\
\hline 0.92 & 0.08 & Incipiente & Ruim & Não \\
\hline
\end{tabular}

Tabela 148 - TPC para o nó Concentracao4

\begin{tabular}{|c|c|c|c|}
\hline Alta & Baixa & QualidadedoSono5 & Distracoes4 \\
\hline 0.94 & 0.06 & Boa & Sim \\
\hline 1.00 & 0.00 & Boa & Não \\
\hline 0.94 & 0.06 & Ruim & Sim \\
\hline 0.88 & 0.12 & Ruim & Não \\
\hline
\end{tabular}

Tabela 149 - TPC para o nó TimoneirodaRespErrada14

\begin{tabular}{|c|c|c|c|c|}
\hline Sim & Não & Concentracao4 & EquipeComunicacao3 & ControleMotor \\
\hline 0.00 & 1.00 & Alta & Bom & Bom \\
\hline 0.20 & 0.80 & Alta & Bom & Ruim \\
\hline 0.20 & 0.80 & Alta & Ruim & Bom \\
\hline 0.40 & 0.60 & Alta & Ruim & Ruim \\
\hline 0.20 & 0.80 & Baixa & Bom & Bom \\
\hline 0.40 & 0.60 & Baixa & Bom & Ruim \\
\hline 0.40 & 0.60 & Baixa & Ruim & Bom \\
\hline 0.60 & 0.40 & Baixa & Ruim & Ruim \\
\hline
\end{tabular}




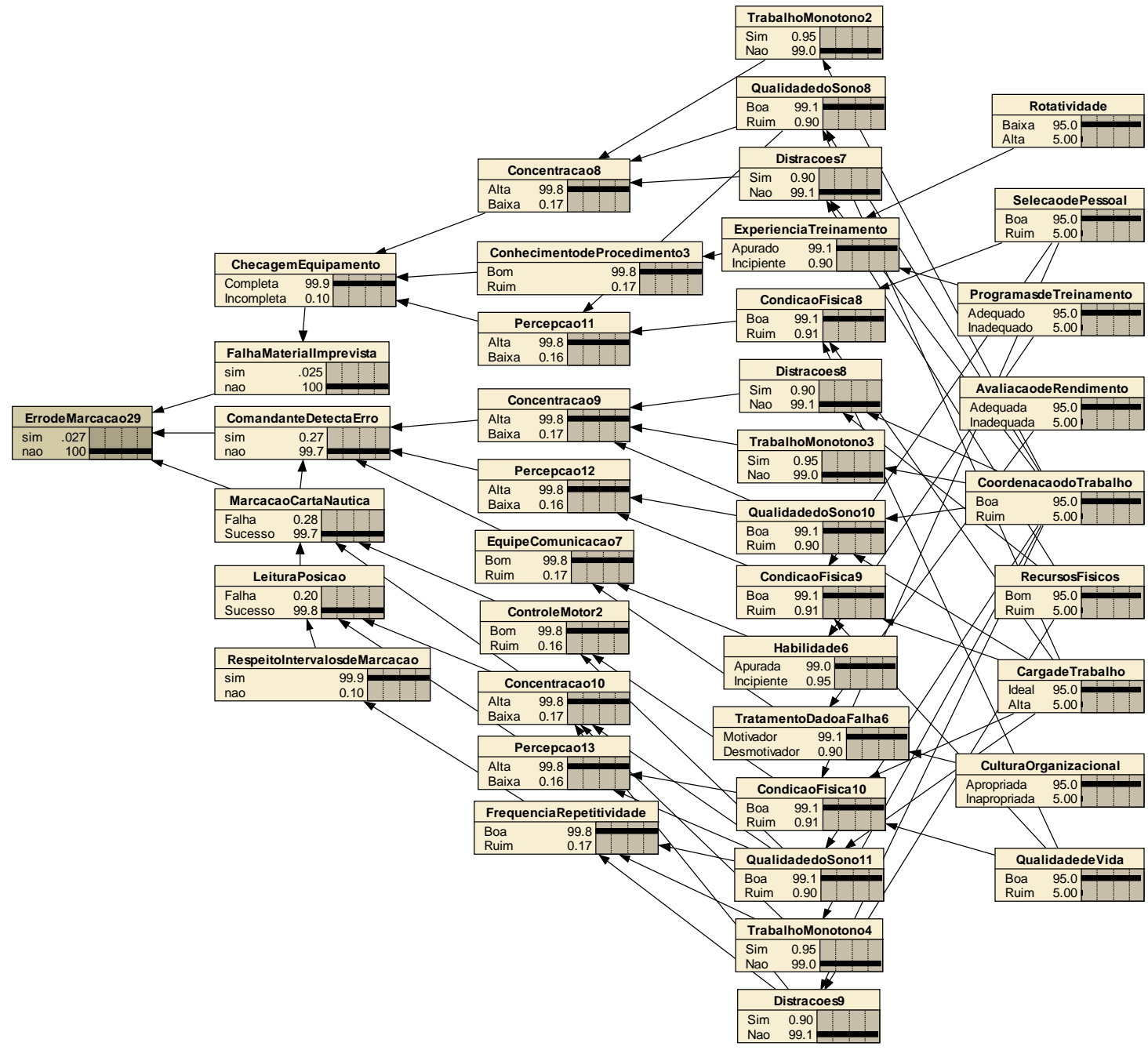

Figura 41 - Rede para o evento 29 - Erro de Marcação

Tabela 150 - TPC para o nó TrabalhoMonotono2

\begin{tabular}{|c|c|c|}
\hline Sim & Não & CoordenacaodoTrabalho \\
\hline 0.00 & 1.00 & Boa \\
\hline 0.19 & 0.81 & Ruim \\
\hline
\end{tabular}

Tabela 151 - TPC para o nó QualidadedoSono8

\begin{tabular}{|l|l|l|l|}
\hline Boa & Ruim & CoordenacaodoTrabalho & CargadeTrabalho \\
\hline
\end{tabular}

\begin{tabular}{|c|c|c|c|}
\hline 1.00 & 0.00 & Boa & Ideal \\
\hline 0.91 & 0.09 & Boa & Alta \\
\hline 0.91 & 0.09 & Ruim & Ideal \\
\hline 0.81 & 0.19 & Ruim & Alta \\
\hline
\end{tabular}

Tabela 152 - TPC para o nó Distracoes7

\begin{tabular}{|c|c|c|c|}
\hline Sim & Não & CoordenacaodoTrabalho & RecursosFisicos \\
\hline 0.00 & 1.00 & Boa & Bom \\
\hline 0.09 & 0.91 & Boa & Ruim \\
\hline 0.09 & 0.91 & Ruim & Bom \\
\hline 0.19 & 0.81 & Ruim & Ruim \\
\hline
\end{tabular}

Tabela 153 - TPC para o nó CondicaoFisica8

\begin{tabular}{|c|c|c|c|c|}
\hline Boa & Ruim & CargadeTrabalho & SelecaodePessoal & QualidadedeVida1 \\
\hline 1.00 & 0.00 & Ideal & Boa & Boa \\
\hline 0.94 & 0.06 & Ideal & Boa & Ruim \\
\hline 0.94 & 0.06 & Ideal & Ruim & Boa \\
\hline 0.87 & 0.13 & Ideal & Ruim & Ruim \\
\hline 0.94 & 0.06 & Alta & Boa & Boa \\
\hline 0.87 & 0.13 & Alta & Boa & Ruim \\
\hline 0.87 & 0.13 & Alta & Ruim & Boa \\
\hline 0.81 & 0.19 & Alta & Ruim & Ruim \\
\hline
\end{tabular}


Tabela 154 - TPC para o nó Distracoes8

\begin{tabular}{|l|l|c|c|}
\hline Sim & Não & CoordenacaodoTrabalho & RecursosFisicos \\
\hline 0.00 & 1.00 & Boa & Bom \\
\hline 0.09 & 0.91 & Boa & Ruim \\
\hline 0.09 & 0.91 & Ruim & Bom \\
\hline 0.19 & 0.81 & Ruim & Ruim \\
\hline
\end{tabular}

Tabela 155 - TPC para o nó TrabalhoMonotono3

\begin{tabular}{|c|c|c|}
\hline Sim & Não & CoordenacaodoTrabalho \\
\hline 0.00 & 1.00 & Boa \\
\hline 0.19 & 0.81 & Ruim \\
\hline
\end{tabular}

Tabela 156 - TPC para o nó QualidadedoSono10

\begin{tabular}{|c|c|c|c|}
\hline Boa & Ruim & CoordenacaodoTrabalho & CargadeTrabalho \\
\hline 1.00 & 0.00 & Boa & Ideal \\
\hline 0.91 & 0.09 & Boa & Alta \\
\hline 0.91 & 0.09 & Ruim & Ideal \\
\hline 0.81 & 0.19 & Ruim & Alta \\
\hline
\end{tabular}

Tabela 157 - TPC para o nó Habilidade6

\begin{tabular}{|c|c|c|}
\hline Apurada & Incipiente & ProgramasdeTreinamento \\
\hline 1.00 & 0.00 & Adequado \\
\hline 0.81 & 0.19 & Inadequado \\
\hline
\end{tabular}

Tabela 158 - TPC para o nó TratamentoDadoaFalha6

\begin{tabular}{|c|c|c|c|}
\hline Motivador & Desmotivador & AvaliacaodeRendimento & CulturaOrganizacional \\
\hline 1.00 & 0.00 & Adequada & Apropriada \\
\hline 0.91 & 0.09 & Adequada & Inapropriada \\
\hline 0.91 & 0.09 & Inadequada & Apropriada \\
\hline 0.81 & 0.19 & Inadequada & Inapropriada \\
\hline
\end{tabular}

Tabela 159 - TPC para o nó QualidadedoSono11 \begin{tabular}{|c|c|c|c|}
\hline Boa & Ruim & CoordenacaodoTrabalho & CargadeTrabalho \\
\hline
\end{tabular}

\begin{tabular}{|c|c|c|c|}
\hline 1.00 & 0.00 & Boa & Ideal \\
\hline 0.91 & 0.09 & Boa & Alta \\
\hline 0.91 & 0.09 & Ruim & Ideal \\
\hline 0.81 & 0.19 & Ruim & Alta \\
\hline
\end{tabular}

Tabela 160 - TPC para o nó TrabalhoMonotono4

\begin{tabular}{|c|c|c|}
\hline Sim & Não & CoordenacaodoTrabalho \\
\hline 0.00 & 1.00 & Boa \\
\hline 0.19 & 0.81 & Ruim \\
\hline
\end{tabular}

Tabela 161 - TPC para o nó Distracoes9

\begin{tabular}{|c|c|c|c|}
\hline Sim & Não & CoordenacaodoTrabalho & RecursosFisicos \\
\hline 0.00 & 1.00 & Boa & Bom \\
\hline 0.09 & 0.91 & Boa & Ruim \\
\hline 0.09 & 0.91 & Ruim & Bom \\
\hline 0.19 & 0.81 & Ruim & Ruim \\
\hline
\end{tabular}

Tabela 162 - TPC para o nó ExperienciaTreinamento \begin{tabular}{|c|c|c|c|}
\hline Apurado & Incipiente & Rotatividade & ProgramasdeTreinamento \\
\hline
\end{tabular}

\begin{tabular}{|c|c|c|c|}
\hline 1.00 & 0.00 & Baixa & Adequado \\
\hline 0.91 & 0.09 & Baixa & Inadequado \\
\hline 0.91 & 0.09 & Alta & Adequado \\
\hline 0.81 & 0.19 & Alta & Inadequado \\
\hline
\end{tabular}

Tabela 163 - TPC para o nó CondicaoFisica9

\begin{tabular}{|c|c|c|c|c|}
\hline Boa & Ruim & CargadeTrabalho & SelecaodePessoal & QualidadedeVida \\
\hline 1.00 & 0.00 & Ideal & Boa & Boa \\
\hline 0.94 & 0.06 & Ideal & Boa & Ruim \\
\hline 0.94 & 0.06 & Ideal & Ruim & Boa \\
\hline 0.87 & 0.13 & Ideal & Ruim & Ruim \\
\hline 0.94 & 0.06 & Alta & Boa & Boa \\
\hline 0.87 & 0.13 & Alta & Boa & Ruim \\
\hline 0.87 & 0.13 & Alta & Ruim & Boa \\
\hline 0.81 & 0.19 & Alta & Ruim & Ruim \\
\hline
\end{tabular}

Tabela 164 - TPC para o nó Percepcao13

\begin{tabular}{|c|c|c|c|}
\hline Alta & Baixa & CondicaoFisica10 & QualidadedoSono11 \\
\hline 1.00 & 0.00 & Boa & Boa \\
\hline 0.91 & 0.09 & Boa & Ruim \\
\hline 0.91 & 0.09 & Ruim & Boa \\
\hline 0.81 & 0.19 & Ruim & Ruim \\
\hline
\end{tabular}


Tabela 165 - TPC para o nó CondicaoFisica10

\begin{tabular}{|c|c|c|c|c|}
\hline Boa & Ruim & CargadeTrabalho & SelecaodePessoal & QualidadedeVida \\
\hline 1.00 & 0.00 & Ideal & Boa & Boa \\
\hline 0.94 & 0.06 & Ideal & Boa & Ruim \\
\hline 0.94 & 0.06 & Ideal & Ruim & Boa \\
\hline 0.87 & 0.13 & Ideal & Ruim & Ruim \\
\hline 0.94 & 0.06 & Alta & Boa & Boa \\
\hline 0.87 & 0.13 & Alta & Boa & Ruim \\
\hline 0.87 & 0.13 & Alta & Ruim & Boa \\
\hline 0.81 & 0.19 & Alta & Ruim & Ruim \\
\hline
\end{tabular}

Tabela 166 - TPC para o nó ErrodeMarcacao29

\begin{tabular}{|l|c|c|c|}
\hline & FalhaMaterialImprevista & MarcacaoCartaNautica & ComandanteDetectaErro \\
\hline $\operatorname{Sim}$ & Sim & Falha & Sim \\
\hline $\operatorname{Sim}$ & $\operatorname{Sim}$ & Falha & Não \\
\hline $\operatorname{Sim}$ & $\operatorname{Sim}$ & Sucesso & Sim \\
\hline $\operatorname{Sim}$ & $\operatorname{Sim}$ & Sucesso & Não \\
\hline Não & Não & Falha & Sim \\
\hline Sim & Não & Falha & Não \\
\hline Não & Não & Sucesso & Sim \\
\hline Não & Não & Sucesso & Não \\
\hline
\end{tabular}

Tabela 167 - TPC para o nó RespeitolntervalosdeMarcacao

\begin{tabular}{|c|c|c|}
\hline Sim & Não & FrequenciaRepetitividade \\
\hline 1.00 & 0.00 & Boa \\
\hline 0.40 & 0.60 & Ruim \\
\hline
\end{tabular}

Tabela 168 - TPC para o nó LeituraPosicao

\begin{tabular}{|c|c|c|c|c|}
\hline Falha & Sucesso & RespeitoIntervalosdeMarcacao & Concentracao10 & Percepcao13 \\
\hline 0.00 & 1.00 & Sim & Alta & Alta \\
\hline 0.30 & 0.70 & Sim & Alta & Baixa \\
\hline 0.30 & 0.70 & Sim & Baixa & Alta \\
\hline 0.60 & 0.40 & Sim & Baixa & Baixa \\
\hline 1.00 & 0.00 & Não & Alta & Alta \\
\hline 1.00 & 0.00 & Não & Alta & Baixa \\
\hline 1.00 & 0.00 & Não & Baixa & Alta \\
\hline 1.00 & 0.00 & Não & Baixa \\
\hline
\end{tabular}

Tabela 169 - TPC para o nó ComandanteDetectaErro

\begin{tabular}{|c|c|c|c|c|c|}
\hline Sim & Não & MarcacaoCartaNautica & Concentracao9 & Percepcao12 & EquipeComunicacao7 \\
\hline 1.00 & 0.00 & Falha & Alta & Alta & Bom \\
\hline 0.80 & 0.20 & Falha & Alta & Alta & Ruim \\
\hline 0.80 & 0.20 & Falha & Alta & Baixa & Bom \\
\hline 0.60 & 0.40 & Falha & Alta & Baixa & Ruim \\
\hline 0.80 & 0.20 & Falha & Baixa & Alta & Bom \\
\hline 0.60 & 0.40 & Falha & Baixa & Alta & Ruim \\
\hline 0.60 & 0.40 & Falha & Baixa & Baixa & Bom \\
\hline 0.40 & 0.60 & Falha & Baixa & Baixa & Ruim \\
\hline 0.00 & 1.00 & Sucesso & Alta & Alta & Bom \\
\hline 0.00 & 1.00 & Sucesso & Alta & Alta & Ruim \\
\hline 0.00 & 1.00 & Sucesso & Alta & Baixa & Bom \\
\hline 0.00 & 1.00 & Sucesso & Alta & Baixa & Ruim \\
\hline 0.00 & 1.00 & Sucesso & Baixa & Alta & Bom \\
\hline 0.00 & 1.00 & Sucesso & Baixa & Alta & Ruim \\
\hline 0.00 & 1.00 & Sucesso & Baixa & Baixa & Bom \\
\hline 0.00 & 1.00 & Sucesso & Baixa & Baixa & Ruim \\
\hline
\end{tabular}

Tabela 170 - TPC para o nó FalhaMateriallmprevista

\begin{tabular}{|c|c|c|}
\hline Sim & Não & ChecagemEquipamento \\
\hline 0.00 & 1.00 & Completa \\
\hline 0.25 & 0.75 & Incompleta \\
\hline
\end{tabular}

Tabela 171 - TPC para o nó MarcacaoCartaNautica

\begin{tabular}{|c|c|c|c|c|}
\hline Falha & Sucesso & LeituraPosicao & ControleMotor2 & Concentracao10 \\
\hline 1.00 & 0.00 & Falha & Bom & Alta \\
\hline 1.00 & 0.00 & Falha & Bom & Baixa \\
\hline 1.00 & 0.00 & Falha & Ruim & Alta \\
\hline 1.00 & 0.00 & Falha & Ruim & Baixa \\
\hline 0.00 & 1.00 & Sucesso & Bom & Alta \\
\hline 0.30 & 0.70 & Sucesso & Bom & Baixa \\
\hline 0.30 & 0.70 & Sucesso & Ruim & Alta \\
\hline 0.60 & 0.40 & Sucesso & Ruim & Baixa \\
\hline
\end{tabular}


Tabela 172 - TPC para o nó ChecagemEquipamento

\begin{tabular}{|c|c|c|c|c|}
\hline Completa & Incompleta & Concentracao8 & ConhecimentodeProcedimento3 & Percepcao11 \\
\hline 1.00 & 0.00 & Alta & Bom & Alta \\
\hline 0.80 & 0.20 & Alta & Bom & Baixa \\
\hline 0.80 & 0.20 & Alta & Ruim & Blta \\
\hline 0.60 & 0.40 & Alta & Boima & Alta \\
\hline 0.80 & 0.20 & Baixa & Bom & Baixa \\
\hline 0.60 & 0.40 & Baixa & Ruim & Alta \\
\hline 0.60 & 0.40 & Baixa & Ruim & Baixa \\
\hline 0.40 & 0.60 & Baixa & & \\
\hline
\end{tabular}

Tabela 173 - TPC para o nó EquipeComunicacao7

\begin{tabular}{|c|c|c|c|}
\hline Bom & Ruim & Habilidade6 & TratamentoDadoaFalha6 \\
\hline 1.00 & 0.00 & Apurada & Motivador \\
\hline 0.91 & 0.09 & Apurada & Desmotivador \\
\hline 0.91 & 0.09 & Incipiente & Motivador \\
\hline 0.81 & 0.19 & Incipiente & Desmotivador \\
\hline
\end{tabular}

Tabela 174 - TPC para o nó Percepcao12

\begin{tabular}{|c|c|c|c|}
\hline Alta & Baixa & QualidadedoSono10 & CondicaoFisica9 \\
\hline
\end{tabular}

\begin{tabular}{|c|c|c|c|}
\hline 1.00 & 0.00 & Boa & Boa \\
\hline 0.91 & 0.09 & Boa & Ruim \\
\hline 0.91 & 0.09 & Ruim & Boa \\
\hline 0.81 & 0.19 & Ruim & Ruim \\
\hline
\end{tabular}

Tabela 175 - TPC para o nó Concentracao9

\begin{tabular}{|c|c|c|c|c|}
\hline Alta & Baixa & QualidadedoSono10 & Distracoes8 & TrabalhoMonotono3 \\
\hline 0.87 & 0.13 & Boa & Sim & Sim \\
\hline 0.94 & 0.06 & Boa & Sim & Não \\
\hline 0.94 & 0.06 & Boa & Não & Sim \\
\hline 1.00 & 0.00 & Boa & Não & Não \\
\hline 0.81 & 0.19 & Ruim & Sim & Sim \\
\hline 0.87 & 0.13 & Ruim & Sim & Não \\
\hline 0.87 & 0.13 & Ruim & Não & Sim \\
\hline 0.94 & 0.06 & Ruim & Não & Não \\
\hline
\end{tabular}

Tabela 176 - TPC para o nó Percepcao11

\begin{tabular}{|c|c|c|c|}
\hline Alta & Baixa & QualidadedoSono8 & CondicaoFisica8 \\
\hline 1.00 & 0.00 & Boa & Boa \\
\hline 0.91 & 0.09 & Boa & Ruim \\
\hline 0.91 & 0.09 & Ruim & Boa \\
\hline 0.81 & 0.19 & Ruim & Ruim \\
\hline
\end{tabular}

Tabela 177 - TPC para o nó Concentracao8

\begin{tabular}{|c|c|c|c|c|}
\hline Alta & Baixa & QualidadedoSono8 & TrabalhoMonotono2 & Distracoes7 \\
\hline 0.87 & 0.13 & Boa & Sim & Sim \\
\hline 0.94 & 0.06 & Boa & Sim & Não \\
\hline 0.94 & 0.06 & Boa & Não & Sim \\
\hline 1.00 & 0.00 & Boa & Não & Não \\
\hline 0.81 & 0.19 & Ruim & Sim & Sim \\
\hline 0.87 & 0.13 & Ruim & Sim & Não \\
\hline 0.87 & 0.13 & Ruim & Não & Sim \\
\hline 0.94 & 0.06 & Ruim & Não & Não \\
\hline
\end{tabular}

Tabela 178 - TPC para o nó Concentracao 10

\begin{tabular}{|c|c|c|c|c|}
\hline Alta & Baixa & QualidadedoSono11 & TrabalhoMonotono4 & Distracoes9 \\
\hline 0.87 & 0.13 & Boa & Sim & Sim \\
\hline 0.94 & 0.06 & Boa & Sim & Não \\
\hline 0.94 & 0.06 & Boa & Não & Sim \\
\hline 1.00 & 0.00 & Boa & Não & Não \\
\hline 0.81 & 0.19 & Ruim & Sim & Sim \\
\hline 0.87 & 0.13 & Ruim & Sim & Não \\
\hline 0.87 & 0.13 & Ruim & Não & Sim \\
\hline 0.94 & 0.06 & Ruim & Não & Não \\
\hline
\end{tabular}

Tabela 179 - TPC para o nó FrequenciaRepetitividade \begin{tabular}{|c|c|c|c|c|}
\hline Boa & Ruim & QualidadedoSono11 & TrabalhoMonotono4 & Distracoes9 \\
\hline
\end{tabular}

\begin{tabular}{|l|c|c|c|c|}
\hline 0.87 & 0.13 & Boa & Sim & Sim \\
\hline 0.94 & 0.06 & Boa & Sim & Não \\
\hline 0.94 & 0.06 & Boa & Não & Sim \\
\hline 1.00 & 0.00 & Boa & Não & Não \\
\hline 0.81 & 0.19 & Ruim & Sim & Sim \\
\hline 0.87 & 0.13 & Ruim & Sim & Não \\
\hline 0.87 & 0.13 & Ruim & Não & Sim \\
\hline 0.94 & 0.06 & Ruim & Não & Não \\
\hline
\end{tabular}


Tabela 180 - TPC para o nó ControleMotor2

\begin{tabular}{|l|c|c|c|}
\hline Bom & Ruim & CondicaoFisica10 & QualidadedoSono11 \\
\hline
\end{tabular}

\begin{tabular}{|c|c|c|c|}
\hline 1.00 & 0.00 & Boa & Boa \\
\hline 0.91 & 0.09 & Boa & Ruim \\
\hline 0.91 & 0.09 & Ruim & Boa \\
\hline 0.81 & 0.19 & Ruim & Ruim \\
\hline
\end{tabular}

Tabela 181 - TPC para o nó ConhecimentodeProcedimento3

\begin{tabular}{|c|c|c|}
\hline Bom & Ruim & ExperienciaTreinamento \\
\hline 1.00 & 0.00 & Apurado \\
\hline 0.81 & 0.19 & Incipiente \\
\hline
\end{tabular}

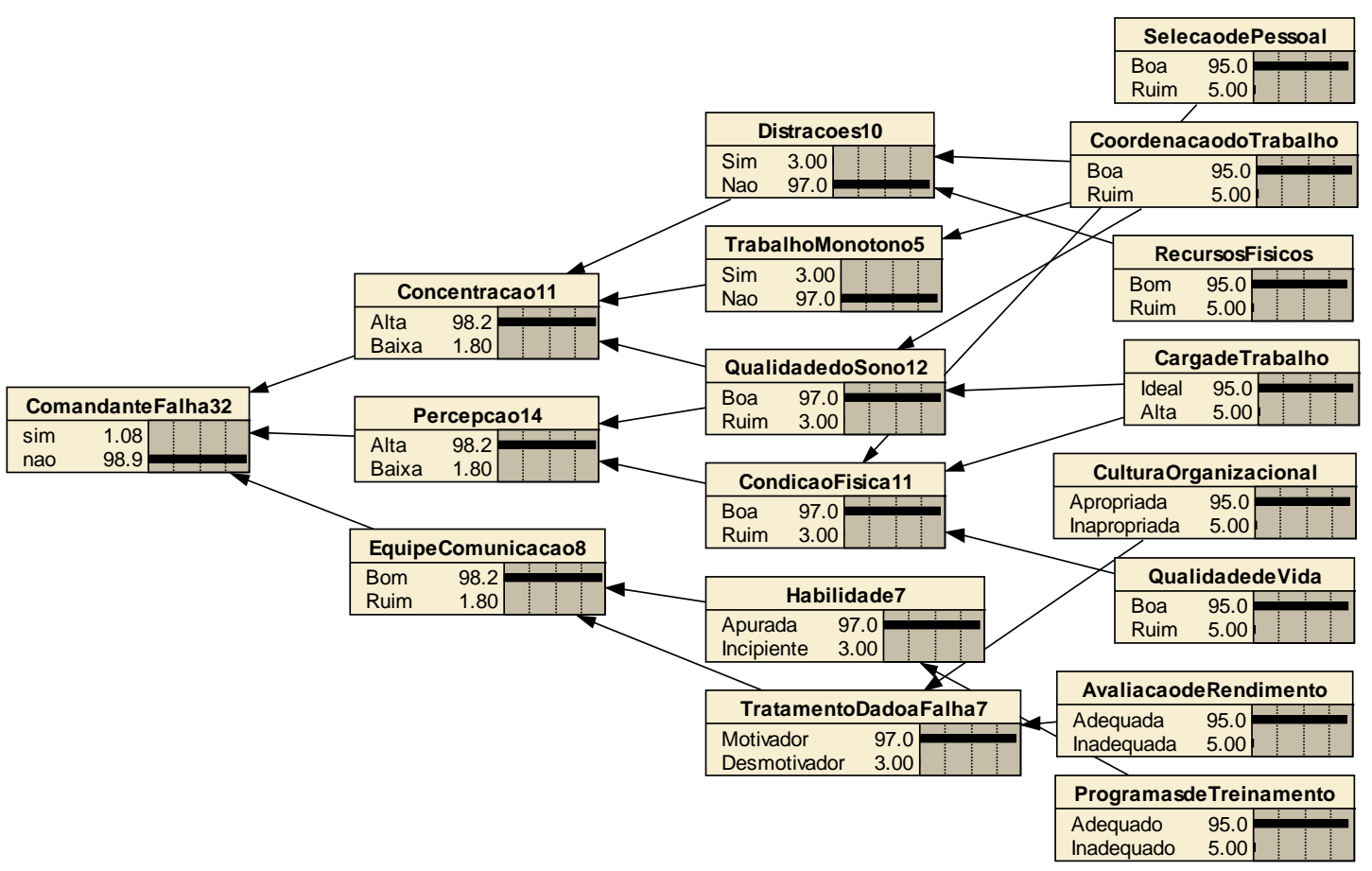

Figura 42 - Rede para o evento 32 - Capitão Falha

Tabela 182 - TPC para o nó EquipeComunicaca08

\begin{tabular}{|c|c|c|c|}
\hline Bom & Ruim & Habilidade7 & TratamentoDadoaFalha7 \\
\hline 1.00 & 0.00 & Apurada & Motivador \\
\hline 0.70 & 0.30 & Apurada & Desmotivador \\
\hline 0.70 & 0.30 & Incipiente & Motivador \\
\hline 0.40 & 0.60 & Incipiente & Desmotivador \\
\hline
\end{tabular}

Tabela 183 - TPC para o nó CondicaoFisica11

\begin{tabular}{|c|c|c|c|c|}
\hline Boa & Ruim & CargadeTrabalho & QualidadedeVida & SelecaodePessoal \\
\hline 1.00 & 0.00 & Ideal & Boa & Boa \\
\hline 0.80 & 0.20 & Ideal & Boa & Ruim \\
\hline 0.80 & 0.20 & Ideal & Ruim & Boa \\
\hline 0.60 & 0.40 & Ideal & Ruim & Ruim \\
\hline 0.80 & 0.20 & Alta & Boa & Boa \\
\hline 0.60 & 0.40 & Alta & Boa & Ruim \\
\hline 0.60 & 0.40 & Alta & Ruim & Boa \\
\hline 0.40 & 0.60 & Alta & Ruim & Ruim \\
\hline
\end{tabular}

Tabela 184 - TPC para o nó Concentracao11

\begin{tabular}{|c|c|c|c|c|}
\hline Alta & Baixa & QualidadedoSono12 & Distracoes10 & TrabalhoMonotono5 \\
\hline 0.60 & 0.40 & Boa & Sim & Sim \\
\hline 0.80 & 0.20 & Boa & Sim & Não \\
\hline 0.80 & 0.20 & Boa & Não & Sim \\
\hline 1.00 & 0.00 & Boa & Não & Não \\
\hline 0.40 & 0.60 & Ruim & Sim & Sim \\
\hline 0.60 & 0.40 & Ruim & Sim & Não \\
\hline 0.60 & 0.40 & Ruim & Não & Sim \\
\hline 0.80 & 0.20 & Ruim & Não & Não \\
\hline
\end{tabular}


Tabela 185 - TPC para o nó Percepcao14

\begin{tabular}{|c|c|c|c|}
\hline Alta & Baixa & QualidadedoSono12 & CondicaoFisica11 \\
\hline 1.00 & 0.00 & Boa & Boa \\
\hline 0.70 & 0.30 & Boa & Ruim \\
\hline 0.70 & 0.30 & Ruim & Boa \\
\hline 0.40 & 0.60 & Ruim & Ruim \\
\hline
\end{tabular}

Tabela 186 - TPC para o nó TrabalhoMonotono5

\begin{tabular}{|c|c|c|}
\hline Sim & Não & CoordenacaodoTrabalho \\
\hline 0.00 & 1.00 & Boa \\
\hline 0.60 & 0.40 & Ruim \\
\hline
\end{tabular}

Tabela 187 - TPC para o nó QualidadedoSono12

\begin{tabular}{|c|c|c|c|}
\hline Boa & Ruim & CoordenacaodoTrabalho & CargadeTrabalho \\
\hline 1.00 & 0.00 & Boa & Ideal \\
\hline 0.70 & 0.30 & Boa & Alta \\
\hline 0.70 & 0.30 & Ruim & Ideal \\
\hline 0.40 & 0.60 & Ruim & Alta \\
\hline
\end{tabular}

Tabela 188 - TPC para o nó Habilidade7 \begin{tabular}{|c|c|c|}
\hline Apurada & Incipiente & ProgramasdeTreinamento \\
\hline
\end{tabular}

\begin{tabular}{|c|c|c|}
\hline 1.00 & 0.00 & Adequado \\
\hline 0.40 & 0.60 & Inadequado \\
\hline
\end{tabular}

Tabela 189 - TPC para o nó TratamentoDadoaFalha7

\begin{tabular}{|c|c|c|c|}
\hline Motivador & Desmotivador & CulturaOrganizacional & AvaliacaodeRendimento \\
\hline 1.00 & 0.00 & Apropriada & Adequada \\
\hline 0.70 & 0.30 & Apropriada & Inadequada \\
\hline 0.70 & 0.30 & Inapropriada & Adequada \\
\hline 0.40 & 0.60 & Inapropriada & Inadequada \\
\hline
\end{tabular}

Tabela 190 - TPC para o nó Distracoes 10

\begin{tabular}{|c|c|c|c|}
\hline Sim & Não & CoordenacaodoTrabalho & RecursosFisicos \\
\hline 0.00 & 1.00 & Boa & Bom \\
\hline 0.30 & 0.70 & Boa & Ruim \\
\hline 0.30 & 0.70 & Ruim & Bom \\
\hline 0.60 & 0.40 & Ruim & Ruim \\
\hline
\end{tabular}

Tabela 191 - TPC para o nó ComandanteFalha32

\begin{tabular}{|c|c|c|c|c|}
\hline Sim & Não & Concentracao11 & Percepcao14 & EquipeComunicacao8 \\
\hline 0.00 & 1.00 & Alta & Alta & Bom \\
\hline 0.20 & 0.80 & Alta & Alta & Ruim \\
\hline 0.20 & 0.80 & Alta & Baixa & Bom \\
\hline 0.40 & 0.60 & Alta & Baixa & Ruim \\
\hline 0.20 & 0.80 & Baixa & Alta & Bom \\
\hline 0.40 & 0.60 & Baixa & Alta & Ruim \\
\hline 0.40 & 0.60 & Baixa & Baixa & Bom \\
\hline 0.60 & 0.40 & Baixa & Baixa & Ruim \\
\hline
\end{tabular}

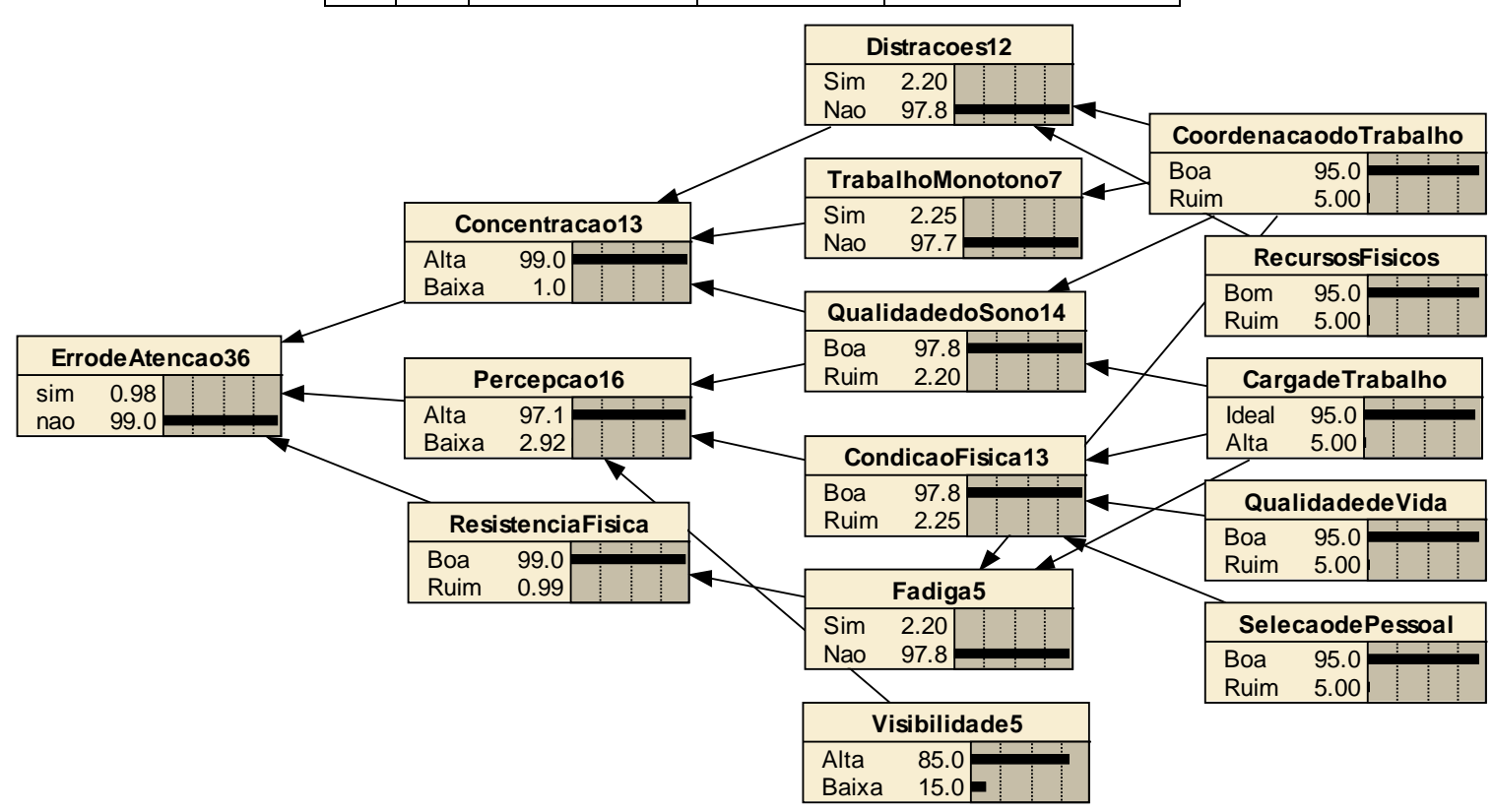

Figura 43 - Rede para o evento 36 - Erro de Atenção

Aplicação de Redes Bayesianas na Análise da Contribuição da Falha Humana em Acidentes de Colisão - 134 
Tabela 192 - TPC para o nó Fadiga5

\begin{tabular}{|l|c|c|c|}
\hline Sim & Não & CoordenacaodoTrabalho & CargadeTrabalho \\
\hline 0.00 & 1.00 & Boa & Ideal \\
\hline 0.22 & 0.78 & Boa & Alta \\
\hline 0.22 & 0.78 & Ruim & Ideal \\
\hline 0.45 & 0.55 & Ruim & Alta \\
\hline
\end{tabular}

Tabela 193 - TPC para o nó CondicaoFisica13

\begin{tabular}{|c|c|c|c|c|}
\hline Boa & Ruim & CargadeTrabalho & QualidadedeVida & SelecaodePessoal \\
\hline 1.00 & 0.00 & Ideal & Boa & Boa \\
\hline 0.85 & 0.15 & Ideal & Boa & Ruim \\
\hline 0.85 & 0.15 & Ideal & Ruim & Boa \\
\hline 0.70 & 0.30 & Ideal & Ruim & Ruim \\
\hline 0.85 & 0.15 & Alta & Boa & Boa \\
\hline 0.70 & 0.30 & Alta & Boa & Ruim \\
\hline 0.70 & 0.30 & Alta & Ruim & Boa \\
\hline 0.55 & 0.45 & Alta & Ruim & Ruim \\
\hline
\end{tabular}

Tabela 194 - TPC para o nó QualidadedoSono14

\begin{tabular}{|c|c|c|c|}
\hline Boa & Ruim & CoordenacaodoTrabalho & CargadeTrabalho \\
\hline 1.00 & 0.00 & Boa & Ideal \\
\hline 0.78 & 0.22 & Boa & Alta \\
\hline 0.78 & 0.22 & Ruim & Ideal \\
\hline 0.55 & 0.45 & Ruim & Alta \\
\hline
\end{tabular}

Tabela 195 - TPC para o nó TrabalhoMonotono7

\begin{tabular}{|c|c|c|}
\hline Sim & Não & CoordenacaodoTrabalho \\
\hline 0.00 & 1.00 & Boa \\
\hline 0.45 & 0.55 & Ruim \\
\hline
\end{tabular}

Tabela 196 - TPC para o nó Distracoes 12

\begin{tabular}{|c|c|c|c|}
\hline Sim & Não & CoordenacaodoTrabalho & RecursosFisicos \\
\hline 0.00 & 1.00 & Boa & Bom \\
\hline 0.22 & 0.78 & Boa & Ruim \\
\hline 0.22 & 0.78 & Ruim & Bom \\
\hline 0.45 & 0.55 & Ruim & Ruim \\
\hline
\end{tabular}

Tabela 197 - TPC para o nó ResistenciaFisica

\begin{tabular}{|c|c|c|}
\hline Boa & Ruim & Fadiga5 \\
\hline 0.55 & 0.45 & Sim \\
\hline 1.00 & 0.00 & Não \\
\hline
\end{tabular}

Tabela 198 - TPC para o nó Percepcao16

\begin{tabular}{|c|c|c|c|c|}
\hline Alta & Baixa & QualidadedoSono14 & CondicaoFisica13 & Visibilidade5 \\
\hline 1.00 & 0.00 & Boa & Boa & Alta \\
\hline 0.85 & 0.15 & Boa & Boa & Baixa \\
\hline 0.85 & 0.15 & Boa & Ruim & Alta \\
\hline 0.70 & 0.30 & Boa & Ruim & Baixa \\
\hline 0.85 & 0.15 & Ruim & Boa & Alta \\
\hline 0.70 & 0.30 & Ruim & Boa & Baixa \\
\hline 0.70 & 0.30 & Ruim & Ruim & Alta \\
\hline 0.55 & 0.45 & Ruim & Baixa \\
\hline
\end{tabular}

Tabela 199 - TPC para o nó Concentracao13

\begin{tabular}{|c|c|c|c|c|}
\hline Alta & Baixa & QualidadedoSono14 & Distracoes12 & TrabalhoMonotono7 \\
\hline 0.70 & 0.30 & Boa & Sim & Sim \\
\hline 0.85 & 0.15 & Boa & Sim & Não \\
\hline 0.85 & 0.15 & Boa & Não & Sim \\
\hline 1.00 & 0.00 & Boa & Não & Não \\
\hline 0.55 & 0.45 & Ruim & Sim & Sim \\
\hline 0.70 & 0.30 & Ruim & Sim & Não \\
\hline 0.70 & 0.30 & Ruim & Não & Sim \\
\hline 0.85 & 0.15 & Ruim & Não & Não \\
\hline
\end{tabular}

Tabela 200 - TPC para o nó ErrodeAtencao36

\begin{tabular}{|c|c|c|c|c|}
\hline Sim & Não & Concentracao13 & Percepcao16 & ResistenciaFisica \\
\hline 0.00 & 1.00 & Alta & Alta & Boa \\
\hline 0.20 & 0.80 & Alta & Alta & Ruim \\
\hline 0.20 & 0.80 & Alta & Baixa & Boa \\
\hline 0.40 & 0.60 & Alta & Baixa & Ruim \\
\hline 0.20 & 0.80 & Baixa & Alta & Boa \\
\hline 0.40 & 0.60 & Baixa & Alta & Ruim \\
\hline 0.40 & 0.60 & Baixa & Baixa & Boa \\
\hline 0.60 & 0.40 & Baixa & Baixa & Ruim \\
\hline
\end{tabular}




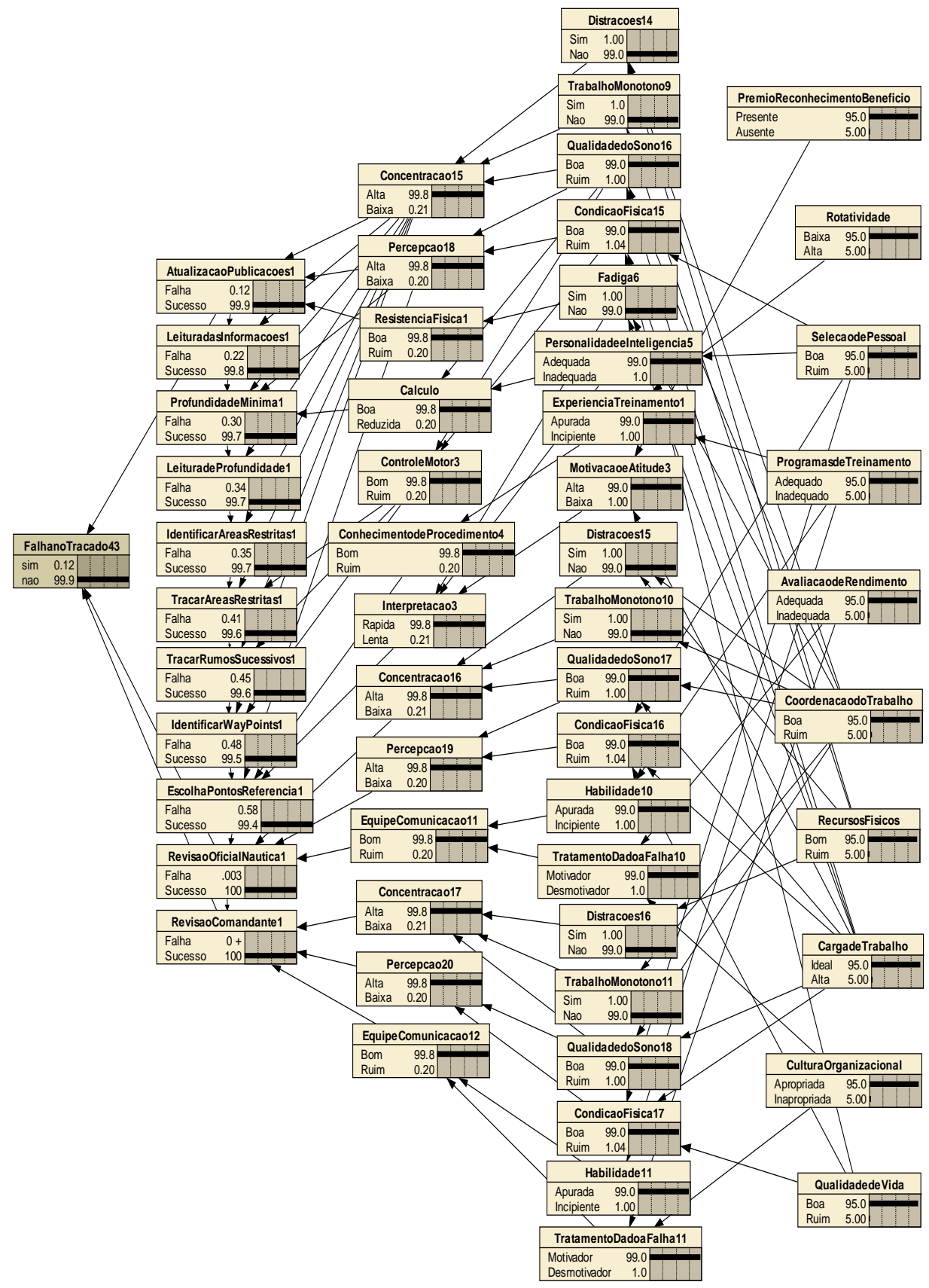

Figura 44 - Rede para o evento 43 - Falha no Traçado

Tabela 201 - TPC para o nó TratamentoDadoaFalha11

\begin{tabular}{|c|c|c|c|}
\hline Motivador & Desmotivador & CulturaOrganizacional & AvaliacaodeRendimento \\
\hline 1.00 & 0.00 & Apropriada & Adequada \\
\hline 0.90 & 0.10 & Apropriada & Inadequada \\
\hline 0.90 & 0.10 & Inapropriada & Adequada \\
\hline 0.80 & 0.20 & Inapropriada & Inadequada \\
\hline
\end{tabular}

Tabela 202 - TPC para o nó CondicaoFisica17

\begin{tabular}{|c|c|c|c|c|}
\hline Boa & Ruim & CargadeTrabalho & QualidadedeVida & SelecaodePessoal \\
\hline 1.00 & 0.00 & Ideal & Boa & Boa \\
\hline 0.93 & 0.07 & Ideal & Boa & Ruim \\
\hline 0.93 & 0.07 & Ideal & Ruim & Boa \\
\hline 0.87 & 0.13 & Ideal & Ruim & Ruim \\
\hline 0.93 & 0.07 & Alta & Boa & Boa \\
\hline 0.87 & 0.13 & Alta & Boa & Ruim \\
\hline 0.87 & 0.13 & Alta & Ruim & Boa \\
\hline 0.80 & 0.20 & Alta & Ruim & Ruim \\
\hline
\end{tabular}


Tabela 203 - TPC para o nó QualidadedoSono18

\begin{tabular}{|c|c|c|c|}
\hline Boa & Ruim & CoordenacaodoTrabalho & CargadeTrabalho \\
\hline 1.00 & 0.00 & Boa & Ideal \\
\hline 0.90 & 0.10 & Boa & Alta \\
\hline 0.90 & 0.10 & Ruim & Ideal \\
\hline 0.80 & 0.20 & Ruim & Alta \\
\hline
\end{tabular}

Tabela 204 - TPC para o nó TratamentoDadoaFalha10

\begin{tabular}{|c|c|c|c|}
\hline Motivador & Desmotivador & CulturaOrganizacional & AvaliacaodeRendimento \\
\hline 1.00 & 0.00 & Apropriada & Adequada \\
\hline 0.90 & 0.10 & Apropriada & Inadequada \\
\hline 0.90 & 0.10 & Inapropriada & Adequada \\
\hline 0.80 & 0.20 & Inapropriada & Inadequada \\
\hline
\end{tabular}

Tabela 205 - TPC para o nó MotivacaoeAtitude3

\begin{tabular}{|c|c|c|c|}
\hline Alta & Baixa & CargadeTrabalho & PremioReconhecimentoBeneficio \\
\hline 1.00 & 0.00 & Ideal & Presente \\
\hline 0.90 & 0.10 & Ideal & Ausente \\
\hline 0.90 & 0.10 & Alta & Presente \\
\hline 0.80 & 0.20 & Alta & Ausente \\
\hline
\end{tabular}

Tabela 206 - TPC para o nó ExperienciaTreinamento1 \begin{tabular}{|c|l|l|l|}
\hline Apurada & Incipiente & ProgramasdeTreinamento & Rotatividade \\
\hline
\end{tabular}

\begin{tabular}{|c|c|c|c|}
\hline 1.00 & 0.00 & Adequado & Baixa \\
\hline 0.90 & 0.10 & Adequado & Alta \\
\hline 0.90 & 0.10 & Inadequado & Baixa \\
\hline 0.80 & 0.20 & Inadequado & Alta \\
\hline
\end{tabular}

Tabela 207 - TPC para o nó QualidadedoSono16

\begin{tabular}{|c|c|c|c|}
\hline Boa & Ruim & CoordenacaodoTrabalho & CargadeTrabalho \\
\hline 1.00 & 0.00 & Boa & Ideal \\
\hline 0.90 & 0.10 & Boa & Alta \\
\hline 0.90 & 0.10 & Ruim & Ideal \\
\hline 0.80 & 0.20 & Ruim & Alta \\
\hline
\end{tabular}

Tabela 208 - TPC para o nó QualidadedoSono17

\begin{tabular}{|c|c|c|c|}
\hline Boa & Ruim & CoordenacaodoTrabalho & CargadeTrabalho \\
\hline 1.00 & 0.00 & Boa & Ideal \\
\hline 0.90 & 0.10 & Boa & Alta \\
\hline 0.90 & 0.10 & Ruim & Ideal \\
\hline 0.80 & 0.20 & Ruim & Alta \\
\hline
\end{tabular}

Tabela 209 - TPC para o nó Habilidade11

\begin{tabular}{|c|c|c|}
\hline Apurada & Incipiente & ProgramasdeTreinamento \\
\hline 1.00 & 0.00 & Adequado \\
\hline 0.80 & 0.20 & Inadequado \\
\hline
\end{tabular}

Tabela 210 - TPC para o nó Habilidade10

\begin{tabular}{|c|c|c|}
\hline Apurada & Incipiente & ProgramasdeTreinamento \\
\hline 1.00 & 0.00 & Adequado \\
\hline 0.80 & 0.20 & Inadequado \\
\hline
\end{tabular}

Tabela 211 - TPC para o nó CondicaoFisica16

\begin{tabular}{|c|c|c|c|c|}
\hline Boa & Ruim & CargadeTrabalho & QualidadedeVida & SelecaodePessoal \\
\hline 1.00 & 0.00 & Ideal & Boa & Boa \\
\hline 0.93 & 0.07 & Ideal & Boa & Ruim \\
\hline 0.93 & 0.07 & Ideal & Ruim & Boa \\
\hline 0.87 & 0.13 & Ideal & Ruim & Ruim \\
\hline 0.93 & 0.07 & Alta & Boa & Boa \\
\hline 0.87 & 0.13 & Alta & Boa & Ruim \\
\hline 0.87 & 0.13 & Alta & Ruim & Boa \\
\hline 0.80 & 0.20 & Alta & Ruim & Ruim \\
\hline
\end{tabular}

Tabela 212 - TPC para o nó Personalidadeelnteligencia5

\begin{tabular}{|c|c|c|}
\hline Adequada & Inadequada & SelecaodePessoal \\
\hline 1.00 & 0.00 & Boa \\
\hline 0.80 & 0.20 & Ruim \\
\hline
\end{tabular}

Tabela 213 - TPC para o nó Distracoes 14

\begin{tabular}{|c|c|c|c|}
\hline Sim & Não & CoordenacaodoTrabalho & RecursosFisicos \\
\hline 0.00 & 1.00 & Boa & Bom \\
\hline 0.10 & 0.90 & Boa & Ruim \\
\hline 0.10 & 0.90 & Ruim & Bom \\
\hline 0.20 & 0.80 & Ruim & Ruim \\
\hline
\end{tabular}


Tabela 214 - TPC para o nó CondicaoFisica15

\begin{tabular}{|c|c|c|c|c|}
\hline Boa & Ruim & CargadeTrabalho & QualidadedeVida & SelecaodePessoal \\
\hline 1.00 & 0.00 & Ideal & Boa & Boa \\
\hline 0.93 & 0.07 & Ideal & Boa & Ruim \\
\hline 0.93 & 0.07 & Ideal & Ruim & Boa \\
\hline 0.87 & 0.13 & Ideal & Ruim & Ruim \\
\hline 0.93 & 0.07 & Alta & Boa & Boa \\
\hline 0.87 & 0.13 & Alta & Boa & Ruim \\
\hline 0.87 & 0.13 & Alta & Ruim & Boa \\
\hline 0.80 & 0.20 & Alta & Ruim & Ruim \\
\hline
\end{tabular}

Tabela 215 - TPC para o nó Fadiga6

\begin{tabular}{|c|c|c|c|}
\hline Sim & Não & CoordenacaodoTrabalho & CargadeTrabalho \\
\hline 0.00 & 1.00 & Boa & Ideal \\
\hline 0.10 & 0.90 & Boa & Alta \\
\hline 0.10 & 0.90 & Ruim & Ideal \\
\hline 0.20 & 0.80 & Ruim & Alta \\
\hline
\end{tabular}

Tabela 216 - TPC para o nó Distracoes15 \begin{tabular}{|l|l|l|l|}
\hline Sim & Não & CoordenacaodoTrabalho & RecursosFisicos \\
\hline
\end{tabular}

\begin{tabular}{|c|c|c|c|}
\hline Sim & Não & CoordenacaodoTrabalho & RecursosFisicos \\
\hline 0.00 & 1.00 & Boa & Bom \\
\hline 0.10 & 0.90 & Boa & Ruim \\
\hline 0.10 & 0.90 & Ruim & Bom \\
\hline 0.20 & 0.80 & Ruim & Ruim \\
\hline
\end{tabular}

Tabela 217 - TPC para o nó TrabalhoMonotono9

\begin{tabular}{|c|c|c|}
\hline Sim & Não & RecursosFisicos \\
\hline 0.00 & 1.00 & Bom \\
\hline 0.20 & 0.80 & Ruim \\
\hline
\end{tabular}

Tabela 218 - TPC para o nó TrabalhoMonotono10

\begin{tabular}{|c|c|c|}
\hline Sim & Não & CoordenacaodoTrabalho \\
\hline 0.00 & 1.00 & Boa \\
\hline 0.20 & 0.80 & Ruim \\
\hline
\end{tabular}

Tabela 219 - TPC para o nó Distracoes 16

\begin{tabular}{|c|c|c|}
\hline Sim & Não & RecursosFisicos \\
\hline 0.00 & 1.00 & Bom \\
\hline 0.20 & 0.80 & Ruim \\
\hline
\end{tabular}

Tabela 220 - TPC para o nó TrabalhoMonotono11

\begin{tabular}{|c|c|c|}
\hline Sim & Não & CoordenacaodoTrabalho \\
\hline 0.00 & 1.00 & Boa \\
\hline 0.20 & 0.80 & Ruim \\
\hline
\end{tabular}

Tabela 221 - TPC para o nó FalhanoTracado43

\begin{tabular}{|c|c|c|c|}
\hline & AtualizacaoPublicacoes1 & RevisaoOficialNautica1 & RevisaoComandante1 \\
\hline Sim & Falha & Falha & Falha \\
\hline Sim & Falha & Falha & Sucesso \\
\hline Sim & Falha & Sucesso & Falha \\
\hline Sim & Falha & Sucesso & Sucesso \\
\hline Sim & Sucesso & Falha & Falha \\
\hline Não & Sucesso & Falha & Sucesso \\
\hline Não & Sucesso & Sucesso & Falha \\
\hline Não & Sucesso & Sucesso & Sucesso \\
\hline
\end{tabular}

Tabela 222 - TPC para o nó RevisaoOficialNautica1

\begin{tabular}{|c|c|c|c|c|c|}
\hline Falha & Sucesso & EscolhaPontosReferencia1 & Concentracao16 & Percepcao19 & EquipeComunicacao11 \\
\hline 0.00 & 1.00 & Falha & Alta & Alta & Bom \\
\hline 0.20 & 0.80 & Falha & Alta & Alta & Ruim \\
\hline 0.20 & 0.80 & Falha & Alta & Baixa & Bom \\
\hline 0.40 & 0.60 & Falha & Alta & Baixa & Ruim \\
\hline 0.20 & 0.80 & Falha & Baixa & Alta & Bom \\
\hline 0.40 & 0.60 & Falha & Baixa & Alta & Ruim \\
\hline 0.40 & 0.60 & Falha & Baixa & Baixa & Bom \\
\hline 0.60 & 0.40 & Falha & Baixa & Baixa & Ruim \\
\hline 0.00 & 1.00 & Sucesso & Alta & Alta & Bom \\
\hline 0.00 & 1.00 & Sucesso & Alta & Alta & Ruim \\
\hline 0.00 & 1.00 & Sucesso & Alta & Baixa & Bom \\
\hline 0.00 & 1.00 & Sucesso & Alta & Baixa & Ruim \\
\hline 0.00 & 1.00 & Sucesso & Baixa & Alta & Bom \\
\hline 0.00 & 1.00 & Sucesso & Baixa & Alta & Ruim \\
\hline 0.00 & 1.00 & Sucesso & Baixa & Baixa & Bom \\
\hline 0.00 & 1.00 & Sucesso & Baixa & Baixa & Ruim \\
\hline
\end{tabular}


Tabela 223 - TPC para o nó EscolhaPontosReferencia1

\begin{tabular}{|c|c|c|c|c|c|}
\hline Falha & Sucesso & IdentificarWayPoints1 & Percepcao18 & ConhecimentodeProcedimento4 & Interpretacao3 \\
\hline 1.00 & 0.00 & Falha & Alta & Bom & Rápida \\
\hline 1.00 & 0.00 & Falha & Alta & Bom & Lenta \\
\hline 1.00 & 0.00 & Falha & Alta & Ruim & Rápida \\
\hline 1.00 & 0.00 & Falha & Alta & Ruim & Lenta \\
\hline 1.00 & 0.00 & Falha & Baixa & Bom & Rápida \\
\hline 1.00 & 0.00 & Falha & Baixa & Bom & Lenta \\
\hline 1.00 & 0.00 & Falha & Baixa & Ruim & Rápida \\
\hline 1.00 & 0.00 & Falha & Baixa & Ruim & Lenta \\
\hline 0.00 & 1.00 & Sucesso & Alta & Bom & Rápida \\
\hline 0.20 & 0.80 & Sucesso & Alta & Bom & Lenta \\
\hline 0.20 & 0.80 & Sucesso & Alta & Ruim & Rápida \\
\hline 0.40 & 0.60 & Sucesso & Alta & Ruim & Lenta \\
\hline 0.20 & 0.80 & Sucesso & Baixa & Bom & Rápida \\
\hline 0.40 & 0.60 & Sucesso & Baixa & Bom & Lenta \\
\hline 0.40 & 0.60 & Sucesso & Baixa & Ruim & Rápida \\
\hline 0.60 & 0.40 & Sucesso & Baixa & Ruim & Lenta \\
\hline
\end{tabular}

Tabela 224 - TPC para o nó IdentificarWayPoints1

\begin{tabular}{|c|c|c|c|c|}
\hline Falha & Sucesso & TracarRumosSucessivos1 & Concentracao15 & ControleMotor3 \\
\hline 1.00 & 0.00 & Falha & Alta & Bom \\
\hline 1.00 & 0.00 & Falha & Alta & Ruim \\
\hline 1.00 & 0.00 & Falha & Baixa & Bom \\
\hline 1.00 & 0.00 & Falha & Baixa & Ruim \\
\hline 0.00 & 1.00 & Sucesso & Alta & Bom \\
\hline 0.30 & 0.70 & Sucesso & Alta & Ruim \\
\hline 0.30 & 0.70 & Sucesso & Baixa & Bom \\
\hline 0.60 & 0.40 & Sucesso & Baixa & Ruim \\
\hline
\end{tabular}

Tabela 225 - TPC para o nó TracarRumosSucessivos 1 \begin{tabular}{|c|c|c|c|c|}
\hline Falha & Sucesso & TracarAreasRestritas1 & Concentracao15 & ControleMotor3 \\
\hline 1.00 & 0.00 & &
\end{tabular}

\begin{tabular}{|c|c|c|c|c|}
\hline 1.00 & 0.00 & Falha & Alta & Bom \\
\hline 1.00 & 0.00 & Falha & Alta & Ruim \\
\hline 1.00 & 0.00 & Falha & Baixa & Bom \\
\hline 1.00 & 0.00 & Falha & Baixa & Ruim \\
\hline 0.00 & 1.00 & Sucesso & Alta & Bom \\
\hline 0.30 & 0.70 & Sucesso & Alta & Ruim \\
\hline 0.30 & 0.70 & Sucesso & Baixa & Bom \\
\hline 0.60 & 0.40 & Sucesso & Baixa & Ruim \\
\hline
\end{tabular}

Tabela 226 - TPC para o nó TracarAreasRestritas1 \begin{tabular}{|c|c|c|c|c|}
\hline Falha & Sucesso & IdentificarAreasRestritas1 & Concentracao15 & ControleMotor3 \\
\hline
\end{tabular}

\begin{tabular}{|c|c|c|c|c|}
\hline Falha & Sucesso & IdentificarAreasRestritas1 & Concentracao15 & ControleMotor3 \\
\hline 1.00 & 0.00 & Falha & Alta & Bom \\
\hline 1.00 & 0.00 & Falha & Alta & Ruim \\
\hline 1.00 & 0.00 & Falha & Baixa & Bom \\
\hline 1.00 & 0.00 & Falha & Baixa & Ruim \\
\hline 0.00 & 1.00 & Sucesso & Alta & Bom \\
\hline 0.30 & 0.70 & Sucesso & Baixa & Ruim \\
\hline 0.30 & 0.70 & Sucesso & Baixa & Ruim \\
\hline 0.60 & 0.40 & Sucesso & & \\
\hline
\end{tabular}

Tabela 227 - TPC para o nó ProfundidadeMinima1

\begin{tabular}{|c|c|c|c|c|c|}
\hline Falha & Sucesso & LeituradasInformacoes1 & Concentracao15 & Percepcao18 & Calculo \\
\hline 1.00 & 0.00 & Falha & Alta & Alta & Boa \\
\hline 1.00 & 0.00 & Falha & Alta & Alta & Reduzida \\
\hline 1.00 & 0.00 & Falha & Alta & Baixa & Boa \\
\hline 1.00 & 0.00 & Falha & Alta & Baixa & Reduzida \\
\hline 1.00 & 0.00 & Falha & Baixa & Alta & Boa \\
\hline 1.00 & 0.00 & Falha & Baixa & Alta & Reduzida \\
\hline 1.00 & 0.00 & Falha & Baixa & Baixa & Boa \\
\hline 1.00 & 0.00 & Falha & Baixa & Baixa & Reduzida \\
\hline 0.00 & 1.00 & Sucesso & Alta & Alta & Boa \\
\hline 0.20 & 0.80 & Sucesso & Alta & Alta & Reduzida \\
\hline 0.20 & 0.80 & Sucesso & Alta & Baixa & Boa \\
\hline 0.40 & 0.60 & Sucesso & Baixa & Baixa & Reduzida \\
\hline 0.20 & 0.80 & Sucesso & Baixa & Alta & Boa \\
\hline 0.40 & 0.60 & Sucesso & Baixa & Baixa & Boa \\
\hline 0.40 & 0.60 & Sucesso & Baixa & Baixa & Reduzida \\
\hline 0.60 & 0.40 & Sucesso & & &
\end{tabular}

Tabela 228 - TPC para o nó ConhecimentodeProcedimento4

\begin{tabular}{|c|c|c|}
\hline Bom & Ruim & EstadoAtual3 \\
\hline 1.00 & 0.00 & Apurada \\
\hline 0.80 & 0.20 & Incipiente \\
\hline
\end{tabular}


Tabela 229 - TPC para o nó IdentificarAreasRestritas1

\begin{tabular}{|c|c|c|c|}
\hline Falha & Sucesso & LeituradeProfundidade1 & Concentracao15 \\
\hline 1.00 & 0.00 & Falha & Alta \\
\hline 1.00 & 0.00 & Falha & Baixa \\
\hline 0.00 & 1.00 & Sucesso & Alta \\
\hline 0.60 & 0.40 & Sucesso & Baixa \\
\hline
\end{tabular}

Tabela 230 - TPC para o nó LeituradeProfundidade1

\begin{tabular}{|c|c|c|c|}
\hline Falha & Sucesso & ProfundidadeMinima1 & Concentracao15 \\
\hline 1.00 & 0.00 & & \\
\hline
\end{tabular}

\begin{tabular}{|c|c|c|c|}
\hline 1.00 & 0.00 & Falha & Alta \\
\hline 1.00 & 0.00 & Falha & Baixa \\
\hline 0.00 & 1.00 & Sucesso & Alta \\
\hline 0.60 & 0.40 & Sucesso & Baixa \\
\hline
\end{tabular}

Tabela 231 - TPC para o nó LeituradasInformacoes 1

\begin{tabular}{|c|c|c|c|}
\hline Falha & Sucesso & AtualizacaoPublicacoes1 & Concentracao15 \\
\hline 1.00 & 0.00 & Falha & Alta \\
\hline 1.00 & 0.00 & Falha & Baixa \\
\hline 0.00 & 1.00 & Sucesso & Alta \\
\hline 0.60 & 0.40 & Sucesso & Baixa \\
\hline
\end{tabular}

Tabela 232 - TPC para o nó AtualizacaoPublicacoes1

\begin{tabular}{|l|l|l|l|l|}
\hline Falha & Sucesso & Concentracao15 & Percepcao18 & ResistenciaFisica1 \\
\hline
\end{tabular}

\begin{tabular}{|c|c|c|c|c|}
\hline 0.00 & 1.00 & Alta & Alta & Boa \\
\hline 0.20 & 0.80 & Alta & Alta & Ruim \\
\hline 0.20 & 0.80 & Alta & Baixa & Boa \\
\hline 0.40 & 0.60 & Alta & Baixa & Ruim \\
\hline 0.20 & 0.80 & Baixa & Alta & Boa \\
\hline 0.40 & 0.60 & Baixa & Alta & Ruim \\
\hline 0.40 & 0.60 & Baixa & Baixa & Boa \\
\hline 0.60 & 0.40 & Baixa & Baixa & Ruim \\
\hline
\end{tabular}

Tabela 233 - TPC para o nó RevisaoComandante1

\begin{tabular}{|c|c|c|c|c|c|}
\hline Falha & Sucesso & RevisaoOficialNautica1 & Concentracao17 & Percepcao20 & EquipeComunicacao12 \\
\hline 0.00 & 1.00 & Falha & Alta & Alta & Bom \\
\hline 0.20 & 0.80 & Falha & Alta & Alta & Ruim \\
\hline 0.20 & 0.80 & Falha & Alta & Baixa & Bom \\
\hline 0.40 & 0.60 & Falha & Alta & Baixa & Ruim \\
\hline 0.20 & 0.80 & Falha & Baixa & Alta & Bom \\
\hline 0.40 & 0.60 & Falha & Baixa & Alta & Ruim \\
\hline 0.40 & 0.60 & Falha & Baixa & Baixa & Bom \\
\hline 0.60 & 0.40 & Falha & Baixa & Baixa & Ruim \\
\hline 0.00 & 1.00 & Sucesso & Alta & Alta & Bom \\
\hline 0.00 & 1.00 & Sucesso & Alta & Alta & Ruim \\
\hline 0.00 & 1.00 & Sucesso & Alta & Baixa & Bom \\
\hline 0.00 & 1.00 & Sucesso & Alta & Baixa & Ruim \\
\hline 0.00 & 1.00 & Sucesso & Baixa & Alta & Bom \\
\hline 0.00 & 1.00 & Sucesso & Baixa & Alta & Ruim \\
\hline 0.00 & 1.00 & Sucesso & Baixa & Baixa & Bom \\
\hline 0.00 & 1.00 & Sucesso & Baixa & Baixa & Ruim \\
\hline
\end{tabular}

Tabela 234 - TPC para o nó Concentracao15

\begin{tabular}{|c|c|c|c|c|}
\hline Alta & Baixa & QualidadedoSono4 & Distracoes3 & TrabalhoMonotono3 \\
\hline 0.87 & 0.13 & Boa & Sim & Sim \\
\hline 0.93 & 0.07 & Boa & Sim & Não \\
\hline 0.93 & 0.07 & Boa & Não & Sim \\
\hline 1.00 & 0.00 & Boa & Não & Não \\
\hline 0.80 & 0.20 & Ruim & Sim & Sim \\
\hline 0.87 & 0.13 & Ruim & Sim & Não \\
\hline 0.87 & 0.13 & Ruim & Não & Sim \\
\hline 0.93 & 0.07 & Ruim & Não & Não \\
\hline
\end{tabular}

Tabela 235 - TPC para o nó Concentracao17

\begin{tabular}{|c|c|c|c|c|}
\hline Alta & Baixa & QualidadedoSono4 & Distracoes3 & TrabalhoMonotono3 \\
\hline 0.87 & 0.13 & Boa & Sim & Sim \\
\hline 0.93 & 0.07 & Boa & Sim & Não \\
\hline 0.93 & 0.07 & Boa & Não & Sim \\
\hline 1.00 & 0.00 & Boa & Não & Não \\
\hline 0.80 & 0.20 & Ruim & Sim & Sim \\
\hline 0.87 & 0.13 & Ruim & Sim & Não \\
\hline 0.87 & 0.13 & Ruim & Não & Sim \\
\hline 0.93 & 0.07 & Ruim & Não & Não \\
\hline
\end{tabular}


Tabela 236 - TPC para o nó Percepcao20

\begin{tabular}{|c|c|c|c|}
\hline Alta & Baixa & QualidadedoSono4 & CondicaoFisica4 \\
\hline 1.00 & 0.00 & Boa & Boa \\
\hline 0.90 & 0.10 & Boa & Ruim \\
\hline 0.90 & 0.10 & Ruim & Boa \\
\hline 0.80 & 0.20 & Ruim & Ruim \\
\hline
\end{tabular}

Tabela 237 - TPC para o nó ResistenciaFisica1

\begin{tabular}{|c|c|c|}
\hline Boa & Ruim & Fadiga6 \\
\hline 0.80 & 0.20 & Sim \\
\hline 1.00 & 0.00 & Não \\
\hline
\end{tabular}

Tabela 238 - TPC para o nó Concentracao16

\begin{tabular}{|c|c|c|c|c|}
\hline Alta & Baixa & QualidadedoSono4 & Distracoes3 & TrabalhoMonotono3 \\
\hline 0.87 & 0.13 & Boa & Sim & Sim \\
\hline 0.93 & 0.07 & Boa & Sim & Não \\
\hline 0.93 & 0.07 & Boa & Não & Sim \\
\hline 1.00 & 0.00 & Boa & Não & Não \\
\hline 0.80 & 0.20 & Ruim & Sim & Sim \\
\hline 0.87 & 0.13 & Ruim & Sim & Não \\
\hline 0.87 & 0.13 & Ruim & Não & Sim \\
\hline 0.93 & 0.07 & Ruim & Não & Não \\
\hline
\end{tabular}

Tabela 239 - TPC para o nó Percepcao19

\begin{tabular}{|c|c|c|c|}
\hline Alta & Baixa & QualidadedoSono4 & CondicaoFisica4 \\
\hline 1.00 & 0.00 & Boa & Boa \\
\hline 0.90 & 0.10 & Boa & Ruim \\
\hline 0.90 & 0.10 & Ruim & Boa \\
\hline 0.80 & 0.20 & Ruim & Ruim \\
\hline
\end{tabular}

Tabela 240 - TPC para o nó Percepcao18

\begin{tabular}{|c|c|c|c|}
\hline Alta & Baixa & QualidadedoSono4 & CondicaoFisica4 \\
\hline 1.00 & 0.00 & & \\
\hline
\end{tabular}

\begin{tabular}{|c|c|c|c|}
\hline Alta & Baixa & QualidadedoSono4 & CondicaoFisica4 \\
\hline 1.00 & 0.00 & Boa & Boa \\
\hline 0.90 & 0.10 & Boa & Ruim \\
\hline 0.90 & 0.10 & Ruim & Boa \\
\hline 0.80 & 0.20 & Ruim & Ruim \\
\hline
\end{tabular}

Tabela 241 - TPC para o nó Calculo

\begin{tabular}{|c|c|c|c|}
\hline Boa & Reduzida & QualidadedoSono16 & PersonalidadeeInteligencia5 \\
\hline 1.00 & 0.00 & Boa & Adequada \\
\hline 0.90 & 0.10 & Boa & Inadequada \\
\hline 0.90 & 0.10 & Ruim & Adequada \\
\hline 0.80 & 0.20 & Ruim & Inadequada \\
\hline
\end{tabular}

Tabela 242 - TPC para o nó ControleMotor3

\begin{tabular}{|l|l|l|l|}
\hline Bom & Ruim & CondicaoFisica15 & QualidadedoSono16 \\
\hline
\end{tabular}

\begin{tabular}{|c|c|c|c|}
\hline 1.00 & 0.00 & Boa & Boa \\
\hline 0.90 & 0.10 & Boa & Ruim \\
\hline 0.90 & 0.10 & Ruim & Boa \\
\hline 0.80 & 0.20 & Ruim & Ruim \\
\hline
\end{tabular}

Tabela 243 - TPC para o nó EquipeComunicacao11

\begin{tabular}{|c|c|c|c|}
\hline Bom & Ruim & TratamentoDadoaFalha2 & Habilidade2 \\
\hline 1.00 & 0.00 & Motivador & Apurada \\
\hline 0.90 & 0.10 & Motivador & Incipiente \\
\hline 0.90 & 0.10 & Desmotivador & Apurada \\
\hline 0.80 & 0.20 & Desmotivador & Incipiente \\
\hline
\end{tabular}

Tabela 244 - TPC para o nó EquipeComunicacao12

\begin{tabular}{|c|c|c|c|}
\hline Bom & Ruim & TratamentoDadoaFalha2 & Habilidade2 \\
\hline 1.00 & 0.00 & Motivador & Apurada \\
\hline 0.90 & 0.10 & Motivador & Incipiente \\
\hline 0.90 & 0.10 & Desmotivador & Apurada \\
\hline 0.80 & 0.20 & Desmotivador & Incipiente \\
\hline
\end{tabular}

Tabela 245 - TPC para o nó Interpretacao3

\begin{tabular}{|c|c|c|c|c|}
\hline Rápida & Lenta & MotivacaoeAtitude1 & PersonalidadeeInteligencia5 & Fadiga6 \\
\hline 0.93 & 0.07 & Alta & Adequada & Sim \\
\hline 1.00 & 0.00 & Alta & Adequada & Não \\
\hline 0.87 & 0.13 & Alta & Inadequada & Sim \\
\hline 0.93 & 0.07 & Alta & Inadequada & Não \\
\hline 0.87 & 0.13 & Baixa & Adequada & Sim \\
\hline 0.93 & 0.07 & Baixa & Adequada & Não \\
\hline 0.80 & 0.20 & Baixa & Inadequada & Sim \\
\hline 0.87 & 0.13 & Baixa & Inadequada & Não \\
\hline
\end{tabular}

